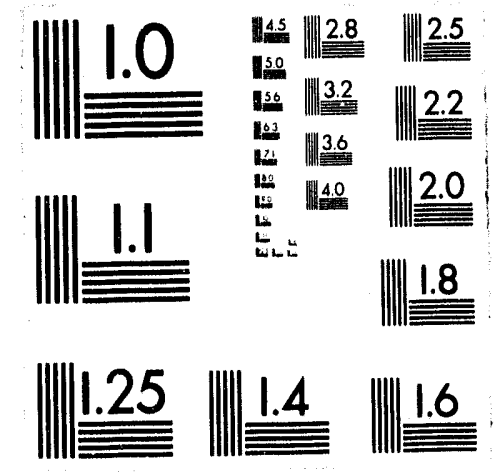



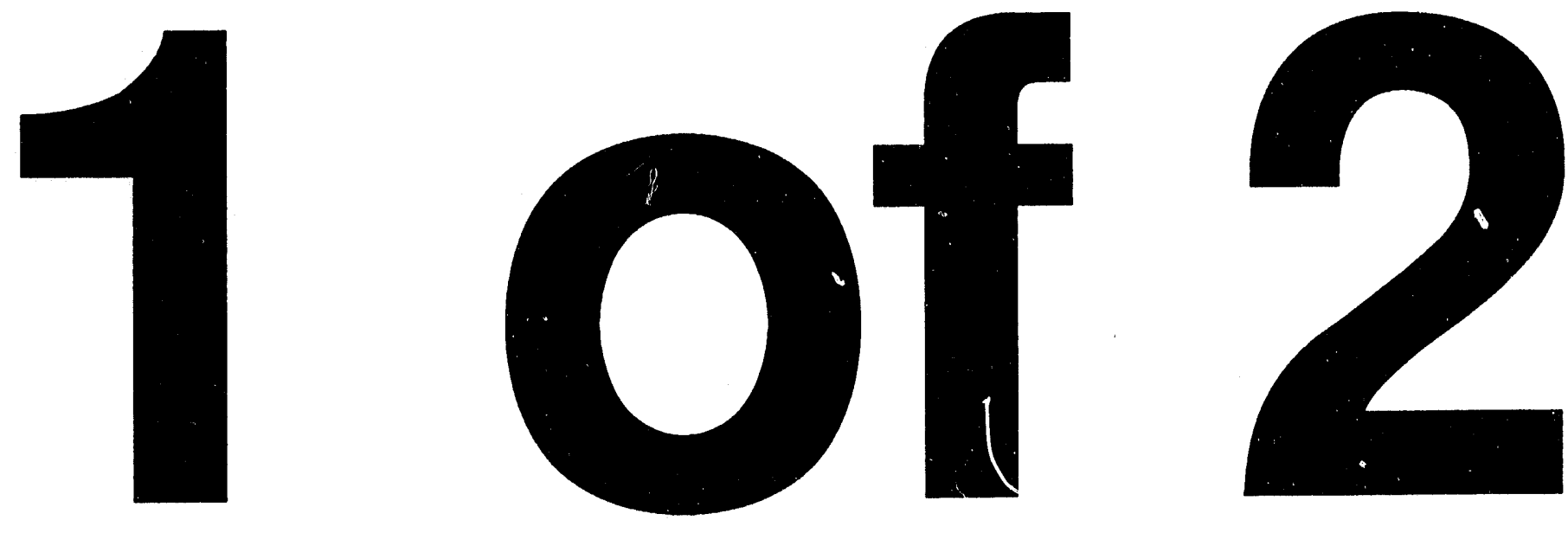


\title{
User's Manual for FLUFIX/MOD2: \\ A Computer Program for Fluid-Solids Hydrodynamics
}

\section{Topical Report}

\author{
R.W. Lyczkowski \\ J.X. Bouillard \\ S.M. Folga
}

April 1992

Work Performed Under Contract No.: DE-AC21-89MC24193

$$
W \cdot 31109-E N G \cdot 38
$$

\section{For}

U.S. Department of Energy

Office of Fossil Energy

Morgantown Energy Technology Center

Morgantown, West Virginia

By

Argonne National Laboratory

Energy Systems Division

Argonne, Illinois 


\section{DISCLAIMER}

This report was prepared as an account of work sponsored by an agency of the United States Government. Neither the United States Government nor any agency thereof, nor any of their employees, makes any warranty, express or implied, or assumes any legal liability or responsibility for the accuracy, completeness, or usefulness of any information, apparatus, product, or process disclosed, or represents that its use would not infringe privately owned rights. Reference herein to any specific commercial product, process, or service by trade name, trademark, manufacturer, or otherwise does not necessarily constitute or imply its endorsement, recommendation, or favoring by the United States Government or any agency thereof. The views and opinions of authors expressed herein do not necessarily state or reflect those of the United States Government or any agency thereof.

This report has been reproduced directly from the best available copy.

Available to DOE and DOE contractors from the Office of Scientific and Technical Information, P.O. Box 62, Oak Ridge, TN 37831; prices available at (615) 576-8401.

Available to the public from the National Technical Information Service, U.S. Department of Commerce, 5285 Port Royal Rd., Springfield, VA 22161; phone orders accepted at (703) 487-4650. 
User's Manual for FLUFIX/MOD2:

A Computer Program for Fluid-Solids Hydrodynamics

\author{
Topical Report
}

\author{
R.W. Lyczkowski \\ J.X. Bouillard \\ S.M. Folga
}

Work Performed Under Contract No.: DE-AC21-89MC24193

\author{
For \\ U.S. Department of Energy \\ Office of Fossil Energy \\ Morgantown Energy Technology Center \\ P.O. Box 880 \\ Morgantown, West Virginia 26507-0880
}

By

Argonne National Laboratory

Energy Systems Division

9700 South Cass Avenue

Argonne, Illinois 60439-4815

April 1992 



\section{CONTENTS}

ACKNOWLEDGMENTS $\ldots \ldots \ldots \ldots \ldots \ldots \ldots \ldots \ldots \ldots \ldots \ldots \ldots \ldots \ldots \ldots \ldots \ldots$

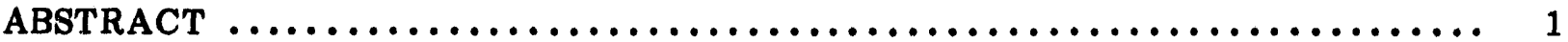

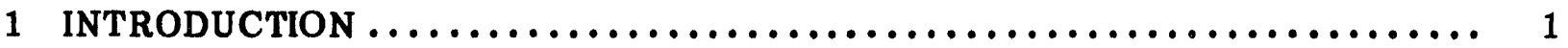

2 HYDRODYNAMIC MODELS $\ldots \ldots \ldots \ldots \ldots \ldots \ldots \ldots \ldots \ldots \ldots \ldots \ldots \ldots \ldots \ldots$

2.1 Hydrodynamic Model A ................................ 4

2.2 Hydrodynamic Model B ................................ 7

3 CONSTITUTIVE RELATIONSHIPS $\ldots \ldots \ldots \ldots \ldots \ldots \ldots \ldots \ldots \ldots \ldots \ldots \ldots \ldots \ldots$

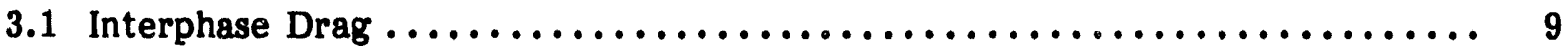

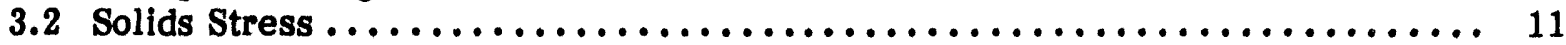

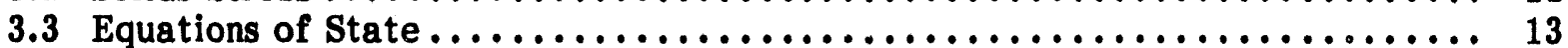

3.4 Miscellaneous Parameters ................................ 14

3.5 Viscous Stress Terms $\ldots \ldots \ldots \ldots \ldots \ldots \ldots \ldots \ldots \ldots \ldots \ldots \ldots \ldots \ldots \ldots \ldots \ldots, 14$

4 FINITE-DIFFERENCE EQUATIONS $\ldots \ldots \ldots \ldots \ldots \ldots \ldots \ldots \ldots \ldots \ldots \ldots \ldots$

4.1 Continuity Equations $\ldots \ldots \ldots \ldots \ldots \ldots \ldots \ldots \ldots \ldots \ldots \ldots \ldots \ldots \ldots \ldots \ldots$

4.2 Momentum Equations $\ldots \ldots \ldots \ldots \ldots \ldots \ldots \ldots \ldots \ldots \ldots \ldots \ldots \ldots \ldots \ldots \ldots$

5 SOLUTION PROCEDURE FOR FINITE-DIFFERENCE EQUATIONS $\ldots \ldots \ldots \ldots 26$

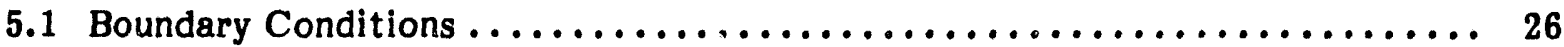

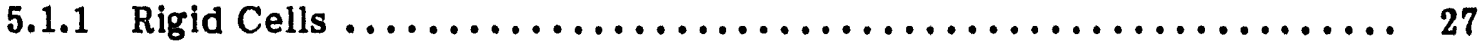

5.1 .2 Inflow Boundary Cells ............................ 31

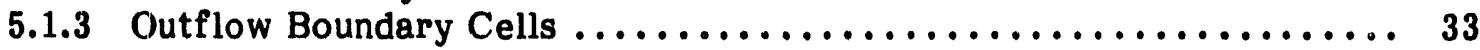

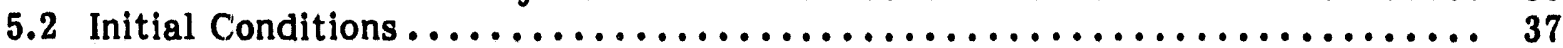

5.3 Solution Procedure in the Fluid Cells $\ldots \ldots \ldots \ldots \ldots \ldots \ldots \ldots \ldots \ldots \ldots \ldots \ldots, 41$

5.4 Stability of the Numerical Scheme ......................... 48

6 GLOBAL STRUCTURE OF THE FLUFIX/MOD2 COMPUTER PROGRAM $\ldots \ldots .49$

6.1 FLUFIX/MOD.2 Subroutines and Their functions ............... 49

6.2 New Subroutine Names Obtained from K-FIX .................. 51

6.3 Subroutines and LASL External Subroutine Calls Deleted from

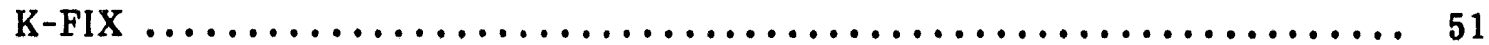

6.4 FLUFIX Program Structure Synopsis $\ldots \ldots \ldots \ldots \ldots \ldots \ldots \ldots \ldots \ldots \ldots \ldots \ldots$. 53

7 DESCRIPTION OF FLUFIX/MOD2 INPUT DATA $\ldots \ldots \ldots \ldots \ldots \ldots \ldots \ldots \ldots \ldots$

8 SAMPLE PROBLEM FOR A FLUIDIZED BED $\ldots \ldots \ldots \ldots \ldots \ldots \ldots \ldots \ldots$

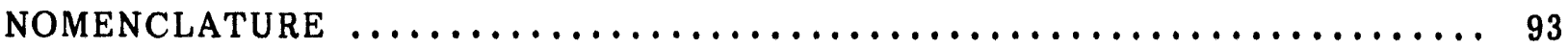

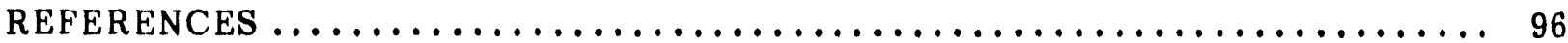




\section{CONTENTS (Cont'd)}

APPENDIX A: Stability Conditions for the FLUFIX/MOD1 Numerical Scheme $\ldots \ldots 101$ APPENDIX B: List of FLUFIX/MOD2 Fortran Symbols and Definitions ........ 109

\section{FIGURES}

1 Spherical Coordinates $\ldots \ldots \ldots \ldots \ldots \ldots \ldots \ldots \ldots \ldots \ldots \ldots \ldots \ldots \ldots \ldots \ldots \ldots$

2 Axisymmetric Cylindrical Coordinates $\ldots \ldots \ldots \ldots \ldots \ldots \ldots \ldots \ldots \ldots \ldots \ldots$

3 Cartesian Coordinates $\ldots \ldots \ldots \ldots \ldots \ldots \ldots \ldots \ldots \ldots \ldots \ldots \ldots \ldots \ldots \ldots \ldots$

4 Three Solids Elastic Moduli -- $G_{1}, G_{2}$, and $G_{3}--$ Plotted against

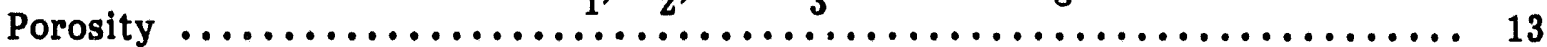

5 A Typical Computational Cell, Showing the Location of Quantities Occurring in the Finite-Difference Equations . ............................ 16

6 The Staggered Computational Mesh for Momentum Equations ............ 21

7 The Computing Mesh and the Surrounding Perimeter of Fictitious Boundary Cells ............................................... 26

8 Single-Subscript Notation for Cell and Cell-Edge Quantities about Cell .............................................. 28

9 Boundary Cell Flags $\ldots \ldots \ldots \ldots \ldots \ldots \ldots \ldots \ldots \ldots \ldots \ldots \ldots \ldots \ldots \ldots \ldots \ldots$

10 A Hypothetical Problem Illustrating the Cell Types $\ldots \ldots \ldots \ldots \ldots \ldots \ldots \ldots \ldots$

11 Top and Right Outflow Boundaries $\ldots \ldots \ldots \ldots \ldots \ldots \ldots \ldots \ldots \ldots \ldots \ldots \ldots \ldots$

12 Bottom and Left Inlet Boundaries $\ldots \ldots \ldots \ldots \ldots \ldots \ldots \ldots \ldots \ldots \ldots \ldots \ldots$

13 Pressure Distribution Initialization for $\mathrm{MFFLAG}=2 \ldots \ldots \ldots \ldots \ldots \ldots$

14 FLUFIX Solution Procedure $\ldots \ldots \ldots \ldots \ldots \ldots \ldots \ldots \ldots \ldots \ldots \ldots \ldots \ldots \ldots \ldots \ldots$

15 The Iteration Loop in Subroutine ITER $\ldots \ldots \ldots \ldots \ldots \ldots \ldots \ldots \ldots \ldots \ldots \ldots$

16 Solution Methods for Pressure Correction $\ldots \ldots \ldots \ldots \ldots \ldots \ldots \ldots \ldots \ldots \ldots$

17 FLUFIX Program Structure and the Main Subroutine Calling Sequence ....... 54

18 Example Showing Two, One, and Zero Inflow Openings along the Bottom Boundary ........................................ 58

19 Noncontinuum Solids Velocity Boundary Condition . . . . . . . . . . . . . 67 


\section{FIGURES (Cont'd)}

20 FLUfIX Sample Problem Geometry $\ldots \ldots \ldots \ldots \ldots \ldots \ldots \ldots \ldots \ldots \ldots \ldots$

A.1 Generated Determination of the Three Real Characteristic Roots.......... 105

\section{TABLES}

1 Summary Comparison of $\mathrm{K}-\mathrm{FIX}$ and FLUFIX Codes $\ldots \ldots \ldots \ldots \ldots \ldots \ldots$

2 Solids Elastic Modulus Parameters $\ldots \ldots \ldots \ldots \ldots \ldots \ldots \ldots \ldots \ldots \ldots \ldots \ldots \ldots$

3 Summary of Initial Condition Options $\ldots \ldots \ldots \ldots \ldots \ldots \ldots \ldots \ldots \ldots \ldots$

4 Summary of Boundary Condition Variables $\ldots \ldots \ldots \ldots \ldots \ldots \ldots \ldots \ldots \ldots \ldots$

5 Automatic Default Values for Given Parameters ................... 67

6 Conversion from CGS to SI Units $\ldots \ldots \ldots \ldots \ldots \ldots \ldots \ldots \ldots \ldots \ldots \ldots \ldots \ldots$

$7 \quad$ FLUfIX Sample Problem Input Data File $\ldots \ldots \ldots \ldots \ldots \ldots \ldots \ldots \ldots \ldots$

8 Sample Problem Output $\ldots \ldots \ldots \ldots \ldots \ldots \ldots \ldots \ldots \ldots \ldots \ldots \ldots \ldots \ldots \ldots \ldots$ 


\section{ACKNOWLEDGMENTS}

The support of the Cooperative R\&D Venture Participants listed on the cover page is gratefully acknowledged. All of the Steering Committee participants contributed materially to this document as a result of the FLUFIX Workshop held at Argonne, October 16-19, 1989.

Thierry Karger, an exchange visitor at Argonne during the summer of 1985, assisted in producing the preliminary automated initialization procedures and generalization of the FLUFIX/MOD1 code. 


\title{
USER'S MANUAL FOR FLUFIX/MOD2: \\ A COMPUTER PROGRAM FOR FLUID-SOLIDS HYDRODYNAMICS
}

by

R.W. Lyczkowski, J.X. Bouillard, and S.M. Folga

\begin{abstract}
This report describes FLUFIX/MOD2, a computer program that was developed as a two-dimensional analytical tool, based on a two-fluid hydrodynamic model, for applleation to fluid-flow simulation in fluid-solids systems and replaces the Interim User's Manual for FLUFIX/MOD1. The field equations that constitute the two-fluid model used in FLUFIX/MOD2 and the constitutive relationships required to close this system of equations, as well as the finite-difference equations that approximate these equations and their solution procedure, are presented and discussed. The global structure of FLUFIX/MOD2 that implements this solution procedure is discussed. The input data for FLUFIX/MOD2 are given, and a sample problem for a fluidized bed is described.
\end{abstract}

\section{INTRODUCTION}

The FLUFIX code effort was begun in 1978 with the development of a step-bystep building-block hydrodynamic modeling approach to understanding the hydrodynamics of fluidized beds, an approach that is closely coupled to validation experiments. ${ }^{1}$ This work formed the basis of a response to a U.S. Department of Energy (DOE) University Program Request for Proposal (RFP). A two-year grant to study solids circulation around a jet in a fluidized bed was awarded to the Illinois Institute of Technology (IIT) in September 1978. In mid-1979, the K-FIX computer progrum was obtained and modified so that it would model a fluidized bed with a central jet. ${ }^{2}$ This required transforming $\mathrm{K}$-FIX from a gas-liquid computer program to a gas-solids cor, more generally, a fluidsolids) computer program.

A two-year grant in January 1980 by the Gas Research Institute (GRI), a threeyear National Science Foundation (NSF) grant in 1982, and a two-year contract with Westinghouse Electric Corp. (Synthetic Fuels Division; now KRW Energy Systems, Inc.) in 1981 made it possible to continue implementing the step-by-step approach. The resulting publications ${ }^{3-13}$ have demonstrated the capabilities of the FI.UFIX code and provided peer recognition of the significance of the results. The collaborative research outlined above produced a code called IIT, which, for purposes of Argonne's work for the Cooperative R\&D Venture "Erosion of FBC Heat Transfer Tubes," we call "FLUFIX." 
The basic differences between K-FIX and FLUFIX are shown in Table 1. A line-by-line comparison of the two codes was performed for METC. ${ }^{14}$

In addition to the version of FLUFIX now being used by Argonne, experimental versions of the code have been developed for the following applications:

1. Gas-solids and wall-solids/wall-gas heat transfer, 15

2. Multiple solids species (to analyze mixing of two particle sizes), ${ }^{16}$

3. Multiple gas species and coal-gasification chemistry, ${ }^{17}$ and

4. Liquid-solid lamella electrosettling. 18

The FLUFIX/MOD2 computer program incorporates the K-FIX numer
scheme. ${ }^{2}$ The major modifications made in order to model fluid-solids systems are:

1. Gas/liquid-solids interphase drag functions to cover the entire range from very dense to very dilute solids flow $(\approx 0.2 \leq \varepsilon \leq 1)$,

2. A solids-phase stress term related to solids pressure to keep the bed from compacting below a packed-bed state $(\varepsilon \approx 0.37)$ and to provide numerical stability,

TABLE 1 Summary Comparison of K-FIX and FLUFIX Codes

\begin{tabular}{|c|c|c|}
\hline It em & $\mathrm{K}-\mathrm{F} I \mathrm{X}$ & FLUF IX \\
\hline Interphase Drag & Gas-1 iquid & Gas-solids \\
\hline Flexibility & LMFBR HCDR specific & $\begin{array}{l}\text { Fluidized bed, pneumatic } \\
\text { transport }\end{array}$ \\
\hline Initial Conditions & Assumed uniform & Uniform and nonuniform \\
\hline \multirow[t]{2}{*}{ Stability } & Unstable equations & $\begin{array}{l}\text { Stabilized equations with solids- } \\
\text { stress term }\end{array}$ \\
\hline & $\begin{array}{l}\text { Transition to single } \\
\text { phase is unstable }\end{array}$ & $\begin{array}{l}\text { Numerical scheme modified to } \\
\text { stabilize transition to single } \\
\text { phase, other stable equation set } \\
\text { included }\end{array}$ \\
\hline
\end{tabular}


3. The option of a second set of field equations with the pressure drop in the gas phase above, and

4. Automatic initialization procedure for fluidized beds.

These are the major changes in K-FIX that resulted in the computer program FLUFIX/MOD2.* The field equations that constitute the two-fluid model basis for FLUFIX/MOD2 are presented and discussed in Sec. 2. However, these field equations are not a closed system of equations until all quantities appearing in them are expressed as functions of the basic variables. The constitutive relationships needed to close this equation system are presented and discussed in Sec. 3.

The complexity of the field equations makes obtaining exact solutions highly unlikely; therefore, numerical solutions must be obtained. To obtain these numerical solutions, finite-difference equations that are consistent approximations to the field equations and that have solutions that converge to the solutions of the field equations must be obtained and solved. Such finite-difference equations are presented and discussed in Sec. 4.

With initial conditions given and appropriate boundary conditions imposed, these finite-difference equations are solved iteratively, using a point relaxation technique. The solution procedure used for these equations, the initial conditions that begin this solution in time, and the boundary conditions that may be imposed are presented and discussed in Sec. 5. The global structure of FLUFIX/MOD2 that implements this solution procedure is discussed in Sec. 6, and the input-data description for FLUFIX/MOD2 is given in Sec. 7.

Finally, a sample problem for a fluidized bed is given in Sec. 8. The appendixes provide a stability analysis of the numerical scheme (App. A) and a list of the FORTRAN symbols and definitions (App. B).

*The major difference between FLUX/MOD2 and FLUFIX/MOD $1^{19}$ is the reinstatement of the viscous stress terms as contained in the K-FIX computer program ${ }^{2}$ together with minor corrections. 


\section{HYDRODYNAMIC MODELS}

The two hydrodynamic models programmed in the FLUFIX/MOD2 code are presented in this section.

\subsection{HYDRODYNAMIC MODEL A}

The hydrodynamic model of fluidization uses the principles of conservation of mass, momentum, and energy. The continuity equations and the separate phase momentum equations for two-dimensional, transient, isothermal two-phase flow (in Cartesian coordinates), which form the basis of the FLUFIX code, are given below (terms are defined in the Nomenclature list at the end of this report). Although the word gas is used throughout, the word fluid meaning gas or liquid is implied.

Gas-phase continuity

$$
\frac{\partial}{\partial t}\left(\rho_{g} \varepsilon\right)+\frac{\partial}{\partial x}\left(\varepsilon \rho_{g} U_{g}\right)+\frac{\partial}{\partial y}\left(\varepsilon \rho_{g} V_{g}\right)=0
$$

Solids-phase continuity

$$
\frac{\partial}{\partial t}\left[\rho_{S}(1-\varepsilon)\right]+\frac{\partial}{\partial x}\left[\rho_{S} U_{S}(1-\varepsilon)\right]+\frac{\partial}{\partial y}\left[\rho_{S} V_{s}(1-\varepsilon)\right]=0
$$

Gas-phase momentum in $x$-direction

$$
\begin{aligned}
\frac{\partial}{\partial t}\left(\rho_{g} \varepsilon U_{g}\right) & +\frac{\partial}{\partial x}\left(\rho_{g} \varepsilon U_{g} U_{g}\right)+\frac{\partial}{\partial y}\left(\rho_{g} \in V_{g} U_{g}\right) \\
& =-\varepsilon \frac{\partial P}{\partial x}+{ }_{A, x}\left(U_{S}-U_{g}\right)+\text { SUG }-\rho_{g} \varepsilon g_{x}
\end{aligned}
$$

Solids-phase momentum in $x$-direction

$$
\begin{aligned}
\frac{\partial}{\partial t}\left[\rho_{s}(1-\varepsilon) U_{s}\right] & +\frac{\partial}{\partial x}\left[\rho_{s}(1-\varepsilon) U_{s} U_{s}\right]+\frac{\partial}{\partial y}\left[\rho_{s}(1-\varepsilon) V_{s} U_{s}\right] \\
& =-(1-\varepsilon) \frac{\partial P}{\partial x}+\beta_{A, x}\left(U_{g}-U_{s}\right)+G(\varepsilon) \frac{\partial \varepsilon}{\partial x}+S U L-\rho_{s}(1-\varepsilon) g_{x}
\end{aligned}
$$


Cras-phase momentum in y-direction

$$
\begin{aligned}
\frac{\partial}{\partial t}\left(\rho_{g} \varepsilon V_{g}\right) & +\frac{\partial}{\partial x}\left(\rho_{g} \varepsilon U_{g} V_{g}\right)+\frac{\partial}{\partial y}\left(\rho_{g} \varepsilon V_{g} V_{g}\right) \\
& =-\varepsilon \frac{\partial P}{\partial y}+\beta_{A, y}\left(V_{s}-V_{g}\right)-\rho_{g} \varepsilon g_{y}+S V G
\end{aligned}
$$

Solids-phase momentum in y-direction

$$
\begin{gathered}
\frac{\partial}{\partial t}\left[\rho_{s}(1-\varepsilon) V_{s}\right]+\frac{\partial}{\partial x}\left[\rho_{s}(1-\varepsilon) U_{s} V_{s}\right]+\frac{\partial}{\partial y}\left[\rho_{s}(1-\varepsilon) V_{s} V_{s}\right] \\
=-(1-\varepsilon) \frac{\partial P}{\partial y}+\beta_{A, y}\left(V_{g}-V_{s}\right)-\rho_{s}(1-\varepsilon) g_{y}+G(\varepsilon) \frac{\partial \varepsilon}{\partial y}+S V L
\end{gathered}
$$

The solids elastic modulus, $G(\varepsilon)$, is used to calculate the normal component of the solids stress through the following relationship:

$$
\partial \tau=\frac{\partial \tau}{\partial \varepsilon} \partial \varepsilon=\mathbf{G}(\varepsilon) \partial \varepsilon
$$

which is similar to what is done in solid mechanics.

Six nonlinear, coupled, partial differential equations must be solved for the six dependent variables: the void fraction, $\varepsilon$; the pressure, $P$; and the gas velocity components $U_{g}$ and $V_{g}$ and the solids velocity components $U_{s}$ and $V_{s}$ in the $x$ - and $y$-directions, respectively. The equations are written in a form similar to that used in the K-FIX computer code, from which FLUFIX has been developed. ${ }^{2}$ The conservation equations in the FLUFIX code are solved in the following three coordinate systems:

1. Spherical coordinates (Fig. 1). Calculations are one-dimensional in the $\mathbf{r}$ direction, with symmetry in the $\theta$ and $\phi$ directions. Although this option was described in the K-FIX computer manual, ${ }^{2}$ it is not actually in the computer program.

2. Axisymmetric cylindrical coordinates (Fig. 2). Calculations are twodimensional in the $r$ and $z$ directions, with symmetry about the $z$ axis. An offset from the axis of symmetry can be incorporated to model annular regions. 


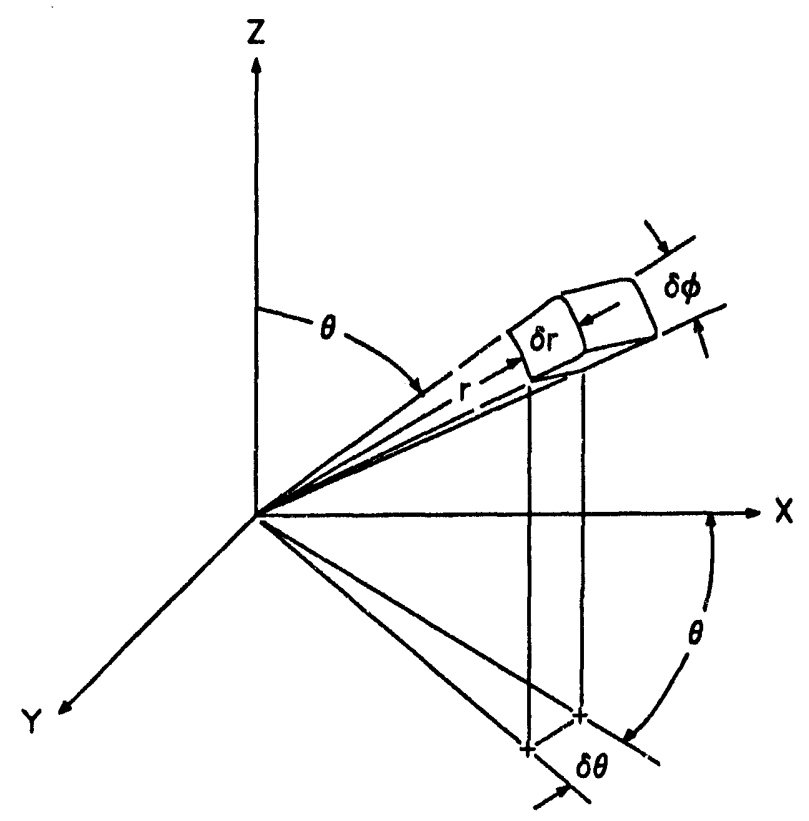

FIGURE 1 Spherical Coordinates

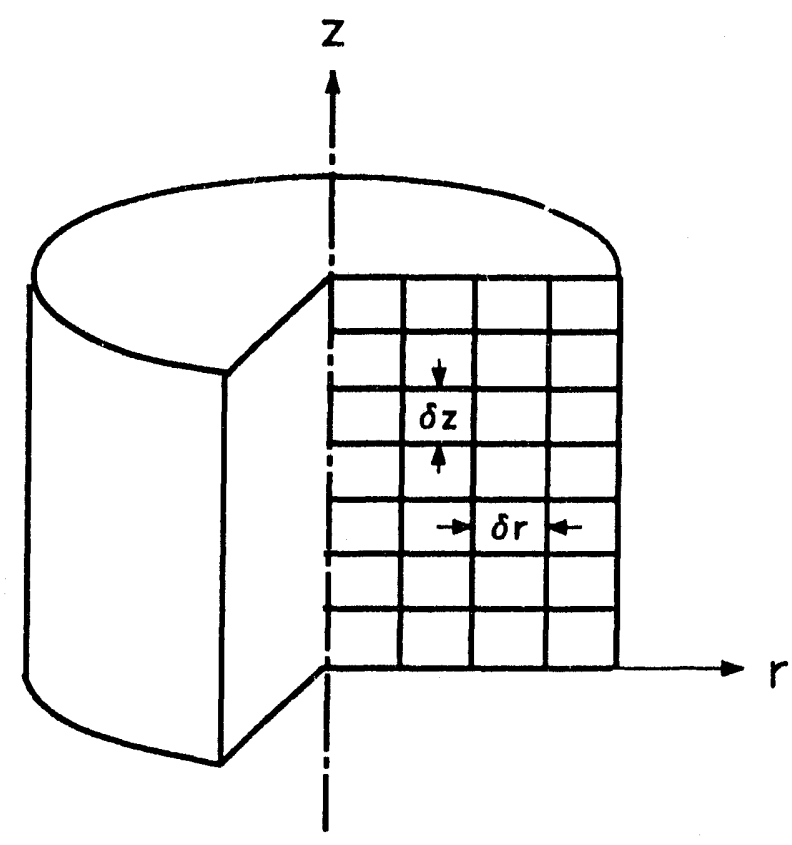

FIGURE 2 Axisymmetric Cylindrical Coordinates

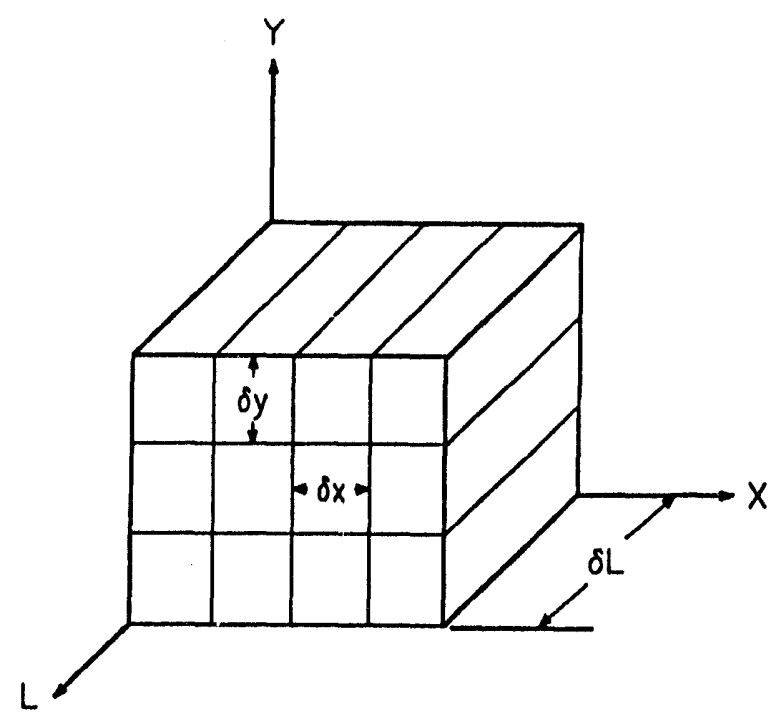

FIGURE 3 Cartesian Coordinates

In the Cartesian coordinate system, the gravity vector may be oriented in any direction in the two-dimensional computing plane by simple modifications to the computer program. In the cylindrical coordinate system, the gravity vector must be parallel to the axis of symmetry. In the spherical coordinate system, the gravity vector should be set to zero.

The solution procedure described in Secs. 3 and 4 uses the Implicit Multifield (IMF) numerical technique. ${ }^{20}$

The treatment of the pressure-gradient term in the gas- and solids-phase momentum equations (Eqs. 2.3-2.6) results in an initial value problem that is ill-posed (i.e., one that possesses complex characteristics, as has been discussed in detail by 
Lyczkowski et al. ${ }^{21}$ ). This situation leads to a generally unstable numerical solution. This set of momentum equations is sometimes referred to as the annular flow model ${ }^{22}$ or the basic equation set. ${ }^{23}$ In this study, we refer to this set as Hydrodynamic Model $\mathrm{A}$.

\subsection{HYDRODYNAMIC MODEL B}

A set of momentum equations that is well-posed (i.e., possesses all real characteristics) was first given by Rudinger and Chang ${ }^{24}$ and was extended by Lyczkowski. ${ }^{25}$ These equations are as follows:

Gas-phase momentum in $x$-direction

$$
\begin{aligned}
\frac{\partial}{\partial t}\left(\rho_{g} \varepsilon U_{g}\right) & +\frac{\partial}{\partial x}\left(\rho_{g} \varepsilon U_{g} U_{g}\right)+\frac{\partial}{\partial y}\left(\rho_{g} \varepsilon V_{g} U_{g}\right) \\
& =-\frac{\partial P}{\partial x}+\beta_{B, x}\left(U_{S}-U_{g}\right)+S U U G-\rho_{g} \varepsilon g_{x}
\end{aligned}
$$

Solids-phase momentum in $x$-direction

$$
\begin{gathered}
\frac{\partial}{\partial t}\left[\rho_{s}(1-\varepsilon) U_{s}\right]+\frac{\partial}{\partial x}\left[\rho_{s}(1-\varepsilon) U_{s} U_{s}\right]+\frac{\partial}{\partial y}\left[\rho_{s}(1-\varepsilon) V_{s} U_{s}\right] \\
=\beta_{B, x}\left(U_{G}-U_{s}\right)+G(\varepsilon) \frac{\partial \varepsilon}{\partial x}+S U L-\rho_{s}(1-\varepsilon) g_{x}
\end{gathered}
$$

Gas-phase momentum in $y$-direction

$$
\begin{aligned}
\frac{\partial}{\partial t}\left(\rho_{g} \varepsilon V_{g}\right) & +\frac{\partial}{\partial x}\left(\rho_{g} \in U_{g} V_{g}\right)+\frac{\partial}{\partial y}\left(\rho_{g} \varepsilon V_{g} V_{g}\right) \\
& =-\frac{\partial P}{\partial y}+B_{B, y}\left(V_{s}-V_{g}\right)-\rho_{g} \varepsilon g_{y}+S V G
\end{aligned}
$$

Solids-phase momentum in $y$-direction

$$
\begin{gathered}
\frac{\partial}{\partial t}\left[\rho_{s}(1-\varepsilon) V_{s}\right]+\frac{\partial}{\partial x}\left[\rho_{s}(1-\varepsilon) U_{s} V_{s}\right]+\frac{\partial}{\partial y}\left[\rho_{s}(1-\varepsilon) V_{s} V_{s}\right] \\
=\beta_{B, y}\left(V_{g}-V_{s}\right)-\rho_{s}(1-\varepsilon) g_{y}+G(\varepsilon) \frac{\partial \varepsilon}{\partial y}+S V L
\end{gathered}
$$


A major difference between Eqs. 2.8-2.11 and Eqs. 2.3-2.6 is that all pressure drops in the former are in the gas-phase momentum equations, with none in the solidsphase momentum equations. We refer to this second set of momentum equations (Eqs. 2.8-2.11) as Hydrodynamic Model B. The continuity equations 2.1 and 2.2 are common to both sets. Hydrodynamic Model $B$ is the default model programmed in the FLUFIX code. FLUFIX has an input flag to select Model B.

The terms SUG, SUL, SVG, and SVL represent the viscous stress terms for the gas and solids phses, respectively, in symbolic form. Their presence marks the primary difference from FLUFIX/MOD1. ${ }^{19}$ For details of their form, the reader is referred to $\mathrm{K}-\mathrm{FIX}{ }^{2}$ and Reference 8. 


\section{CONSTITUTIVE RELATIONSHIPS}

The constitutive relationships that close the two sets of hydrodynamic models are described in this section.

\subsection{INTERPHASE DRAG}

A significant difference between Hydrodynamic Model $\mathrm{A}$ and Hydrodynamic Model $B$ is the fluid-particle friction (drag) tensors $\overline{\bar{B}}_{A}$ and $\overline{\bar{\beta}}_{B}$. In order to relate them, we perform a simple analysis following Gidaspow. ${ }^{9}$

The $y$-direction (vertical) momentum equations for Hydrodynamic Model A (Eqs. 2.5 and 2.6), with negligible acceleration and stress, are as follows:

$$
\begin{aligned}
& 0=-\varepsilon \frac{\partial P}{\partial y}+\beta_{A, y}\left(V_{g}-V_{g}\right)-\rho_{g} \varepsilon g \\
& 0=-(1-\varepsilon) \frac{\partial P}{\partial y}+\beta_{A, y}\left(V_{g}-V_{s}\right)-\rho_{s}(1-\varepsilon)_{g}
\end{aligned}
$$

The sum of Eqs. 3.1 and 3.2 gives the mixture momentum equation, usually called the manometer formula:

$$
-\frac{\partial P}{\partial y}=g\left[\rho_{g} \varepsilon+\rho_{g}(1-\varepsilon)\right]
$$

which is the well-known equation in Kunil and Levenspiel's book. ${ }^{26}$ Equation 3.3 states that the pressure drop equals the weight of the bed. Solving for $\partial \mathrm{P} / \partial y$ from Eq. 3.1 and combining with Eq. 3.3 gives

$$
-\left(\frac{A_{1} y}{\varepsilon}\right)\left(V_{s}-V_{g}\right)=(1-\varepsilon)\left(\rho_{s}-\rho_{g}\right) g=-\left.\frac{\Delta P}{\Delta y}\right|_{\text {frict, } A}
$$

This equation, also found in Kunii and Levenspiel's book, makes it clear that the principal loss term in fluidization is due to the drag. Equation 3.4 states that the frictional loss equals the buoyant force.

The y-direction (vertical) momentum equations for Hydrodynamic Model B (Egs. 2.10 and 2.11), with negligible acceleration and normal stress, are as follows:

$$
0=-\frac{\partial P}{\partial y}+\beta_{B, y}\left(V_{s}-V_{g}\right)-\rho_{g} \varepsilon g
$$




$$
0=\beta_{B, y}\left(V_{g}-V_{s}\right)-\rho_{s}(1-\varepsilon)_{B}
$$

The sum of Egs. 3.5 and 3.6 also gives the mixture momentum equation (manomometer formula), Eg. 3.3. Solving for $\partial \mathrm{P} / \partial y$ from Eq. 3.5 and combining with Eq. 3.3 gives

$$
-\beta_{B, y}\left(V_{8}-V_{g}\right)=(1-\varepsilon) \rho_{8} g
$$

By combining Egs. 3.4 and 3.7, the fluid-particle friction coefficients ${ }_{A, y}$ and ${ }_{B, y}$ are related as follows:

$$
B_{B, y}=\frac{{ }^{B} A_{,} x_{s}}{\varepsilon\left(\rho_{s}-\rho_{g}\right)} \propto \frac{{ }^{\beta} A, y}{\varepsilon}
$$

Thus, whatever interphase drag expression, ${ }^{B} \mathrm{~A}, \mathrm{y}$, is chosen for the Hydrodynamic Model A momentum equations, the expression for Hydrodynamic Model B interphase drag, ${ }^{\beta} \mathrm{B}, \mathrm{y}$, should divide it approximately by the gas-phase volume fraction, $\varepsilon$, since $\rho_{s}$ is much greater than $\rho_{\mathrm{g}}$. The interphase drag expressions in the $x$ direction are related in the same way, for similar reasons:

$$
B_{B, X} \simeq \frac{{ }^{B} A, x}{\varepsilon}
$$

The coefficient ${ }^{\beta} \mathrm{A}, \mathrm{x}$ is obtained from standard correlations. ${ }^{7}$ Below a porosity of $0.8,{ }^{\beta} \mathrm{A}$ is given by the Ergun equation; ${ }^{27}$ above 0.8 , it is given by Wen and Yu's expression 28 as discussed by Gidaspow. ${ }^{9}$ These expressions may be summarized as follows:

$$
B_{A}= \begin{cases}150 \frac{(1-\varepsilon)^{2} \mu_{g}}{\varepsilon\left(d_{p} \phi_{s}\right)^{2}}+1.75 \frac{\rho_{g}\left|\vec{v}_{g}-\vec{v}_{s}\right|(1-\varepsilon)}{d_{p} \phi_{s}} & \varepsilon \leq 0.8 \\ \frac{3}{4} c_{d y} \frac{\varepsilon\left|\vec{v}_{g}-\vec{s}_{s}\right| \rho_{g}(1-\varepsilon)}{d_{p} \phi_{s}} \varepsilon^{-2.70} & \varepsilon>0.8\end{cases}
$$

$$
C_{d y}= \begin{cases}24\left(1+0.15 \operatorname{Re}_{y}^{0.687}\right) / \operatorname{Re} y & \operatorname{Re}_{y} \leq 1000 \\ 0.44 & \operatorname{Re}_{y}>1000\end{cases}
$$


where the Reynolds number is given by

$$
R e_{y}=\frac{\left|\vec{v}_{g}-\vec{v}_{g}\right| d_{p} \phi_{g} \rho_{g} \varepsilon}{\mu_{g}}
$$

Two forms for $\left|\vec{v}_{g}-\vec{v}_{s}\right|$ are available in FLUFIX/MOD2. The first is the vector form given by $\left|\vec{v}_{g}-\vec{v}_{g}\right|=\left|\left(U_{g_{g}}-u_{g}|,| v_{g_{g}}-v_{s}\right)\right|$. The second is the scalar form given by $\left|\vec{v}_{g}-\vec{v}_{s}\right|^{g}=\left[\left(u_{g}^{2}-U_{s}^{8}\right)^{1 / 2^{g}}+\left(v_{g}^{g}-v_{s}^{2}\right)^{1 / 2}\right]$.

\subsection{SOLIDS STRESS}

The two sets of momentum equations contain a normal component of solids-phase stress, $\tau$, sometimes associaied with solids-phase pressure or particle-to-particle interactions in the solids-phase momentum equations (Eqs. 2.4, 2.6, 2.9, and 2.11). A general formulation of such a term would include the effects of porosity, pressure, and the displacement tensors of solids velocity, gas velocity, and relative velocity. No such formulation with appropriate material constants is available today. This solids stress is physically necessary to prevent the particles from compacting to unreasonably low gas volume fractions. The static normal component of this stress, usually called the Coulomb's component, has been used by Pritchett et al., ${ }^{29}$ Gidaspow et al., $3-13,15-18$ Padhye, 30 and Concha and Bustos. 31

This Coulomb's component is quite small at minimum fluidization, but it becomes increasingly important as the particles contact each other. In fact, it acts as a repulsive pressure at high solids fraction. Molerus ${ }^{32}$ interpreted this phenomenon as the direct result of Hertz's contact pressure, which is a function of the particle Young's elasticity modulus. This interpretation allows us to relate solids stress measurements to material properties of the powder.

The measurement of this term has been reported by Rietema and Mutsers ${ }^{33}$ and by Piepers et al. 34 There is considerable disagreement as to the exact form of this stress. Shinohara summarizes 15 different expressions correlating the solids repulsive pressure with the bulk solids volume fraction. 35 Unfortunately, these relations lack any strong physical basis.

To place the Coulomb's component in perspective, we must consider the mechanisms of particulate compaction in agglomeration. 35,36 The motivation for the most generally satisfactory expression is the experimental observation that plotting the logarithm of consolidating pressure vs. volume yields a substantially straight line for both metallic and nonmetallic powders undergoing compaction. We used this simple theory to derive a generalized solids elastic modulus coefficient, $G(\varepsilon)$, of the form

$$
G(\varepsilon) / G_{0}=\exp \left[-c\left(\varepsilon-\varepsilon^{*}\right)\right]
$$


where c (called the compaction modulus) is the slope of $\ln (G)$ vs. $\varepsilon$ and $\varepsilon^{*}$ is the compaction gas volume fraction. The normalizing units factor, $G_{0}$, has been taken to be $1.0 \mathrm{~Pa}$ for convenience. For $\varepsilon>\varepsilon^{*}$, the exponent of $\mathrm{Eg}$. 3.13 becomes negative, and the solids elasticity modulus $G$ becomes smaller as $\varepsilon$ becomes larger. However, for $\varepsilon<\varepsilon^{*}$, elasticity modulus $G$ becomes larger as $\varepsilon$ decreases, thus preventing the solids volume fractions from being larger than $1-\varepsilon^{*}=\varepsilon_{\mathrm{s}}{ }^{*}$.

Equation 3.13 is a convenient and consistent expression with which to interpret the physical significance of solids pressure data. We haye converted the following into the form of Eq. 3.13: (1) the Rietema and Mutsers data, ${ }^{33}$ as curve fit by Gidaspow and Ettehadieh; ${ }^{7}$ (2) the expression used by Gidaspow and Syamlal for solids-gas critical flow; ${ }^{10}$ and (3) the expression used for hydrodynamics and erosion calculations for a fluldized bed containing an obstacle. $8,11,12$ Results are indicated in Table 2 and plotted in Fig. $\%$

In the above analysis, $\mathrm{G}(\varepsilon)=1.0 \mathrm{~Pa}$ when $\varepsilon=\varepsilon^{*}$. The Rietema and Mutsers model is inappropriate to keep the bed from compacting, because the model was developed for data taken at a much higher compaction porosity (0.62), and the compaction modulus is very low. Porr sities below 0.2 have resulted with this model. Gidaspow and Syamlal's model, developed from data on solids-gas flow through aerated hoppers, is appropriate at a compaction porosity near minimum fluidization (0.422). 37 The compaction modulus is high because the particles are being compacted as they flow down through the hopper. Our model has a somewhat higher compaction modulus and a lower compaction porosity, more appropriate for a packed bed (0.376). This is necessary because of the greater compaction resulting from solids striking the obstacle.

Fanucci et al. ${ }^{38}$ obtained the characteristic directions for one-dimensional incompressible flow for the set of equations constituting Hydrodynamic Model A (Eqs. 2.1-2.6). One such characteristic direction, $\mathrm{C}$, is as follows:

$$
C=\left(\frac{\rho_{s}}{\varepsilon_{s}}+\frac{\rho_{g}}{\varepsilon_{g}}\right)^{-1 / 2}\left[\frac{-\left(v_{g}-v_{s}\right)^{2}}{\frac{\varepsilon_{g}}{\rho_{g}}+\frac{\varepsilon_{g}}{\rho_{s}}}+\frac{G(\varepsilon)}{\varepsilon_{s}}\right] 1 / 2
$$

TABLE 2 Solids Elastic Modulus Parameters

\begin{tabular}{ccccc}
\hline Modulus & $c$ & $\left(G\right.$ in $\left.^{\varepsilon^{*}} \mathrm{~Pa}\right)$ & Reference & $\begin{array}{c}\varepsilon^{*} \\
\left.\text { (G in dynes } / \mathrm{cm}^{2}\right)\end{array}$ \\
\hline$G_{1}$ & 600 & 0.376 & Lyczkowski et $\mathrm{al.8,11,12}$ & 0.384 \\
$\mathrm{G}_{2}$ & 500 & 0.422 & Gidaspow and Syamlal 10 & 0.427 \\
$\mathrm{G}_{3}$ & 20 & 0.62 & $\begin{array}{l}\text { Gidaspow and Ettehadieh } \\
\text { Rietema and Mutsers } 33\end{array}$ & 0.735
\end{tabular}




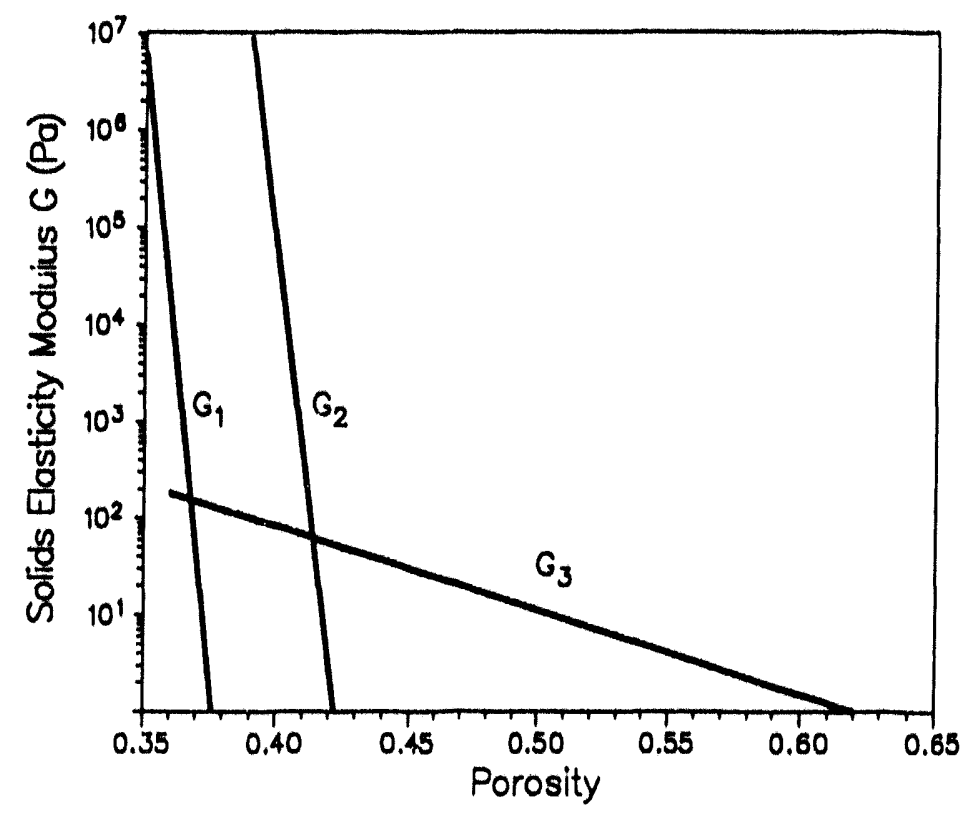

FIGURE 4 Three Solids Elastic Moduli $-G_{1}, G_{2}$, and $\mathrm{G}_{3}-$ Plotted against Porosity

This equation shows that, as the solids stress modulus, $G(\varepsilon)$, becomes increasingly large, real characteristic directions are maintained. Therefore, this term helps to stabilize the system of equations describing Hydrodynamic Model A, which are conditionally stable as an initial-value problem. ${ }^{2}$

However, as Boulllard ${ }^{39}$ has explained (see App. A), the FLUFIX numerical scheme appears to give a stable and acceptable solution to the 111 -posed model, because the numerical characteristics of the numerical scheme are real. No major difficulties should exist for Hydrodynamic Model $B$, because this model is well-posed. 25,40 For this reason, we recommend the use of Hydrodynamic Model $B$.

\subsection{EQUATIONS OF STATE}

The equations of state for the gas and solids phases are given by simple expressions that can be easily changed to reflect more complicated functional relationships. The expressions used, in terms of the FLUFIX internal (cgs) units, are as follows:

$$
\begin{aligned}
& \text { ROC }=\rho_{g}=R O G C 1+R O C C 2 \cdot T+P /(R O C C 3 \cdot T), g / \mathrm{cm}^{3} \\
& \text { ROL }=\rho_{s}=\text { ROLCL }+ \text { ROLC2 } \cdot T+P \cdot R O L C 3 / T, g / \mathrm{cm}^{3}
\end{aligned}
$$


wheres $T=$ temperature $(K)$ and $P=$ pressure $\left(\right.$ dynes $\left./ \mathrm{cm}^{2}\right)$.

Default values for the constants are given by

$$
\text { ROGC1 }-0.0, \text { ROGC2 }=0.0 \text {, and ROGC3 }=2.87 \times 10^{6} \mathrm{erg} /(8 \cdot K)=R / M
$$

where $R=8.314 \times 10^{7} \mathrm{erg} /(\mathrm{g}-\mathrm{mole} \cdot \mathrm{K}$ ) and $M=29 \mathrm{~g} / \mathrm{g}-\mathrm{mol}$ (air)

$$
\text { ROLC1 }=2.611 \mathrm{~g} / \mathrm{cm}^{3}, \text { ROLC2 }=0.0 \text {, and ROLC3 }=0.0
$$

At present, $\rho_{g}$ is a constant, whereas $\rho_{g}$ is given by an ideal compressible gas. The square of the speed of sound for the gas is given for an ideal gas as

$$
c_{8}^{2}=\rho_{g} / p
$$

\subsection{MISCELLANEOUS PARAMETERS}

The default values for the remaining physical properties and parameters used in the interphase drag are:

$$
\begin{aligned}
& \text { MMUC }=\mu_{g}=1.82 \times 10^{-4} \text { poise, } \mathrm{PHI}=\phi_{g}=0.86, \\
& \text { and DP }=d_{P}=0.0503 \mathrm{~cm}
\end{aligned}
$$

\subsection{VISCOUS STRESS TERMS}

The viscous stress terms, $\bar{\tau}_{k v}$, are given by:

$$
\bar{\tau}_{k v}=2 \mu_{k} \overline{\bar{D}}_{k}-\frac{2}{3} \mu_{k} \nabla \cdot \vec{v}_{k} \bar{I}
$$

where the deformation tensor $\overline{\bar{D}}_{k}$ is given by:

$$
\bar{D}_{k}=\frac{1}{2}\left[\nabla \vec{v}_{k}+\left(\nabla \vec{v}_{k}\right)^{\mathrm{T}}\right]
$$


and $I$ is the unit tensor. $\bar{\tau}_{\text {kV }}$ includes the terms SUG, SUL, SVG, and SVL in the gas $(k=g)$ and solids $(k=s)$ momentum equations for both hydrodynamic models $A$ and $B$. The default values of the viscosities used in the viscous stress terms are given by:

$$
\text { MUG }=\mu_{g}=1.82 \times 10^{-4} \text { poise and MUL }=\mu_{s}=1 \text { poise }
$$

The coefficient (2/3) in Eg. 3.21 is the default value in FLUFIX given by LAMBG = LAMBL $=2 / 3$. 


\section{FINITE-DIFFERENCE RQUATIONS}

Numerical solutions to Eqs. 2.1-2.6 or 2.8-2.11 must be obtained, because the complexity of these field equations makes obtaining exact solutions unlikely. To obtain these numerical solutions, finite-difference equations that are consistent approximations to the fleld equations and have solutions that converge to the solutions of the field equations must be obtained and solved. Such finite-difference equations are presented and discussed in this section.

The representation of the flelds with these finite-difference equations is accomplished by using a completely Eulerian mesh of finite-difference cells. In Cartesian coordinates $(x, y)$, these cells are rectangles with dimensions $\delta x$ and $\delta y(F i g .3)$; in cylindrical coordinates $(r, z)$, these cells are toroids about the $z$ axis with rectangular cross sections and dimensions of $\delta \mathrm{r}$ and $\delta z$ (Fig. 2).

A typical computational cell, cell $(i, j)$, in Cartesian coordinates and the relative spatial locations of the quantities that appear in the finite-difference equations are shown in Fig. 5. In this figure and in subsequent figures, the $x$ (or $r$ ) components of the gas and liquid velocities are denoted by $U_{g}$ and $U_{\ell}$, respectively. The Indexes $i$ and $j$ (or $I$ and $J)$ that label cell $(i, j)$ count cell centers in the $x$ or $r$ direction and the $y$ or $z$ direction, respectively, and assume only positive integer values. In Fig. 5 and elsewhere, half-integer indexes denote cell edge positions. The velocity components $U_{\mathfrak{g}}, U_{\ell}, V_{g}$ '

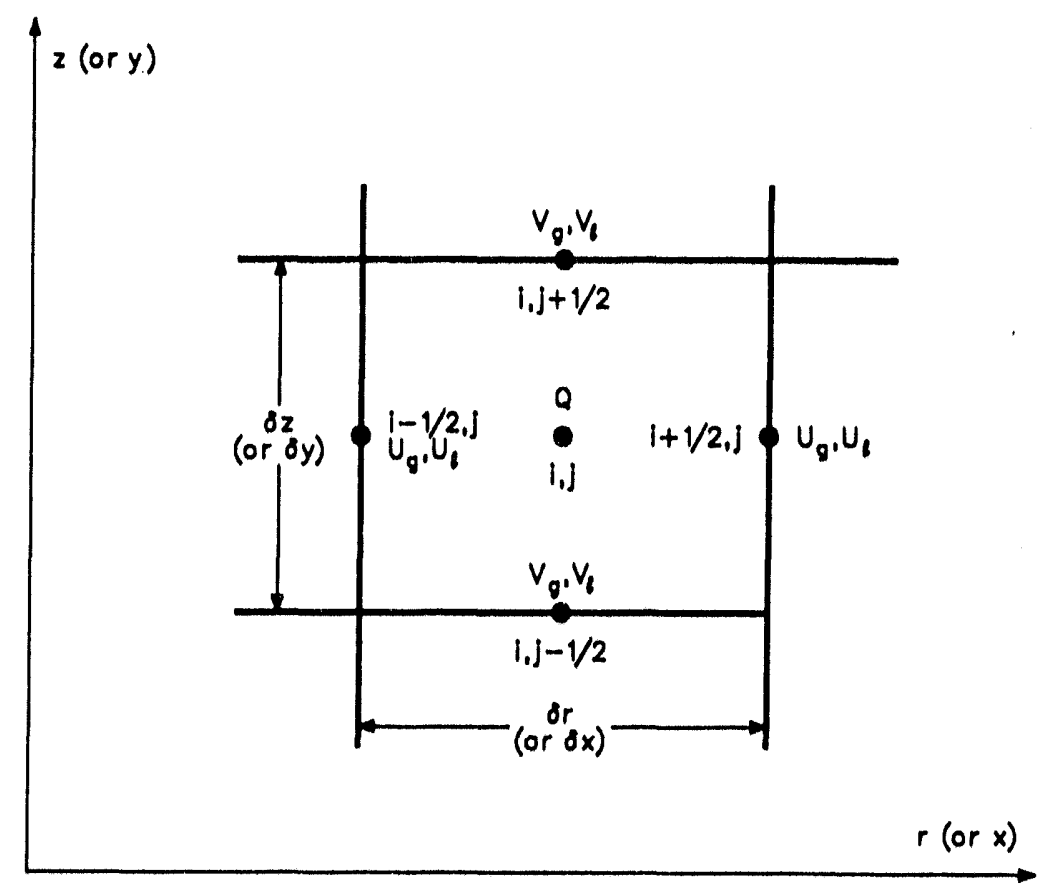

FIGURE 5 A Typical Computational Cell, Showing the Location of Quantities Occurring in the FiniteDifference Equations 
and $V_{\ell}$ are located at the centers of cell boundaries, as shown; the remaining quantities $\rho_{g}, \rho_{g}^{\prime}, \rho_{\ell}, \rho_{\ell}^{\prime}, \theta, B$, and $P$, collectively denoted by $Q$ in Fig. 5, are located at the center of the cell.

The following symbol equivalents are used in this section and in Sec. 5:

$$
\begin{aligned}
\rho_{\ell} & +\rho_{s} \\
\rho_{l}^{\prime} & =(1-\theta) \rho_{\ell}+\rho_{s}^{\prime}=(1-\varepsilon) \rho_{s} \\
\theta & +\varepsilon \\
\rho_{g}^{\prime} & =\theta \rho_{g}+\varepsilon \rho_{g}, \text { and } \\
K_{x}, K_{y} & \rightarrow{ }_{A}^{B}, x,{ }_{A, y}^{B}
\end{aligned}
$$

Using these symbols will enable the reader to compare the FLUFIX code finitedifference equations and solution scheme more easily with those of the original $\mathrm{K}$-FIX code. ${ }^{2}$

The finite-difference approximations to the field equations form a system of nonlinear algebraic equations relating quantities at time $t=(n+1) \delta t$, where $n$ is zero or a positive integer and $\delta t$ is the time increment by which these quantities advance each computational cycle. In these equations,

$$
\left(B_{g}\right)^{n}
$$

denotes the quantity $B$ for the gas at time $n \delta t$ and at the spatial location labeled by indexes $i, j$. Here and elsewhere, the index $n$ assumes the value zero or positive integer values and the indexes $i$ and $j$ assume positive integer or half-integer values. The corresponding quantity for the liquid has the subscript \&, rather than the subscript $g$. Quantities in these equations required at spatial locations other than where they are defined are obtained by arithmetic averaging; for example,

$$
\left(U_{g}\right)_{i, j}^{n}=\frac{1}{2}\left[\left(U_{g}\right)_{i-\frac{1}{2}, j}^{n}+\left(U_{g}\right)_{i+\frac{1}{2}, j}^{n}\right]
$$

The finite-difference approximations to terms that are the divergence of a scalar multiplied by a velocity are obtained by donor-cell differencing. This donor-cell differencing assists in the elimination of numerical instability resulting from truncation errors without the use of artificial diffusion. In the finite-difference equations, these donor-cell difference terms are denoted by

$$
<B U>_{i, j}^{n}
$$


where $B$ is given by $\theta,(1-\theta), \rho_{g}^{\prime}, \rho_{\ell}^{\prime},\left(\rho_{g}^{\prime} U_{g}\right),\left(\rho_{g}^{\prime} V_{g}\right),\left(\rho_{l}^{\prime} U_{l}\right)$, and $\left(\rho_{\ell}^{\prime} V_{\ell}\right)$, respectively. This quantity is given in general terms by

$$
<B U>_{i, j}^{n}=\{B U\}_{i, j}^{n}-\{B U\}_{i-1, j}^{n}
$$

where:

$$
\{B U\}_{i, j}^{n}=U_{i+\frac{1}{2}, j}^{n}\left[\left(\frac{1}{2}+\xi\right) B_{i, j}^{n}+\left(\frac{1}{2}-\xi\right) B_{i+1, j}^{n}\right]
$$

and

$$
\xi=\frac{1}{2} \operatorname{sign}\left(u_{i+\frac{1}{2}, j}^{n}\right)
$$

where "sign" denotes the signum function used in Fortran coding.

The expression for

$$
<B V>_{i, j}^{n}
$$

is given by

$$
<B V>_{i, j}^{n}=\{B V\}_{i, j}^{n}-\{B V\}_{i, j-1}^{n}
$$

where:

$$
\{B V\}_{i, j}^{n}=v_{i, j+\frac{1}{2}}^{n}\left[\left(\frac{1}{2}+\eta\right) B_{i, j}^{n}+\left(\frac{1}{2}-\eta\right) B_{i, j+1}^{n}\right]
$$

and

$$
n=\frac{1}{2} \operatorname{sign}\left(v_{i, j+\frac{1}{2}}^{n}\right)
$$

These finite-difference equations are written in cylindrical coordinates $(r, z)$ for generality. Some coordinate-system-dependent terms will now be defined. For Cartesian coordinates, 


$$
r_{i}=r_{i+\frac{1}{2}}=1
$$

for all $i$, and for cylindrical coordinates

$$
\begin{array}{rlrl}
r_{1} & =\delta r / 2 & \\
r_{i} & =\left(i-\frac{3}{2}\right) \delta r & i=2,3, \ldots, i_{\max } \\
r_{\frac{3}{2}} & =0 & \\
r_{i+\frac{1}{2}} & =(i-1) \delta r & i=2,3, \ldots, i_{\max }
\end{array}
$$

Geometrically, in cylindrical coordinates, $r_{i}$ is the $r$ coordinate of the center of cell $(i, j)$ and $r_{i+\frac{1}{2}}$ is the $r$ coordinate of points on the right edge of this cell, where $r$ is measured from the left edge of the $i=2$ column of cells.

\subsection{CONTINUITY EQUATIONS}

The finite-difference forms of the gas and liquid continuity equations are given by the following:

Finite-difference gas-phase continuity

$$
\begin{aligned}
\left(\rho_{g}^{\prime}\right)^{n+1} & =\left(\rho_{g}^{\prime}\right)_{i, j}^{n}+\delta t\left[-<\left(\rho_{g}^{\prime}\right)^{n+1} u_{g}^{n+1} r>{ }_{i, j} /\left(r_{i} \delta r\right)\right. \\
& -\left\langle\left(\rho_{g}^{\prime}\right)^{n+1} v_{g}^{n+1}>_{i, j} / \delta z\right]
\end{aligned}
$$

Finite-difference liquid-phase continuity

$$
\begin{aligned}
\left(\rho_{\ell}^{\prime}\right)^{n+1} & =\left(\rho_{\ell}^{\prime}\right)_{i, j}^{n}+\delta t\left[-<\left(\rho_{\ell}^{\prime}\right)^{n+1} u_{\ell}^{n+1} r>_{i, j} /\left(r_{i} \delta r\right)\right. \\
& \left.-<\left(\rho_{\ell}^{\prime}\right)^{n+1} v_{\ell}^{n+1}>_{i, j} / \delta z\right]
\end{aligned}
$$

The reduction of Eqs. 4.7 and 4.8 to Cartesian coordinates is accomplished by letting $r_{i}=1$ for all $i$. 


\subsection{MOMENTUM EQUATIONS}

The finite-difference momentum equations in this section are given for Hydrodynamic Model A. The meshes for similar Hydrodynamic Model B finite-difference momentum equations are shown in Fig. 6 for the $\mathrm{r}$ or $\mathrm{x}$ and $\mathrm{z}$ or $\mathrm{y}$ directions. Because all $\delta r$ (or $\delta x$ ) are the same and all $\delta z$ (or $\delta y$ ) are the same, the momentum cell sizes in these two directions equal the continuity cell sizes in these directions.

The finite-difference form of the $\mathrm{x}$ or $\mathrm{r}$ component of the momentum equation for the gas is given by

$$
\begin{aligned}
\left(\rho_{g}^{\prime} U_{g}\right)_{i+\frac{1}{2}, j}^{n+1} & =\overline{\left(\rho_{g}^{\prime} U_{g}\right)^{n}}+\delta t\left\{\begin{array}{c}
-\theta_{i+\frac{1}{2}, j}^{n+1} \\
i+\frac{1}{2}, j \\
+\left(R_{x}\right)_{i+1, j}^{n+1}, j
\end{array}-P_{i, j}^{n+1}\right) / \delta r \\
& \left.\left.\left(U_{\ell}\right)_{i+\frac{1}{2}, j}^{n+1}-\left(U_{g}\right)_{i+\frac{1}{2}, j}^{n+1}\right]\right\}
\end{aligned}
$$

where all the explicit terms have been grouped into $\overline{\left(\rho_{g}^{\prime} U_{g}\right)^{n}}$ as

$$
\begin{aligned}
& \overline{\left(\rho_{g}^{\prime} U_{g}\right)^{n}}=\left(\rho_{g+\frac{1}{2}, j}^{\prime} U_{g}\right)_{i-\frac{1}{2}, j}^{n}+\delta t \quad\left\{-\left\langle\left(\rho_{g}^{\prime}\right)^{\left.n_{U^{n}} n_{U_{g}}^{n} r\right\rangle_{i+\frac{1}{2}, j}} /\left(r_{i+\frac{1}{2}} \delta r\right)\right.\right.
\end{aligned}
$$

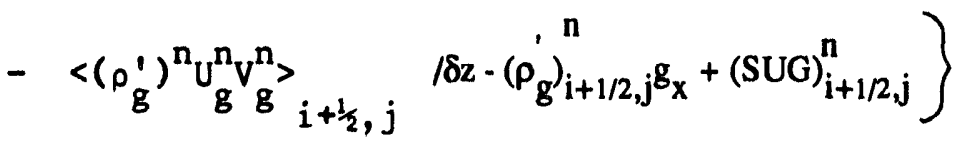

The finite-difference form of the $x$ or $r$ component of the momentum equation for the liquid is given by

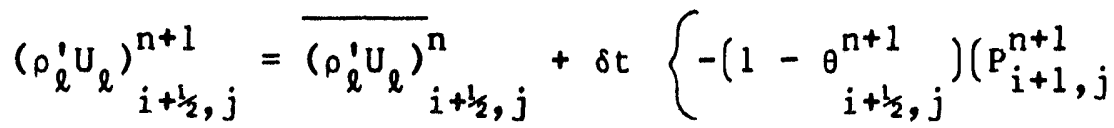

$$
\begin{aligned}
& \left.-P_{i, j}^{n+1}\right) / \delta r+\left(K_{x}\right)_{i+\frac{1}{2}, j}^{n}\left[\left(U_{g}\right)_{i+\frac{1}{2}, j}^{n+1}-\left(U_{\ell}\right)_{i+\frac{1}{2}, j}^{n+1}\right] \\
& \left.+G(\theta)_{i+\frac{1}{2}, j}^{n+1}\left(\theta_{i+1, j}^{n+1}-\theta_{i, j}^{n+1}\right) / \delta r\right\}
\end{aligned}
$$




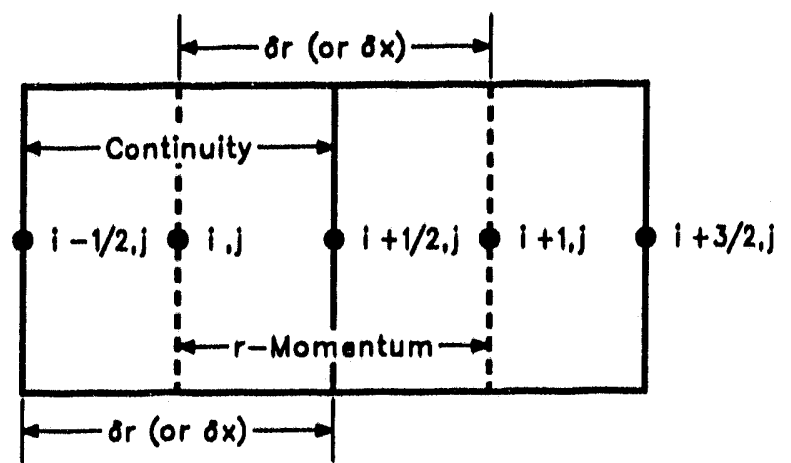

(a) $r$ or $x$ Momentum Equotions

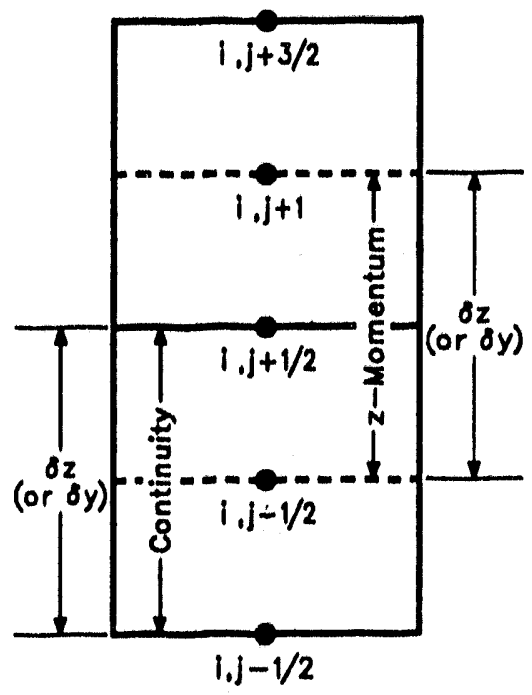

(b) $z$ or y Momentum Equations

FIGURE 6 The Staggered Computational Mesh for Momentum Equations

where all the explicit terms have been grouped into $\overline{\left(\rho_{\ell}^{\prime} U_{\ell}\right)^{n}}$ as

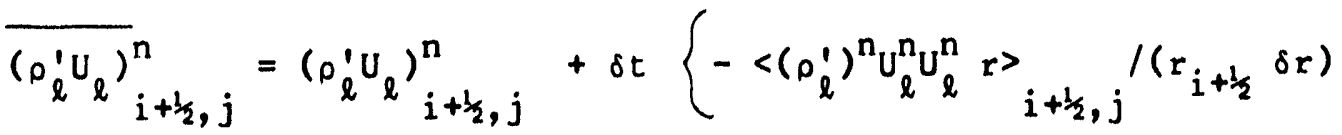

$$
\begin{aligned}
& \left.-\left\langle\left(\rho_{\ell}^{\prime}\right)^{n} U_{\ell}^{n} v_{\ell}^{n}\right\rangle_{i+\frac{1}{2}, j} / \delta z-\left(\rho_{\ell}^{\prime}\right)_{i+1 / 2, j^{j} x}^{n}+(S U L)_{i+1 / 2, j}^{n}\right\}
\end{aligned}
$$

The finite-difference form of the $y$ or $z$ component of the momentum equation for the gas is given by

$$
\begin{aligned}
\left(\rho_{g}^{\prime} v_{g}\right)_{i, j+\frac{1}{2}}^{n+1} & =\overline{\left(\rho_{g}^{\prime} v_{g}\right)_{i, j+\frac{1}{2}}^{n}}+\delta t\left\{-\theta_{i, j+\frac{1}{2}}^{n+1}\left(p_{i, j+1}^{n+1}-P_{i, j}^{n+1}\right) / \delta z\right. \\
& \left.+\left(k_{y}\right)_{i, j+\frac{1}{2}}^{n}\left[\left(v_{\ell}\right)_{i, j+\frac{1}{2}}^{n+1}-\left(v_{g}\right)_{i, j+\frac{1}{2}}^{n+1}\right]\right\}
\end{aligned}
$$


where:

$$
\begin{aligned}
\overline{\left(\rho_{g}^{\prime} v_{g}\right)_{i, j+\frac{1}{2}}^{n}} & =\left(\rho_{g}^{\prime} v_{g}\right)_{i, j+\frac{1}{2}}^{n}+\delta t\left\{-\left\langle\left(\rho_{g}^{\prime}\right)^{n} v_{g}^{n} u_{g}^{n} r\right\rangle\right. \\
& -\left\langle\left(\rho_{g}^{\prime}\right)^{n} v_{g}^{n} v_{g}^{n}\right\rangle_{i, j+\frac{1}{2}} /\left(r_{i} \delta r\right)
\end{aligned}
$$

The finite-difference form of the $y$ or $z$ component of the momentum equation for the liquid is given by

$$
\begin{aligned}
& \left(\rho_{\ell}^{\prime} v_{\ell}\right)_{i, j+\frac{1}{2}}^{n+1}=\overline{\left(\rho_{\ell}^{\prime} v_{\ell}\right)^{n}}+\delta t \quad\left\{-\left(1-\theta_{i, j+\frac{1}{2}}^{n+1}\right)\left(P_{i, j+1}^{n+1}\right.\right. \\
& \left.-p_{i, j}^{n+1}\right) / \delta z+\left(k_{y}\right)_{i, j+\frac{1}{2}}^{n}\left[\left(v_{g}\right)_{i, j+\frac{1}{2}}^{n+1}-\left(v_{\ell}\right)_{i, j+\frac{1}{2}}^{n+1}\right] \\
& \left.+G(\theta)_{i, j+\frac{1}{2}}^{n+1}\left[\theta_{i, j+1}^{n+1}-\theta_{i, j}^{n+1}\right] / \delta z\right\}
\end{aligned}
$$

where:

$$
\begin{aligned}
& \overline{\left(\rho_{\ell}^{\prime} v_{\ell}\right)^{n}}=\left(\rho_{\ell, j+\frac{1}{2}}^{\prime} v_{\ell}\right)_{i, j+\frac{1}{2}}^{n}+\delta t \quad\left\{-\left\langle\left(\rho_{\ell}^{\prime}\right)^{n} v_{\ell}^{n_{U}} U_{\ell}^{n} r{ }_{i, j+\frac{1}{2}} /\left(r_{i} \delta r\right)\right.\right. \\
& \left.-\left\langle\left(\rho_{\ell}^{\prime}\right)^{n} v_{\ell}^{n} v_{\ell}^{n}\right\rangle_{i, j+\frac{1}{2}} / \delta z-(\rho)_{i, j+1 / 2}^{\prime} g_{y}+(S V L)_{i, j+1 / 2}^{n}\right\}
\end{aligned}
$$

The use of time level $n$ values in the overscored terms and in the interphase friction functions, $\mathrm{K}_{\mathrm{x}}$ and $\mathrm{K}_{\mathrm{y}}$, implies that Eqs. 4.9 and 4.10 form a system of two linear equations in the two unknowns $\left(U_{g}\right)^{n+1}$ and $\left(U_{\ell}\right)^{n+1}, j$ and that Eqs. 4.11 and 4.12 a system of two linear equations in the two unknowns $\left(v_{g}\right)_{i, j+\frac{1}{2}}^{n+1}$ and $\left(v_{\ell}\right)_{i, j+\frac{1}{2}}^{n+1}$. The 
solutions to these two systems of equations yield the velocity components in cell $(1, j)$ as follows:

$$
\begin{aligned}
& \left(U_{B}\right)_{i+\frac{1}{2}, j}^{n+1}=\left\{{\overline{\left(\sigma_{B}^{\prime} U_{g}\right)_{i+\frac{1}{2}, j}^{n}}}^{n}-\theta_{i+\frac{1}{2}, j}^{n+1} \text { ot }\left(P_{i+1, j}^{n+1}-P_{i, j}^{n+1}\right) / \delta r\right. \\
& {\left[\left(o_{\ell}^{\prime}\right)_{i+\frac{1}{2}, j}^{n+1}+\delta t\left(k_{x}\right)_{i+\frac{1}{2}, j}^{n}\right]+\delta t\left(k_{x}\right)_{i+\frac{1}{2}, j}^{n}} \\
& \text { - }\left[{\overline{\left(\rho_{\ell}^{\prime} U_{\ell}\right)_{i+\frac{1}{2}, j}}}-\delta t\left(1-\theta_{i+\frac{1}{2}, j}^{n+1}\right)\left(P_{i+1, j}^{n+1}-P_{i, j}^{n+1}\right) / \delta r\right. \\
& \left.\left.+(\delta t / \delta r) G(\theta)_{i+\frac{1}{2}, j}^{n+1}\left(\theta_{i+i, j}^{n+1}-\theta_{i, j}^{n+1}\right)\right]\right\} / \Delta_{x, i+\frac{1}{2}, j}^{(\text {velocity }} \\
& \left(U_{\ell}\right)_{i+\frac{1}{2}, j}^{n+1}=\left\{\left(\sum_{\ell}^{\prime} U_{\ell}^{\prime}\right)_{i+\frac{1}{2}, j}^{n}-\delta t\left(1-\theta_{i+\frac{1}{2}, j}^{n+1}\right)\left(P_{i+1, j}^{n+1}-P_{i, j}^{n+1}\right) / \delta r\right. \\
& \left.+(\delta t / \delta r) G(\theta)_{i+\frac{1}{2}, j}^{n+1}\left(\theta_{i+1, j}^{n+1}-\theta_{i, j}^{n+1}\right)\right]\left[\left(\rho_{g_{i+1 / 2}}^{n}\right)^{n+1}+\delta t\left(k_{x}\right)_{i+\frac{1}{2}, j}^{n}\right] \\
& +\delta t\left(k_{x_{i+\frac{1}{2}, j}}^{n}\left[\left(\operatorname{lo}_{g}^{\prime} U_{g}\right)_{i+\frac{1}{2}, j}^{n}-\theta_{i+\frac{1}{2}, j}^{n+1}\right) \delta t\right. \\
& \left.\left.\left(p_{i+\frac{1}{2}, j}^{n+1}-p_{i, j}^{n+1}\right) / \delta r\right]\right\} / \Delta \Delta_{x, i+\frac{1}{2}, j}(\text { velocit } y)
\end{aligned}
$$

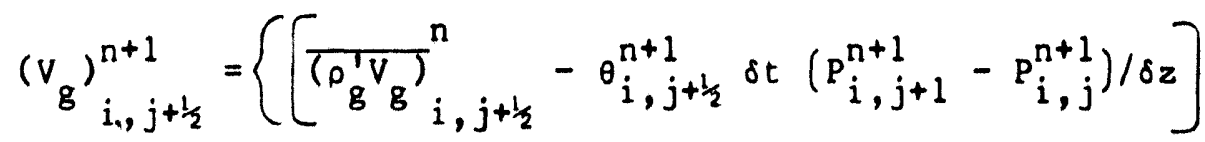

$$
\begin{aligned}
& {\left[\left(0_{l}^{\prime}\right)_{i, j+1}^{n+1}+\delta t\left(k_{y}\right)^{n}{ }_{i, j+\frac{1}{3}}\right]+\delta t\left(k_{y}\right)^{n}} \\
& \cdot\left[\left(\rho_{\ell}^{\prime} V_{\ell}\right)_{i, j+\frac{1}{2}}^{n}-\left(1-\theta_{i, j+\frac{1}{2}}\right) \delta t\left(P_{i, j+1}-P_{i, j}\right) / \delta z\right. \\
& \left.\left.\left.\cdot(\delta t / \delta z) G(\theta)_{i, j+\frac{1}{2}}^{n+1}\left(\theta_{i, j+1}^{n+1}-\theta_{i, j}^{n+1}\right)\right]\right\} / \Delta_{y, i, j+\frac{1}{2}}^{(v e l o c i t}\right)
\end{aligned}
$$




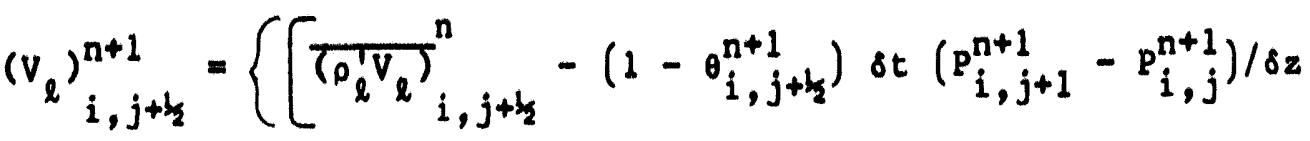

$$
\begin{aligned}
& \left.+(\delta t / \delta z) G(\theta)_{i, j+\frac{1}{2}}^{n+1}\left(\theta_{i, j+1}^{n+1}-\theta_{i, j}^{n}\right)\right]\left[\left(\rho_{g}^{\prime}\right)_{i, j+\frac{1}{2}}^{n+1}+\delta t\left(k_{y}\right)_{i, j+\frac{1}{2}}^{n}\right] \\
& +\delta t\left(K_{y}\right)_{i, j+\frac{1}{2}}^{n}[\overbrace{g}^{\left(\rho_{g}^{\prime}\right)_{i, j+\frac{1}{2}}}-\theta_{i, j+\frac{1}{2}}^{n+1} \delta t \\
& \left.\left(p_{i, j+1}^{n+1}-p_{i, j}^{n+1}\right) / \delta z\right] / \Delta y_{y, i, j+\frac{1}{z}}^{(\text {velocit } y)}
\end{aligned}
$$

where:

$$
\begin{aligned}
& \Delta_{\xi, k, m}^{(v e l o c i t y)}=\left(\rho_{g}^{\prime}\right)_{k, m}^{n+1}\left[\left(\rho_{\ell}^{\prime}\right)_{k, m}^{n+1}+\delta t\left(k_{\xi}\right)_{k, m}^{n}\right] \\
& +\left(p_{\ell}^{\prime}\right)_{k, m}^{n+1} \delta t\left(k_{\xi}\right)_{k, m}^{n} \\
& k, m=i+\frac{1}{2}, j \text { or } i, j+\frac{1}{2}
\end{aligned}
$$

and

$$
\xi=x \text { or } y
$$

The solids stress terms could be at either time level $n$ or $n+1$. We chose time level $n+1$, because this term can become important very quickly.

The interphase drag functions, $\mathrm{K}_{\mathrm{x}}$ and $\mathrm{K}_{\mathrm{y}}$, are evaluated at the cell centers and then averaged to obtain values at the cell edges. For example, with reference to Fig. $6 \mathrm{a}$, $\mathrm{K}_{\mathrm{x}_{\mathrm{i}+\frac{1}{2}, \mathrm{j}}}$ is evaluated as

$$
\left(k_{x}\right)_{i+\frac{1}{2}, j}=\frac{1}{2}\left[\left(k_{x}\right)_{i+1, j}+\left(k_{x}\right)_{i, j}\right]
$$


wheres

$$
\left(k_{x}\right)_{i, j}=k_{x} \theta_{i, j},\left(v_{8}\right)_{i, j},\left(o_{8}\right)_{i, j}
$$

and

$$
\left(v_{8}\right)_{i, j}=\frac{1}{2}\left(v_{8}\right)_{i+\frac{1}{2}, j}+\left(v_{8}\right)_{i-\frac{1}{2}, j}
$$

$\left(K_{x}\right)_{i+1, j}$ is evaluated analogously.

Expressions for SVG, SUL, SVG, and SVL may be found in K-FIX. ${ }^{2}$ The solids elastic modulus, G, at cell edges is evaluated from the porosity at the cell edges obtained by averaging the porosities defined at cell centers. 


\section{SOLUTION PROCEDURE POR FINITE-DIPFERENCE EQUATIONS}

With Initial conditions given and appropriate boundary conditions imposed, the nonlinear finite-difference equations in Sec. 4 are solved iteratively using a point relaxation technique. Before the calculations are begun, however, the rectangular region In which they are to be performed must be partitioned into cells of dimensions $\delta x$ or $\delta \mathrm{r}$ in the $x$ or $r$ direction and $\delta y$ or $\delta z$ in the $y$ or $z$ direction. It is within this computing mesh that the iterative solution of the finite-dlfference equations is obtained.

A perimeter of fletitious (dummy) boundary cells surrounding the computing mesh is used to enforce boundary conditions. The computing mesh and this boundary perimeter are shown in Fig. 7. The computing mesh begins at cell $(2,2)$ in the lower left corner and ends at cell (IB1,JB1) at the upper right corner. The flctitious (dummy) cells are outside the computational region. Internal to the FLUFIX code, a single subscript notation is used to keep track of the indexes of cells surrounding cell $(1, j)$, as well as the velocities (see Fig. 8).

For example, the velocity $\left(U_{g}\right)_{i+1, j}$ has the index $\left[J\right.$, as does $\left(V_{g}\right)_{i, j+t}$. The cell above cell $(i, j)$ has the index $[J P$.

\subsection{BOUNDARY CONDITIONS}

In the bottom row of boundary cells, up to two inflow openings (each having a length that is a positive integer multiple of $\delta r$ ) may be specified. In the left column of boundary cells, up to two inflow openings (each having a length that is a positive integer multiple of $\delta z$ ) may be specified. In the top row of boundary cells, up to two outflow

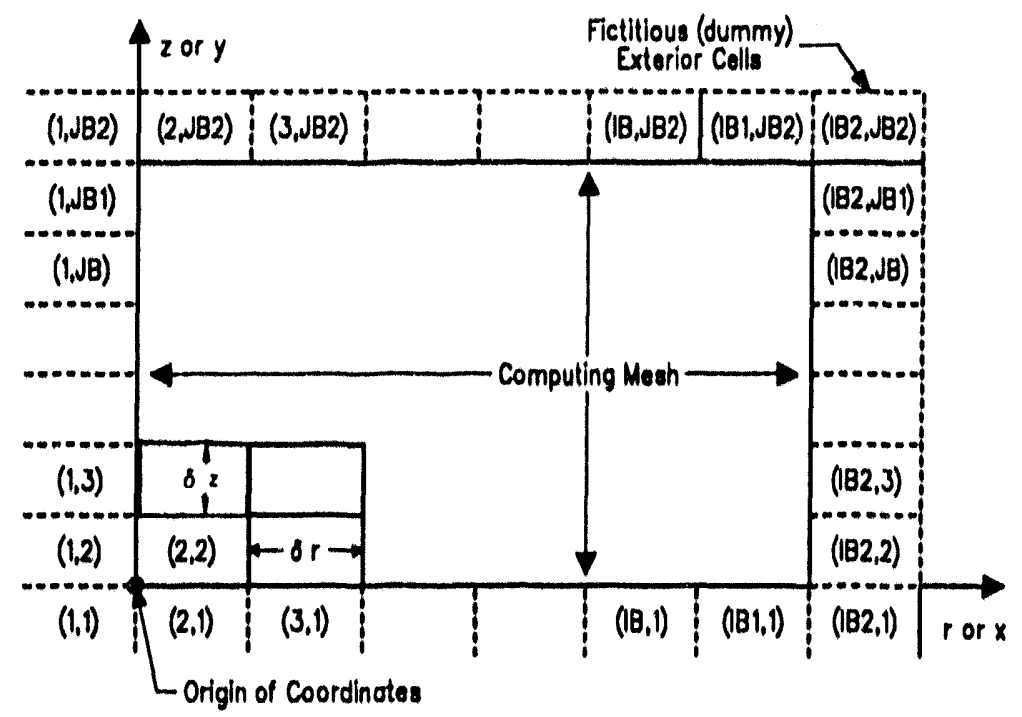

FIGURE 7 The Computing Mesh and the Surrounding Perimeter of Fictitious Boundary Cells 
openings (each having a length that is a positive integer multiple of $\delta$ ) may be specifled. In the right column of boundary cells, up to two outflow openings (each having a length that is a positive integer multiple of $\delta z$ ) may be speclfled. Figure 9 contains a summary of the nomenclature for each of the two openings on the four boundarles. The cell flag types, FL(l,J), allowed are indicated. Flag types 2 and 3 may be prescribed on any of the four boundarles to represent rigid (or solid) cells. Flag types 5 and 6 may be prescribed only at the left and bottom boundarles. Flag types 4 and 7 may be prescribed only at the top and right boundaries. All cells in the computing mesh boundary perimeter that are not inflow or outflow boundary cells must be rigid cells.

Obstacles within the computing mesh are built from rigld cells, flag types FL $=2$ or 3 , the positions of which coinclde with rectangular cells within the computing mesh. Calculations are not performed in these obstacle cells, only in the remaining fluid cells within the computing mesh.

Figure 10 illustrates a hypothetical problem with an obstacle, to illustrate the cell flag type usage. Cell plag type $F L=1$ is a computational cell.

\subsubsection{Rigid Cells}

Two types of boundary conditions may be specifled for a rigid (solid) cells freeslip or no-sllp (FL $=2$ or 3). In two dimensions, a free-slip boundary represents a line of symmetry or a nonadhering boundary that exerts no drag on the fluld; a no-sllp boundary represents a viscous boundary that exerts a drag on the fluid.

Consider cell $(i, j)$, which is a fluid cell, an inflow boundary cell, or an outflow boundary cell. An adlabatic rigid cell is sald to be a corner cell if and only if it has at least two adjacent edges, each of which is shared with a fluid cell, an inflow boundary cell, or an outflow boundary cell. Suppose Plrst that cell $(i, j)$ does not share an edge with a rigid cell that is a corner cell.

If cell $(i+1, j)$ is a rigid cell and if free-slip boundary conditions (FL $=2$ ) are Imposed, then for all $n$

$$
\begin{aligned}
& \left(U_{g}\right)^{n+1}=0=\left(U_{\ell}\right)^{n+1} \\
& \left(v_{g}\right)^{n+1}, j=\left(v_{g}\right)^{n} \\
& i+1, j+\frac{1}{2}, j \\
& \left(v_{\ell}\right)^{n+1}=\left(v_{\ell}\right)^{n+\frac{1}{2}} \\
& i+1, j+\frac{1}{2}
\end{aligned}
$$




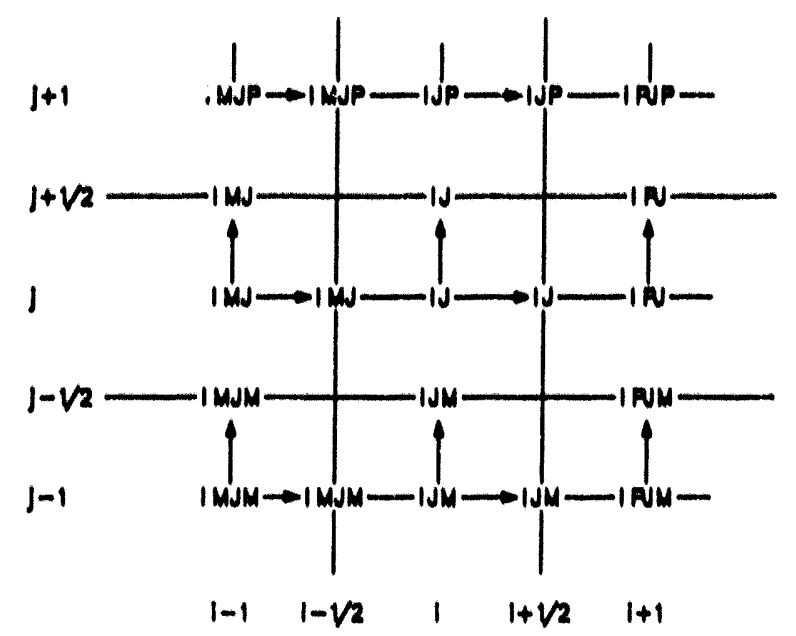

FIGURE 8 single-subsoript Notation for Cell and Cell-Edge Quantities about Cell (1,J)
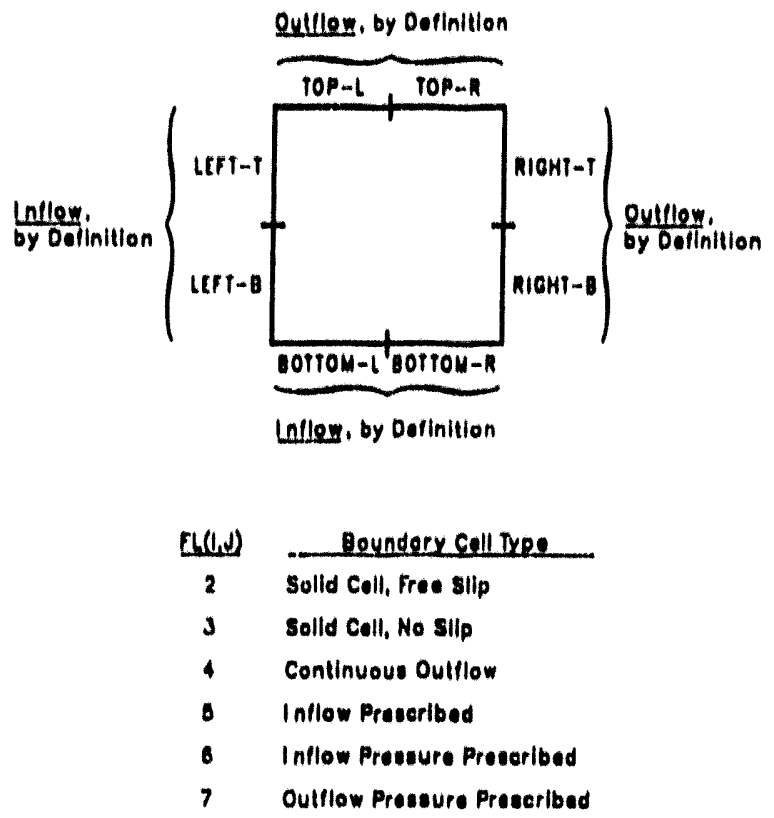

FIGURE 8 Boundary Cell Flags

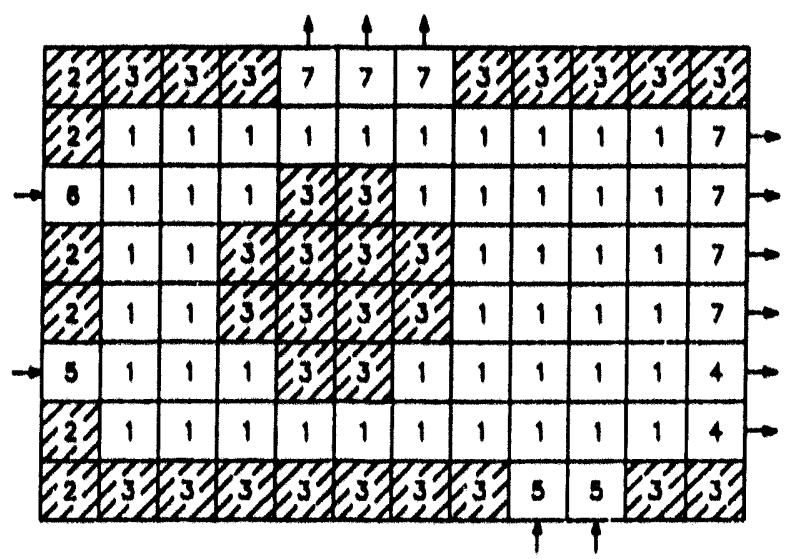

FIGURE 10 A Hypothetical Problem Ilustrating the Cell Types 
If cell $(1+1, j)$ is a rigid coll and if no-slip boundary conditions $\mathrm{FL}=3$ are Imposed, then for all $n$

$$
\begin{aligned}
& \left(u_{8}\right)^{n+1}=0=\left(u_{\ell}\right)^{n+1} \\
& \left(v_{8}\right)_{i+k_{2}, j}^{n+1}=-\left(v_{8}\right)^{n} \\
& \left(v_{\ell+1, j+\frac{1}{2}}^{n+1}{ }_{i+1, j+\frac{1}{2}}^{n}=-\left(v_{\ell}\right)^{n}\right.
\end{aligned}
$$

At a right outflow boundary (see Flg. 11a), $i+1, j=[B 2, J$, hence $I+t]=,[B 1, J\} 1+1, j+t=$ $\mathrm{IB2}, \mathrm{J} ;$ and $\mathrm{I}, \mathrm{J}+\mathrm{I}=\mathrm{IB} 1, \mathrm{~J}$.

$$
\begin{aligned}
& \left(u_{g}\right)^{n+1}=\left(u_{g}\right)^{n} \\
& \left(u_{\ell}\right)^{n+1}, j+1, j \\
& i+\frac{k_{2}, j+1}{2}=\left(u_{\ell}\right)^{n} \\
& \left(v_{g}\right)^{n+1}=0=\left(v_{\ell}\right)^{n+1}, j \\
& i, j+\frac{1}{2}
\end{aligned}
$$

If cell $(i, f+1)$ is a rigid cell and if no-slip boundary conditions (FL $=3$ ) are imposed, then for all $n$

$$
\begin{aligned}
& \left(u_{8}\right)_{i+\frac{1}{2}, j+1}^{n+1}=-\left(u_{8}\right)^{n} \\
& \left(u_{\ell}\right)_{i+\frac{1}{2}, j+1}^{n+1}=-\left(u_{\ell}\right)^{n} \\
& \left(v_{B}\right)_{i, j+\frac{1}{2}}^{n+1}=0=\left(v_{\ell}\right)_{i, j+\frac{1}{2}}^{n+1}
\end{aligned}
$$


At a top outflow boundary (Fig. $11 \mathrm{~b}), 1, j+1=1, \mathrm{JB} 2 ;$ thus, $1+1, j+1=1, \mathrm{JB} 2 ; \mathrm{i}+\mathrm{t}, \mathrm{j}=1, \mathrm{JB} 1$; and $1, j+1=1, J B 1$.

If cell $(1-1, j)$ is a rigid cell and if free-slip boundary conditions (FL $=2$ ) are Imposed, then for all $n$

$$
\begin{aligned}
& \left(U_{8}\right)_{i-\frac{1}{2}, j}^{n+1}=0=\left(U_{\ell}\right)_{i-\frac{1}{2}, j}^{n-1} \\
& \left(v_{8}\right)_{i-1, j+\frac{1}{2}}^{n+1}=\left(v_{8}\right)^{n} \\
& \left(v_{\ell}\right)_{i-1, j+\frac{1}{2}}^{n+1}=\left(v_{\ell}\right)^{n}{ }_{i, j+\frac{1}{2}}
\end{aligned}
$$

If cell $(l-1, j)$ is a rigid cell and if no-slip boundary conditions (FL $=3$ ) are Imposed, then for all $n$

$$
\begin{aligned}
& \left(U_{g}\right)_{i-\frac{1}{2}, j}^{n+1}=0=\left(U_{\ell}\right)_{i-\frac{1}{2}, j}^{n+1} \\
& \left(v_{8}\right)_{i-1, j+1 / 2}^{n+1}=-\left(v_{8}\right)_{i, j+\frac{1}{2}}^{n} \\
& \left(v_{\ell}\right)_{i-1, j+1 / 2}^{n+1}=-\left(v_{\ell}\right)^{n+1}
\end{aligned}
$$

At a left inflow boundary (Fig. 12a), $i-1, j=1, J$, and hence $l-\frac{t}{2}, j=1, J ; i-1, j+t=1, J$; and $i, j+\frac{1}{2}=2, \mathrm{~J}$.

If cell $(1, j-1)$ is a rigid cell and if free-slip boundary conditions (FL $=2$ ) are imposed, then for all $n$

$$
\left(U_{g}\right)_{i+1 / 2, j-1}^{n+1}=\left(U_{g}\right)_{i+\frac{1}{2}, j}^{n}
$$




$$
\begin{aligned}
& \left(u_{\ell}\right)^{n+1}=\left(u_{\ell}\right)^{n} \\
& i+\frac{1}{2}, j-1 \\
& \left(v_{8}\right)^{n+1}=0=\left(v_{\ell}\right)^{n+1} \\
& i, j-\frac{1}{2}
\end{aligned}
$$

If cell $(i, j-1)$ is a rigid cell and if no-slip boundary conditions (FL $=3$ ) are imposed, then for all $n$

$$
\begin{aligned}
& \left(U_{8}\right)_{i+\frac{1}{2}, j-1}^{n+1}=-\left(U_{8}\right)^{n} \\
& \left(U_{\ell}\right)_{i+\frac{1}{2}, j}^{n+1}=-\left(U_{\ell}\right)^{n} i+\frac{1}{2}, j \\
& \left(v_{8}\right)_{i, j-\frac{1}{2}, j-1}^{n+1}=0=\left(v_{\ell}\right)^{n+1}
\end{aligned}
$$

At a bottom inlet boundary (Fig. 12b), $i, j-1=I, 1$ and, hence, $i+\frac{1}{2}, j-1=I, 1 ; i+\frac{1}{2}, j=I, 2$; and $\mathrm{l}, \mathrm{j}-\mathbf{t}=\mathrm{l}=\mathrm{I}, \mathrm{P}$

If any one of the cells $(i, j+1),(i+1, j),(i-1, j)$, or $(i, j-1)$ is both a rigid cell and a corner cell, then, for both free-slip and no-slip boundary conditions, all its velocity components located at the center of edges it shares with the fluid, inflow boundary, or outflow boundary cells are set equal to zero.

\subsubsection{Inflow Boundary Cells}

The inlet boundaries are shown in Fig. 12. For each inflow opening a pressure, $P$, and a void fraction, $\theta$, must be specified. The values of $P$ and $\theta$ are those specified in the input data.

The types of boundary conditions used are rigid (solid) cells, FL $=2$ or 3 ; inflow prescribed, $\mathrm{FL}=5$; or inflow pressure prescribed. The pressure, $\mathrm{P}$, is required for both $\mathrm{FL}=5$ and $\mathrm{FL}=6$ to compute the mass fluxes. However, when the inflow pressure is prescribed, the radial or axial velocity components are computed using Egs. 4.13-4.17. 


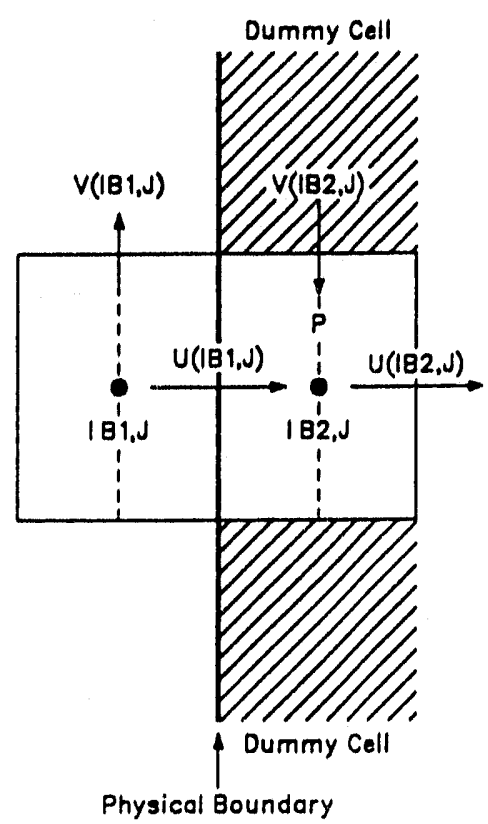

$P(\mid B 2, J)$ May Be

Prescribed, FL $=7$

Physicol Boundary

(o) Right Outflow Boundary

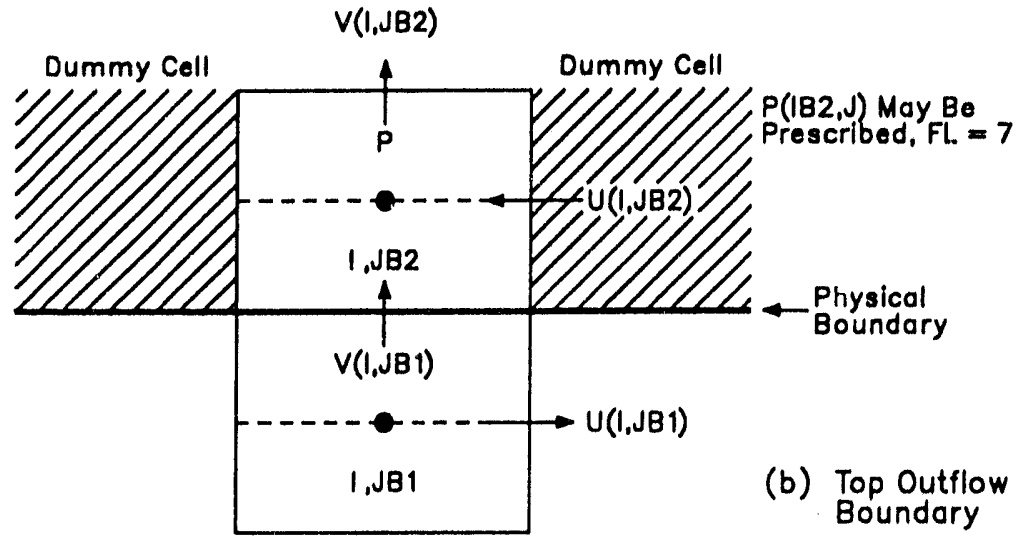

FIGURE 11 Top and Right Outflow Boundaries

In the calculation of the overscored momenta (Eqs. $4.9 \mathrm{a}-4.12 \mathrm{a}$ ) required in these equations, a special treatment of certain terms appearing in the momenta is necessary for the inflow boundary cells. An examination of Egs. 4.9a-4.12a for an inflow boundary cell in the $j=1$ row reveals that these equations require quantities from the nonexisting $j=0$ row. To remedy this difficulty, for any quantity $\left(B_{g}\right)_{i, 0}^{n}$ or $\left(B_{\ell}\right)_{i, o}^{n}$ needed from the $j=0$ row, the corresponding quantity $\left(B_{g}\right)_{i, 1}^{n}$ or $\left(B_{\ell}\right)_{i, 1}^{n}$ from the $j=1$ row is used instead. A similar examination of these equations for an inflow boundary cell in the $i=1$ column reveals that these equations require quantities from the nonexisting $i=0$ column. To remedy this difficulty, for any quantity $\left(B_{g}\right)_{o, j}^{n}$ or $\left(B_{\ell}\right)_{o, j}^{n}$ needed from the $i=0$ column, the corresponding quantity $\left(B_{g}\right)_{1, j}^{n}$ or $\left(B_{\ell}\right)_{1, j}^{n}$ from the $i=1$ column is used instead. With this reflection treatment used in the inflow boundary cells, the explicit 


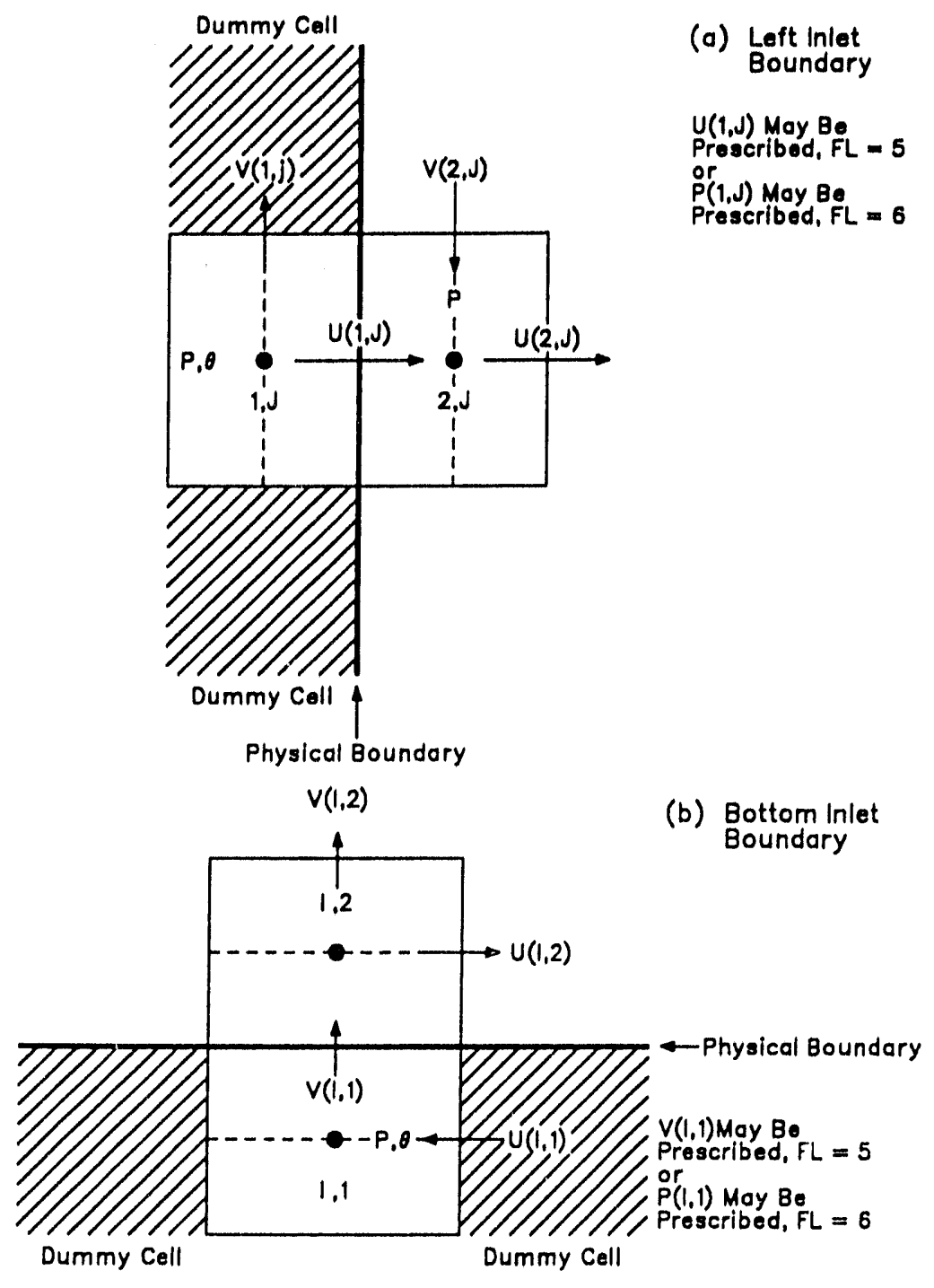

FIGURE 12 Bottom and Left Inlet Boundaries

terms (called "tilde momenta") in the momentum equations, Eqs. 4.9b-4.12b, and then the components of the gas and the liquid velocities, can be calculated using Egs. 4.13-4.17.

Knowledge of the pressure, the void fraction, the gas and liquid temperatures, and the gas and liquid velocities in the inflow boundary cells enables all remaining thermodynamic, transport, and interphase quantities to be calculated for these cells.

\subsubsection{Outflow Boundary Cells}

The outlet boundaries are shown in Fig. 11. For each outflow opening, a pressure, $P$, may be specified at the beginning of each computational cycle. For constant boundary conditions, the value of $P$ is that specified in the input data. 
The types of boundary conditions used are rigid (solid) cells, FL $=2$ or 3; continuous outflow, $\mathrm{FL}=4$; or outflow pressure prescribed.

For both pressure-specified and continuative outflow boundary conditions, the void fraction, for a given cell of an outflow opening, is obtained by reflection. The tangential components of the gas velocity are set to zero, and a numerical screen is used to keep solids from leaving the fluidized bed. Therefore, for prescribed pressure at a top outflow boundary, FL $=7$, with reference to Fig. $11 \mathrm{~b}$,

$$
\begin{aligned}
& P_{i, J B 2}^{n+1}=P 0 \text { (initial pressure read in) } \\
& \underbrace{n+1}_{i, J B 2}=\theta_{i, J B 2-1}^{n}=\theta_{i, J B 1}^{n} \\
& \left(U_{g}\right)^{n+1}=0 \\
& \left(U_{\ell}\right)^{n+1}{ }_{i+\frac{1}{2}, J B 2}=0 \\
& \left(V_{g}\right)^{n+1}=\left(\rho_{g}^{\prime}\right)^{n+1} \quad\left(v_{g}\right)^{n+1} /\left(\rho_{g}^{\prime}\right)^{n+1} \\
& \left(V_{\ell}\right)^{n+1}=0 \\
& i, J B 2
\end{aligned}
$$

For continuous outflow at a top outflow boundary, $F L=4$, with reference to Fig. 11b,

$$
\begin{aligned}
& p_{i, J B 2}^{n+1}=P_{i, J B 2-1}^{n}=P_{i, J B 1}^{n} \\
& e_{i, J B 2}^{n+1}=\theta_{i, J B 2-1}^{n}=\theta_{i, J B 1}^{n} \\
& \left(U_{g}\right)_{i+\frac{1}{2}, J B 2}^{n+1}=0
\end{aligned}
$$




$$
\begin{aligned}
& \left(U_{\ell}\right)^{n+1}=0 \\
& \left(v_{g}\right)^{n+1}=\left(\rho_{g}^{\prime}\right)^{n+1}{ }_{i, J B 2}\left(v_{g}\right)^{n+1} /\left(\rho_{g}^{\prime}\right)^{n+1} \\
& \left(v_{\ell}\right)^{n+1}=0 \\
& i, J B 2
\end{aligned}
$$

Fig. 11a,

For prescribed pressure at a right outflow boundary, FL $=7$, with reference to

$$
\begin{aligned}
& n+1 \\
& P_{I B 2, j}=P O \\
& \theta_{I B 2, j}^{n+1}=\theta_{I B 2-1, j}^{n}=\theta_{I B 1, J}^{n} \\
& \left(U_{g}\right)_{I B 2, j}^{n+1}=\left[\left(r_{i+1}+r_{i}\right) r_{i+\frac{1}{2}}\left(U_{g}\right)_{I B 1, j}^{n+1}\right. \\
& \left.-\left(r_{i+1}\right)\left(r_{i+\frac{1}{2}}\right)\left(U_{g}\right)_{I B 1-1, j}^{n+1}\right] /\left(r_{i+\frac{1}{2}}\right)\left(r_{i}\right) \\
& \left(U_{\ell}\right)_{I B 2, j}^{n+1}=\left[\left(r_{i+1}+r_{i}\right) r_{i+\frac{1}{2}}\left(U_{\ell}\right)^{n+1}\right. \\
& \left.-\left(r_{i+1}\right)\left(r_{i+\frac{1}{2}}\right)\left(U_{\ell}\right)^{n+1}\right] /\left(r_{i+\frac{1}{2}}\right) r_{i}
\end{aligned}
$$

where:

$$
\mathbf{i}=\text { IB2 }
$$




$$
\begin{aligned}
& \left(v_{g}\right)_{I B 2, j+\frac{1}{2}}^{n+1}=\left(v_{g}\right)_{I B 2-1, j+\frac{1}{2}}^{n}=\left(v_{8}\right)_{I B 1, J}^{n} \\
& \left(v_{\ell}\right)_{I B 2, j+\frac{1}{2}}^{n+1}=\left(v_{\ell}\right)_{I B 2-1, j+\frac{1}{2}}^{n}=\left(v_{\ell}\right)_{I B 1, J}^{n}
\end{aligned}
$$

Fig. 11a,

For continuative outflow at a right outflow boundary, $F L=4$, with reference to

$$
\begin{aligned}
& P_{I B 2, j}^{n+1}=P_{I B 2-1, j}^{n}=P_{I B 1, J}^{n} \\
& \theta_{I B 2, j}^{n+1}=\theta_{I B 2-1, j}^{n}=\theta_{I B 1, j}^{n} \\
& \left(U_{g}\right)_{I B 2, j}^{n+1}=\left[\left(r_{i+1}+r_{i}\right) r_{i+\frac{1}{2}}\left(U_{g}\right)_{I B 1, j}^{n+1}\right. \\
& \left.-\left(r_{i+1}\right)\left(r_{i+\frac{1}{2}}\right)\left(U_{8}\right)_{I B I-1, j}^{n+1}\right] /\left(r_{i+\frac{1}{2}}\right)\left(r_{i}\right) \\
& \left(U_{\ell}\right)_{I B 2, j}^{n+1}=\left[\left(r_{i+1}+r_{i}\right)\left(r_{i+\frac{1}{2}}\right)\left(U_{\ell}\right)^{n+1}\right. \\
& \left.-\left(r_{i+1}\right)\left(r_{i+\frac{1}{2}}\right)\left(U_{\ell}\right)^{n+1} \quad\right] /\left(r_{i+\frac{1}{2}}\right)\left(r_{i}\right) \\
& \left(v_{g}\right)^{n+1}=\left(v_{g}\right)^{n}=\left(v_{g}\right)^{n}={ }_{I B 2-1, j+\frac{1}{2}}={ }_{I B 1 / 2} \\
& \left(v_{\ell}\right)_{I B 2, j+\frac{1}{2}}^{n+1}=\left(v_{\ell}\right)^{n}=\left(v_{\ell}\right)^{n}=
\end{aligned}
$$


Knowledge of the pressure, void fraction, gas and liquid velocities, and gas and liquid temperatures in the outflow boundary cells enables the calculation of all remaining thermodynamic, transport, and interphase quantities for these cells.

\subsection{INITIAL CONDITIONS}

Six different options are available for initial conditions. They are chosen by an input flag, called MFFLAG, and a parameter, BHITE, which is the initial height of the fluidized bed. Table 3 is a summary of the six options.

When BHITE $=0$, there is no fluidized bed, and the problem is initialized as all gas. The value of the flag MFFLAG $=1$ initializes the axial gas velocity, using the total gas flow entering at the bottom of the bed, WGY, given in Table 3. The pressure in the axial direction is initialized by the gravity head of the gas for all three cases. For MFFLAG $=2$, the inlet pressure is set to PI, which is equal to PO (read in) plus 1.2 times the gravity head; the inlet velocity is set uniform at minimum fluidization conditions. (The calculation of minimum fluidization conditions is described in Sec. 5.3.) For MMFLAG = 0, the axial gas velocity is initialized, using VO and THO, which are the initial values of axial velocity and gas-phase volume fraction (read in).

Where BHITE is positive, the problem is initialized as a fluidized bed having an initial height of solids BHITE and a free board having no solids. As in the case where BHITE $=0$, the difference in the three options is the treatment of the gas-phase initial axial velocity distribution and in the inlet boundary conditions.

In all cases, the pressure distribution is computed from the weight of the bed as follows (see Fig. 13). First, the index of the cell containing the bed height is computed according to:

$$
\begin{aligned}
& \mathrm{JH}=\operatorname{INTEGER}(\text { BHITE } / \mathrm{DZ}+1.01) \\
& \mathrm{JH} 1=\mathrm{JH}+1
\end{aligned}
$$

where $\mathrm{DZ}$ is the variable name (read in from input data) for the cell dimension in the axial direction.

The fraction of cell $\mathrm{JH} 1$ above the bed height is given by

$$
D Z B=J H-B H I T E / D Z
$$




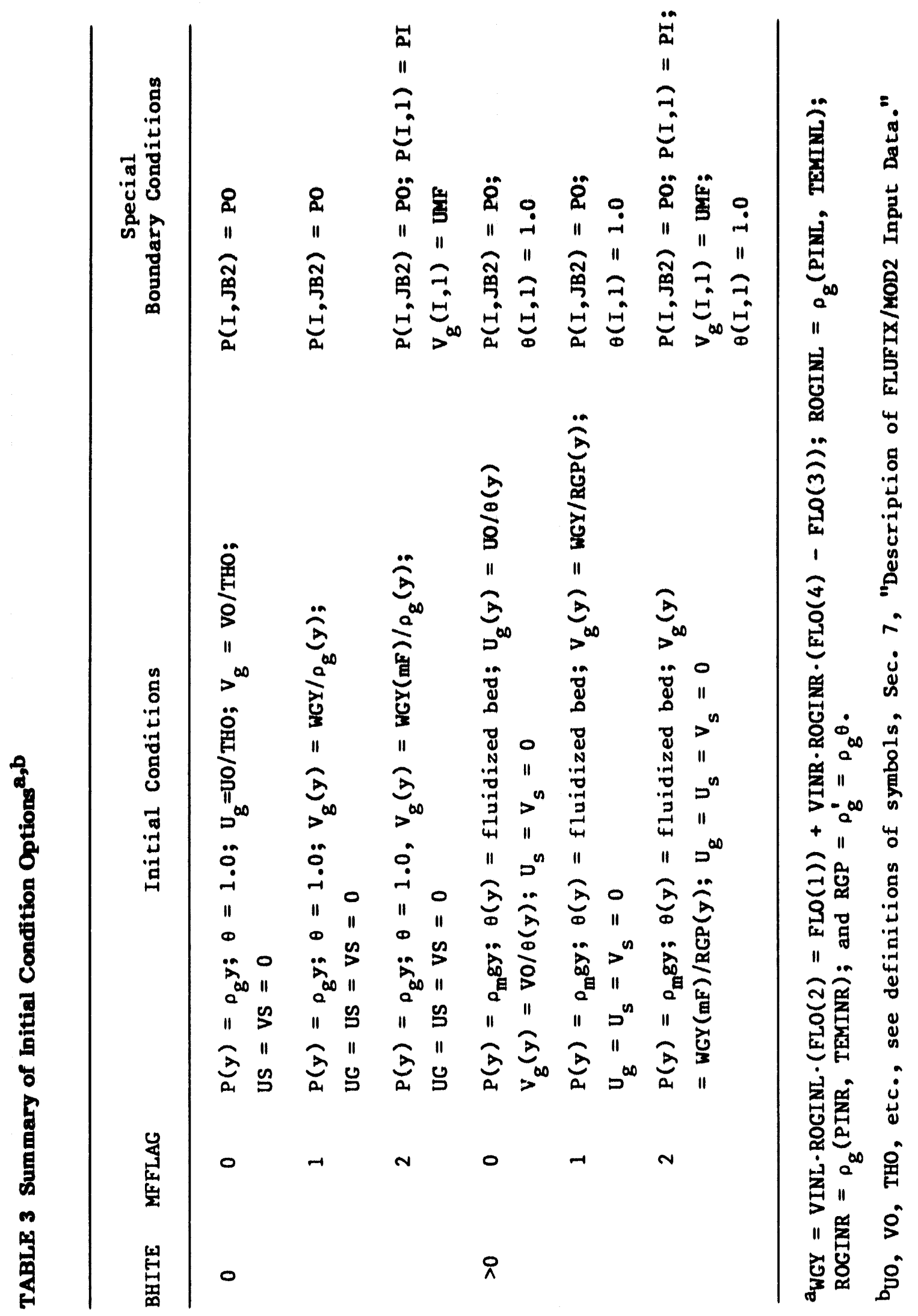




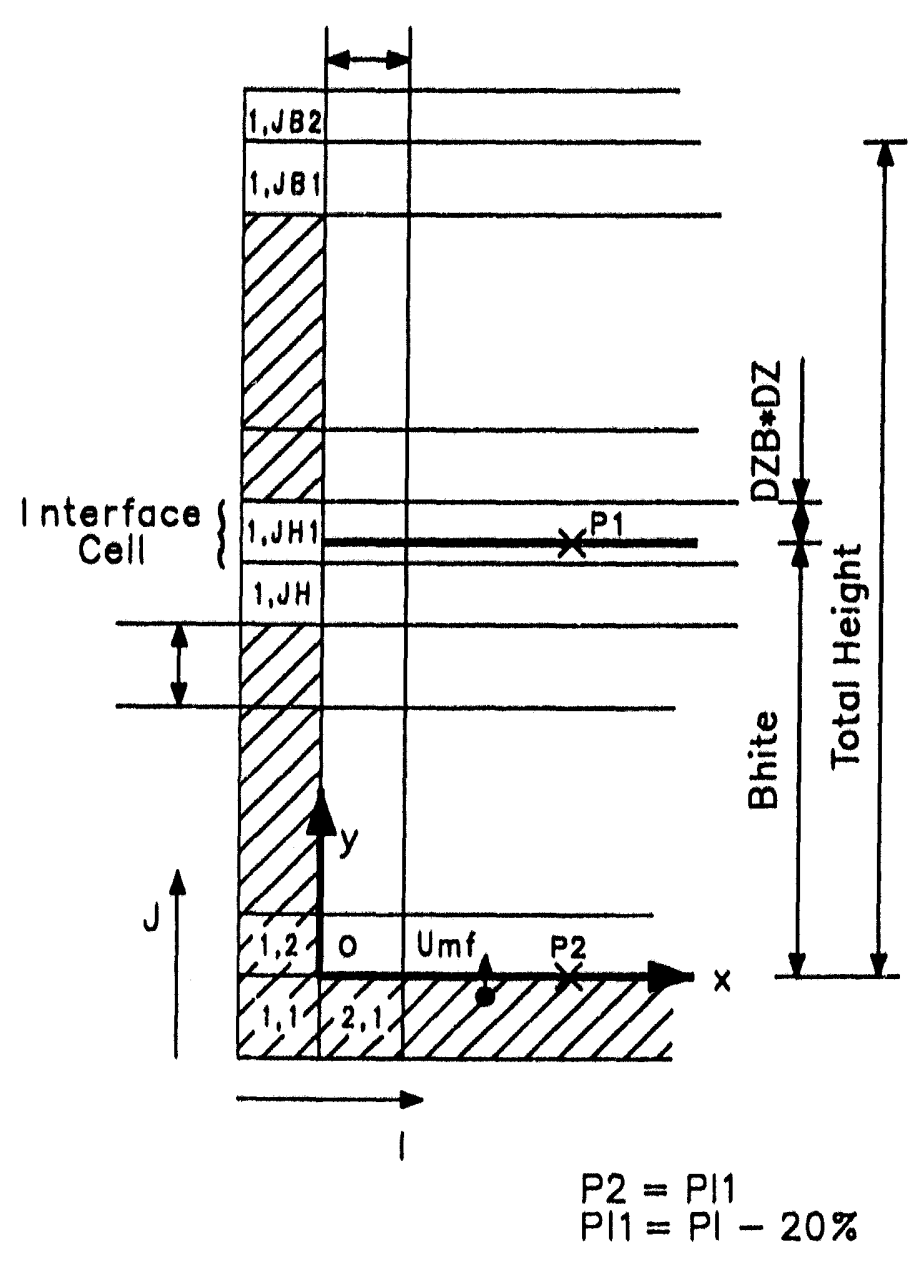

$\square$ Dummy Cell

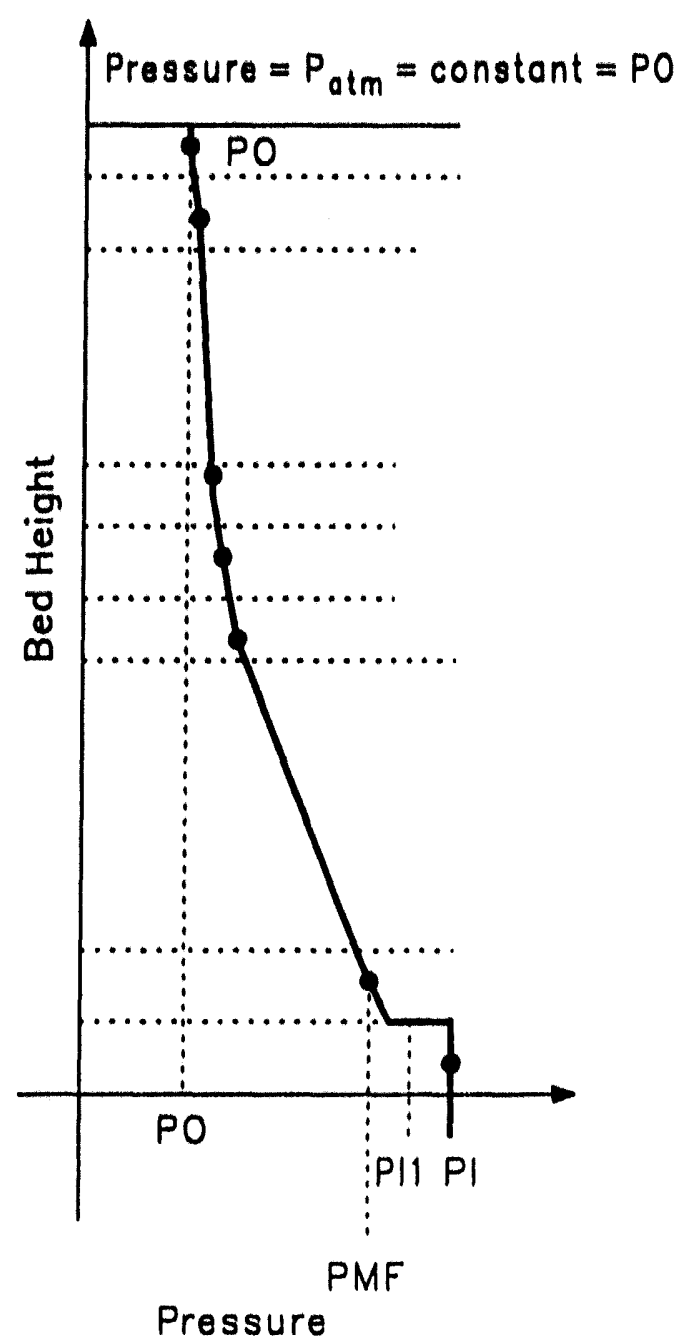

FIGURE 13 Pressure Distribution Initialization for MFFLAG = 2

Next, the mixture density is computed using the sollds and gas densities at the initial pressure, PO, and temperature, TEMPO, and initial gas volume fraction by

$$
\text { ROMIX }=(1-\mathrm{THO}) \cdot \rho_{8}+\mathrm{THO} \cdot \rho_{8}
$$

THO is assumed to be the void fraction at minimum fluidization, which may be estimated from $^{41}$

$$
\text { THO }=\varepsilon_{\mathrm{mf}}=\left(14 \phi_{\mathrm{s}}\right)^{-1 / 3}
$$

where $\phi_{S}$ is the particle sphericity. To a high degree of accuracy, the mixture density may be assumed constant. This makes the computation of the initial axial pressure 
distribution simpler. The inlet boundary pressure PI is set equal to 1.2 times the total bed helght, as follows:

$$
\begin{aligned}
P I= & P O+1.2 \cdot(- \text { GRAV })(B H I T E \cdot R O M I X)+(J B 1-J H 1+D Z B+0.5) \\
& \cdot \rho_{8} \cdot D Z
\end{aligned}
$$

The inlet void fraction is set equal to 1.0 .

The inltial vold and pressure axial distribution are thus given by

$$
\begin{aligned}
J=1: & \begin{array}{l}
T H(I J)=1.0 \\
P(I J)=P I
\end{array} \\
2 \leq J<J H 1: & \begin{array}{l}
T H(I J)=T H O \\
P(I J)=P I 1-(J-1.5) \cdot D P P
\end{array} \\
J=J H 1: & \begin{array}{l}
T H(I J)=D Z B+(1.0-D Z B) \cdot T H O \\
P(I J)=P I 1-(J H 1-1) \cdot D P P
\end{array} \\
J H 1<J<J B 2: & \begin{array}{l}
T H(I J)=1.0 \\
P(I J)=P O+(J B 2-J) \cdot D P T
\end{array} \\
& \\
J=J B 2: & \begin{array}{l}
P(I J)=P O \\
T H(I J)=1.0
\end{array}
\end{aligned}
$$

A prescribed outlet boundary pressure, cell type $=7$, is recommended.

For MFFLAG $=0$ and MFFLAG $=1$, the initial axial gas velocity is obtained from VO or WGY, respectively, and the partial density is obtained by averaging. For MFFLAG $=2$, the axial gas velocity and inlet velocity are computed from, and set to minimum fluidization conditions, which are assumed to exist at the pressure in the center of the cell next to the distributor, $J=2 P=P M F$. This pressure is indicated in Fig. 13. The gas density is computed at this pressure and the input pressure TEMPO. The minimum fluldization superficial velocity, $V_{m f}$, is computed from the Ergun equation, written as 41

$$
\frac{\Delta P}{L}=\frac{150\left(1-\varepsilon_{m f}\right)^{3} \mu_{g} V_{m f}}{\varepsilon_{m f}^{3}\left(d_{p} \phi_{s}\right)^{2}}+\frac{1.75 \rho_{g}\left(1-\varepsilon_{m f}\right) V_{m f}^{2}}{\varepsilon_{m f}^{3} d_{p} \phi_{s}}
$$


The axial velocity is then computed as follows:

$$
V G(I J)=V_{m f} /(0.5(R G P(I J P)+R G P(I J))
$$

The pressure drop, $\Delta \mathrm{P}$, used is

$$
\Delta P=\operatorname{ROMIX} \cdot(-G R A V) \cdot B H I T E
$$

and $L$ is the bed height, BHITE.

Because the inlet void fraction is assumed to be 1.0 , the inlet veloolty $V G(I, 1)$ is set equal to $V_{m f}$.

This completes the description of the present approach. Future versions of the FLUFIX code will extend the foregoing initial-condition treatment.

\subsection{SOLUTION PROCEDURE IN THE FLUID CELLS}

Assume that computational cycle $n$ is completed and that all boundary conditions for computational cycle $(n+1)$ are imposed. Then the first step in this solution procedure is the calculation of the tilde momenta, $\left(\overline{\rho_{8}^{\top} U_{8}}\right),\left(\overline{\rho_{8}^{\top} V_{8}}\right),\left(\overline{\rho_{l}^{\top} U_{l}}\right)$, and $\left(\overline{\rho_{l}^{T} V_{l}}\right)$, using Eqs. 4.9b-4.12b, and $K^{n}$ and $G^{n}$ for all fluid cells and all inflow boundary cells. From these quantities, estimated values of the velocity components are calculated, using Egs. 4.13-4.17. These velocity estimates are then used to obtain estimates of the mass fluxes for the cells:

$$
\begin{aligned}
& \left\langle\left(\rho_{8}^{\prime}\right)^{n+1}\left(U_{8}\right)^{n+1} r\right\rangle,\left\langle\left(\rho_{8}^{\prime}\right)^{n+1}\left(v_{8}\right)^{n+1}\right\rangle \\
& \left\langle\left(\rho_{\ell}^{\prime}\right)^{n+1}\left(U_{\ell}\right)^{n+1} r\right\rangle,\left\langle\left(\rho_{\ell}^{\prime}\right)^{n+1}\left(v_{\ell}\right)^{n+1}\right\rangle .
\end{aligned}
$$

This is called the "explicit stage" of the solution procedure, outlined in Fig. 14. In the K-FIX computer code, a parameter denoted by $\theta^{*}$ causes a switch in the solution procedure when the gas-phase volume fraction, $\theta$, falls below that value $\left(\theta<\theta^{*}\right)$. In FLUFIX, we recommend using a value of $\theta^{*}$ low enought that $\theta$ is never less than $\theta^{*}$. At present, $\theta^{*}=0.19$ is used; thus, only a gas mass residual, $\left(D_{g}\right)$, is used to adjust the pressure. The solution procedure described below, called the "impllolt stage" (see Fig. 14), is only for $\theta \equiv \theta^{*}$. (The coding for $\theta<\theta^{*}$ exists but is inactivated.)

The next step is the iterative part of the solution procedure, as Indicated in Figs. 14-15. The pressure is adjusted in each fluid cell until the gas mass residual, $\mathrm{D}_{g}$, is smaller in magnitude than a speclfied small quantity convergence, CONV, simultaneously in all fluid cells. For cell $(i, j)$, the mass residuals are 


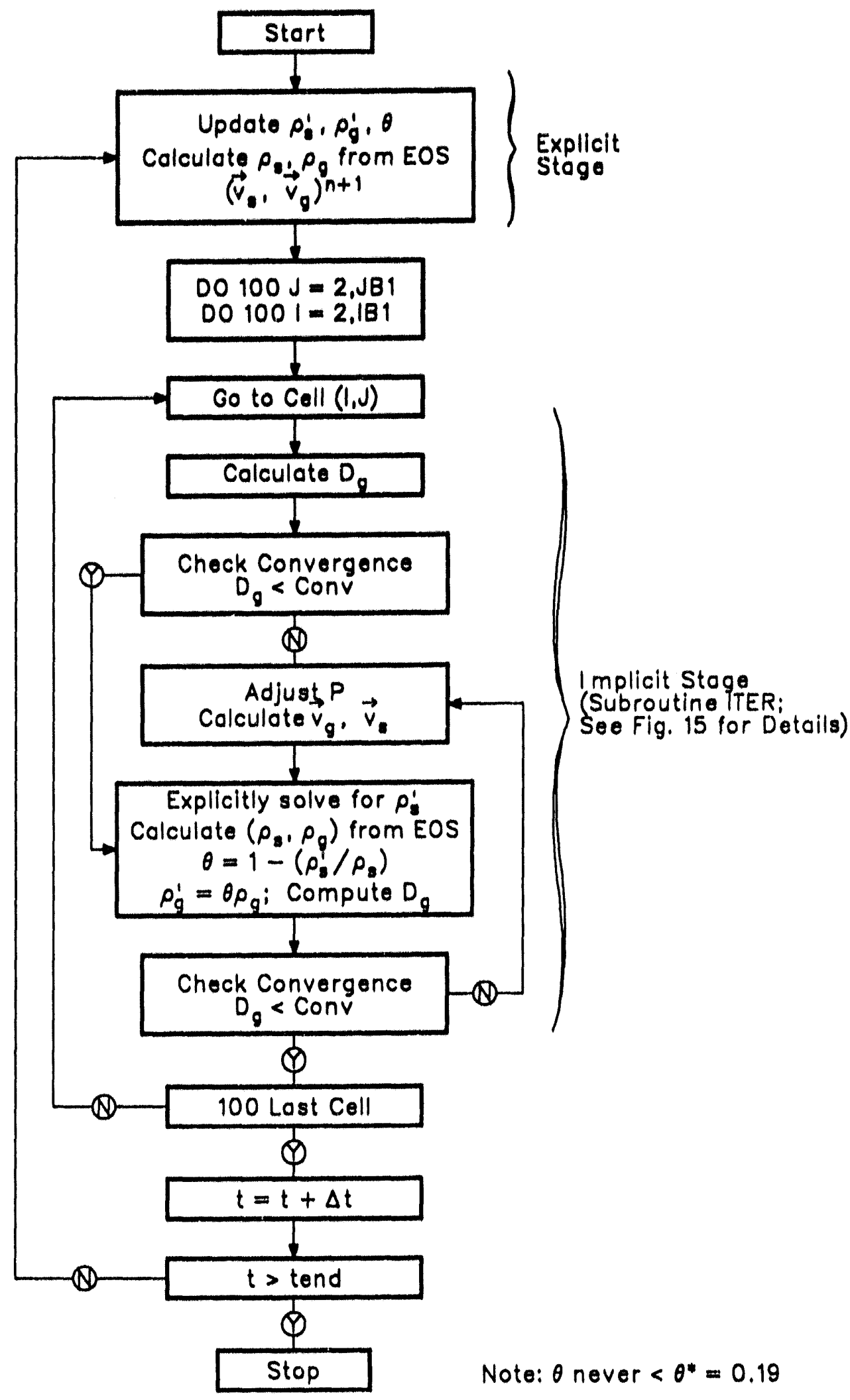

FIGURE 14 FLUFIX Solution Procedure 


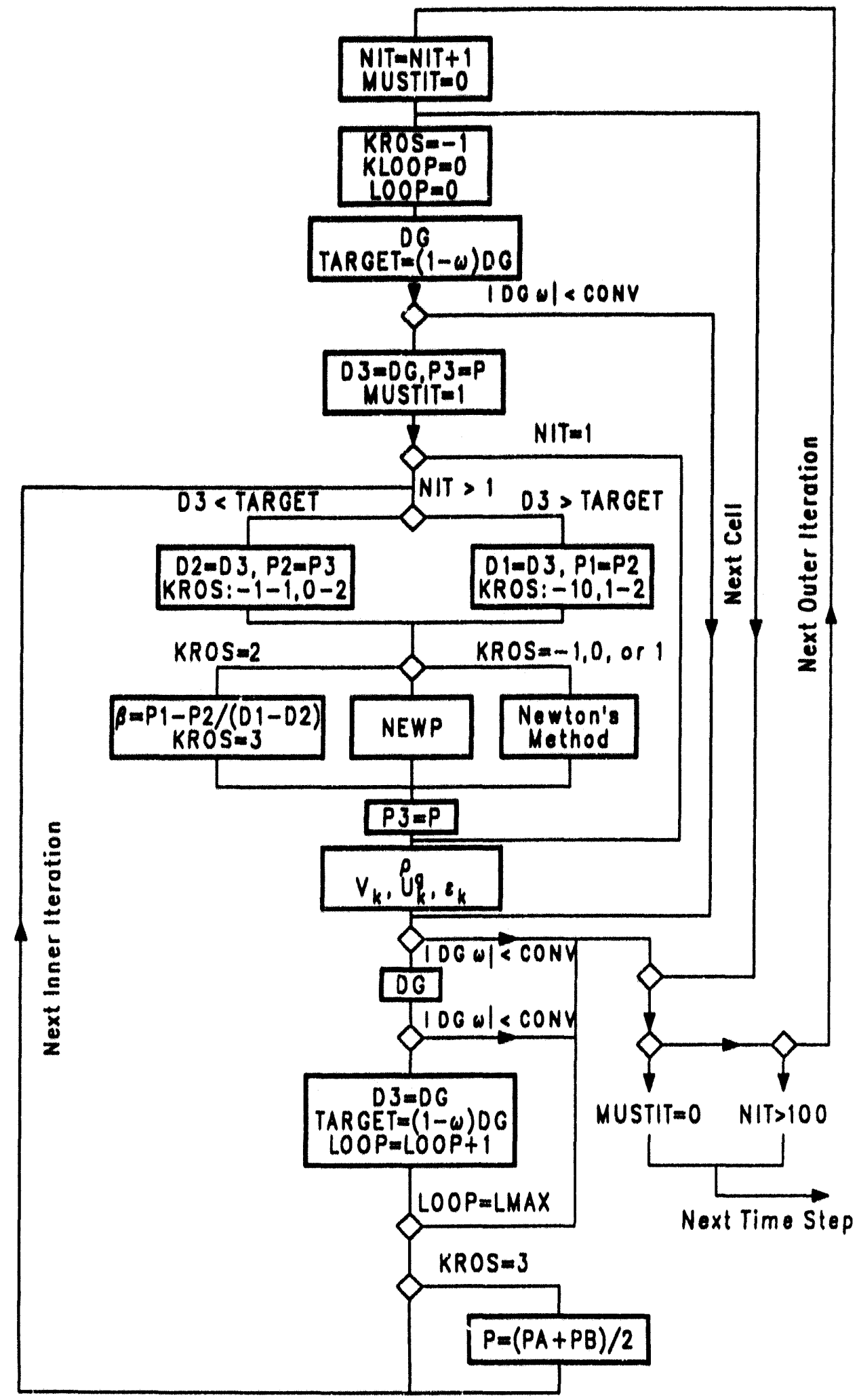

FIGURE 15 The Iteration Loop in Subroutine ITER 


$$
\begin{aligned}
\left(D_{8}\right)_{i, j} & =\left(\rho_{8}^{\prime}\right)_{i, j}^{n+1}-\left(\rho_{8}^{\prime}\right)_{i, j}^{n}+\delta t\left[\left\langle\left(\rho_{8}^{\prime}\right)^{n+1}\left(U_{8}\right)^{n+1} r\right\rangle_{i, j} /\left(r_{i} \delta r\right)\right. \\
& +\left\langle\left(\rho_{8}^{\prime}\right)^{n+1}\left(v_{8}\right)^{n+1}>/ \delta z\right]
\end{aligned}
$$

and the value of the convergence criterion is

$$
\left(D_{g}\right)_{i, j} \leq \operatorname{CONV}_{i, j}^{n+1}=\operatorname{EPsc}\left(\rho_{8}^{\prime}\right)_{i, j}^{n} \text { for } \theta_{i, j}^{n} \geq \theta^{*}
$$

where EPSG is read in. The default and recommended value of EPSG is $5 \times 10^{-4}$.

If $\mathrm{D}_{\mathrm{g}}$ fails to satisfy the convergence criterion in cell $(i, j)$, the pressure is adjusted Iterătively in this cell in subroutine ITER, as shown in Fig. 15. For $\theta_{1, j} \geq \theta^{*}$ as

$$
P_{i, j}-\omega\left(D_{8}\right)_{i, j}^{n} /\left(\partial D_{8} / \partial P\right)_{i, j} \rightarrow P_{i, j}
$$

This is equivalent to using Newton's method ${ }^{42}$ for each cell, where $w$ is a parameter for under $(\omega<1)$ or over $(\omega>1)$ relaxation. The present FLUFIX default value is $w=1$.

The lengthy derivation of $\partial \mathrm{D}_{\mathrm{g}} / \partial \mathrm{P}$ was given first by Harlow and Amsden, whose mass residue differed from that of the K-FIX code by a factor of $1 / \delta t^{20}$ We use the formula for $\partial D_{g} / \partial P$ derived by these authors and extended by us to account for $K_{x}$ and $\mathrm{K}_{\mathbf{y}}$ as

$$
\begin{aligned}
\left(\frac{1}{\beta_{g}}\right)_{i, j} & =\left(\partial D_{g} / \partial P\right)_{i, j}=\theta_{i, j}^{n} / a_{g}^{2}+\frac{(\delta t)^{2}}{r_{i} \delta r}\left\{\frac { 1 } { \delta r } \left(r_{i+\frac{1}{2}} \theta_{i+\frac{1}{2}, j}^{n}+r_{\left.i-\frac{1}{2} \theta_{i-\frac{1}{2}, j}^{n}\right)}\right.\right. \\
& +r_{i+\frac{1}{2}}\left(k_{x}\right)_{i+\frac{1}{2}, j}^{n}\left(\frac{\partial}{\partial P}\right)_{i, j}\left[\left(U_{\ell}\right)_{i+\frac{1}{2}, j}^{n}-\left(U_{g}\right)_{i+\frac{1}{2}, j}^{n}\right] \\
& \left.-r_{i-\frac{1}{2}}\left(k_{x}\right)_{i+\frac{1}{2}, j}^{n}\left(\frac{\partial}{\partial P}\right)_{i, j}\left[\left(U_{\ell}\right)_{i-\frac{1}{2}, j}^{n}-\left(U_{g}\right)_{i-\frac{1}{2}, j}^{n}\right]\right\} \\
& +\frac{(\delta t)^{2}}{\delta z}\left\{\frac { 1 } { \delta z } \left(\theta{ }_{i, j+\frac{1}{2}}^{n}+\theta_{i, j-\frac{1}{2}}^{n}\right.\right.
\end{aligned}
$$




$$
\begin{aligned}
& +\left(k_{y}\right)_{i, j+\frac{1}{2}}^{n}\left(\frac{\partial}{\partial P}\right)_{i, j}\left[\left(v_{\ell}\right)_{i, j+\frac{1}{2}}^{n}-\left(v_{g}\right)_{i, j+\frac{1}{2}}^{n}\right] \\
& \left.-\left(k_{y}\right)_{i, j-\frac{1}{2}}^{n}\left(\frac{\partial}{\partial P}\right)_{i, j}\left[\left(v_{\ell}\right)_{i, j-\frac{1}{2}}^{n}-\left(v_{g}\right)_{i, j-\frac{1}{2}}^{n}\right]\right\}
\end{aligned}
$$

To complete the derivation requires the velocity derivatives, obtained through the differentiation of Egs, 4.13 through 4.16 evaluated at time level $n$. The detalls are given by Harlow and Amsden. ${ }^{20}$ Equation $\mathbf{5 . 2 2}$ is an approximation to the $\mathrm{P}$ derivative of Eq. 5.19. Geometrically, the left side of Eq. 5.21 is the value of the pressure at the point where the line with slope $\left(\mathrm{dD}_{\mathrm{g}} / \mathrm{dP}\right)_{1, j}$, passing through point $\left(\mathrm{P}_{1, j},\left[\mathrm{D}_{\mathrm{g}}\left(\mathrm{P}_{\mathrm{l}, \mathrm{j}}\right)\right]_{\mathrm{i}, \mathrm{j}}\right)$, intersects the $\mathrm{P}$-axis in the $\left(P, D_{g}\right)$-plane.

At this stage, just before the new velocities are calculated, an estimate of the vold fraction is needed. If $\theta_{i, j}^{n} \geq \theta *$, in this case, the latest available value of the void fraction is a sufficiently accurate estimate, and no special treatment is needed.

From this estimation of vold fraction, new values of the velocity components are calculated, using Egs. 4.13-4.17. These new velocity compunents reflect the new values of the pressure, void fraction, and densitles.

If $\theta_{\mathrm{l}, \mathrm{j}}^{\mathrm{n}} \geq \theta^{*}$, then the new velocities are used to calculate new mass fluxes for the liquid and a new value of $\left(\rho_{\ell}^{\prime}\right)^{n+1}$ from the liquid continuity equation, Eq. 4.8. From this value of $\left(\rho_{\ell}^{\prime}\right)_{i, j}^{n+1}$, a new valu'e of the void fraction is computed from

$$
\theta_{i, j}^{n+1}=1-\left(\rho_{\ell}^{\prime}\right)_{i, j}^{n+1} /\left(\rho_{\ell}\right)_{i, j}
$$

and a new value of the gas macroscopic density is computed from

$$
\left(\rho_{g}^{\prime}\right)^{n+1}=\theta_{i, j}^{n+1}\left(\rho_{g}\right)_{i, j}
$$

The mass residual $\left(D_{g}\right)_{i, j}$ is then calculated. If it satisfies the convergence criterion, the calculations for cell $(i, j)$ are completed, and the iteration procedure is begun in the next cell. If $\left(\mathrm{D}_{\mathrm{g}}\right)_{\mathfrak{i}, \mathfrak{j}}$ does not satisfy the convergence criterion, an additional pressure adjustment and the ensuing calculations are made, unless the number of pressure adjustments in cell $(i, j)$ would exceed the parameter LMAX. In the latter situation, the iteration procedure also is begun in the next cell. At present, LMAX is set equal to five. 
A new value of $\left(\mathrm{D}_{\mathrm{g}}\right)_{\mathrm{i}, \mathrm{j}}$ follows each pressure adjustment. The initial pressure adiustment is necessary if the mass residual does not satisfy the convergence criterion and, if necessary, is made using $P_{i, j}^{n}$ in Eq. 5.21. After the ensuing calculation, further pressure adjustments using Eg. 5.21 are made until a mass residual satisfying the convergence criterion is obtained, the number of pressure adjustments in cell $(i, j)$ is LMAX, or a pair of pressures, $P_{1}$ and $P_{2}$ (the corresponding mass residuals of which, $D_{1}$ and $\mathrm{D}_{2}$, have different signs and do not satisfy the convergence criterion), is obtained. Without loss of generality, $D_{1}$ may be assumed to be positive (Fig. 16a). In the first two cases, the iteration procedure starts in the next cell; in the third case, a new pressureadjustment technique is used, because continued use of Eq. 5.21 in the third case may not lead to mass residuals that satisfy the convergence criterion.

With reference to Fig. 16a, in order to apply the pressure-adjustment technique to the third case, a third pressure, $P_{3}$, between $P_{1}$ and $P_{2}$ is needed. This pressure is obtained as follows:

$$
P_{3}=\left(P_{2} D_{1}-P_{1} D_{2}\right) /\left(D_{1}-D_{2}\right)
$$

As shown geometrically in Fig. $16 \mathrm{a}, \mathrm{P}_{3}$ is the value of the pressure at which the line through the points $\left(P_{1}, D_{1}\right)$ and $\left(P_{2}, D_{2}\right)$ intersects the $P$ axis in the $(P, D)$ plane. The value of the derivative of the mass residual with respect to the pressure is then changed to

$$
\left(d D_{g} / d P\right)_{i, j}=\left(D_{1}-D_{2}\right) /\left(P_{1}-P_{2}\right) \text {. }
$$

This technique is basically a Reguli-falsi, or false-position, method. 42

Because the maximum number of pressure adjustments permitted in each cell is LMAX (see Fig. 15), the mass residuals may not satisfy the convergence criteria simultaneously in all cells after a single series of pressure adjustments. If this is the case, it is necessary to repeat the series of pressure adjustments, again permitting up to LMAX adjustments and using ?q. 5.21 to initiate them. Should the pressure in cell $(i, j)$ need adjusting during this new series of adjustments, the derivative of the mass residual given by Eq. 5.26 ensures that the new pressure obtained from Eq. 5.21 will result in a mass residual smaller than that corresponding to the original pressure. The use of Eq. 5.22 may not lead to a new pressure for which the mass residual is smaller.

After the new pressure, $\mathrm{P}_{3}$, has been obtained using Eq. 5.25, the mass residual $D_{3}$ is obtained as discussed previously. If $D_{3}$ satisfies the convergence criterion, the iteration procedure commences in the next cell. Otherwise, three pressures exist, $\mathrm{P}_{1}$, $P_{2}$, and $P_{3}$, such that $P_{3}$ is between $P_{1}$ and $P_{2}$ and the respective mass residuals $D_{1}, D_{2}$, and $D_{3}$, do not satisfy the convergence criterion in cell $(i, j), D_{1}>0$, and $D_{2}<0$. 
With three pressures and their mass residuals obtained as described, or otherwise, a constrained two-sided secant technique is used to obtain further pressure adjustments. ${ }^{2}$ From these pressures and their mass residuals, the pressures $P_{A}$ and $P_{B}$ are obtained, where

$$
P_{A}= \begin{cases}\left(P_{3} D_{1}-P_{1} D_{3}\right) /\left(D_{1}-D_{3}\right) & \text { for } D 1 \neq D_{3} \\ \left(P_{2}+P_{3}\right) / 2 & \text { for } D_{1}=D_{3}\end{cases}
$$

and

$$
P_{B}= \begin{cases}\left(P_{3} D_{2}-P_{2} D_{3}\right) /\left(D_{2}-D_{3}\right) & \text { for } D_{2} \neq D_{3} \\ \left(P_{1}+P_{3}\right) / 2 & \text { for } D_{2}=D_{3}\end{cases}
$$

Geometrically, $P_{A}$ for $D_{1} \neq D_{3}$ is the value of the pressure at the point where the line through points $\left(P_{1}, D_{1}\right)$ and $\left(P_{2}, D_{2}\right)$ intersects the $P$ axis in the $(P, D)$ plane; and $P_{B}$ for $D_{2} \neq D_{3}$ is the value of the pressure at the point where the line through points $\left(\mathrm{P}_{2}, \mathrm{D}_{2}\right)$ and $\left(\mathrm{P}_{3}, \mathrm{D}_{3}\right)$ intersects the $P$ axis in the $(P, D)$ plane (see Fig. 16b). If $D_{3}>0$ and $P_{A}$ is not between $\mathrm{P}_{2}$ and $\mathrm{P}_{3}$, then

$$
P_{A}=\left(P_{2}+P_{3}\right) / 2
$$

replaces the $P_{A}$ of Eq. 5.27; if $D_{3}<0$ and $P_{B}$ is not between $P_{1}$ and $P_{3}$, then

$$
P_{B}=\left(P_{1}+P_{3}\right) / 2
$$

replaces the $P_{B}$ of Eq. 5.28. Using $P_{A}$ from Eqs. 5.27 or 5.29 and $P_{B}$ from Eqs. 5.28 or 5.30 , the new estimate for $P_{i, j}^{n}$ is

$$
P_{i, j}^{n+1}=\left(P_{A}+P_{B}\right) / 2 .
$$

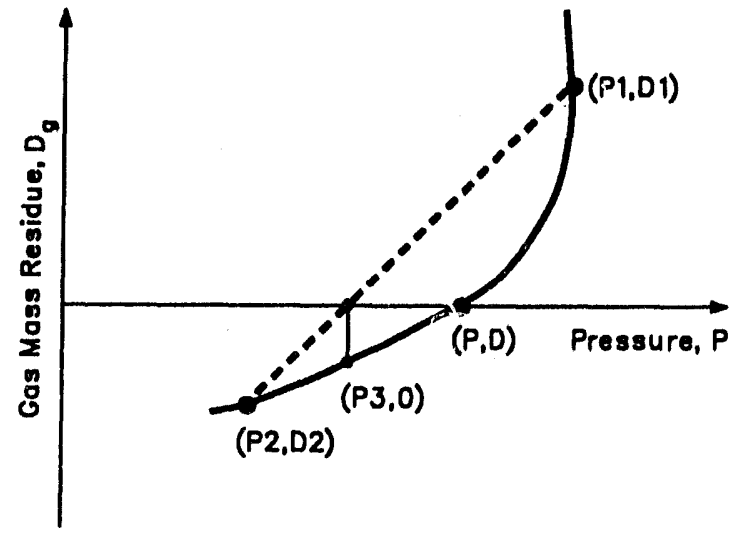

(a) Reguli Falsi Method

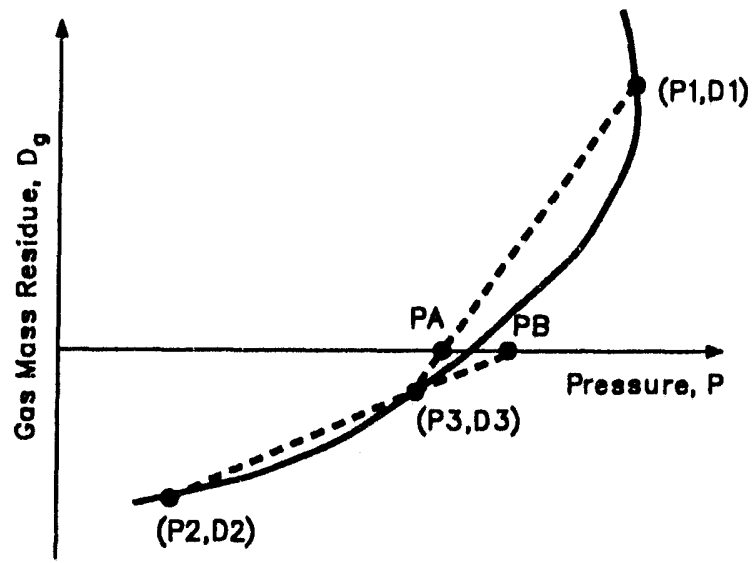

(b) Constrained Two-Sided Secont Method

FIGURE 16 Solution Methods for Pressure Correction 
The sequence of calculations following any pressure adjustment then leads to the calculation of a mass residual corresponding to this new pressure. If the mass residual satisfies the convergence criterion, then the iteration procedure begins in the next cell. Otherwise, if $D_{3}>0$, then $P_{3}$ becomes $P_{1}$ and $D_{3}$ becomes $D_{1}$; or if $D_{3}<0$, then $P_{3}$ becomes $P_{2}$ and $D_{3}$ becomes $D_{2}$. The new values of $P_{3}$ and $D_{3}$ are the estimate (from Eq. 5.31) of $P_{i, j}^{n+1}$ and its mass residual, respectively. The new values of $P_{1}, P_{2}$, and $P_{3}$ and $D_{1}, D_{2}$, and $D_{3}$ are then used to obtain a new pressure estimate using the constrained, two-sided secant technique. A new mass residual is obtained, and this pressure-adjustment technique is repeated, if necessary, until a mass residual satisfying the convergence criterion is obtained, or a total of LMAX pressure adjustments is made. In either case, the pressure adjustments are begun in the next fluid cell.

Several series of pressure adjustments may be necessary to obtain mass residuals that satisfy the convergence criteria simultaneously in all fluid cells. In FLUFIX/MOD1, each such series is counted as one iteration. At present, the number of iterations is limited to 100 .

If, during any iteration, $\left(D_{g}\right)_{i, j}$ for $\theta_{i, j}^{n} \geq \theta^{*}$ satisfies the convergence criterion, then $\left(\rho_{\ell}^{\prime}\right)_{i, j}^{n+1}$ is calculated to ensure mass conservation for the liquid. Also, in this case, $\theta_{i, j}^{n+1}$ and $\left(\theta_{g}^{\prime}\right)_{i, j}^{n+1}$ are calculated using Eqs. 5.23 and 5.24, respectively.

When the mass residuals satisfy the convergence criteria simultaneously in all cells, a solution to the mass and momentum equations is obtained for computational cycle $(n+1)$. Figure 15 summarizes the iteration scheme, as solved in subroutine ITER.

\subsection{STABILITY OF THE NUMERICAL SCHEME}

No detailed numerical-stability analysis has been performed for the IMF numerical scheme. However, approximate analyses have been performed. Prosperetti performed a linear stability analysis on the one-dimensional equations with constant densities and drag coefficient for Hydrodynamic Model $\mathrm{A}^{43}$ and found that, without drag, because of the complex characteristics, the numerical scheme is unstable. For finite interface drag and long wavelengths, Prosperetti found stability, provided that the drag was sufficiently large. This problem should not exist for Hydrodynamic Model B.

Appendix A presents a possible explanation of why there are usually no stability problems, computationally, even for Hydrodynamic Model A. 


\section{GLOBAL STRUCTURE OF THE FLUFIX/MOD2 COMPUTER PROGRAM}

In this section, the global : tructure of the FLUFIX/MOD2 computer program is described. First, however, it is necessary to describe briefly the FLUFIX/MOD2 subroutines.

\subsection{FLUFIX/MOD 2 SUBROUTINES AND THEIR FUNCTIONS}

An alphabetical listing of the FLUFIX/MOD2 subroutines, together with brief descriptions, follows:

BDRY Sets the velocity boundary conditions in all rigid cells and in all outflow boundary cells; sets the remaining boundary conditions in all outflow boundary cells.

BETAS Calculates the reciprocal derivatives of the mass residuals with respect to pressure for the iteration procedure.

CNVERT Calculates the values of the microscopic and macroscopic densities from the pressure, temperatures, and void fraction.

EOSG Calculates from the pressure and the temperature, the microscopic density and the reciprocal of the speed of sound squared for the gas.

EOSL Calculates from the pressure and the temperature, the microscopic density and the reciprocal of the speed of sound squared for the liquid.

FLIC Sets cell flags on the basis of input data.

INDEX,

INDEXA Calculate indexes for array quantities and reflect cell quantities in the rigid cells.

ITER Calculates the iterative solution of the mass and momentum equations.

KDRAGG Calculates the Richardson-Zaki equation for vapor volume fraction $\theta \geq 0.8$.

KDRAGL Calculates the Ergun equation for vapor volume fraction $\theta<0.8$. 
KDRAGS Calculates the values of the interphase friction function; calls KDRAGG and KDRAGL.

MASFG,

MASFGA Calculate the mass fluxes for the gas.

MASFL,

MASFLA Calculate the mass fluxes for the solids.

NEWP Calculates a new estimate of the advanced time pressure from three (pressure, residual) points.

PROG Controls the main part of the calculation.

RTAPE5 Reads a restart tape from Unit 9 and initializes all array quantities in all cells for a continuation of a previous calculation.

SETC Sets the C array, which is used to store equation of state or transport properties data, coefficients of functions, and related constants.

SETUP Sets some problem constants and defines the initial values of quantities in the fluid and inflow boundary cells, using the input data and prints the flags.

SETXTRA Calls the subroutines EOSC, EOSL, and KDRAGS.

THGAS Calculates the void fraction implicitly from the gas continuity equation (retained but disabled, because $\theta$ is assumed to be $\geq \theta^{*}$ ).

TILDE Calculates momenta due to convection and gravity and velocity estimates in all fluid cells and inflow boundary cells.

TLEFT ANL off-line subroutine, calculates the time remaining for the job in increments of $0.01 \mathrm{~s}$ (e.g., $1 \mathrm{~s}=100$ units of $0.01 \mathrm{~s}$ left).

UGMOMF Calculates fluxes of radial momentum for the gas ( $r$ or $x$ direction).

UGVS Calculates the stress tensor terms SVG used in UGMOMF.

ULMOMF Calculates fluxes of radial momentum for the solids ( $r$ or $\mathbf{x}$ direction). 
ULVS Calculates the stress tensor terms SUL used in ULMOMF.

VELS Calculates the gas and solids velocities.

VGMOMF Calculates fluxes of axial momentum for the gas (z or $y$ direction).

VGVS Calculates the stress terms SVG used in VGMOMF.

VLMOMF Calculates fluxes of axial momentum for the solids ( $z$ or $y$ direction).

VLVS Calculates the stress tersm used in VLMOMF.

\subsection{NEW SUBROUTINE NAMES OBTAINED FROM K-FIX}

Included in the foregoing are several subroutines that were entry points in the $\mathrm{K}$ FIX code. These were made separate subroutines in FLUFIX:

INDEXA was an entry point in subroutine INDEX.

MASFGA was an entry point in subroutine MASFG.

MASFLA was an entry point in subroutine MASFL.

VELS2 was an entry point in subroutine VELS.

In addition, there was one name change:

CNVERT was subroutine CONVERT.

\subsection{SUBROUTINES AND LASL EXTERNAL SUBROUTINE CALLS DELETED FROM K-FIX}

In the process of creating FLUFIX, the following subroutines, which are listed here for reference, were deleted from K-FIX:

ADV LASL external plotting routine call.

ASURFS Calculates the interphase surface area per unit volume, the gas bubble or liquid droplet radius, and the ratio of these quantities.

BOIL Calculates the evaporation rate.

CNPLOT Contour plotting. 
COND Calculates the condensation rate.

DATAREL LASL external plotting routine call.

DLIO Calculates the liquid mass residual from the solids continuity equation.

DLNLN Purpose unknown; called by subroutine GRAPH.

DVAP Calculates the gas mass residual from the continuity equation.

FRICT Calculates by iteration the Colebrook friction factor from a specifled Reynolds number for a fixed surface roughness.

GETO LASL external plotting routine call.

GRAPH Automatically graphs a set of points.

HEATCG Calculates the heat flux for the gas, using the gas conductivity.

HEATCL Calculates the heat flux for the solids, using the solids conductivity.

ICONV Updates the specific internal energies to account for the effects of convection, viscous and pressure work, and conduction.

IGIL Updates the specific internal energies during the iteration procedure, to account for the effects of mass, momentum, and energy exchange.

IGVS Calculates the viscous stress work terms in the gas-specific internal energy equation.

ILVS Calculates the viscous stress work terms in the solidsspecific internal energy equation.

LINCNT LASL external plotting routine call.

RHEATS Calculates the values of the interphase heat-transfer function.

SAT Calculates the saturation temperature, latent heat, and other saturation quantities from the pressure.

SBLIN Purpose unknown; called by GRAPH. 
SIEGF Caloulates fluxes of speolfic internal energy for the gas.

SIELF Calculates fluxes of specific internal energy for the llds.

SLLIN Purpose unknown; called by GRAPH.

THERCON Calculates the thermal conductivities of the gas and the solids.

THF Calculates fluxes of vold fraction for the energy equations.

TRANS Calls the subroutines THERCON and VISC

TURBD Calculates the turbulent thermal diffusivities for the gas and the sollds.

VISC Calculates the microscopic and turbulent viscosities for the gas and the solids.

VPLOT Vector plots.

VWORKG Calculates the viscous work for the gas.

VWORKL Calculates the viscous work for the solids.

\subsection{FLUFIX PROGRAM STRUCTURE BYNOPSIS}

The FLUFIX/MOD 2 program structure and the main subroutine calling sequence are shown in Fig. 17. The calculation begins with the FLUFIX/MOD 2 main program, where the input data are read and printed. (These input data are given in Sec. 7.) If the calculation is being continued from the results of a previous calculation, subroutine RTAPE5 is called to define the values of all array quantities in all cells. These quantities include $P, \theta, U_{\mathbf{g}}, V_{\mathbf{g}}, U_{\ell}, V_{\ell}$, and their sums for time-averaging. Otherwise, these quantities are obtained from the input data. Subroutine FLIC is called to assign the values to the matrix of flags $F L(I, J)$, used to distinguish the various types of cells in the computing mesh and its boundary perimeter. The seven types of cells, described in Sec. 5.1, are repeated here for reference:

$$
\begin{aligned}
\mathrm{FL}(\mathrm{I}, \mathrm{J}) & =1 \text { for a fluid cell } \\
& =2 \text { for a solid (rigid) cell with free-slip boundaries } \\
& =3 \text { for a solid (rigid) cell with no-slip boundaries } \\
& =4 \text { for a continuative outflow boundary } \\
& =5 \text { for a specified inflow cell } \\
& =6 \text { for a specified inflow pressure } \\
& =7 \text { for a specified outflow pressure }
\end{aligned}
$$




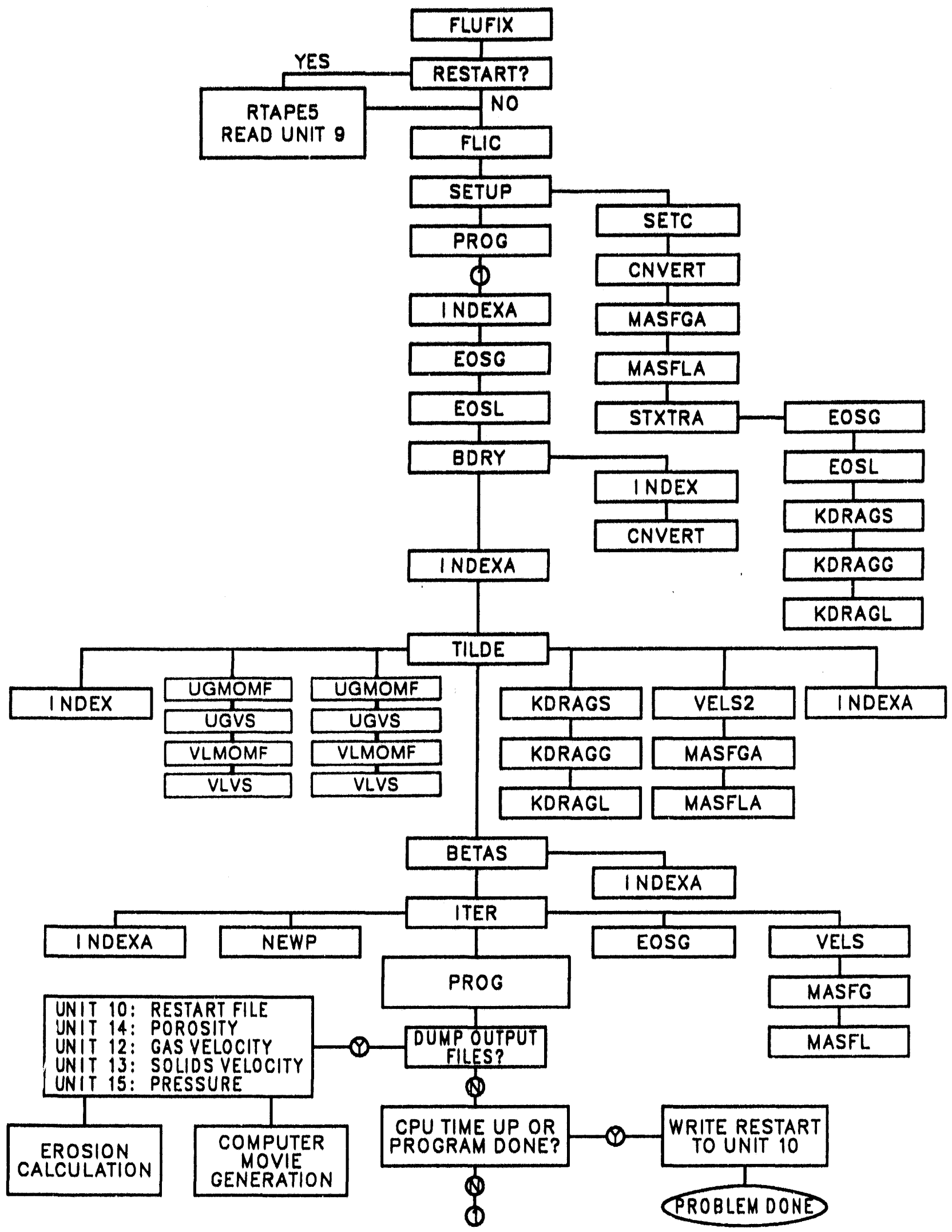

FIGURE 17 FLUPIX Program Structure and the Main Subroutine Calling Bequence 
Subroutine SETUP is called to define various problem constants and to calculate values for $\rho_{g}, \rho_{g}^{\prime}, \rho_{\ell}, \rho_{l}^{\prime}, K_{x}$, and $k_{y}$ from the input data, using subroutine CNVERT, which, in turn, calls EOSG, EOSL, KDRAGS, KDRAGG, and KDRAGL.

Subroutine PROG is then called. PROG controls the main part of the calculation. Subroutine BDRY is called to set boundary conditions in the rigid cells and the outflow boundary cells. The rigid walls can be specifled along any mesh boundary. The free-slip wall can serve as a reflective plane of symmetry. Two inflow openings each can be specified along the bottom and left boundaries. Similarly, two outflow openings each can be prescribed along the top and right boundaries. The boundary conditions are enforced, using the fictitlous boundary cells, for which flags may be programmed, as shown in Figs. $\theta$ and 10. For rigid walls, the tangential velocities in the flotitious cells are set by reflection for a free-sllp wall and by reflection with a change in sign for no-slip walls. The continuative outflow boundaries are gradient-free in their normal direction.

Flow around rectangular obstacles may be calculated by specifying rectangular obstacles in the computing mesh interlor. Obstacles are bullt from rectangular cells. Their boundaries can be a combination of free-slip and no-slip rigid walls. The obstacle boundary conditions are enforced in the same way as they are around the mesh perimeter. To enforce the velocity boundary condition properly, obstacles must be at least two cells wide.

At this stage, all the boundary conditions discussed in Sec. 5.1 are Imposed for this computational cycle, and the solution scheme in the fluld cells, discussed in Sec. 5.2, begins. This scheme commences with the calling of subroutine TILDE. In all inflow and fluid cells, TILDE calculates the tilde momentum densities given by Egs. 4.9a-4.12a, the values of the interphase friction function, estimates of the new velocities, and the mass fluxes. Subroutine BETAS is called to calculate the convergence criterla from Eq. 5.20 and the values of $\mathrm{dD}_{\mathrm{g}} / \mathrm{dP}$ as given by Eq. 5.22.

Subroutine ITER is called to adjust the pressure in each fluid cell until the convergence criteria are met simultaneously in all fluid cells or 100 iterations are completed. Also in ITER, the latest values of the velocitles, pressure, and vold fraction are calculated.

At the end of the iteration cycle, data print, dump, and plot options are checked. At that time, data are sent to the paper output files, the contents of the arrays are written on restart tape TAPE10, or to Units 12-14 for later use in the post-process plotting and erosion computer programs. If the program terminates because of CPU time being exceeded (minus approximately 10 seconds), a restart is written to UNIT10.

This completes the computational cycle. If the time to stop has not been reached, then the sequence of steps in PROG is repeated.

Appendix B lists the FORTRAN symbols and their description. 


\section{DRSCRIPTION OF FLUFIX/MOD\& INPUT DATA}

In this section, the FLUFIX/MOD2 Input data are described. Free format has been used for FLUFIX/MOD2 using FORTRAN 77 as opposed to the formated input for FLUFIX/MOD1 using FORTRAN 66.

\section{Line No. 1}

NAME (Format 40A2)

NAME $\quad=$ Problem identifler (up to 80 columns)

Line No. 2

CPSTOP

CPSTOP $=$ Time in units of $0.01 r$ to allow sufficient time for restart and plot flles to be writ" . to disk when CPU time is up. Used with ANL system subroutise TLEFT. A value of 1000. is adequate but, at present, it must exceed the time required for converging a time step.

Line No. 3

IB2, JB2 (Integers)

IB2 = Total number of cells in $x$ or $r$ direction.

JB2 $=$ Total number of cells in $y$ or $z$ direction.

Line No. 4

$\operatorname{SCALE}(I), I=1,4$

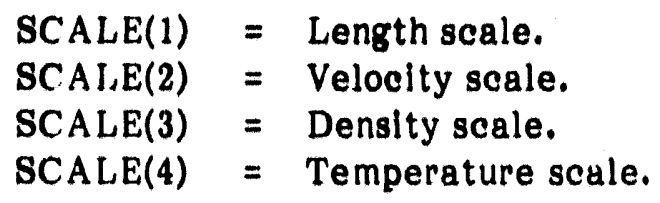

These are the scale factors used to establish the dimensionless input data. At present, they are set to 1.0 . 


\section{Line No. 5}

ITC, DR, DZ, BHITE

ITC $=2$ for one-dimensional spherical coordinates (use not
$=1$ recommended).
$=0$ for Cartesian coordinates.
DR $\quad=\delta r$ or $\delta x$, the cell dimension in the $r$ or $x$ direction, $c m$.
DZ $\quad=\delta z$ or $\delta y$, the cell dimension in the $z$ or $y$ direction, $\mathrm{cm}$.
BHITE $\quad=$ Height of fluldized bed where solids are present, $\mathrm{cm}$.

Line No. 6

$\operatorname{KFLIN(M),~} M=1,4$ (Integers)
$\operatorname{KFLIN}(M)=$ Cell flag types for the inflow boundaries, BOTTOM-L and BOTTOM-R openings $(M=1,2)$ and LEFT-B and LEFT-T openings $(M=3,4)$. Refer to Fig. 9.

Line No. 7

FLO(M),M $=1,4$

$F L O(1)$ and $F L O(2)$ are the $x$ or $r$ coordinates of the left inflow opening on the BOTTOM-L boundary, om; FLO(3) and FLO(4) are the $x$ or $r$ coordinates of the right inflow opening on the BOTTOM-R boundary, $\mathrm{cm}$. Refer to Fig. 9.

Line No. 8

$F L O(M), M=5,8$

$\mathrm{FLO}(5)$ and $\mathrm{FLO}(6)$ are the $y$ or $\mathrm{z}$ coordinates of the bottom inflow opening on the LEFT-B boundary, cm; FLO(7) and FLO(8) are the $y$ or z coordinates of the top inflow opening on the LEFT-T boundary, cm. Refer to Fig. 9.

NOTE: The coordinates of the openings along the left boundary must be integral multiples of $\delta \mathrm{z}$; those along the bottom boundary must be integral multiples of $\delta r$. The openings on the bottom and left boundaries are, by definition, inflow openings. A maximum of two openings may be specified along each boundary. Figure 18 shows examples with two, one, and zero flow openings along the bottom. 


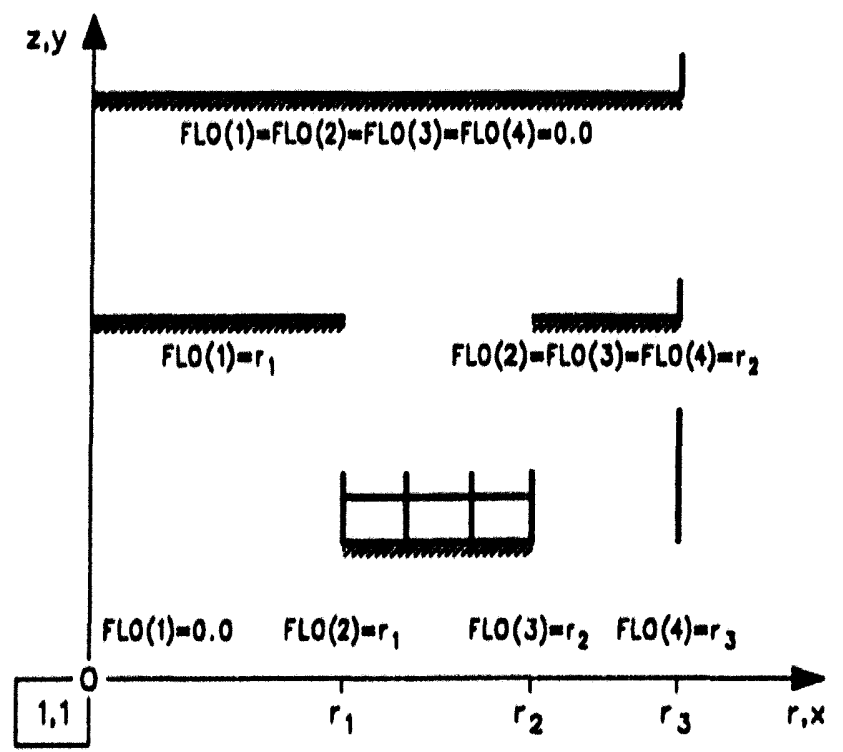

\section{FIQURE 18 Example Bhowing Two, One, and Zero Inflow Openings along the Bottom Boundary}

\section{Line No. 8}

$\operatorname{KFLOUT}(M), M=1,4$ (Integers)

KFLOUT(M) = Cell flag types for the outflow boundarles, TOP-L and TOP-R openings $(M=1,2)$ and RIGHT-B and RIGHT-T openings $(M=3,4)$. Refer to Fig. 9.

Line No. 10

FLO(M),M $=9,12$

FLO(9) and FLO(10) are the $x$ or $r$ coordinates of the left outflow opening on the TOP-L boundary, cm; FLO(11) and FLO(12) are the $x$ or $r$ coordinates of the right outflow opening on the TOP-R boundary, cm. Refer to Fig. 9.

Line No. 11

$\mathrm{FLO}(\mathrm{M}), \mathrm{M}=13,16$

FLO(13) and FLO(14) are the $y$ or $z$ coordinates of the bottom outflow opening on the RIGHT-B boundary, cm; $F L O(15)$ and $F L O(16)$ are the $y$ or $z$ coordinates of the top outflow opening on the RIGHT-T boundary, cm. Refer to Fig. 9. 
NOTE The coordinates of the top boundary must be Integral multiples of $8 x$ or $\delta r$, and those along the right must be integral multiples of sy or $\delta z$. The openings on the top and right boundaries are, by definition, outflow openings. A maximum of two openings may be speclfied along each boundary.

Line No. 12

$\operatorname{NSL}(M), M=1,4$

NSL(M) indicates free-slip or no-slip boundary conditions for rigld walls adjoining the dummy cells around the computing mesh perimeter. Values of 0 for free-slip or 1 for no-slip are assigned for the bottom $(M=1)$, left $(M=2)$, top $(M=3)$, and right $(M=4)$ boundaries, in that order. The assigned values are ignored across inflow or outflow openings. This flag overrides KFLIN or KFLOUT $=2$ or 3.

Line No. 13

NO, MFFLAG (Integers)

NO = Number of interior obstacle cells. Each obstacle region consisting of obstacle cells must contain at least two cells in the $r$ direction and two in the $z$ direction to enforce no-slip boundary conditions unequivocally when the viscous shear terms are present. If this is not done, the obstacle region should be made free slip. By combining several obstacles, complex shapes can be obtained. If $\mathrm{NO}=0$, no additional lines are read. If $\mathrm{NO}>0$, then one line is read for each obstacle. The format of Line No. $13+$ $\mathrm{N}, \mathrm{N}=1, \mathrm{NO}, \mathrm{NO}>\mathrm{0}$, describes the format for obstacle $\mathrm{N}$. Note: Presently NO $=20$ and must be increased if NO $>20$.

MFFLAG, a flag used in conjunction with the parameter BHITE on line no. 5 , is used to initialize the axial pressure and gas velocity distributions. Refer to Table 3 and Sec. 5.2 for a summary and detalled description of the six combinations.

$M F F L A G=0 \quad$ The initial axial and radial gas velocities are computed from UO and VO, line no. $14+\mathrm{N}$, and the axial vold equation, $\theta(\mathrm{I}, \mathrm{J})$.

$U_{g}(I, J)=U O / \theta(I, J)$
$V_{g}^{g}(I, J)=V O / \theta(I, J)$

MFFLAG = 1 WGY (gas mass flux) is computed from the total bottom inlet get flow only. Then $\mathrm{V}_{\mathrm{g}}(\mathrm{I}, \mathrm{J})=\mathrm{WGY} /\left((0.5 \cdot(\mathrm{RGP}(\mathrm{IJ})+\mathrm{RGP}(\mathrm{IJP}))) \mathrm{U}_{\mathrm{G}}(\mathrm{I}, \mathrm{J})\right.$ $=0$. 
MFFLAG $=2$ WGY is computed for minimum fluidization. Then $V_{g}(I, J)$ and $U_{g}(I, J)$ are computed as for MFFLAG $=1$. The entire inlet bottom gas velocity is set to minimum fluidization velocity, the inlet porosity is set to 1.0 , and the inlet pressure is set $20 \%$ greater than the total weight of the fluidized bed.

Line No. $13+N^{*}$

$\operatorname{NOS}(N),(O B(M, N), M=1,4)$

NOS(N) $\quad=0$ for free-slip boundary conditions for obstacle $N$.

$=1$ for no-slip boundary conditions for obstable $\mathrm{N}$.

$\mathrm{OB}(1, \mathrm{~N})=\mathrm{x}$ or $\mathbf{r}$ coordinate of the left side of obstacle $\mathrm{N}, \mathrm{cm}$.

$\mathrm{OB}(2, \mathrm{~N})=\mathrm{x}$ or $\mathrm{r}$ coordinate of the right side of obstacle $\mathrm{N}, \mathrm{cm}$.

$\mathrm{OB}(3, \mathrm{~N})=\mathrm{y}$ or $\mathrm{z}$ coordinate of the bottom of obstacle $\mathrm{N}, \mathrm{cm}$.

$\mathrm{OB}(4, \mathrm{~N})=\mathrm{y}$ or $\mathrm{z}$ coordinate of the top of obstacle $\mathrm{N}, \mathrm{cm}$.

Line No. $14+N$

UO, VO, PO, THO, TEMPO, GY

This card specifies the uniform initial data used to begin the calculation.

UO = Initial radial velncity of the liquid and gas, $\mathrm{cm} / \mathrm{s}$.

VO = Initial axial velocity of the liquid and gas, $\mathrm{cm} / \mathrm{s}$.

PO = Initial pressure, dynes $/ \mathrm{cm}^{2}$.

THO = Initial void fraction.

TEMPO = Initial temperature of the liquid and gas, $\mathrm{K}$.

GY = Gravitational acceleration in the $\mathrm{y}$ or $\mathrm{z}$ direction, normally $-980 . \mathrm{cm} / \mathrm{s}^{2}$.

Nonuniform initial data may be specified by modifying the subroutine SETUP.

$*_{N}=1$, NO, NO $>0$. 
The next four lines are used to specify the boundary conditions for the bottom and left inflow boundaries. In summary, the order is as listed in Table 4 (refer to Fig. 9).

Note: Velocities in the transverse direction on each boundary are over-written by no-slip or free-slip boundary condition prescriptions (see line 12).

\section{Line No. $15+\mathbf{N}$}

UINL, VINL, PINL, THINL, TEMPINL

$$
\begin{aligned}
& \text { UINL = } \begin{array}{l}
\text { Radial superficial velocity of the liquid and gas entering the } \\
\text { inflow opening along the BOTTOM-L computing mesh boundary, } \\
\mathrm{cm} / \mathrm{s} .
\end{array} \\
& \text { VINL } \\
& \begin{array}{l}
\text { Axial superficial velocity of the liquid and gas entering the } \\
\text { inflow opening, } \mathrm{cm} / \mathrm{s} .
\end{array} \\
& \text { THINL } \quad=\text { Pressure of the incoming fluid, dynes } / \mathrm{cm}^{2} . \\
& \text { TEMPINL }=\text { Void fraction. }
\end{aligned}
$$

\begin{tabular}{|c|c|c|c|c|c|c|}
\hline \multirow{2}{*}{$\begin{array}{l}\text { Line } \\
\text { No. }\end{array}$} & \multirow[b]{2}{*}{ Boundary } & \multicolumn{2}{|c|}{ Velocity } & \multirow[b]{2}{*}{ Pressure } & \multirow{2}{*}{$\begin{array}{c}\text { Void } \\
\text { Fraction }\end{array}$} & \multirow[b]{2}{*}{ Temperature } \\
\hline & & Radial & Axial & & & \\
\hline $15+N$ & Bottom-Left & UINL & VINL & PINL & THINL & TEMPINL \\
\hline $16+N$ & Bottom-Right & UINR & VINR & PINR & THINR & TEMP INR \\
\hline $17+N$ & Left-Bottom & UINB & VINB & PINB & THINB & TEMPINB \\
\hline $18+N$ & Left-Top & UINT & VINT & PINT & THINT & TEMPINT \\
\hline
\end{tabular}

TABLE 4 Summary of Boundary Condition Variables 


\section{Line No. $16+\mathbf{N}$}

UINR, VINR, PINR, THINR, TEMPINR

$$
\begin{aligned}
& \text { UINR } \quad \begin{array}{l}
\text { Radial superficial velocity of the liquid and gas entering the } \\
\text { right inflow opening along the BOTTOM-R boundary, } \mathrm{cm} / \mathrm{s} .
\end{array} \\
& \text { VINR } \\
& \text { PINR }
\end{aligned}
$$

Line No. $17+\mathbf{N}$

UINB, VINB, PINB, THINB, TEMPINB

$$
\begin{aligned}
& \text { UINB }=\begin{array}{l}
\text { Radial superficial velocity of the liquid and gas entering the } \\
\text { bottom (lower) inflow opening along the LEFT-B computing mesh } \\
\text { boundary, } \mathrm{cm} / \mathrm{s} .
\end{array} \\
& \text { VINB } \quad=\begin{array}{l}
\text { Axial superficial velocity of the liquid and gas entering the } \\
\text { bottom inflow opening, } \mathrm{cm} / \mathrm{s} .
\end{array} \\
& \text { PINB } \quad=\text { Pressure of the incoming fluid, dynes } / \mathrm{cm}^{2} . \\
& \text { THINB } \quad=\text { Void fraction. } \\
& \text { TEMPINB }=\text { Temperature of the inflowing liquid and gas, } \mathrm{K} .
\end{aligned}
$$

Line No. $18+\mathbf{N}$

UINT, VINT, PINT, THINT, TEMPINT

UINT $=$ Radial superficial velocity of the liquid and gas entering the top (upper) inflow opening along the LEFT-T computing mesh boundary, $\mathrm{cm} / \mathrm{s}$.

VINT $=$ Axial superficial velocity of the liquid and gas entering the top inflow opening, $\mathrm{cm} / \mathrm{s}$.

PINT $=$ Pressure of the incoming fluid, dynes $/ \mathrm{cm}^{2}$. 
THINT $=$ Void fraction.
TEMPINT $=$ Temperature of the inflowing liquid and gas, $\mathrm{K}$.

Line No. $19+N$

ITD, NTD, NSDMP, NFILE, NWDMP (Integers)

ITD $=0$ No restart file is written, and no restart file is read (NTD through NWDMP are not used).

ITD $=1$ Restart file is written to UNIT10, but no restart file is read. Used to start a problem at time zero.

ITD $=2$ Restart file is read from UNIT9, but no restart file is written.

ITD $=3$ Restart file is read from UNIT9, and restart file is written to UNIT 10. Used to restart a problem at time greater than zero.

NTD $=$ Number of the last post-processing data set written (dumped) to UNITS 12-15, e.g., 30.

NSDMP $=$ Number of computational cycles between writes (dumps) on UNITS 12-15 (normally $=0$ ).

NFILE = Number of the last dump that was written to UNITS 12-15, e.g., 30.

NWDMP = Number of the first dump to be written to UNITS 12-15. Generally, NWDMP = NFILE + 1, e.g., 31 .

Note 1: NTD,NSDMP, NFILE, and NWDMP are for bookkeeping purposes only and do not control the dumping.

Note 2: A restart data set is also written to UNIT 10 every dump and then written over when the next dump is produced.

Line No. $20+\mathbf{N}$

TIME, TSTOP, DT, CYCLE

TIME = Initial time for the problem. TIME is also counter and is advanced by $\delta$ t each cycle.

TSTOP $=$ Time at which the calculation is to stop. The total number of computational cycles to be made is (TSTOP - TIME)/DT. 
DT $\quad=\delta t$, the computational time step.

CYCLE = Number of the computational cycle at which the calculation is to (Integer) begin. CYCLE is also a counter that is advanced by one each time step. Note: TIME and CYCLE are used for bookkeeping purposes only and do not control anything.

\section{Line No. $21+\mathbf{N}$}

LPR, TPR, TPL, TPLD

LPR = 2 Allows standard output to be written to UNIT6.

(LPR should be set to 2.)

TPR = Time interval for standard output to be written to UNIT6.

TPL = Time interval for writing plot information for porosity, pressure, and gas and solids velocities to UNIT12 through UNIT15, in that order (as shown in Fig. 17). Note: A restart data set is also written to UNIT 10 every dump and then written over when the next dump is produced.

TPLD = Used to determine frequency of printing solids mass balance. Also used as the time interval for time-averaging of these same variables.

Line No. $22+\mathbf{N}$

ROLC1, ROLC2, ROLC3

Parameters for the solids state equation,

$\rho_{s}=\mathrm{ROLCl}+\mathrm{ROLC2} \cdot \mathrm{T}+\mathrm{P}(\mathrm{IJ}) \cdot \mathrm{ROLC} 3 / \mathrm{T}, \mathrm{g} / \mathrm{cm}^{3}$

\section{Line No. $23+\mathbf{N}$}

ROGC1, ROGC2, ROGC3

Parameters for the gas state equation,

$\rho_{\mathrm{g}}=\mathrm{ROGCl}+\mathrm{ROGC} 2 \cdot \mathrm{T}+\mathrm{P}(\mathrm{IJ}) / \mathrm{ROGC} 3 \cdot \mathrm{T}$

See Sec. 3.3 for details and units for lines $22+N$ and $23+N$. 
Line No. $24+\mathbf{N}$

MMUG, PHI, DIAP

PHI $=$ Particle sphericity, $\phi_{S}\left(0.0<\phi_{s} \leq 1.0\right)$. The default value is DIAP = Particle diameter, $\mathrm{cm}$. The default value is $0.0503 \mathrm{~cm}$.

MMUG = Fluid viscosity, poise, used in the interphase drag. The default value is $1.82 \times 10^{-4}$ poise.

Line No. $25+\mathbf{N}$

THSTAR, OMEGA, DOMEGA, EPSG, EPSL

THSTAR $=\theta^{*}$, switch over-porosity for numerical solution scheme.

OMEGA = Over- or under-relaxation parameter for pressure iteration.

DOMEGA = Second over- or under-relaxation parameter for pressure iteration.

EPSG $=$ Convergence parameter for $\theta \geq \theta *$

EPSL $\quad=$ Convergence parameter for $\theta<\theta^{*}$

Line No. $26+\mathbf{N}$

SLOPE, THZERO

Parameters for the elastic modulus $G=\exp [-\operatorname{SLOPE}(\theta-\mathrm{THZERO})], \mathrm{dynes} / \mathrm{cm}^{2}$.

Line No. $27+N$

MUG, MUL, LAMBG, LAML (Reals)

MUG = Fluid viscosity, poise, used in the viscous stress Eq. 3.21. The default value is $1.82 \times 10^{-4}$ poise.

MUL = Solids viscosity, poise, used in the viscous stress Eq. 3.21. The default value is 1.0 poise.

LAMBG = Coefficient in the fluid viscous stress Eq. 3.21. The default value is $2 . / 3$. 
LAMBL = Coefficient in the fluid viscous stress Eq. 3.21. The default value is $2 . / 3$.

See Sec. 3.5 for details for line $27+N$.

Line No. $28+\mathbf{N}$

IPRES, IVG, GX

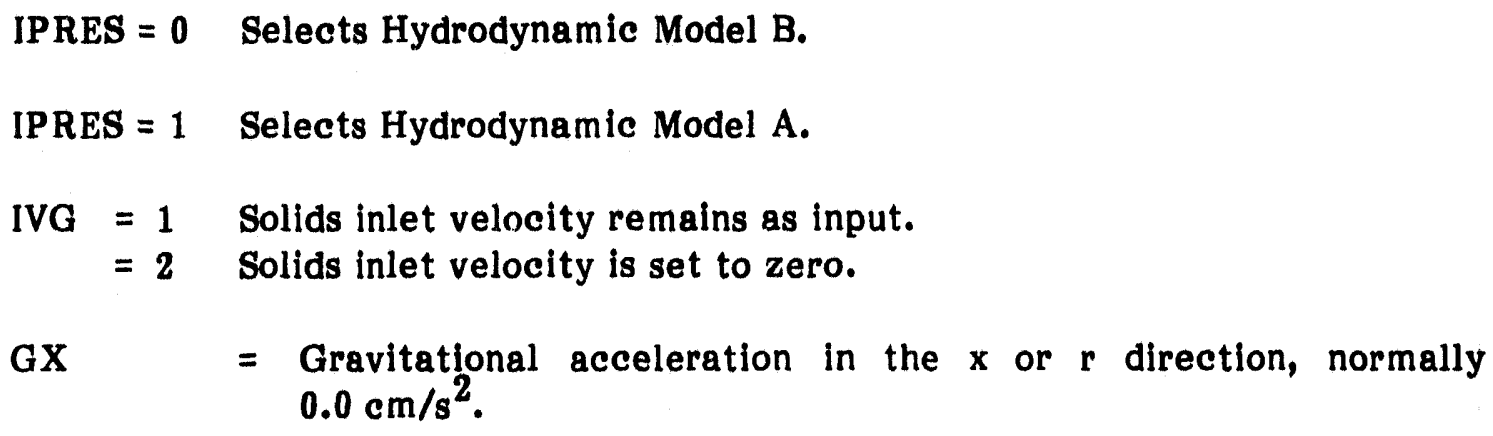

Line No. $29+\mathbf{N}$

IDRAG, ISLIP (Integers)

IDRAG $=0$ Vector form of interphase drag is used.

$=1$ Scalar form of interphase drag is used.

See Sec. 3.1.

ISLIP = 0 Partial slip solids boundary is not actuated. Free-slip or no-slip are used as described in Sec. 5.1.

= 1 Partial slip solids boundary condition is actuated according to the model shown below This boundary condition overrides the free-slip or no-slip boundary conditions at all boundaries according to the model sketched below for a boundary on the right (Fig. 19).

If input lines are missing or not assigned for some parameter, a set of default values is set automatically. These parameters and their default values are shown in Table 5. 


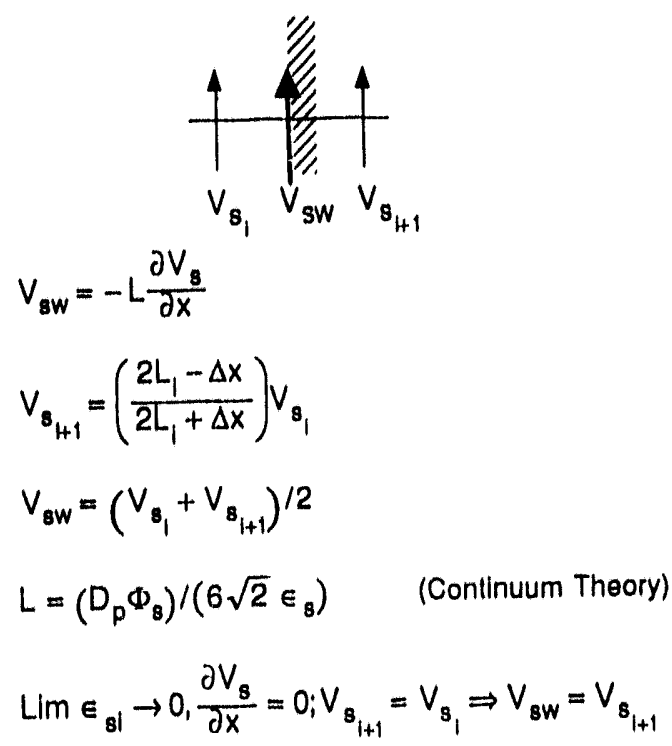

FIGURE 19 Noncontinuum

Solids Velocity Boundary

Condition

TABLE 5 Automatic Default Values for Given Parameters

\begin{tabular}{lcll}
\hline Parameter & Value & Parameter & \multicolumn{2}{c}{ Value } \\
& & & \\
\hline GX & 0.0 & GY & 0.0 \\
THO & 0.44 & MMUG & $1.82 \times 10^{-4}$ \\
TEMPO & 300.0 & PHI & 0.86 \\
ROLC1 & 2.611 & DIAP & 0.0503 \\
ROLC2 & 0.0 & THSTAR & 0.19 \\
ROLC3 & 0.0 & OMEGA & 1.0 \\
ROGC1 & 0.0 & DOMEGA & 0.95 \\
ROGC2 & 0.0 & EPSL & 0.005 \\
ROGC3 & $2.87 \times 10^{6}$ & EPSG & 0.0005 \\
LAMGB & $2 . / 3$. & MUG & $1.82 \times 10^{-4}$ \\
LAMLB & $2 . / 3$. & MUL & 1.0 \\
IDRAG & 0 & IPRES & 0 \\
& & & \\
\hline
\end{tabular}




\section{SAMPLE PROBLEM FOR A FLUIDIZED BED}

The georetry of the sample problem given here for a fluidized bed is shown in Fig. 20. The computational region is $19.685 \mathrm{~cm}$ wide, $\mathbf{5 8 . 4 4}$ $\mathrm{cm}$ high. The cell dimensions are $\Delta x$ $=\delta x=0.635 \mathrm{~cm}$ and $\Delta y=\delta y=4.87 \mathrm{~cm}$, so that the number of computational cells is 31 in the $x$ direction and 12 in the $y$ direction, for a total of 372 . In the figure, the numbers in parentheses refer to key cell numbers $(I, J)$. Symmetry about the central jet is assumed; hence the actual bed width is $39.37 \mathrm{~cm}$. (In previous modeling work without an obstacle, ${ }^{7}$ symmetry was assumed, and the agreement with experimental data was good.) The jet half-width is $0.635 \mathrm{~cm}$ (one cell width). The jet velocity is $578 \mathrm{~cm} / \mathrm{s}$, and the secondary air velocity of 26.0 $\mathrm{cm} / \mathrm{s}$ maintains the bed without a jet at minimum fluidization. The particle diameter is $503 \mu \mathrm{m}$, and the density is $2.44 \mathrm{~g} / \mathrm{cm}^{3}$. The obstacle is placed two nodes above the jet and is two nodes $(1.27 \mathrm{~cm})$ wide by two nodes $(9.74 \mathrm{~cm})$ high. Because the initial bed height is $29.22 \mathrm{~cm}$ (six cells high), the obstacle lies completely within the bed. Although this configuration is not typical of FBC geometries, it was selected because (1) it is similar to the model without the obstacle, so that prior experience is relevant, and (2) it serves to further validate the hydrodynamic model.

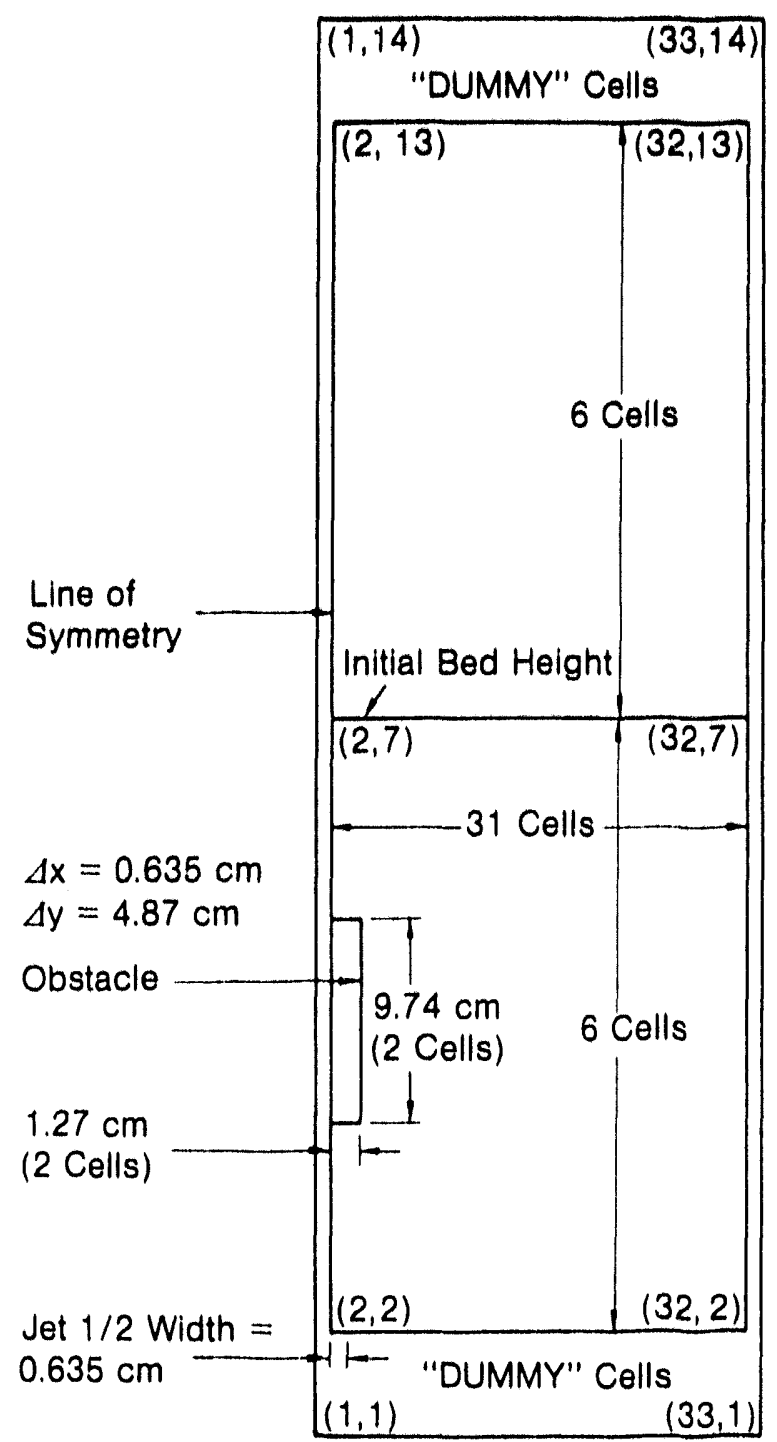

\section{FIGURE 20 FLUFIX Sample} Problem Geometry

The boundary conditions are described here. At the inlet $(\mathrm{J}=2)$, the axial gas velocity of $26.0 \mathrm{~cm} / \mathrm{s}$ is set equal to the minimum fluidization superficial velocity as computed from the Ergun equation (with solids velocity set to zero), using an assumed gas volume fraction at minimum fluidization, $\varepsilon_{\mathrm{mf}}$, of $\mathbf{0 . 4 2}$. Because no solids are entering, the inlet porosity is set to 1.0. The pressures in the dummy cells at the top $(J=14)$ are set equal to atmospheric pressure $\left(1.013 \times 10^{5} \mathrm{~Pa}\right)$, and $\mathrm{V}_{\mathrm{S}}=0$ at the exit 
$(\mathrm{J}=13)_{\text {) }}$ that is, wire mesh is simulated to prevent solids carry-over. The pressures in the bottoli. row of dummy cells $(J=1)$ are set equal to atmospheric pressure plus 1.2 times the total bed weight $\left(1.0549 \times 10^{5} \mathrm{~Pa}\right)$. On all solld surfaces except the inlet, outlet, and line of symmetry, no-slip boundary conditions are used (l.e., normal and tangential velocitles for each phase are set equal to zero). Free-slip boundary conditions are used along the 1 ne of symmetry and at the inlet and outlet. Initially, the radial gas velocity is zero, the axial gas velocity is equal to the interstitial gas velocity at minimum fluidization, and the solids radial and axial velocities are zero. The bed porosity is uniform at $\mathbf{0 . 4 2}$. The initial pressure distribution corresponds to the hydrostatic bed height. At time, $t$, greater than zero $(0+)$, the gas flow through the jet is increased to $578 \mathrm{~cm} / \mathrm{s}$. A fixed-time stop of $0.1 \mathrm{~ms}$ is used. Typical running time on an IBM 3033 computer is approximately one hour for each second of transient time and approximately four times faster on a CRAY-XMP.

Because all the printout is in cgs units, conversion factors for ogs-to-sI units are given in Table 6.

The input data file for the sample problem is given in Table 7, and the output in Table 8. In the latter, the problem input and the cell types are first summarized. The time-zero initialization begins with the line "Cycle $=0 .$. ." (second page of the table). The time-zero printout is followed by a printout of every cycle, together with the number of Iterations and the time remaining for the job in CPU seconds. At 0.01 and $0.02 \mathrm{~s}$, the solids mass balance is printed out. At $0.02 \mathrm{~s}$, the major code variables are printed out.

The only differences between the input for the standard problem in FLUFIX/MOD2 and FLUFIX/MOD1 19 is setting the initial porosity THO to 0.42 (vs, 0.44 ) and THSTAR $=0.42$ (vs. 0.384 ).
TABLE 6 Conversion from Cas to SI Units

\begin{tabular}{lll}
\hline Quantity & SI Unit & CGS Unit \\
\hline Density & $1 \mathrm{~kg} / \mathrm{m}^{3}$ & $10^{3} \mathrm{~g} / \mathrm{cm}^{3}$ \\
Length & $1 \mathrm{~m}$ & $100 \mathrm{~cm}$ \\
Mass & $1 \mathrm{~kg}$ & $10^{3} \mathrm{~g}$ \\
Pressure & $1 \mathrm{~Pa}$ & $10 \mathrm{dynes} / \mathrm{cm}^{2}$ \\
\hline
\end{tabular}




\section{TABLE 7 FLUFIX Sample Problem Input Data FHle}

\section{Line No.}

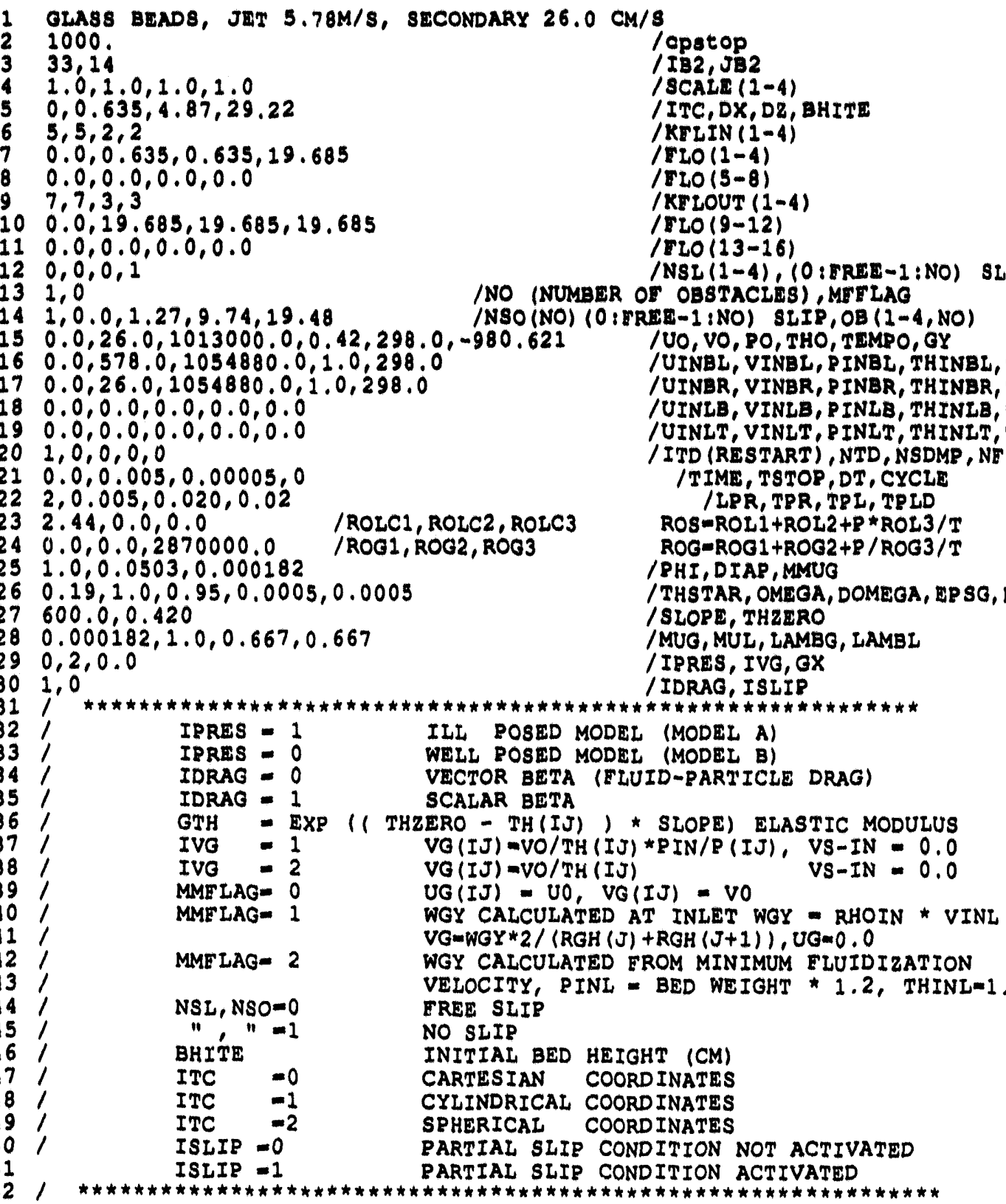




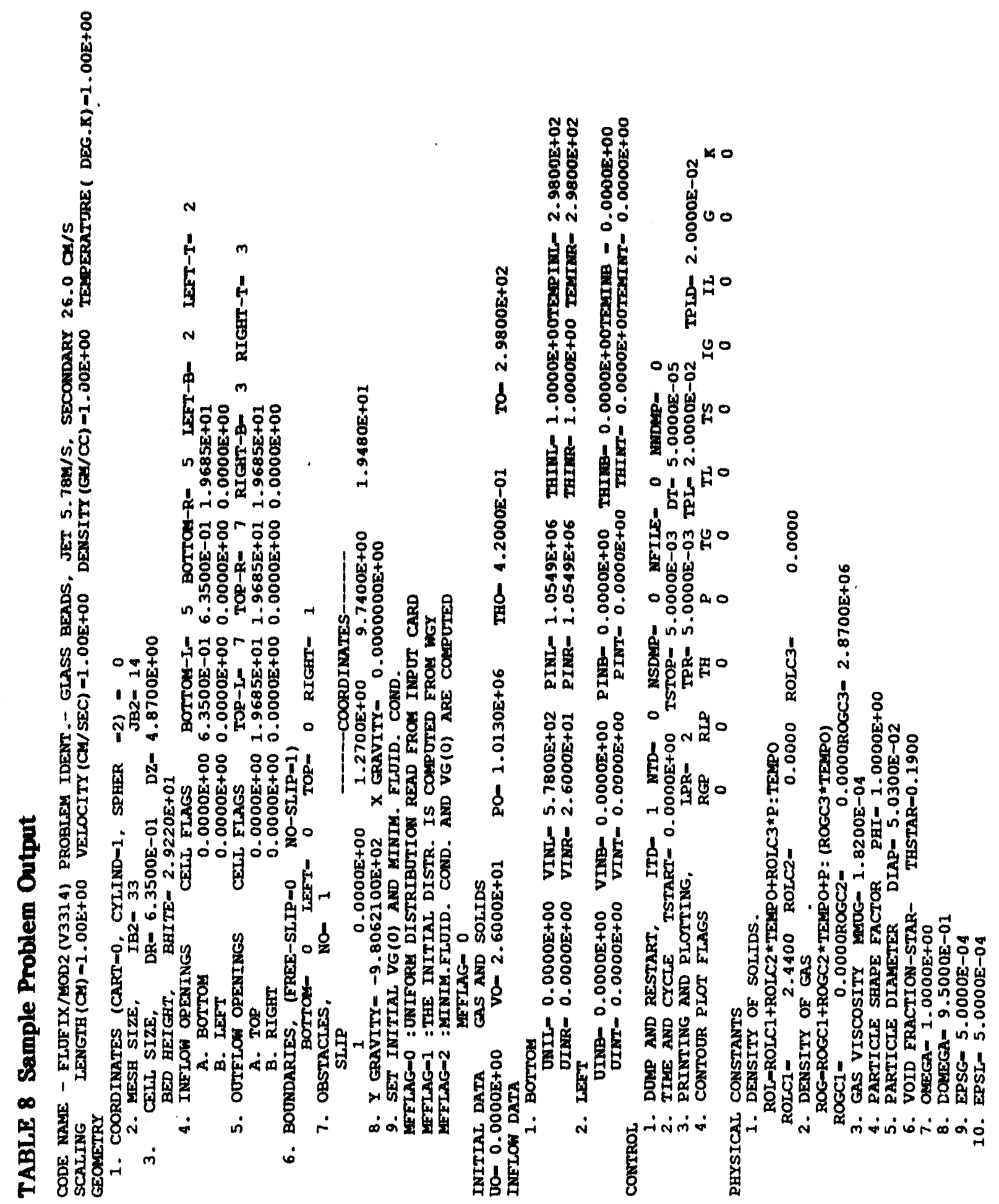




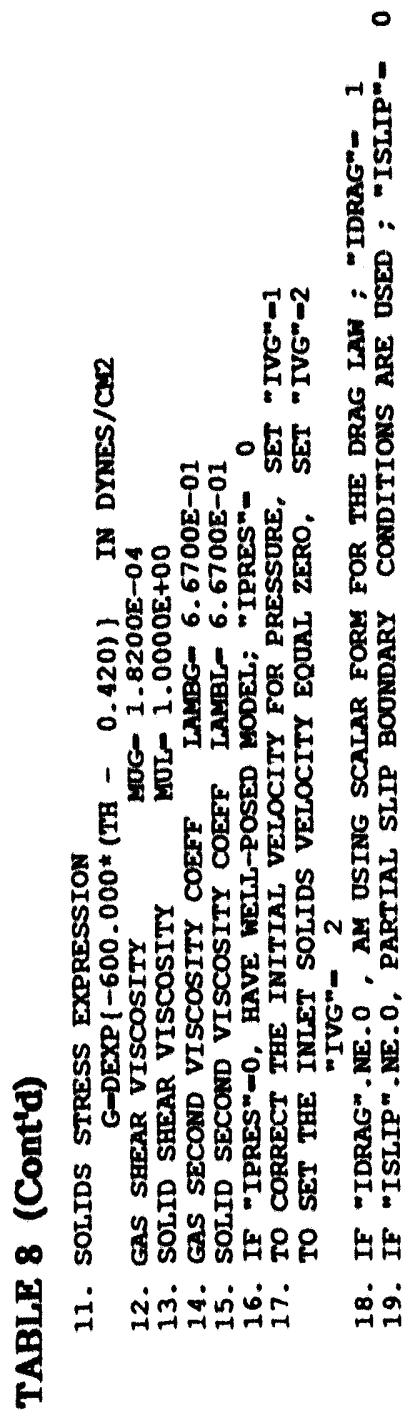

mommmmmmommmmm NHWHWHATHATH D

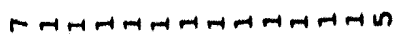

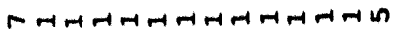

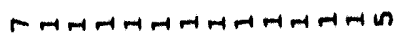

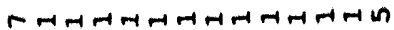

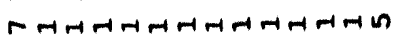

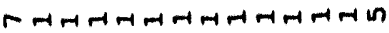

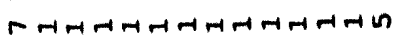

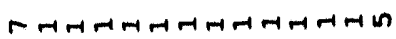

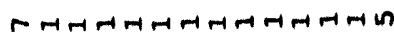

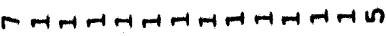

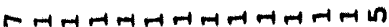
NMHMHATHWHAHW

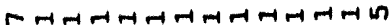
RHATHWHAHAHA

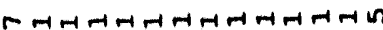

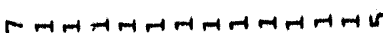

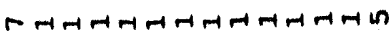

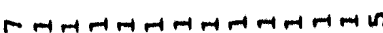

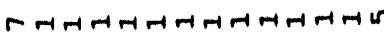

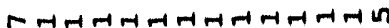

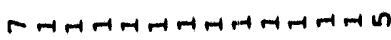
م

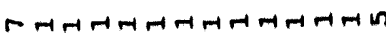

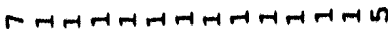
مMHसHWHAHWHWH

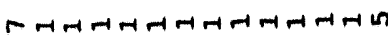
मनन

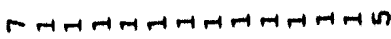

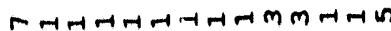

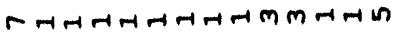
NNNNNMNNNNNNNN

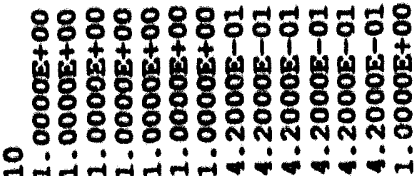

ก

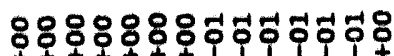

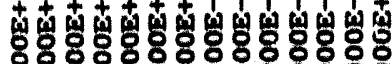

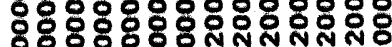

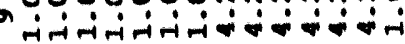

9

888888805010001000

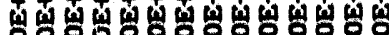

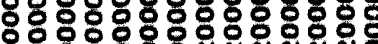

ס80

$\stackrel{\infty}{\sim}$

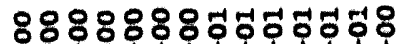

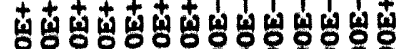

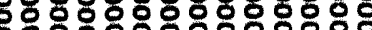

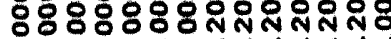

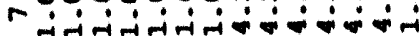

ก

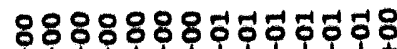

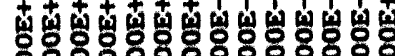

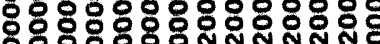

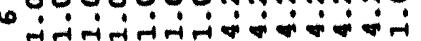

$\stackrel{\sim}{-1}$

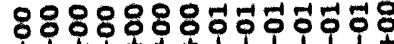

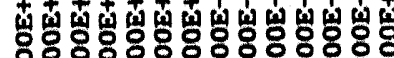

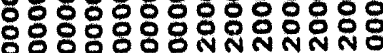

n

$\cong$

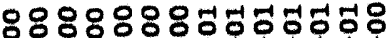

$+ \pm+t+t$

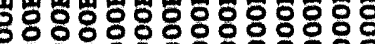

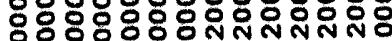

-

$\pm$

용용ㅇㅇ영덩용ㄷㅎㅇㅇㅛ

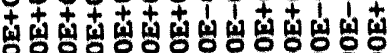

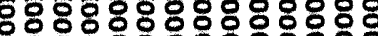

융융영융융ㅇㅇ윤융

m

$m$

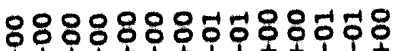

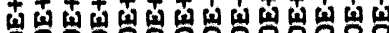

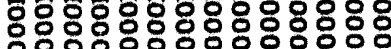

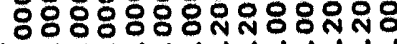

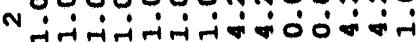

กับ

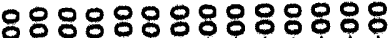

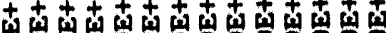

80808080800

앙융용ㅇㅇㅇ용ㅇㅇ용용용

- $0^{\circ} 0^{\circ} 0_{0}^{\circ} 0^{\circ} 0^{\circ} 0^{\circ} 0^{\circ} 0^{\circ}$

$=1$

it

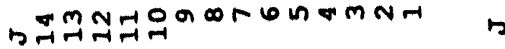




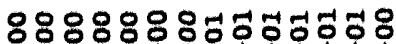

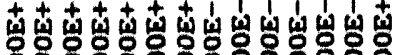

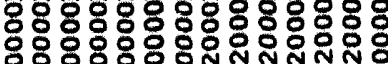

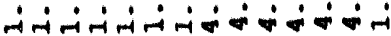

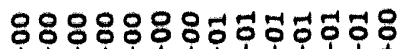

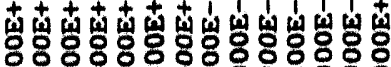

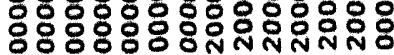

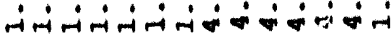

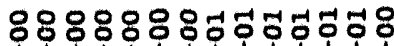

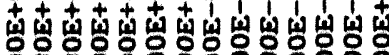

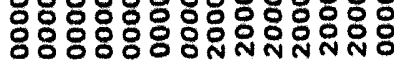

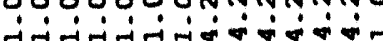

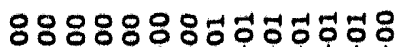

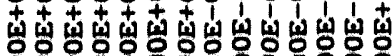

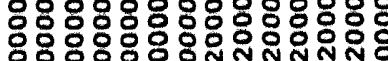

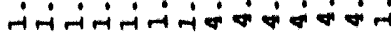

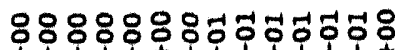

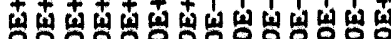

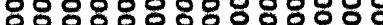

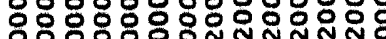

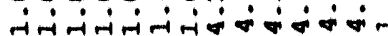

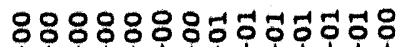

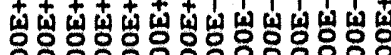

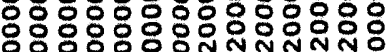

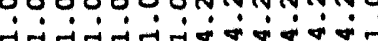

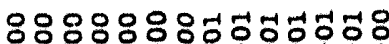

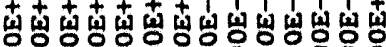

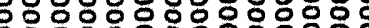

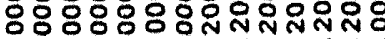

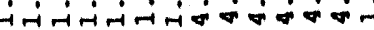

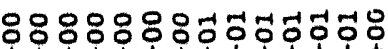

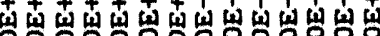

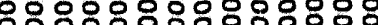
응응응응ㅇㅇㅇㅇㅇㅇㅇㅇㅇㅇㅇㅇㅇㅇㅇㅇㅇㅇㅇㅇㅇㅇㅇ

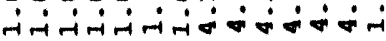

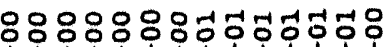

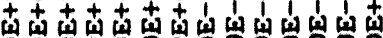
응응응응응응응응응

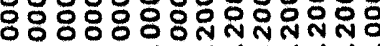

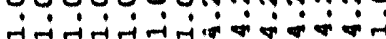

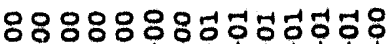

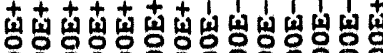

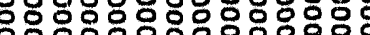

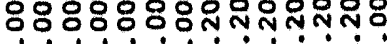

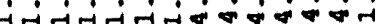

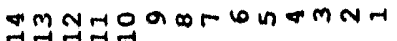

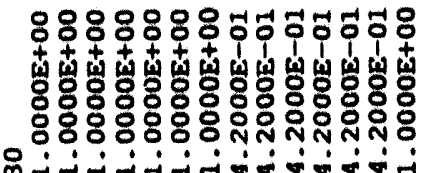

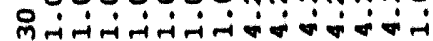

웅

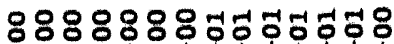

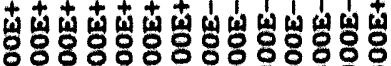

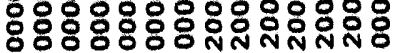

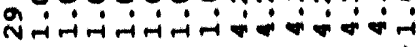

요

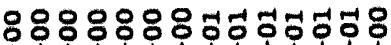

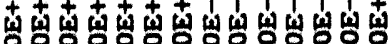

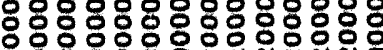

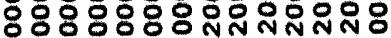

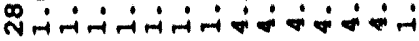

$\Phi$

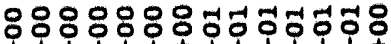

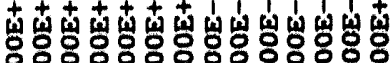

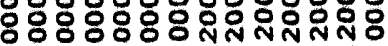

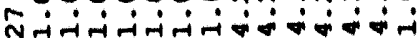

ก

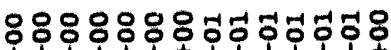

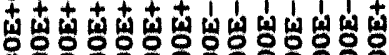

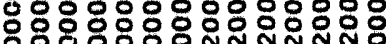

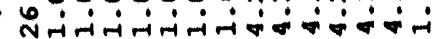

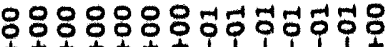

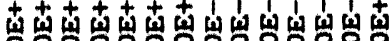

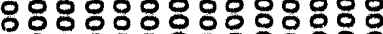

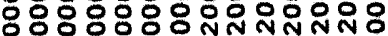

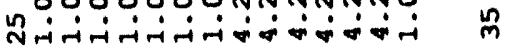

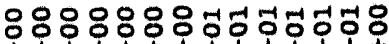

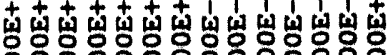

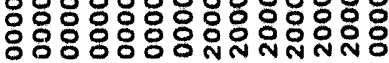

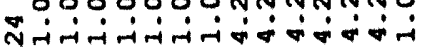

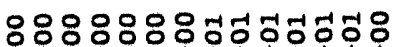

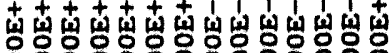

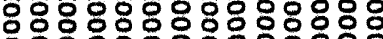

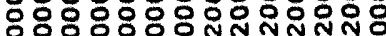

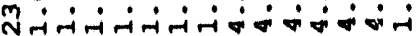

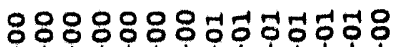

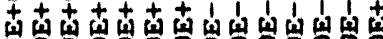

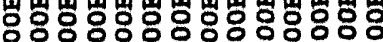

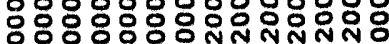

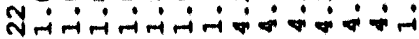

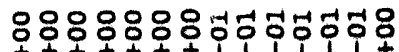

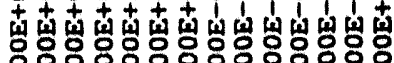

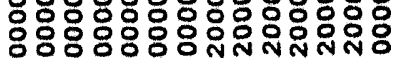

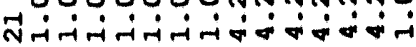

I

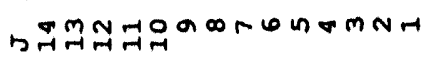

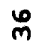

ले

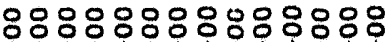

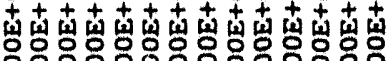

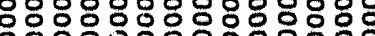

ㅇํㅇㅇㅇㅇㅇㅇㅇํㅇ

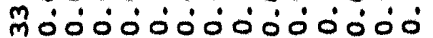

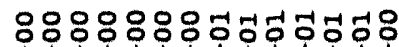

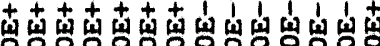

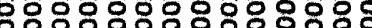

ㅇํㅇㅇㅇㅇㅇㅇㅇㅇㅇㅇㅇㅇㅇํㅇํㅇㅇํㅇ

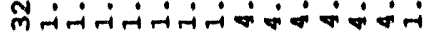

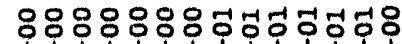

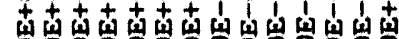

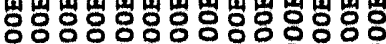

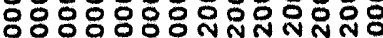

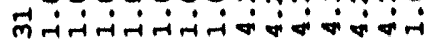

म

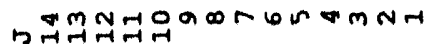




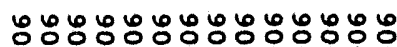

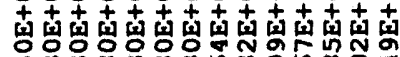

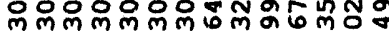

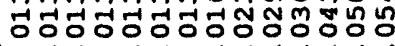

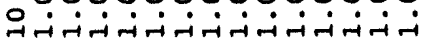

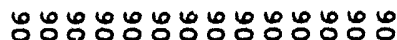

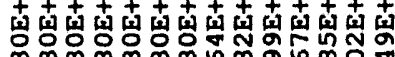
ปี่

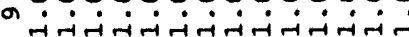

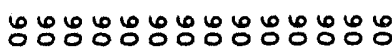

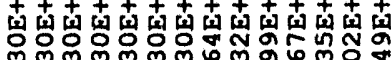

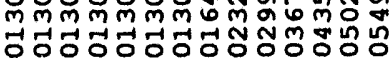

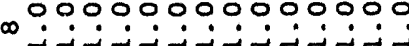

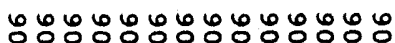

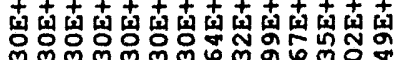

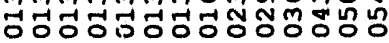

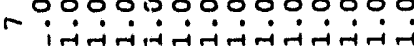

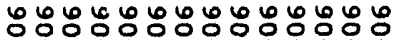

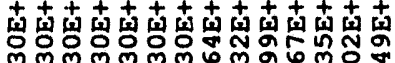

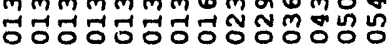

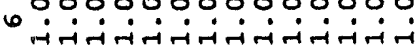

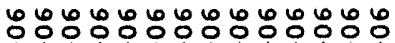

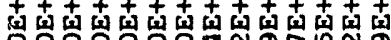
ํํำ

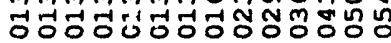

m

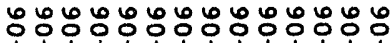

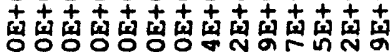

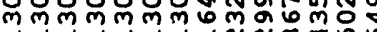

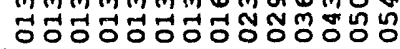

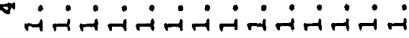

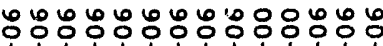

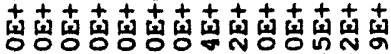

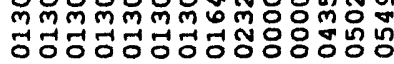

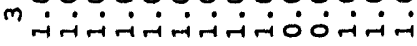

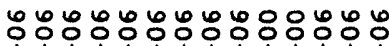

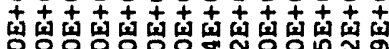

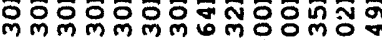

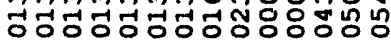

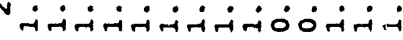

양ㅇㅇㅇㅇㅇㅇㅇㅇㅠ

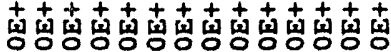

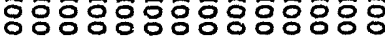
ㅇㅇㅇㅇㅇㅇㅇㅇㅇㅇㅇㅇㅇㅇㅇㅇㅇㅇㅇㅇㅇㅇㅇ

$\infty$ ijojojoiojoió

관

מำ

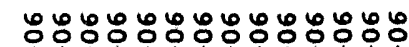

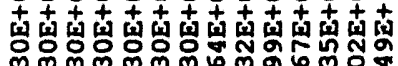

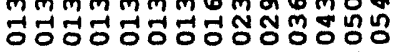

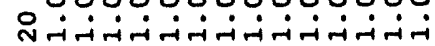

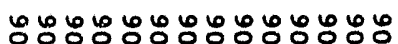

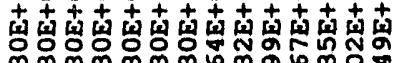

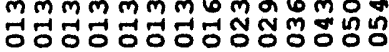

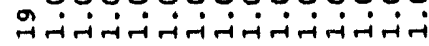

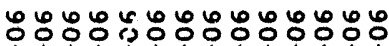

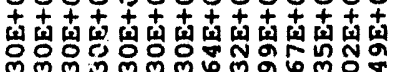

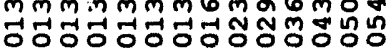

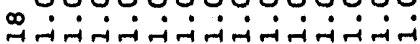

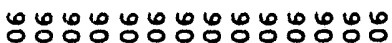

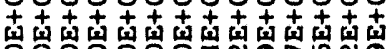

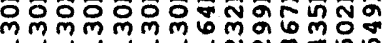

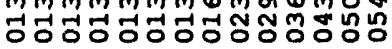

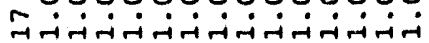

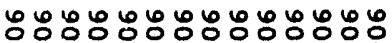

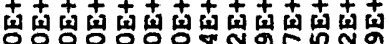
일일

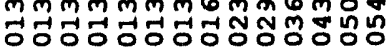

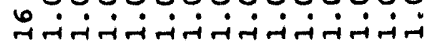

ஃะ๐ั

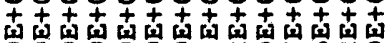

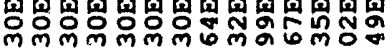

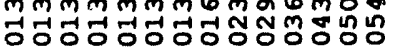

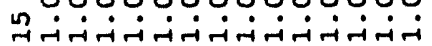

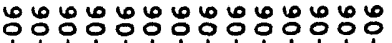

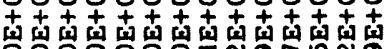

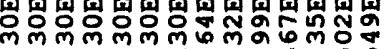

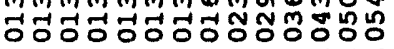

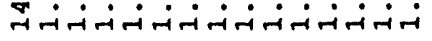

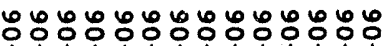

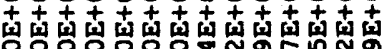

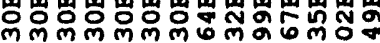

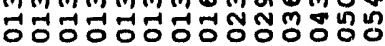

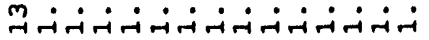

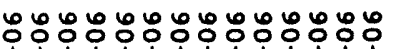

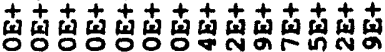

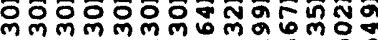

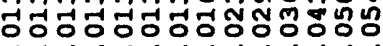

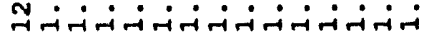

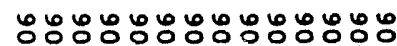

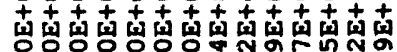

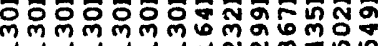

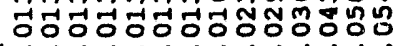

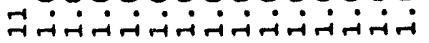

A

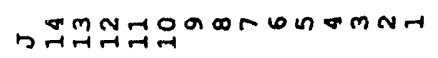

ஜั0ั0ั

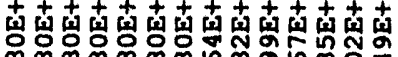

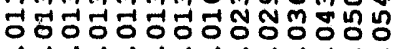

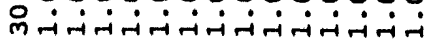

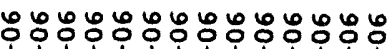

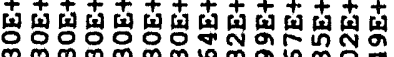

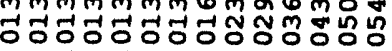

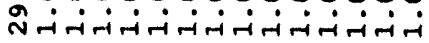

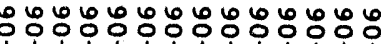

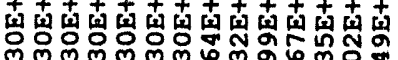

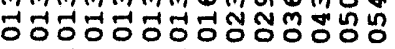

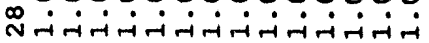

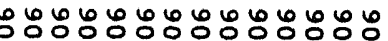

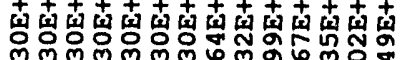

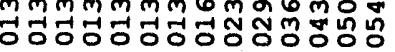

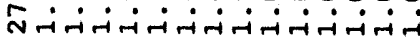

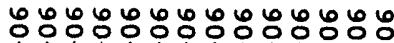

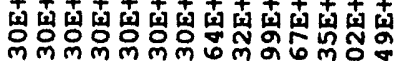

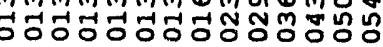

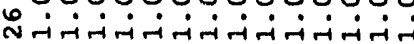

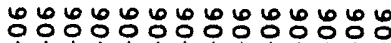

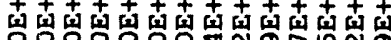

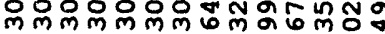

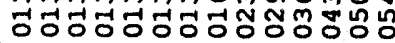

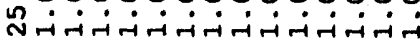

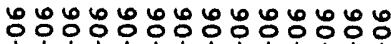

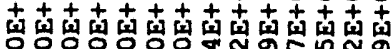

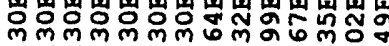

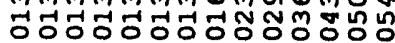

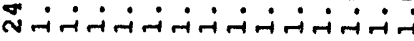

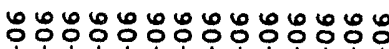

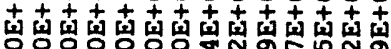

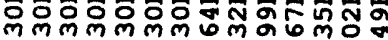

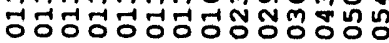

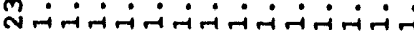

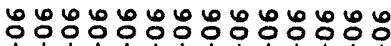

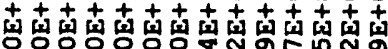

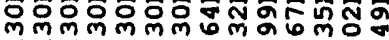

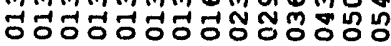

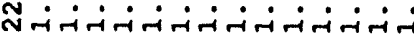

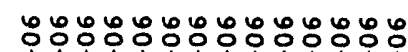

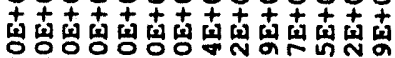

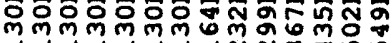

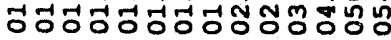

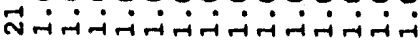

a

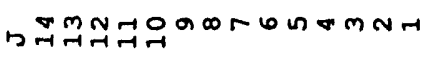

웅

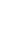

m

$\ddot{m}$

m

옹응

헝형명

응응응

mं்0ं

웅

䲞商声



लैन्नंन्

ㅇํㅇ

声产产

क्षे

लिन्न

a

मन्त 


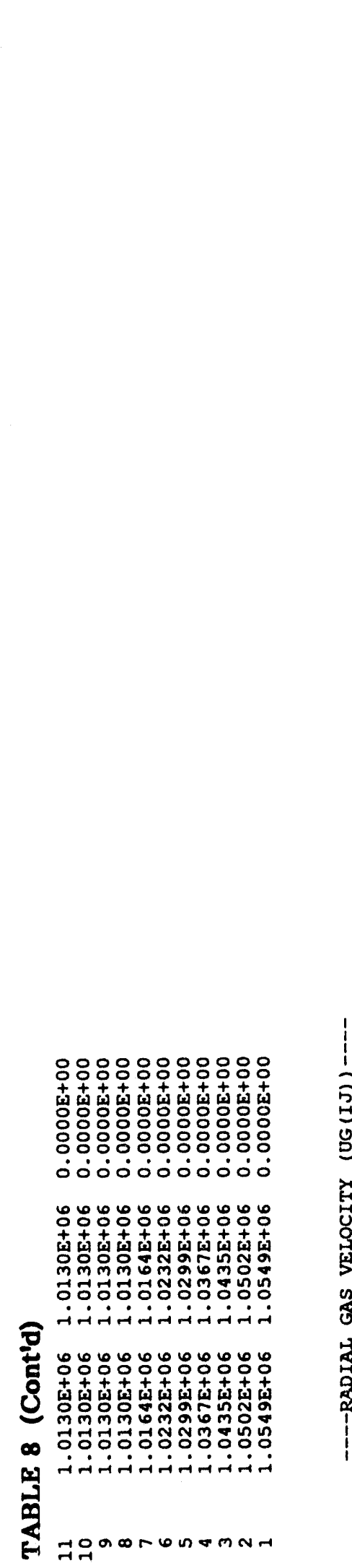

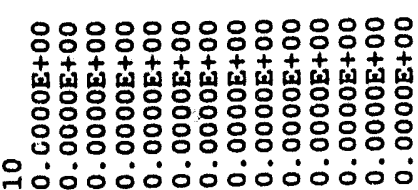

- 000000000000

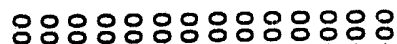

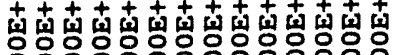
응응응응융응응ㅇㅇㅇㅇㅇㅇㅇㅇㅇㅇㅇ

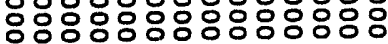

a ioióióióió

৪৪৪৪৪৪৪৪৪৪০৪ঃঃ

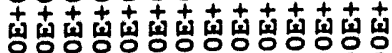

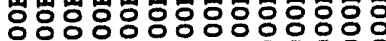

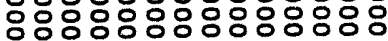

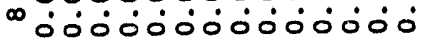

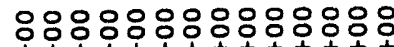

南南南南南南南南南南南南

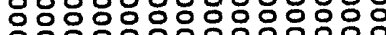
ㅇํㅇㅇㅇㅇㅇㅇㅇㅇㅇㅇㅇㅇㅇㅇํㅇ

ró000000000000

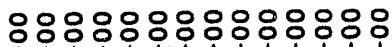

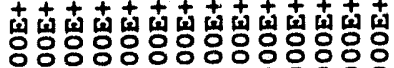

응응응응응응응응영양양융

- ióóióióió

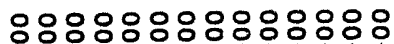

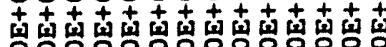

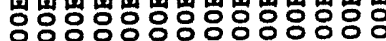

앙ㅇㅇㅇㅇㅇㅇㅇㅇㅇㅇㅇㅇㅇㅇㅇㅇㅇㅇㅇㅇㅇㅇㅇㅇㅇㅇㅇㅇㅇㅇㅇㅇ

n ióóióióió

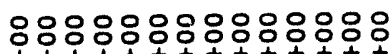

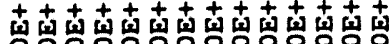

응응ㅇㅇㅇㅇㅇㅇㅇㅇㅇㅇㅇㅇㅇㅇㅇㅇㅇㅇㅇㅇㅇㅇㅇ

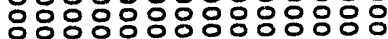

- O0ं0்0000000

ঃ৪ঃঃ৪০ঃ৪ঃ৪৪৪০ঃ

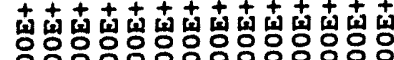

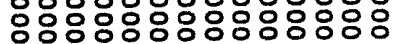

m ióoióoióió

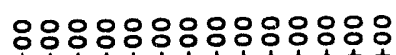

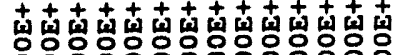

응ㅇㅇㅇㅇㅇㅇㅇㅇㅇㅇㅇㅇㅇㅇㅇㅇㅇㅇㅇㅇㅇ융응응

Nó00000000000

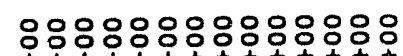

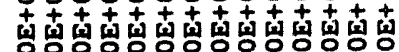

ㅇㅇㅇㅇㅇㅇㅇㅇㅇㅇㅇㅇㅇㅇㅇㅇㅇㅇㅇㅇㅇㅇㅇㅇㅇㅇㅇㅇㅇ

- 0000000000000

4

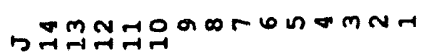

ㅇㅇㅇㅇㅇㅇㅇㅇㅇㅇㅇㅇㅇ

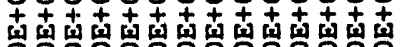

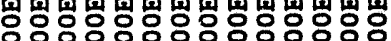

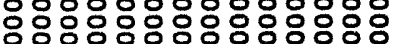

NO00000000000

응ㅇㅇㅇㅇㅇㅇㅇㅇㅇㅇㅇㅇ

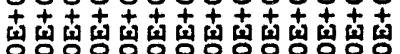

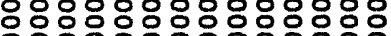

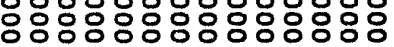

नेo0jojó000000

৪ঃ৪৪৪৪৪ঃ৪৪৪৪৪০

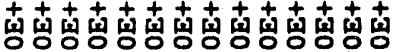

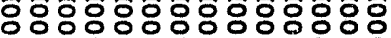

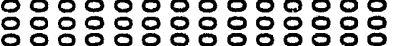

ڤóóóóóó

৪৪০৪৪৪৪০৪৪০৪০৪

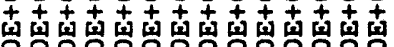

영영영형형영영영영영영

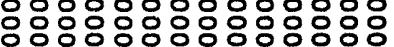

Fó00000000000

৪৪৪৪৪৪৪৪৪৪৪৪৪৪

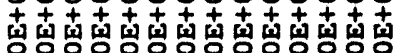

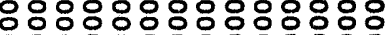

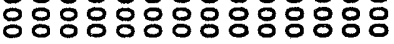

†000000000000.

응응응응응응응응

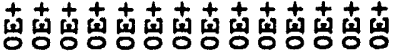

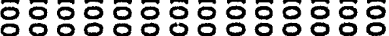

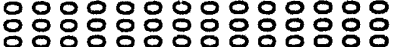

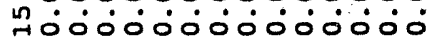

৪৪৪৪৪৪৪৪৪৪৪৪৪৪

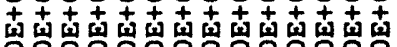

영영영영영영영영영

응응ㅇㅇㅇㅇㅇㅇㅇㅇㅇㅇㅇㅇㅇㅇㅇㅇㅇㅇㅇㅇㅇ

न000000000000

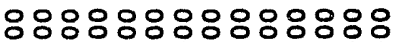

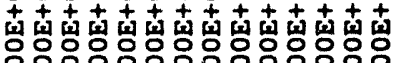

양양ㅇㅇㅇㅇㅇㅇㅇㅇㅇㅇㅇㅇㅇㅇㅇㅇㅇㅇㅇㅇㅇㅇㅇㅇㅇㅇㅇㅇㅇㅇ

mó0000000000

응용ㅇㅇㅇㅇㅇㅇㅇㅇ응

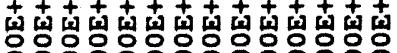

ㅇㅇㅇ잉응응응응응응응응

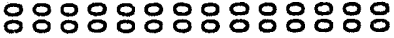

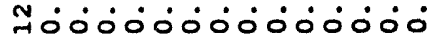

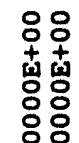

ले००

응웅

育高

응웅

N่ㅇํํ

옹우

壳志

응웅

ஸั:

옹음

高高

응응

Nิo:

웅용

형형

응융

No:

ㅇㅇㅇㅇ

高高

응응

No:

응웅

离志

응응

กับ

응응

育志

응융

กั่

ㅇㅇㅇㅇ

농형

응응

Nิธ่

৪৪ঃ৪৪৪৪৪৪৪৪৪৪০

웅으

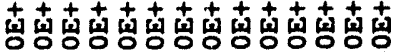

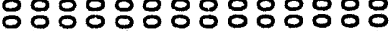

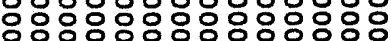

चojoiojoiojó

쇵횡

응웅

ลั่อ

I

$H$

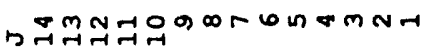

$n=m$ 
৪৪০০০৪০০৪০০০

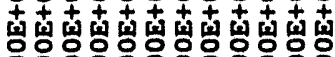
ㅇํㅇㅇㅇㅇㅇㅇㅇํㅇํㅇํำ ऽó00000000்

운

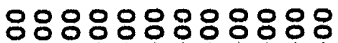

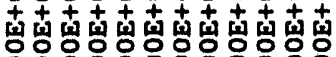
ㅇํㅇㅇํㅇㅇㅇㅇㅇㅇㅇㅇㅇํㅇ ○00000000000

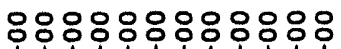

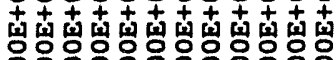
ㅇํㅇㅇㅇㅇㅇㅇㅇㅇㅇㅇㅇㅇํㅇ ó000000000

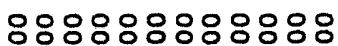

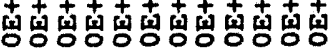

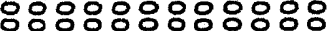
ㅇํㅇㅇㅇㅇㅇㅇㅇำ ó0000000000

৪৪৪৪৪৪৪৪৪৪৪০

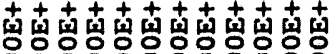
ㅇํㅇํㅇㅇํㅇㅇㅇㅇㅇㅇㅇㅇำ ojojojojojó

ㅇ৪৪০৪৪৪৪৪

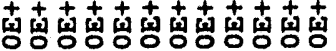
응ㅇㅇㅇㅇㅇㅇㅇㅇㅇㅇㅇㅇㅇㅇㅇㅇㅇㅇㅇㅇㅇㅇㅇㅇㅇㅇㅇㅇㅇㅇㅇㅇㅇ ○0000000000

৪৪৪৪৪৪৪৪৪৪ঃ৪

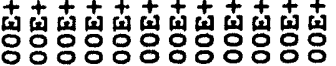
ㅇํㅇㅇㅇㅇㅇㅇㅇㅇㅇㅇㅇㅇㅇํㅇ ó0000000000

৪৪৪৪৪৪ঃ৪৪৪ঃ৪ 南南南南南南南南南 ㅇㅇㅇㅇㅇㅇㅇㅇㅇㅇㅇㅇㅇㅇㅇㅇㅇㅇㅇㅇ영

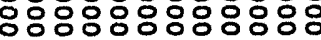
ơojojojóó

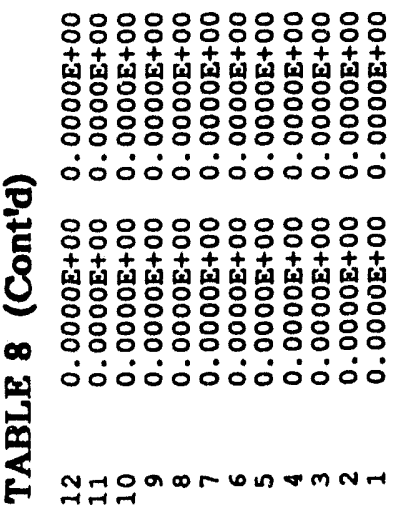

mे

$\stackrel{\infty}{m}$

ติ

$\stackrel{\circ}{m}$

m

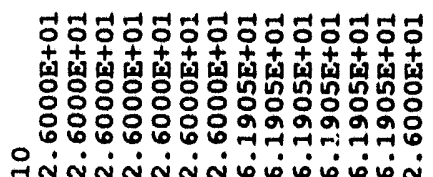

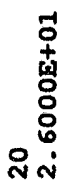

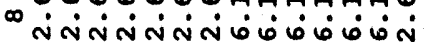

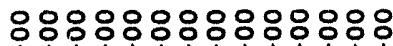

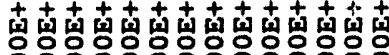
ㅇํㅇㅇํㅇㅇㅇㅇㅇㅇㅇㅇㅇㅇㅇㅇㅇㅇㅇํํํำ mi0000000000000

ㅇ๐ㅇㅇㅇㅇㅇㅇㅇำ

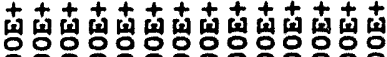

ㅇํㅇㅇㅇㅇㅇㅇㅇㅇㅇㅇㅇㅇㅇㅇㅇํㅇํำ

mơं000000000000

৪৪৪৪৪৪৪৪৪৪৪৪৪০

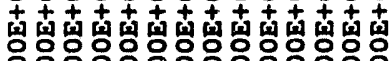

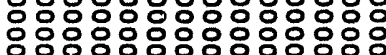

mं00ं00000000000 응ㅇㅇㅇㅇㅇㅇㅇㅇㅇㅇㅇㅇㅇㅇㅇㅇㅇㅇ

מ

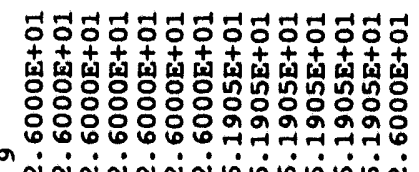

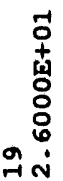

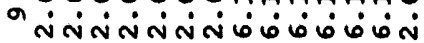

$\pi$ N

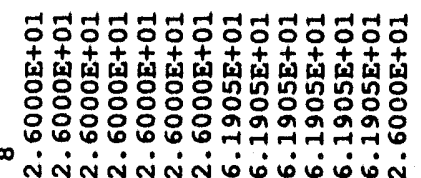

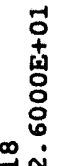

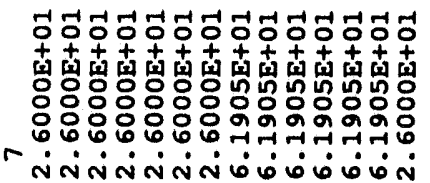

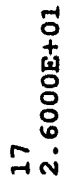

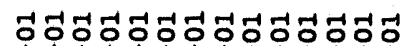

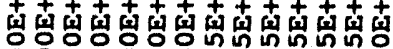

列

ํํํํำ 국 군

- NंNiñNiñobón

$\rightarrow$ n

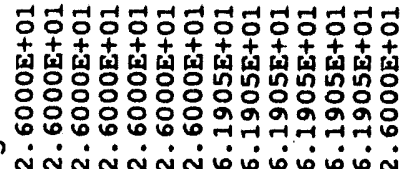

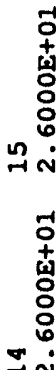

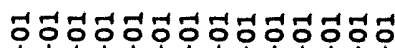

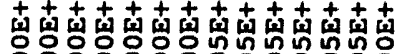

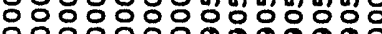

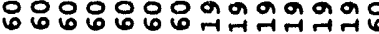

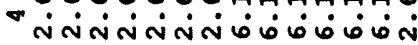

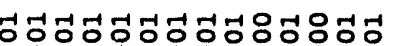

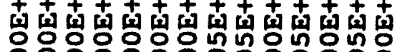
응ㅇㅇㅇㅇㅇㅇㅇㅇㅇㅇㅇㅇㅇㅇ응

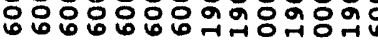

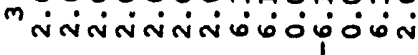

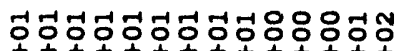

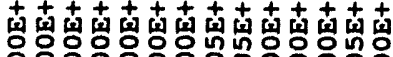
응응ㅇㅇㅇㅇㅇㅇㅇㅇㅇㅇㅇㅇㅇ

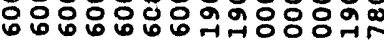

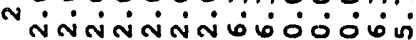

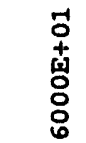

जั

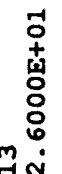

0
+
+1
8
8

สุก

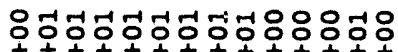

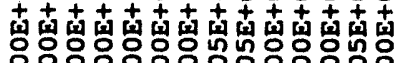

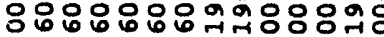

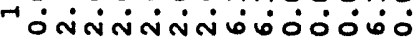

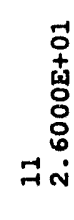

म

\section{西}

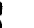

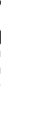

.

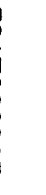

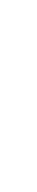

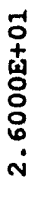

.

$$
\text { 啚 }
$$

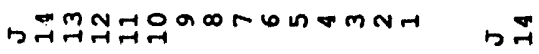




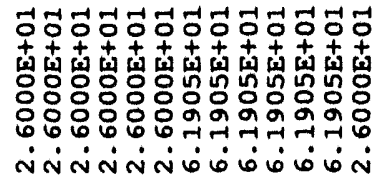

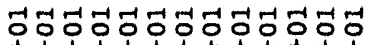

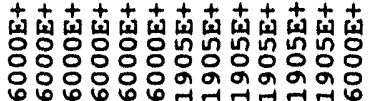
NंNinNivobion

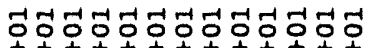

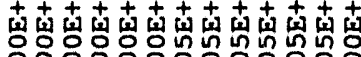
잉ㅇㅇㅇㅇㅇㅇㅇㅇㅇㅇㅇㅇㅇㅇㅇㅇㅇㅇ

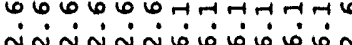

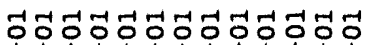

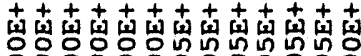

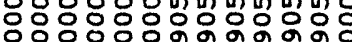

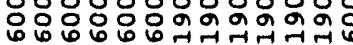

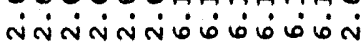

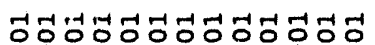

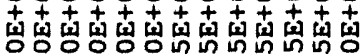

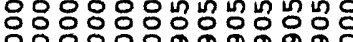

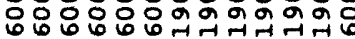

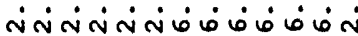

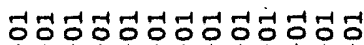

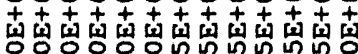

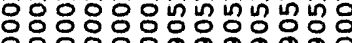

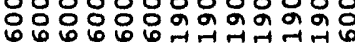

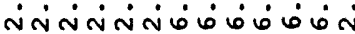

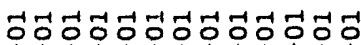

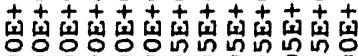

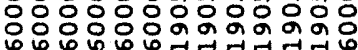

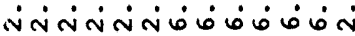

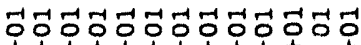

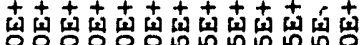

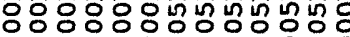

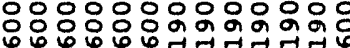

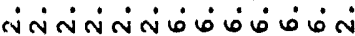

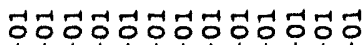
声南南南南南南南南南南南

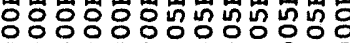

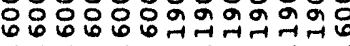

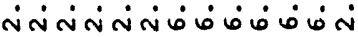

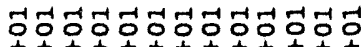
南南南南南南南南南

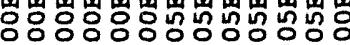

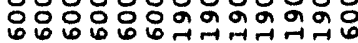

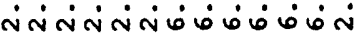

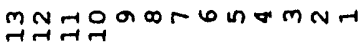

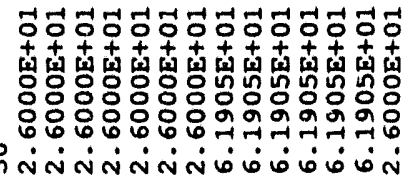

용

$\stackrel{4}{\circ}$

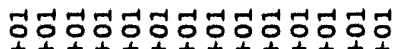

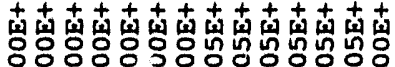

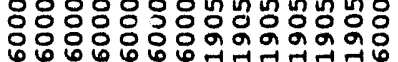

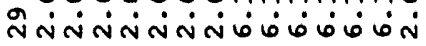

in

$a$

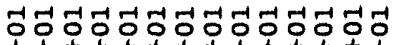

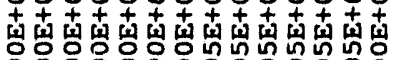

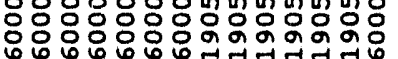

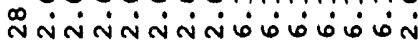

$\stackrel{\infty}{m}$

$\infty$

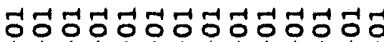

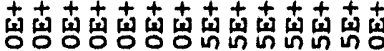

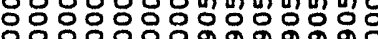

ㅇํㅇㅇํㅇㅇㅇㅇำ

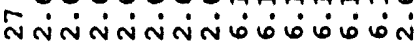

m

$N$

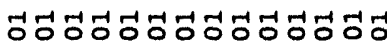

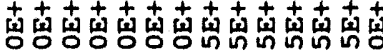

응응응ㅇㅇㅇㅇㅇㅇㅇㅇㅇㅇㅇㅇㅇㅇㅢ

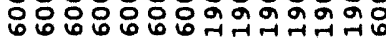

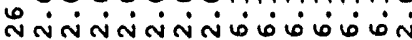

$\stackrel{\circ}{m}$

6

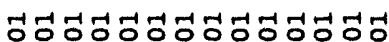

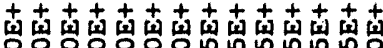

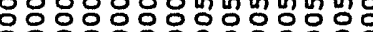

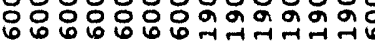

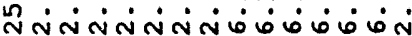

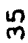

in

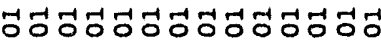

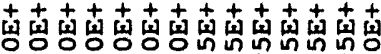

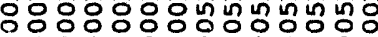

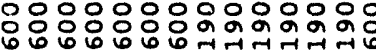

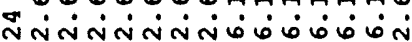

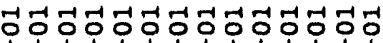

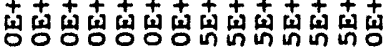

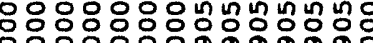

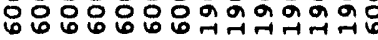

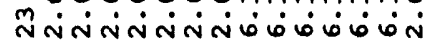

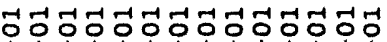

血南南南南声南南南南南南

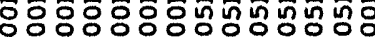

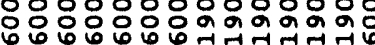

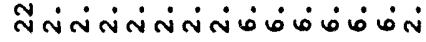

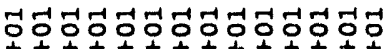

南南南南南南南南南南南南

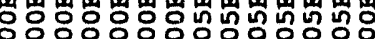

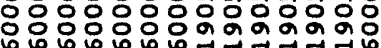

NีNNNNNNivOBOON

$\dot{H}$

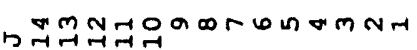

m

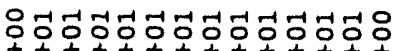

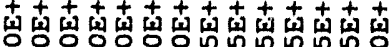

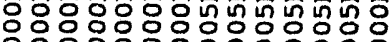

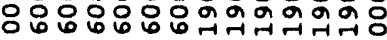

MONNiNiNipipipio

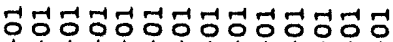

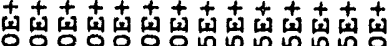

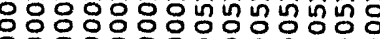

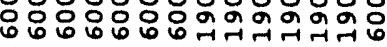

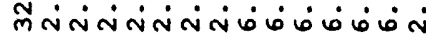

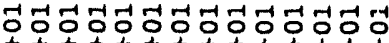

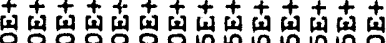

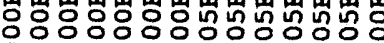

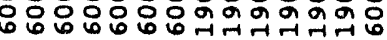

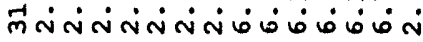

H

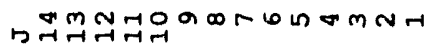




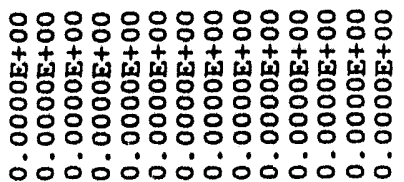

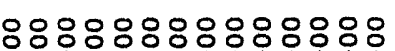

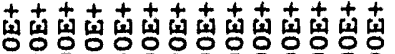

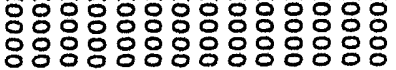
óojóóóóó

응응용ㅇㅇㅇㅇㅇㅇㅇㅇㅇ응

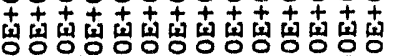
응응ㅇㅇㅇㅇㅇㅇㅇㅇㅇㅇㅇㅇㅇㅇㅇㅇㅇㅇㅇㅇㅇㅇㅇㅇㅇㅇㅇㅇ

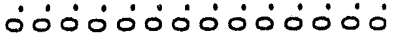

응응응응ㅇㅇㅇㅇㅇㅇㅇㅇㅇㅇㅇ

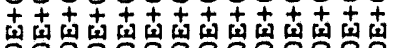
영영영영영영영ㅇㅇㅇㅇㅇㅇ영 ㅇㅇㅇㅇㅇㅇㅇㅇㅇㅇㅇㅇㅇㅇㅇㅇㅇㅇㅇㅇㅇㅇ

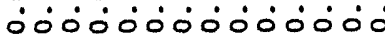

৪৪ㅇ৪ঃ৪ㅇঃ

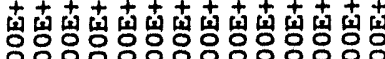
응ㅇㅇㅇ응ㅇㅇㅇㅇㅇㅇㅇㅇㅇㅇㅇㅇㅇㅇㅇㅇㅇㅇㅇㅇㅇㅇㅇㅇ

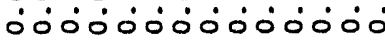

ㅇ๐ㅇㅇㅇㅇㅇㅇㅇㅇํ

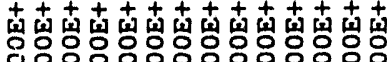
잉영융ㅇㅇㅇㅇㅇㅇㅇㅇㅇㅇㅇㅇㅇㅇㅇㅇㅇㅇㅇㅇㅇㅇㅇㅇ

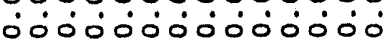

응ㅇㅇㅇㅇㅇㅇㅇㅇㅇㅇㅇㅇㅇㅇㅇㅇㅇ

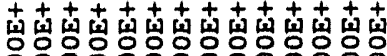
응ㅇㅇㅇㅇㅇㅇㅇㅇㅇㅇㅇ응 ㅇㅇㅇㅇㅇㅇㅇㅇㅇㅇㅇㅇㅇㅇㅇㅇㅇㅇㅇㅇㅇ

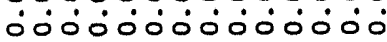

응응응응ㅇㅇㅇㅇㅇㅇㅇㅇㅇㅇㅇㅇ

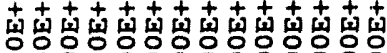
ㅇㅇㅇㅇㅇㅇㅇㅇㅇㅇㅇㅇㅇㅇㅇㅇㅇㅇㅇㅇㅇㅇㅇㅇㅇㅇㅡ. 응응ㅇㅇㅇㅇㅇㅇㅇㅇㅇㅇㅇㅇㅇㅇㅇㅇㅇㅇ응 ○ं0000000000

응응응응응ㅇㅇㅇㅇㅇㅇ

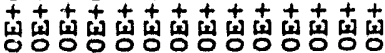
응융ㅇㅇㅇㅇㅇㅇㅇㅇㅇㅇㅇㅇㅇㅇㅇㅇㅇㅇㅇㅇㅇㅇㅇㅇㅇㅇㅇ ¿00000000000

ㅇㅇㅇㅇㅇㅇㅇㅇㅇㅇㅇㅇㅇㅇㅇㅇㅇㅇ

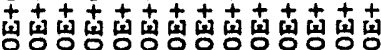
응ㅇㅇㅇㅇㅇㅇㅇㅇㅇㅇㅇㅇㅇㅇ응

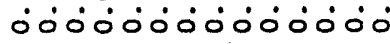

a)

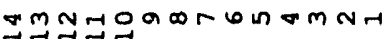

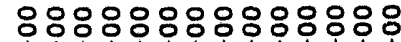

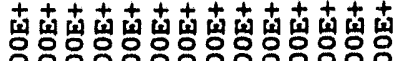

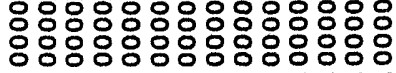

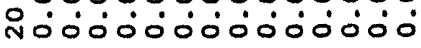

용용ㅇㅇㅇㅇㅇㅇㅇㅇㅇㅇㅇ

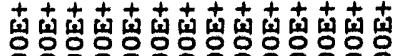

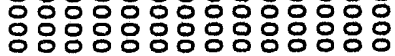

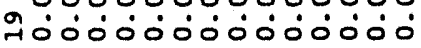

웅용ㅇㅇㅇㅇㅇㅇㅇㅇㅇㅇㅇ응

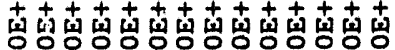

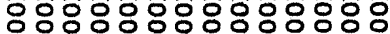

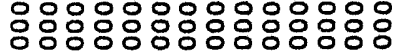
$0^{\circ} 0^{\circ} 0^{\circ} 0^{\circ} 0^{\circ} 0^{\circ} 0^{\circ} 0^{\circ}$

용ㅇㅇㅇㅇㅇㅇㅇㅇㅇㅇㅇㅇㅇㅇㅇㅇㅇ

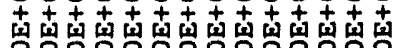
영영영영영영영영영영영 응응ㅇㅇㅇㅇㅇㅇㅇㅇㅇㅇㅇㅇㅇㅇㅇㅇㅇㅇㅇㅇㅇㅇㅇㅇ F000000000000

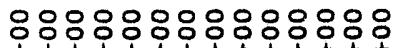

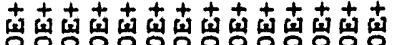

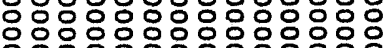
- $0^{\circ} 0^{\circ} 0^{\circ} 0^{\circ} 0^{\circ} 0^{\circ} 0^{\circ} 0^{\circ}$

৪৪৪৪৪৪৪৪৪৪৪ঃ৪ঃ

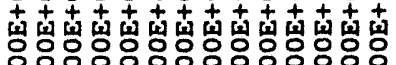
응ㅇㅇㅇㅇㅇㅇㅇㅇㅇㅇㅇㅇㅇㅇㅇㅇㅇㅇㅇㅇㅇㅇㅇㅇㅇㅇㅇ ñó

응용용ㅇㅇ용용ㅇㅇ응

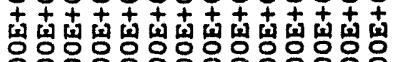

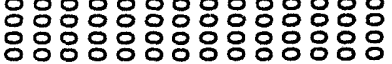

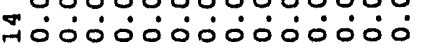

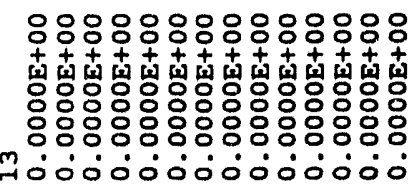
응응용응응응용응

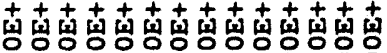
응ㅇㅇㅇㅇㅇㅇㅇㅇㅇㅇㅇㅇㅇㅇㅇㅇㅇㅇㅇㅇㅇㅇㅇㅇㅇㅇㅇㅇㅇㅇ Nó0000000000

ㅇㅇㅇ용ㅇㅇㅇㅇㅇㅇㅇㅇㅇ응

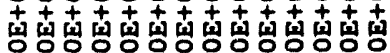

송영영영영영영영영영

잉용ㅇㅇㅇㅇㅇㅇㅇㅇㅇㅇㅇㅇㅇㅇㅇㅇㅇㅇㅇㅇㅇㅇㅇ

ت000000000000

A

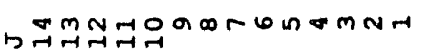

용ㅇㅇㅇㅇㅇㅇㅇㅇㅇㅇ응

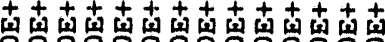
ㅇㅇㅇㅇㅇㅇㅇㅇㅇㅇㅇㅇㅇㅇㅇㅇㅇㅇㅇㅇㅇㅇㅇ응 응ㅇㅇㅇㅇㅇㅇㅇㅇㅇㅇㅇㅇㅇㅇㅇㅇㅇㅇㅇㅇㅇ

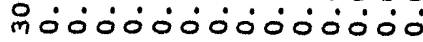

웅

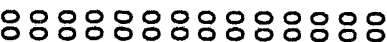

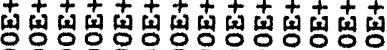

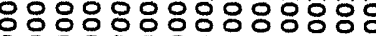
응ㅇㅇㅇㅇㅇㅇㅇㅇㅇㅇㅇㅇㅇㅇㅇㅇㅇㅇㅇㅇ

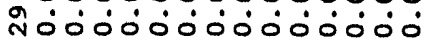

in

ㅇㅇㅇㅇㅇㅇㅇㅇㅇㅇㅇㅇㅇㅇㅇㅇ

直十南南南南南南南南南

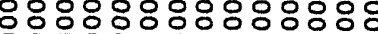
양ㅇㅁㅇㅇㅇㅇㅇㅇㅇㅇㅇㅇㅇㅇㅇㅇㅇㅇㅇㅇㅇㅇㅇㅇㅇ

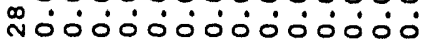

$\stackrel{\infty}{m}$

웅ㅇㅇㅇㅇㅇㅇㅇㅇㅇㅇㅇ응

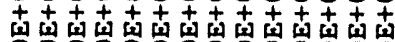

영영영영영영영영영영영

양ㅇㅇㅇㅇㅇㅇㅇㅇㅇㅇㅇㅇㅇㅇㅇㅇㅇㅇㅇㅇㅇㅇㅇㅇ

Nó000000000

ㅇㅇㅇㅇㅇㅇㅇㅇㅇㅇㅇㅇ

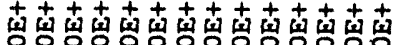

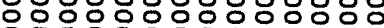

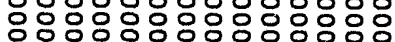

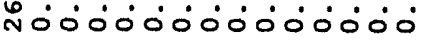

$\stackrel{m}{m}$

응응ㅇㅇㅇㅇㅇㅇㅇㅇㅇㅇㅇㅇㅇㅇㅇㅇ응

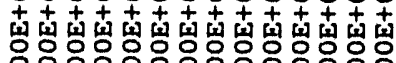

응응ㅇㅇㅇㅇㅇㅇㅇㅇㅇㅇㅇㅇㅇㅇㅇㅇㅇㅇㅇㅇㅇㅇㅇㅇㅇ

Nó0000000000

nn

응ㅇㅇㅇㅇㅇㅇㅇㅇㅇㅇㅇㅇㅇㅇㅇㅇ응

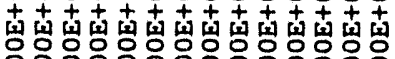

응ㅇㅇㅇㅇㅇㅇㅇㅇㅇㅇㅇㅇㅇㅇㅇㅇㅇㅇㅇㅇㅇㅇㅇㅇㅇㅇㅇㅇㅇㅇㅇㅇ

Nó0000000000.

m

응ㅇㅇㅇㅇㅇㅇㅇㅇㅇㅇㅇㅇㅇㅇㅇㅇㅇ

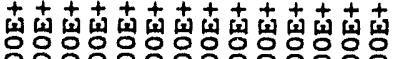

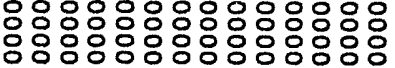

Nó0.0000000.0.

응응응응응응응응응

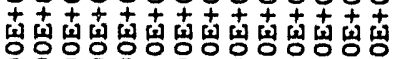

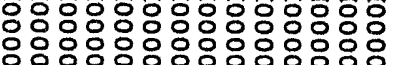

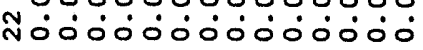

응ㅇㅇㅇㅇㅇㅇㅇㅇㅇㅇㅇㅇㅇㅇㅇ응

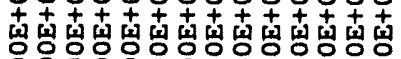

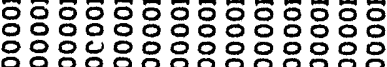

NंO0ं0000000000

!

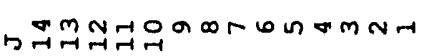

응응응

弐高高壆

응ㅇㅇㅇㅇㅇㅇ

mó0.

응응응응

矛产高志

응응응융

लैo0

응옹용

武言志

응응

응응응

móo:

H

מन्म円न्त 


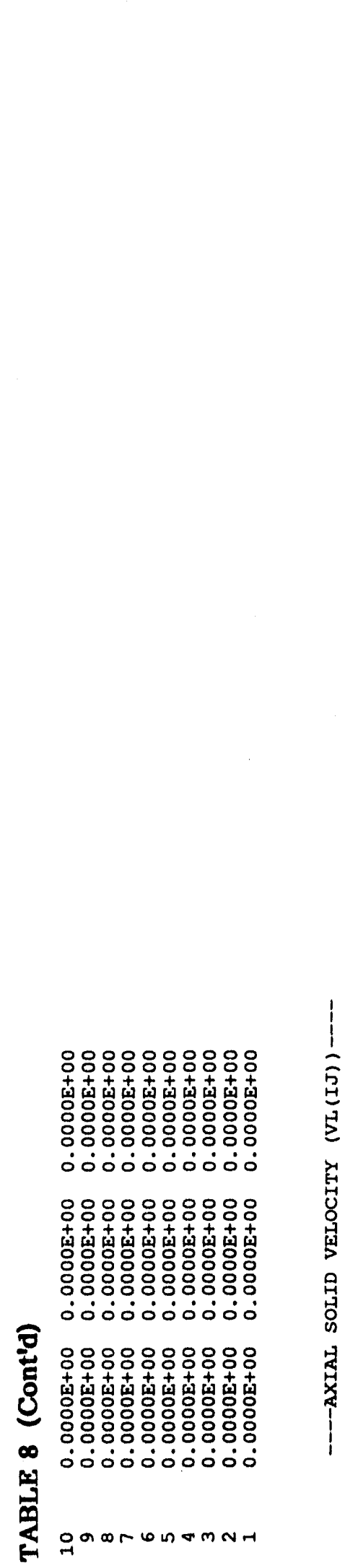

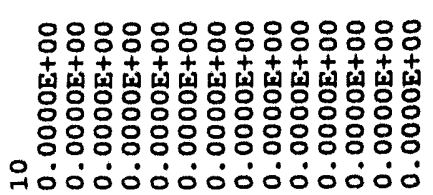

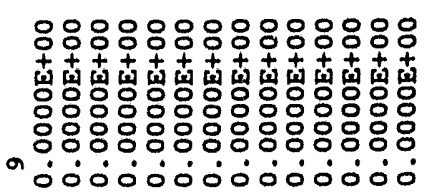

ঃ৪ঃ৪ঃঃ৪৪ঃ৪ঃ৪ঃঃ

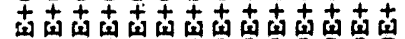
응응ㅇㅇㅇㅇㅇㅇㅇㅇㅇ응응응

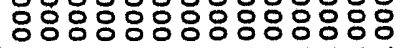

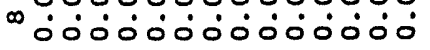

৪৪৪৪৪৪৪৪৪৪৪৪৪৪

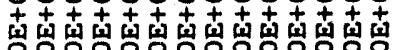

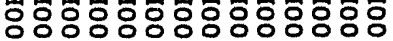

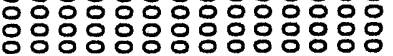

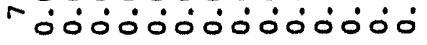

৪৪৪৪৪৪৪৪৪৪৪৪ঃ

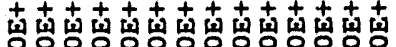

응ㅇㅇㅇㅇㅇㅇㅇㅇㅇㅇㅇㅇㅇㅇㅇㅇㅇㅇㅇㅇ응

๐๐๐๐ㅇㅇㅇ

'000000000000

৪৪৪৪৪৪৪৪৪ঃ৪৪৪ঃ

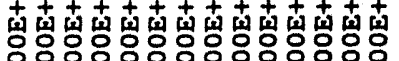
응융ㅇㅇㅇㅇㅇㅇㅇㅇㅇㅇㅇㅇㅇㅇㅇㅇㅇㅇㅇㅇㅇㅇㅇㅇㅇ

" iojó000000

৪৪৪৪৪৪৪৪৪৪৪৪৪৪

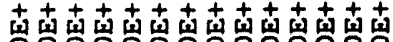

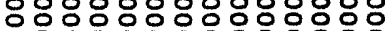

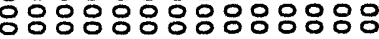

- jó0ं0́00000

$\stackrel{5}{3}$

ঃ৪ঃঃ৪৪৪ঃ৪৪৪৪ঃঃ

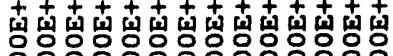

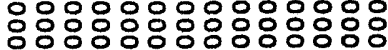

m óóó 0 óó

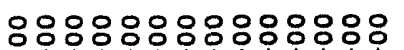

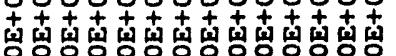

응응응영잉응응응

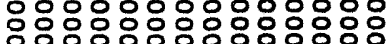

Nóojóóóóó

৪৪৪৪৪৪৪৪৪৪৪৪ঃ০

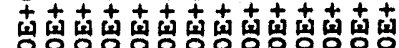

영영응영영영영영영영

응ㅇㅇㅇㅇㅇㅇㅇㅇㅇㅇㅇㅇㅇㅇㅇㅇㅇㅇㅇㅇ

- O00000000000

'

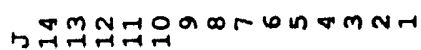

ঃঃঃঃঃঃঃ০ঃ৪ঃঃ৪ঃ 南南南南南南南南南南南

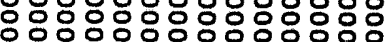

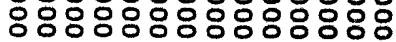

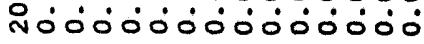

৪৪৪৪৪৪৪৪৪৪৪৪৪ঃ

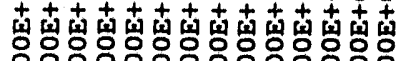

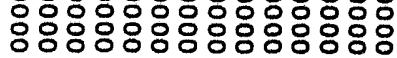

ने00000000000.

৪৪৪৪ঃঃ৪৪৪৪৪৪৪ঃ

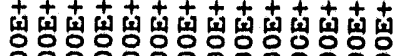

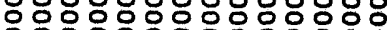

양ㅇㅇㅇㅇㅇㅇㅇㅇㅇㅇㅇㅇㅇㅇㅇㅇㅇㅇㅇㅇㅇ

m00000000000்

৪৪৪৪৪৪০৪৪৪৪৪৪ঃ

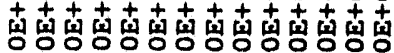

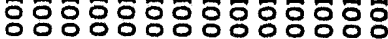

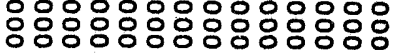

Fóó00000000்

ㅇঃㅇㅇㅇㅇㅇㅇㅇํ

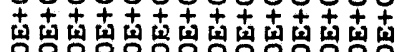

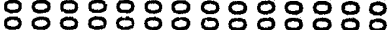

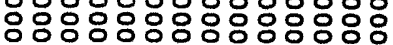

-

ঃ৪ঃ৪ঃ৪৪৪৪৪৪৪৪৪

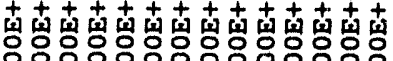

응ㅇㅇㅇㅇㅇㅇㅇㅇㅇㅇㅇㅇㅇㅇㅇㅇㅇㅇㅇㅇㅇㅇㅇㅇㅇ

ño $0^{\circ} 0^{\circ} 0^{\circ} 0^{\circ} 0^{\circ} 0^{\circ} 0^{\circ}$

৪৪৪৪৪৪৪৪৪৪৪৪ঃঃ

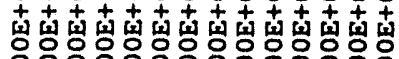

응ㅇㅇㅇㅇㅇㅇㅇㅇㅇㅇㅇㅇㅇㅇㅇㅇㅇㅇㅇㅇㅇㅇㅇㅇㅇㅇㅇㅇㅇㅇㅇㅇ

-000000

৪৪৪৪৪৪৪৪৪৪৪৪৪ঃ

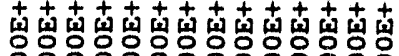

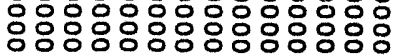

$\stackrel{m}{\rightarrow} 0_{0} 0_{0} 0_{0} 0_{0}^{\circ} 0_{0}^{\circ} 0_{0}^{\circ} 0^{\circ}$

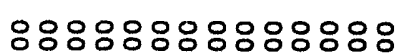

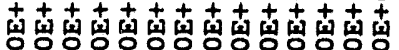

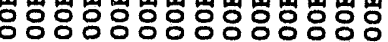

응응ㅇㅇㅇㅇㅇㅇㅇㅇㅇㅇㅇㅇㅇㅇㅇㅇㅇㅇㅇㅇㅇㅇㅇㅇ

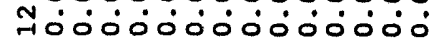

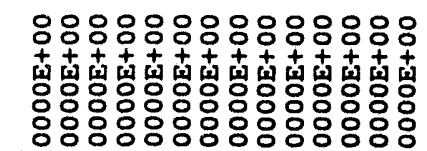

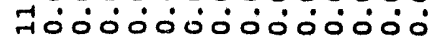

A

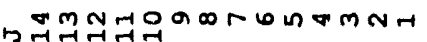

ㅇํㅇㅇ

产南南

ㅇํㅇㅇํㅇ

ํํㅇㅇํ

:०:

克目目

ㅇํㅇ응

กิ่0ْ

요

홍형형

ㅇํㅇㅇㅡ

Nั0ல்

ㅇㅇ

南異商

ㅇㅇㅇㅇㅇㅇ

กัดั

요

홍형형

ㅇํㅇ응

กั0.ं

৪৪:

南南

응응

Nกำ

৪ঃ:

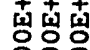

응응

กับำ

ㅇㅇㅇ

㯖南南

ㅇํㅇ융

Nั00

요응

克南南

잉으

กิธ่อ

용

南南南

ㅇํㅇ응

Nล0.

4

מ표 
৪৪৪৪০৫:৪৪৪ঃ

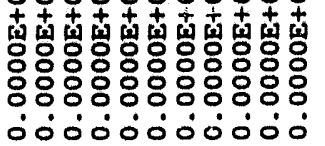

웅

৪৪৪৪৪৪৪৪৪৪৪

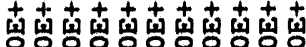
응ㅇํㅇㅇํㅇํㅇㅇํㅇ 응잉ㅇㅇㅇㅇㅇㅇㅇㅇㅇㅇㅇㅇㅇㅇ

¿000000000

৪৪ঃㅇঃㅇㅇ

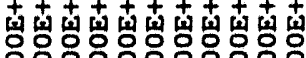
앙응응응응응융융융영응 ऽ0000000000

৪৪৪৪৪৪৪৪৪৪ঃ

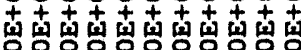
응응응응용응응응응응응 응응응응용응융융융융응 ऽ00000000

৪৪৪৪ঃ৪৪৪৪৪ঃ 南南南南南南南南 응응ㅇㅇㅇㅇㅇㅇㅇㅇㅇㅇㅇㅇㅇㅇㅇㅇㅇㅇㅇㅇㅇ 응옹응응응응융융응ㅇㅇㅇ응 ○ं0் $0 \dot{0} 0 \dot{0} 0 \dot{0}$

৪৪৪৪৪৪৪৪৪৪ঃ

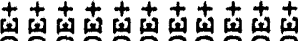
ㅇㅇㅇㅇㅇㅇㅇㅇㅇㅇㅇㅇㅇㅇㅇㅇㅇㅇㅇㅇㅇㅇㅇㅇㅇ

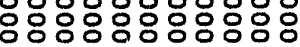

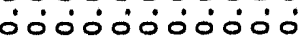
ঃঃঃঃ৪ঃঃঃ৪ঃঃ

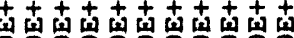

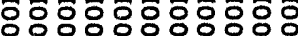
응응응응응응응융응융응 ○0́000000000

৪৪৪৪৪৪৪৪৪৪ঃ 南南南南南南南南南 응응용ㅇㅇㅇㅇㅇㅇㅇㅇㅇㅇㅇㅇ응 응응응응응응응응응응응

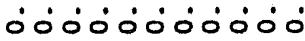

\section{ㅇঃ:ঃ৪৪৪০০ঃ

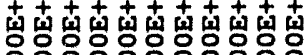 응응융응응응응응응응응} ¿0ं0்00000

ஃ৪৪ঃ৪৪ㅇ

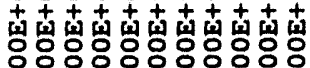

응응응응응응응응응응응

ல் $0 \dot{0} 0 \dot{0} 0 \dot{0}$

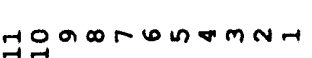

के

$\stackrel{\infty}{m}$

m

$\stackrel{\circ}{m}$

$\stackrel{n}{m}$

है

৪৪০৪ঃ৪৪৪৪৪৪০ঃঃ

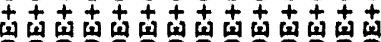

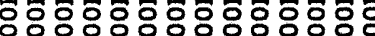
응ㅇㅇㅇㅇㅇㅇㅇㅇㅇㅇㅇㅇㅇㅇㅇㅇㅇㅇㅇㅇㅇㅇ

m̃ojojojojojojo

ঃㅇঃㅇঃㅇㅇঃㅇ

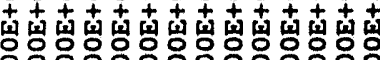

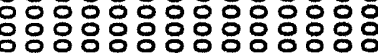

mó0ं000000000000

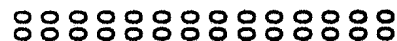

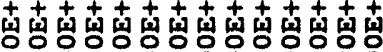

응응응응응응응응응응응응응응

m0000000000000

H

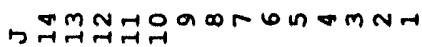

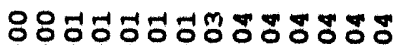

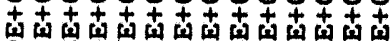

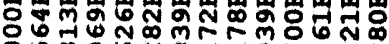

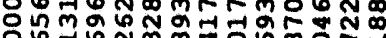

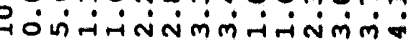

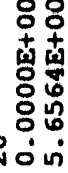

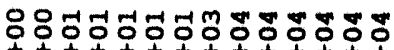

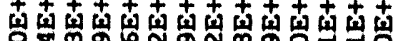

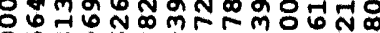

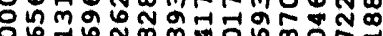

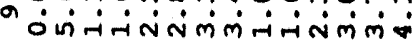

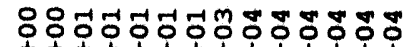

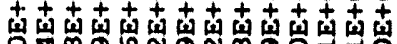

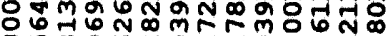

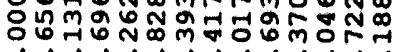

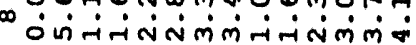

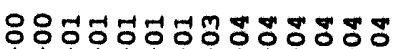

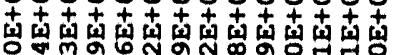

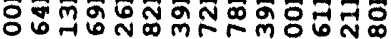

ㅇํำ

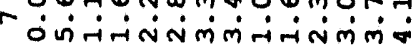

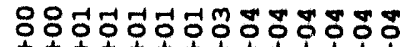

血血南南南南南南南南

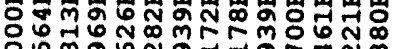

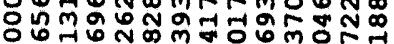

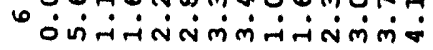

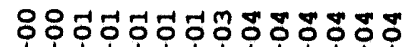

南南南南南南南南南南南

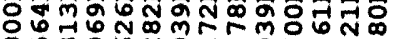

ᄋํำ

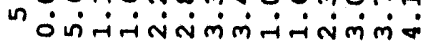

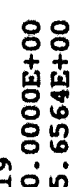

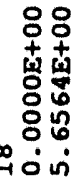

ㅇ

产图

递

Fิำ

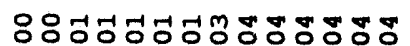

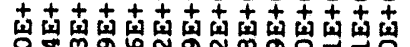

ㅋํำ ํํำ

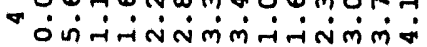

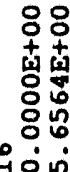

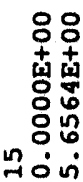

요

壴異

융

नं。ं

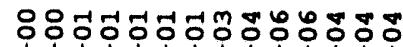

南南南南南南南血南南南

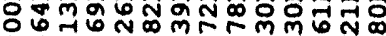

ำ $m$ a

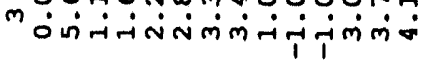

: :

率異

ㅇํㅇ

moin

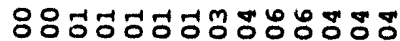

南南南南南南南南南南南南

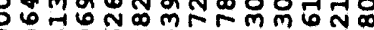

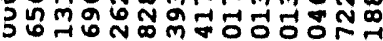

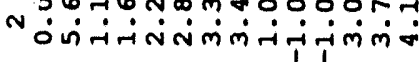

:ㅇ

产高

ㅇํำ

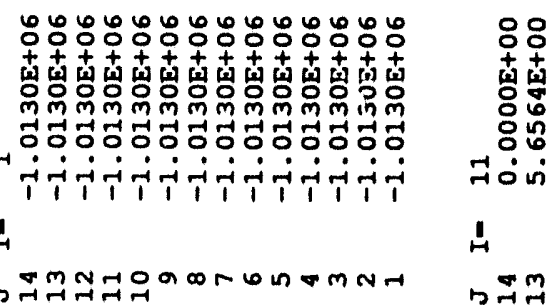




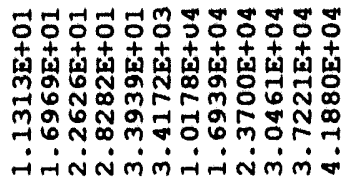

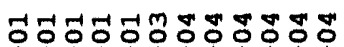

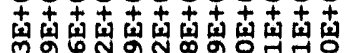

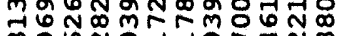
mơ 웠

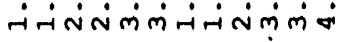

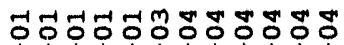
南南南南南南南南南南声

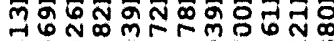
m

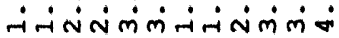

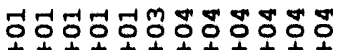

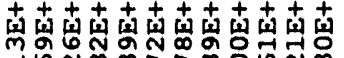
-1

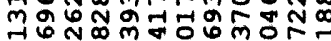

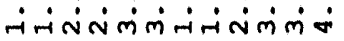

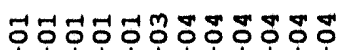

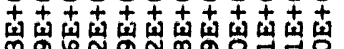
M - $\dot{\sim} \dot{N} \dot{m} \dot{m} \dot{-i} \dot{\sim} \dot{m} \dot{0}$

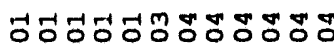
南南南南南南南南南

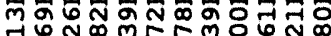
mดู -i $\dot{\sim} \dot{N} \dot{m} \dot{m} \dot{-i} \dot{m} \dot{m}$

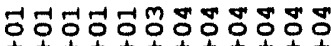

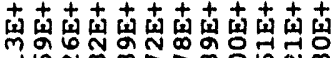
- 6 Nom MOMON

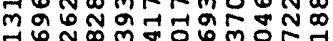

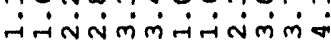

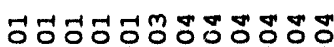

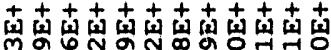
M

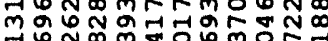

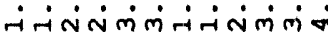

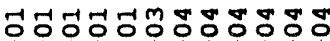
声南南南南南南南南南 m mơ№̛

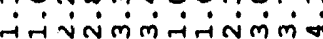

南南南南南南南南南南南 - 0 NomNMO mด రN

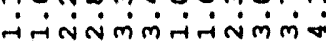

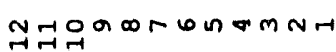

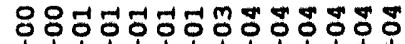
南南南南南南南南南南 ㅇํำ 응

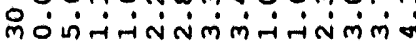

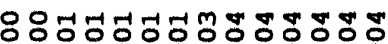

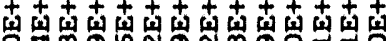
菏

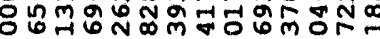

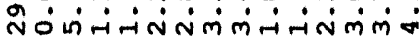

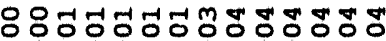
南南南南南南南南南南 금

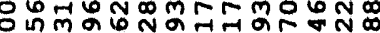

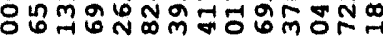

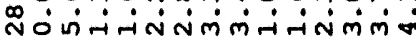

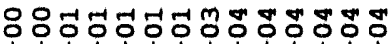

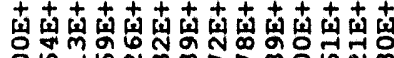
O 잉

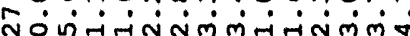

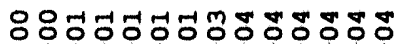

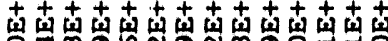

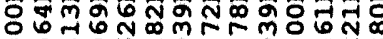

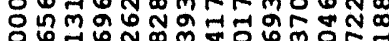

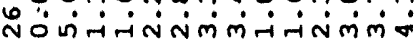

$\stackrel{\infty}{m}$

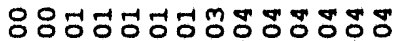
南南南南南南南南南南南

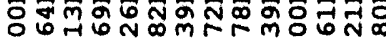
ำ

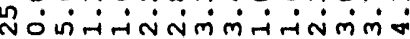

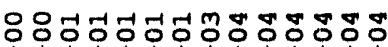

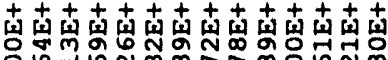

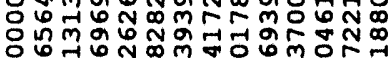

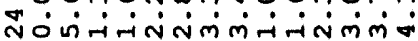

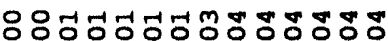

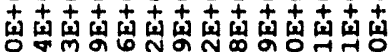

윰ำ 응 ํํำ

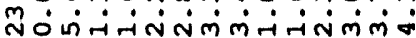

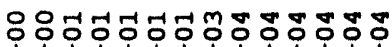

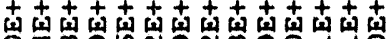

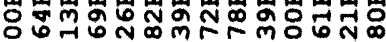
ํำ

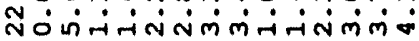

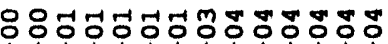

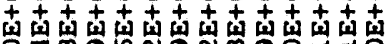

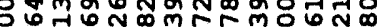
○ก

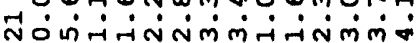
A

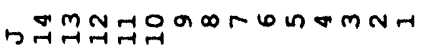

mั I कor

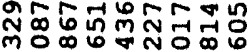
制

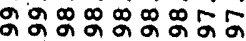

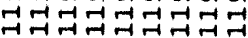

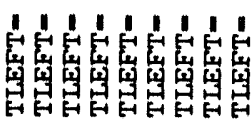

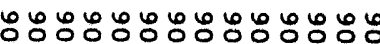

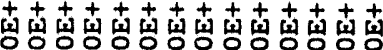

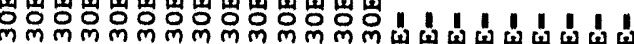

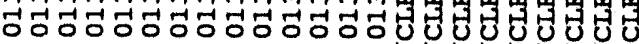

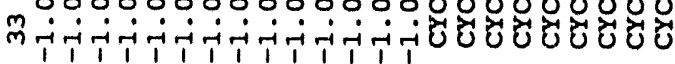

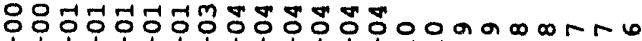

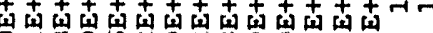

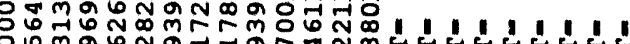

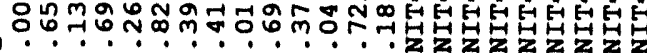

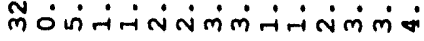

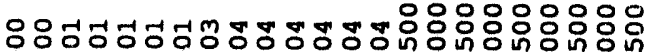

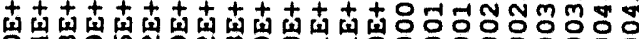
겅 约

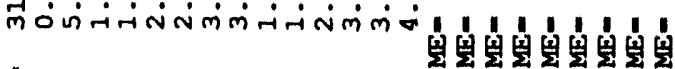

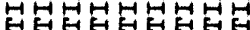




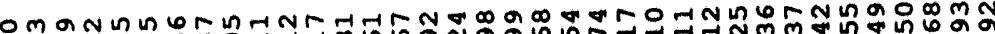

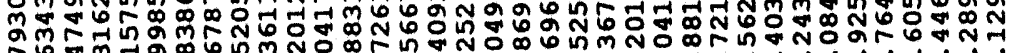

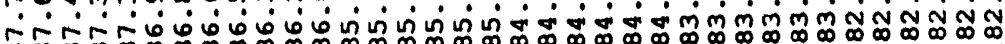
कि

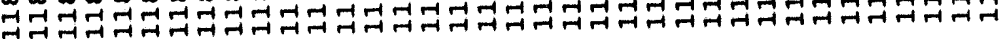

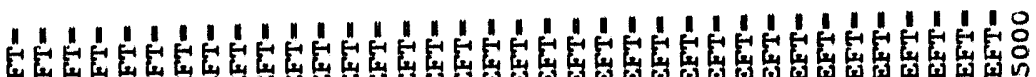

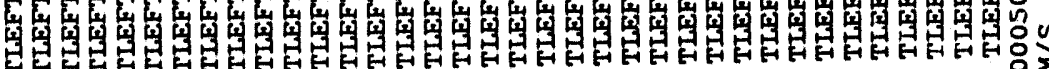
ก

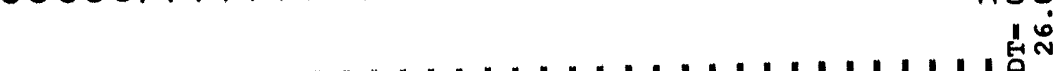

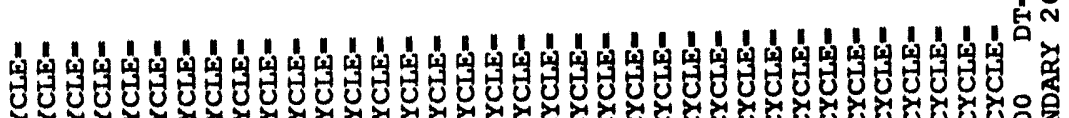

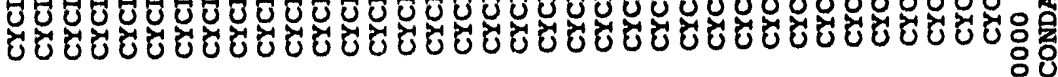

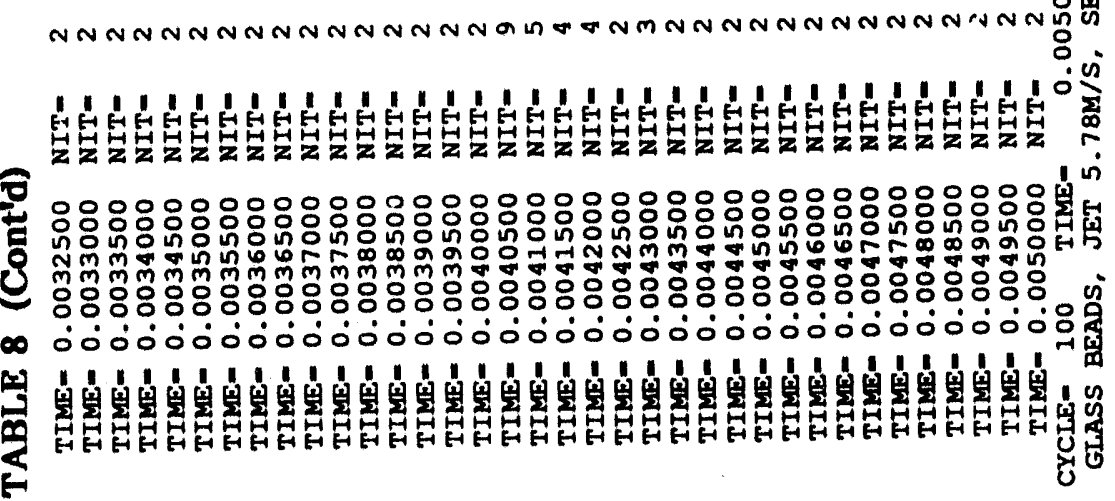
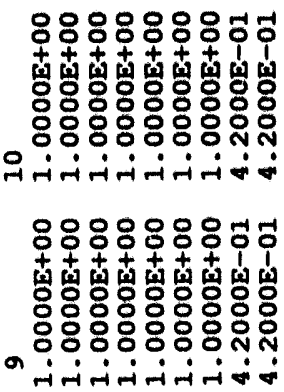

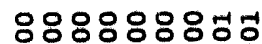

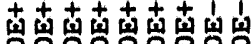
0000080

ㅇㅇㅇ영용요윤

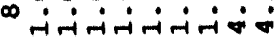

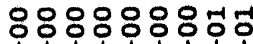

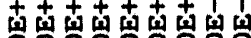

응응응응응

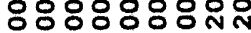

rifindiniष

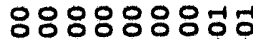

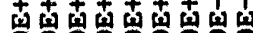

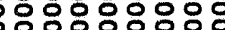

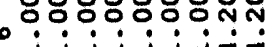

웅ㅇㅇㅇㅇㅇㅇ유엉

南+十+t们 응응응응 응응ㅇㅇㅇㅇㅇㅇㅇㅇㅇㅇㅝ

n

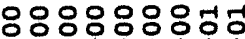

南南南声

응응응으의 .

-iनirifiनi

8ㅇㅇㅇㅇㅇํํำ

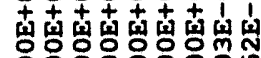

잉ㅇㅇㅇㅇㅇㅇㅇㅇㅇㅇㅇ

응ㅇㅇㅇㅇㅇㅇㅇㅇㅇㅇㅇㅇㅢ

m

옹웅ㅇㅇㅇ욛ㄷㅇㄷㅜ

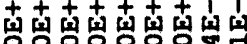

응용응

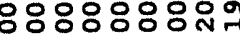

N

८৪৪:८०८००

南南直直南南南南

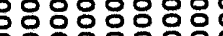

ㅇㅇㅇㅇㅇㅇㅇㅇㅇㅇㅇㅇ응

-

I

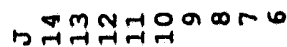




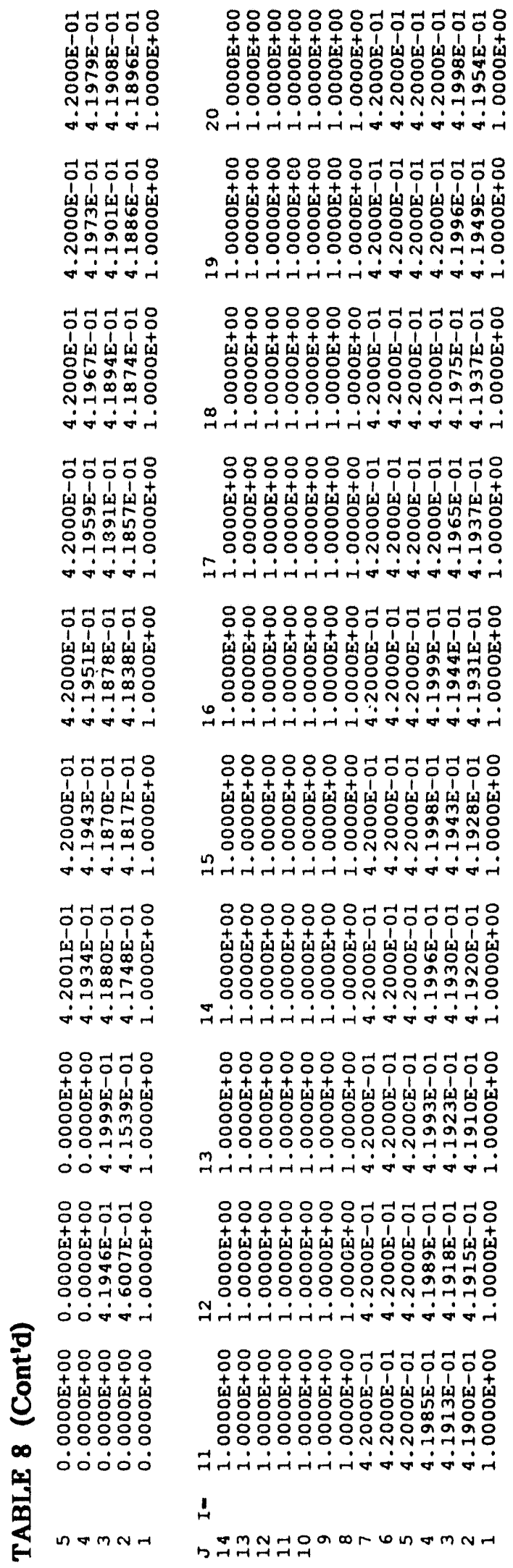

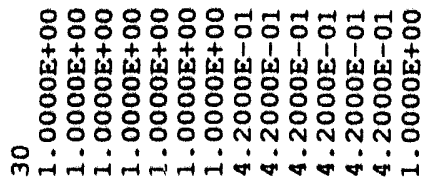

운

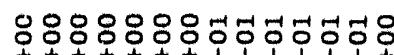

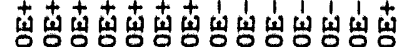

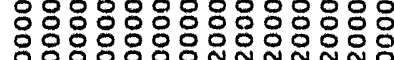

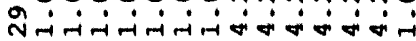

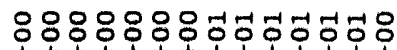

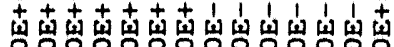
:००००:00:08:08

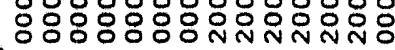

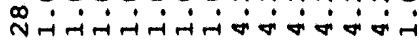

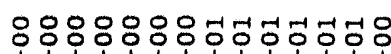

更 ㅇํㅇㅇํㅇㅇํㅇㅇํㅇํㅇ

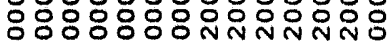

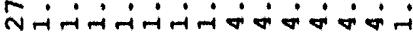

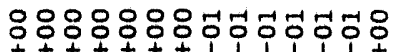

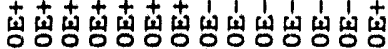

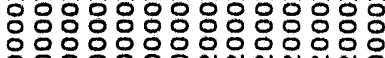

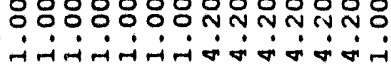

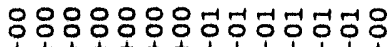

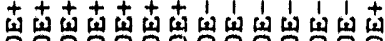

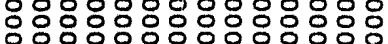

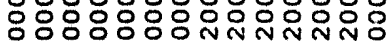

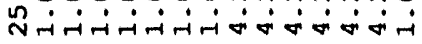

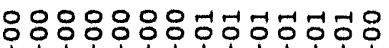

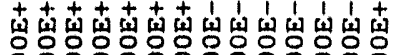

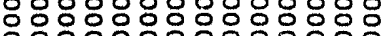

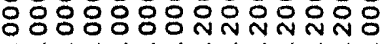

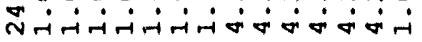

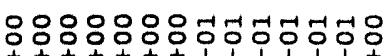

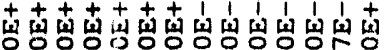

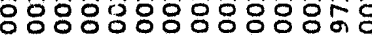

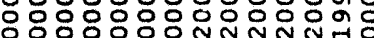

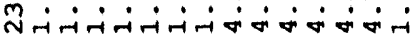

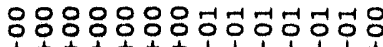

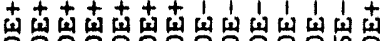

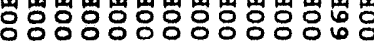

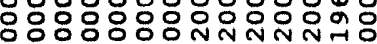

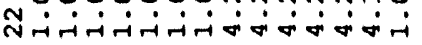

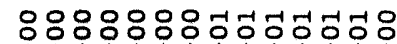

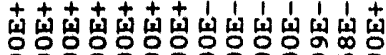

잉ㅇㅇㅇㅇㅇㅇㅇㅇำ

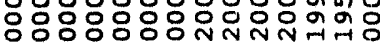

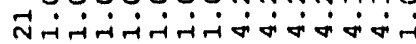

A

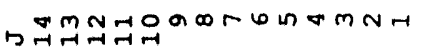

in $\stackrel{\circ}{m}$

$\stackrel{m}{m}$

m

$\stackrel{\infty}{m}$

m

ঃ৪৪৪৪৪৪৪ঃ৪৪ঃঃ

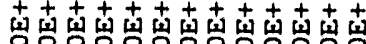

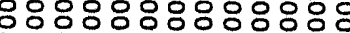

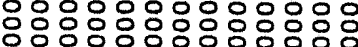

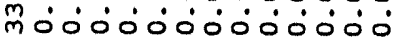

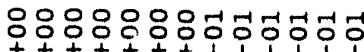

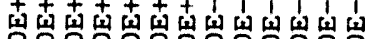

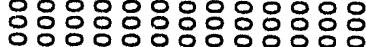

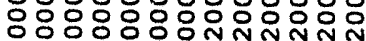

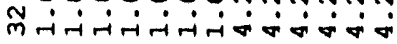

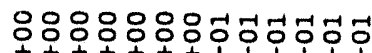

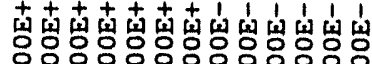

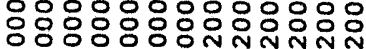

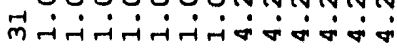

is

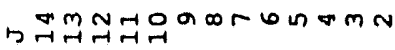




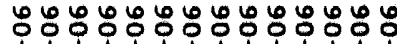

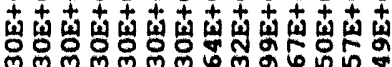

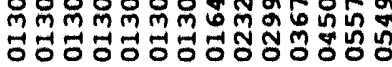

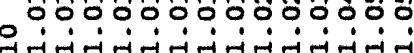

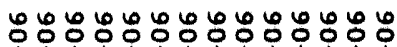

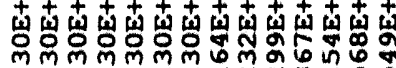

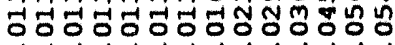

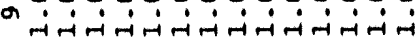

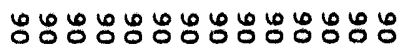

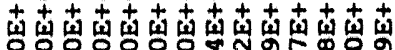

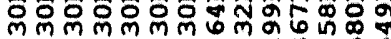

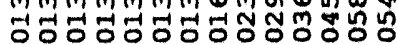

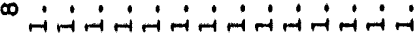

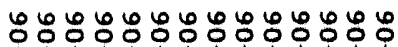

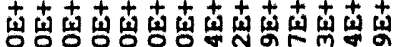

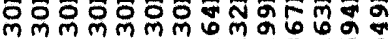

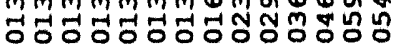

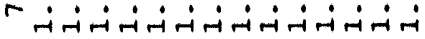

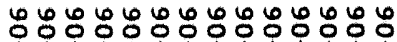

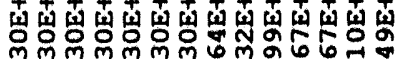

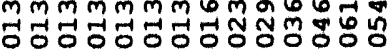

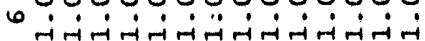

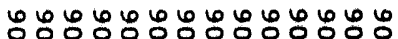
南南南直南南南南南南南南

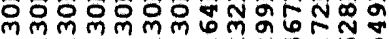

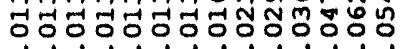

थ

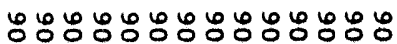

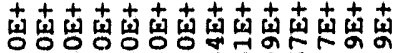
作

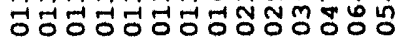

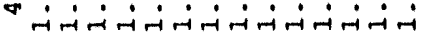

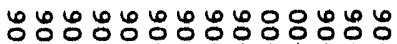

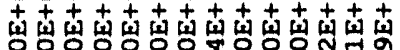

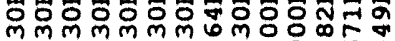

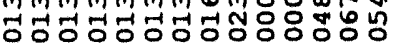

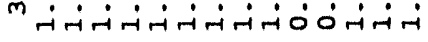

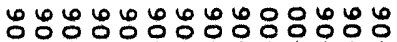

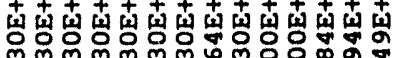

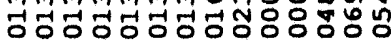

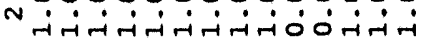

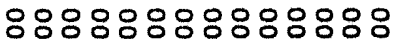

南南南南南南南南南南南

ํํㅇㅇㅇㅇㅇํㅇํㅇํำ

ㅇํㅇㅇํㅇㅇㅇㅇํㅇㅇำ

- 000000000000

I

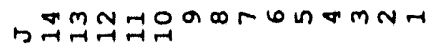

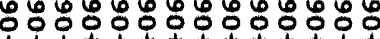

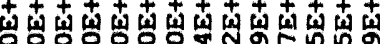

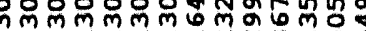

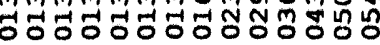

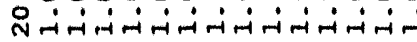

๑ัดั

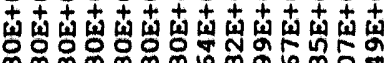

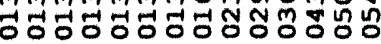

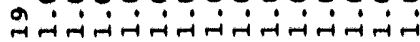

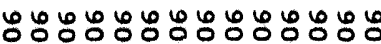

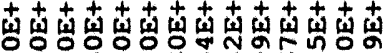

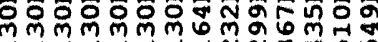

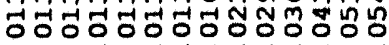

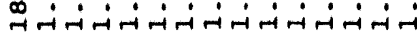

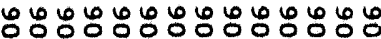

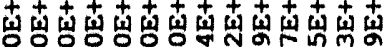

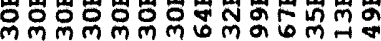

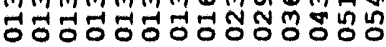

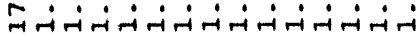

๕ั๐ั

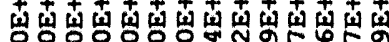

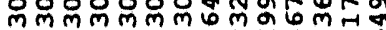

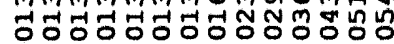

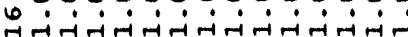

遇:

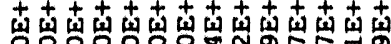

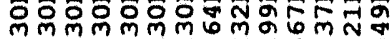

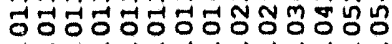

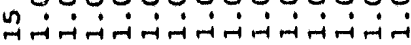

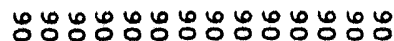

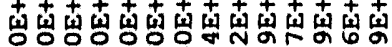

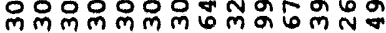

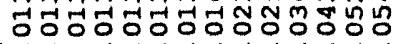

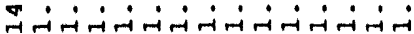

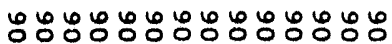

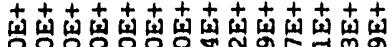

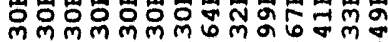

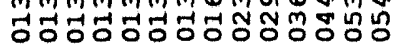

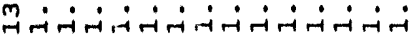

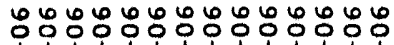

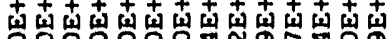

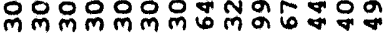

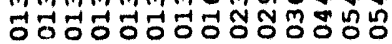

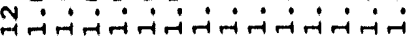

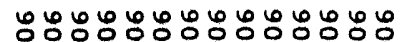

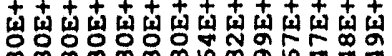

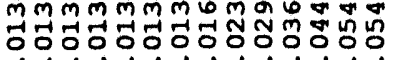

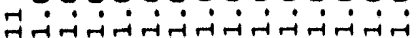

A

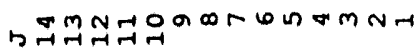

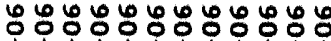

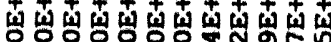

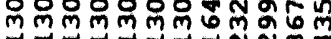
ปี่

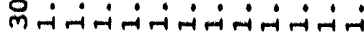

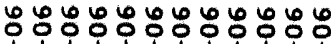

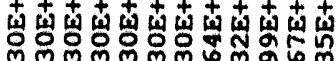

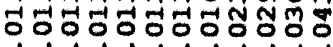

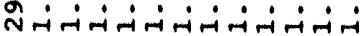

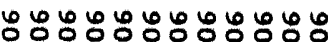

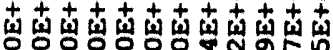

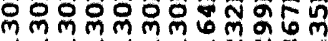

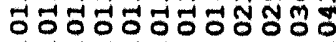

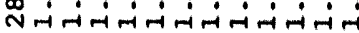

๖ั๐ั

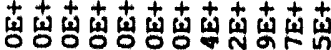

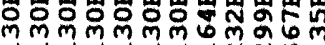

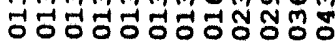

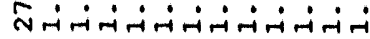

๕ั:

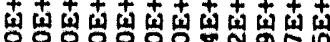
品

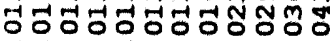

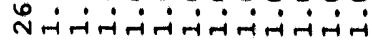

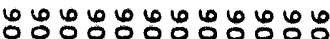

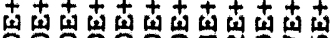

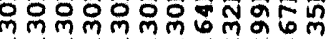

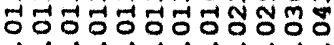

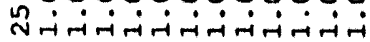

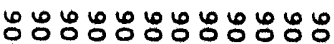

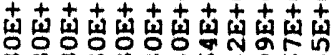

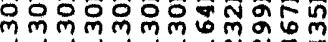

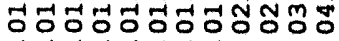

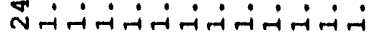

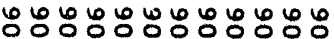
高直南南南南南南南南南

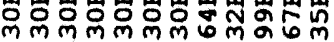

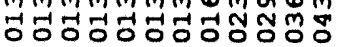

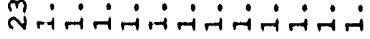

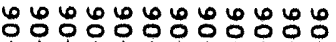

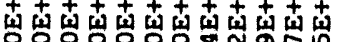

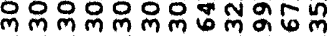

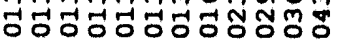

สีम्नंनंनंनंनंनंनं

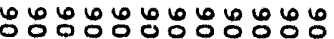
南南南南南南南南南南

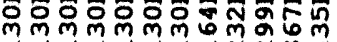

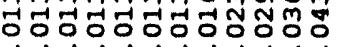

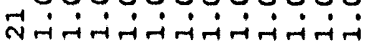

in

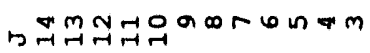


范

๕ั

离索

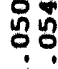

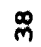

○ั

㕝苟

पू्้ष

in

ะั

高育

ถูํํㅇ

$\ddot{m}$

\%ั0

产密

莒骂

哭

○ั

商

in

○ั

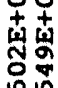

约骂

त्न

ஃ

商高

\%

i-i

题古

운

के

ติ

ले
ㅇํㅇㅇㅇㅇㅇㅇㅇㅇㅇㅇㅇ

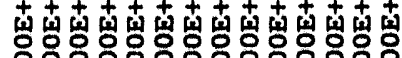

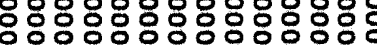

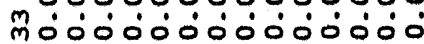

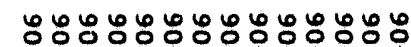

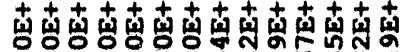

似

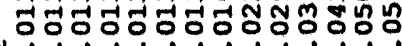

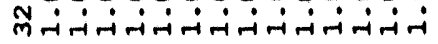

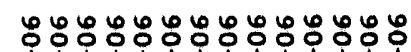

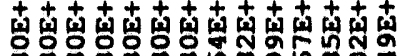

m

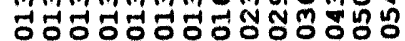

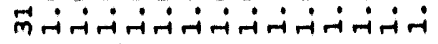

A

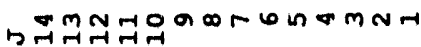

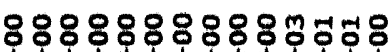

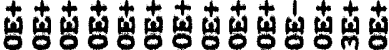

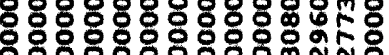

Tojojojojóóñó

$8888888888 \%$

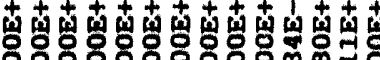

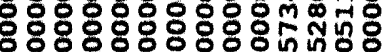

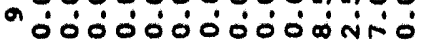

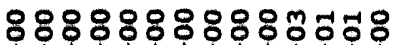

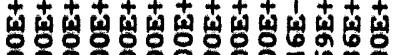

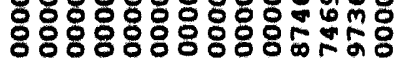

هojojojojóninió

8888888888 넝ำ

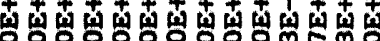

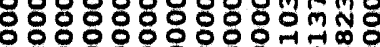

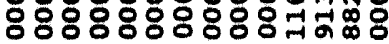

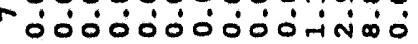

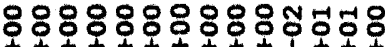

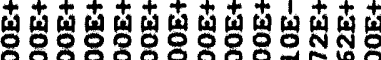

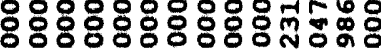

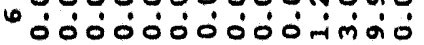

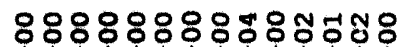

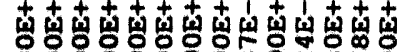

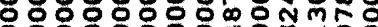

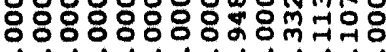

nல்0ல0ல0ல்

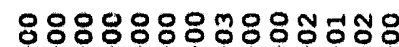

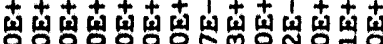

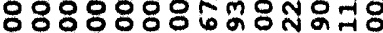

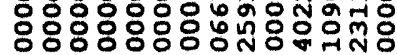

- 0000007イ

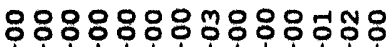

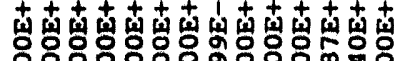

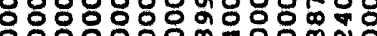

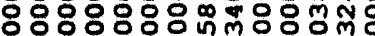

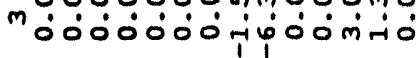

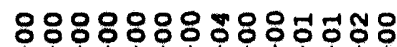

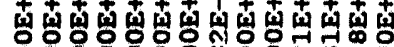

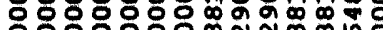

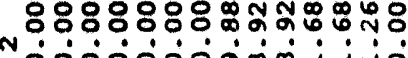

O000000 १िम

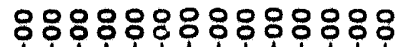

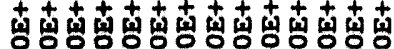

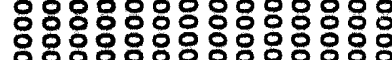

"Dojojó0000000

i

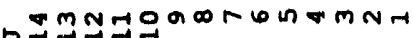

용요요용

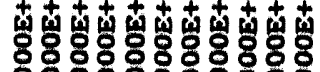

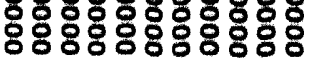

Nóó丶00்000

88888808888

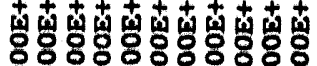

ㅇㅇㅇㅇํㅇㅇㅇㅇㅇㅇㅇํㅇ

नิ000000000ல

80888888888

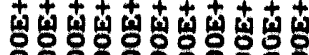

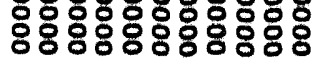

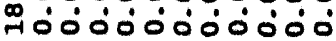

৪৪8:88:8:8

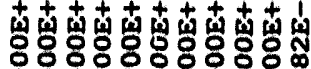

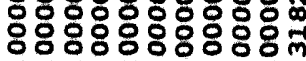

Fơ 0000000100

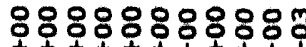

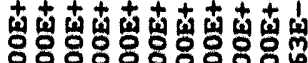

ㅇํㅇํㅇㅇํㅇํㅇำ

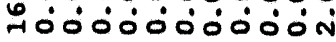

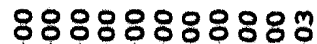

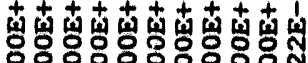
ถัำํํํํำำ

जó0000000ं

৪৪:ঃ৪৪৪৪৪০\%

南南南南南南南出

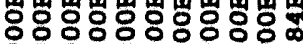

ㅇํㅇㅇㅇㅇㅇㅇำ

Fó00000000ல

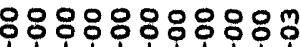

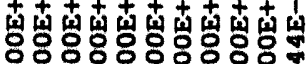

ํํํํํํํำํํำ

ज00000000000ं

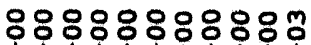

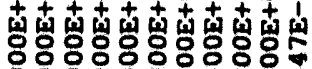

ㅇํㅇㅇํㅇㅇㅇㅇํㅇㅇํㅇ

70ं000000000\%

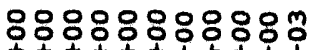

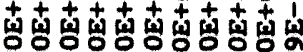

ㅇํㅇㅇํㅇํㅇㅇํㅇํㅇำ

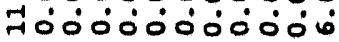

4

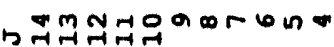




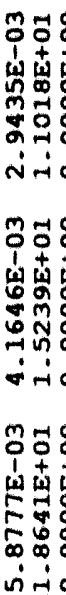

$8 \div 8$

南南南

舟品

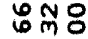

mंก่อ

옹ํำ

䖵产产

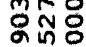

रंखं०

응응

率魚育

N

ஸึ:

rimo

동용

芶苗南

กิำ

ôn

भimं

홍ํㅇ

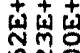

गुํㅇำ

तंबं

덩ㅇㅇㅇ

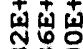

mo

象

둥ㅇㅇㅇ

高怘志

तิํㅇㅇ

$\infty$

inio

突

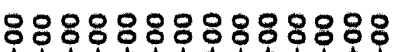

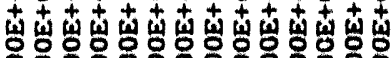

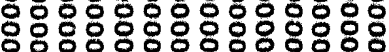

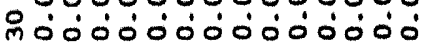

:ㅇ:8:8:8:8:8:

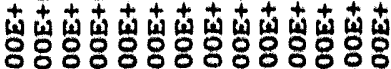

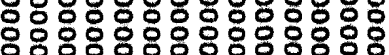

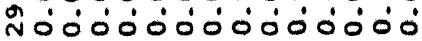

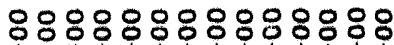

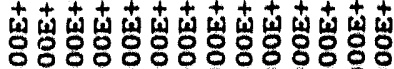

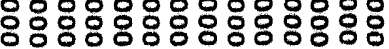

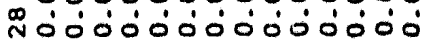

৪৪৪৪৪:৪৪:৪৪৪:৪

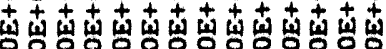

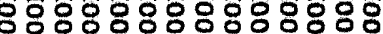

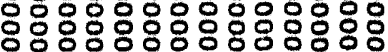

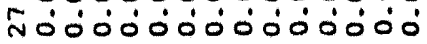

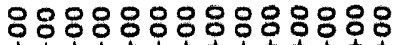

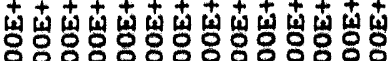

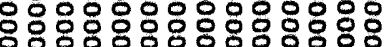

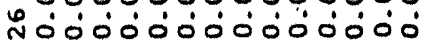

৪৪৪৪৪৪৪৪৪৪:ㅇ

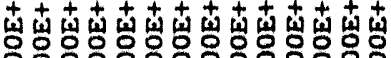

응융용용용용용요융

Nó0 $0^{\circ} 0_{0}^{\circ} 0_{0}^{\circ} 0^{\circ} 0^{\circ} 0^{\circ}$

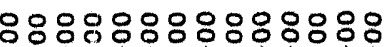

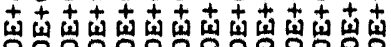

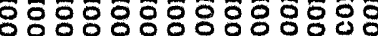

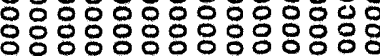

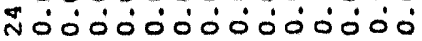

ㅇํㅇㅇㅇㅇㅇㅇㅇㅇ

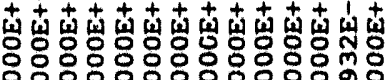

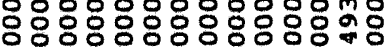

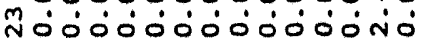

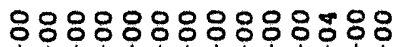

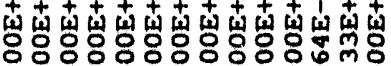

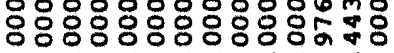

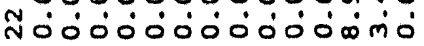

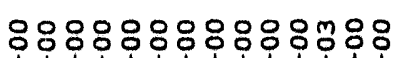

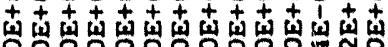

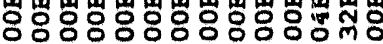

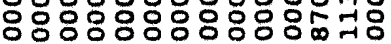

Ñó

it

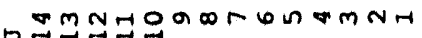

\&

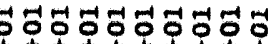

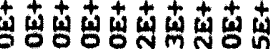

วั0

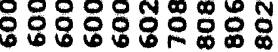

INNNiNiNivini

ì

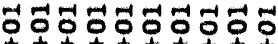

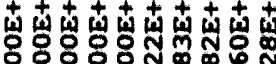

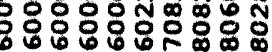

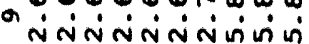

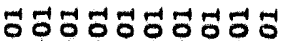

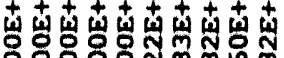

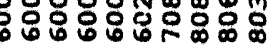

$\stackrel{\infty}{m}$

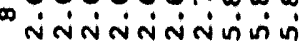

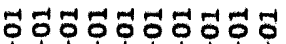

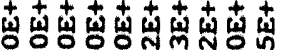

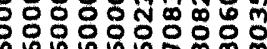

NंNiNiNinivivi

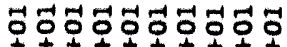

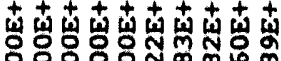

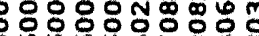

- NंNiñNiñvisio

$\stackrel{m}{m}$

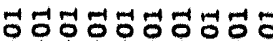

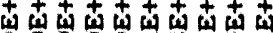

ำำำ

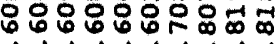

亗

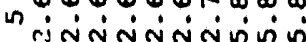

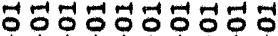

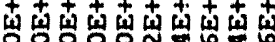

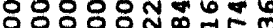

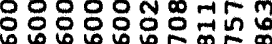

- NंNंNiñNinis

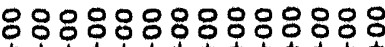

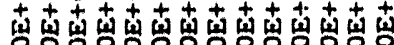

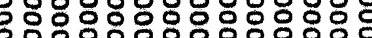

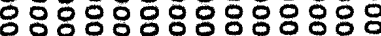

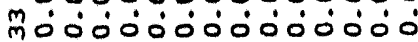

৪৪৪৪৪৪৪৪৪৪০৪৪ঃ

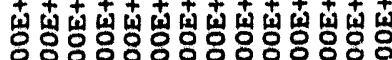

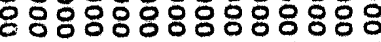

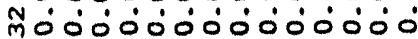

ㅇ๐ㅇㅇㅇㅇㅇㅇㅇㅇㅇㅇㅇㅛ

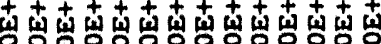

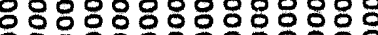

응응ㅇㅇㅇㅇㅇㅇㅇㅇㅇㅇㅇㅇㅇㅇㅇㅇㅇㅇㅇㅇ

m̄óóó

H

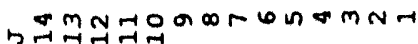

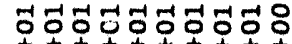

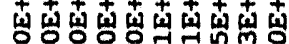

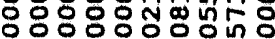

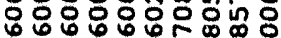

m NंNiñiniviso

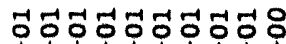

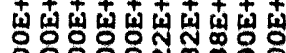

응ำ

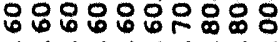

Niñininivivio

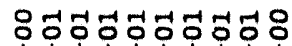

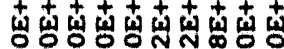

ㅇํㅇㅇํำ

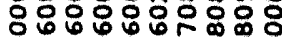

OnNininivivio

A

กำสำ 


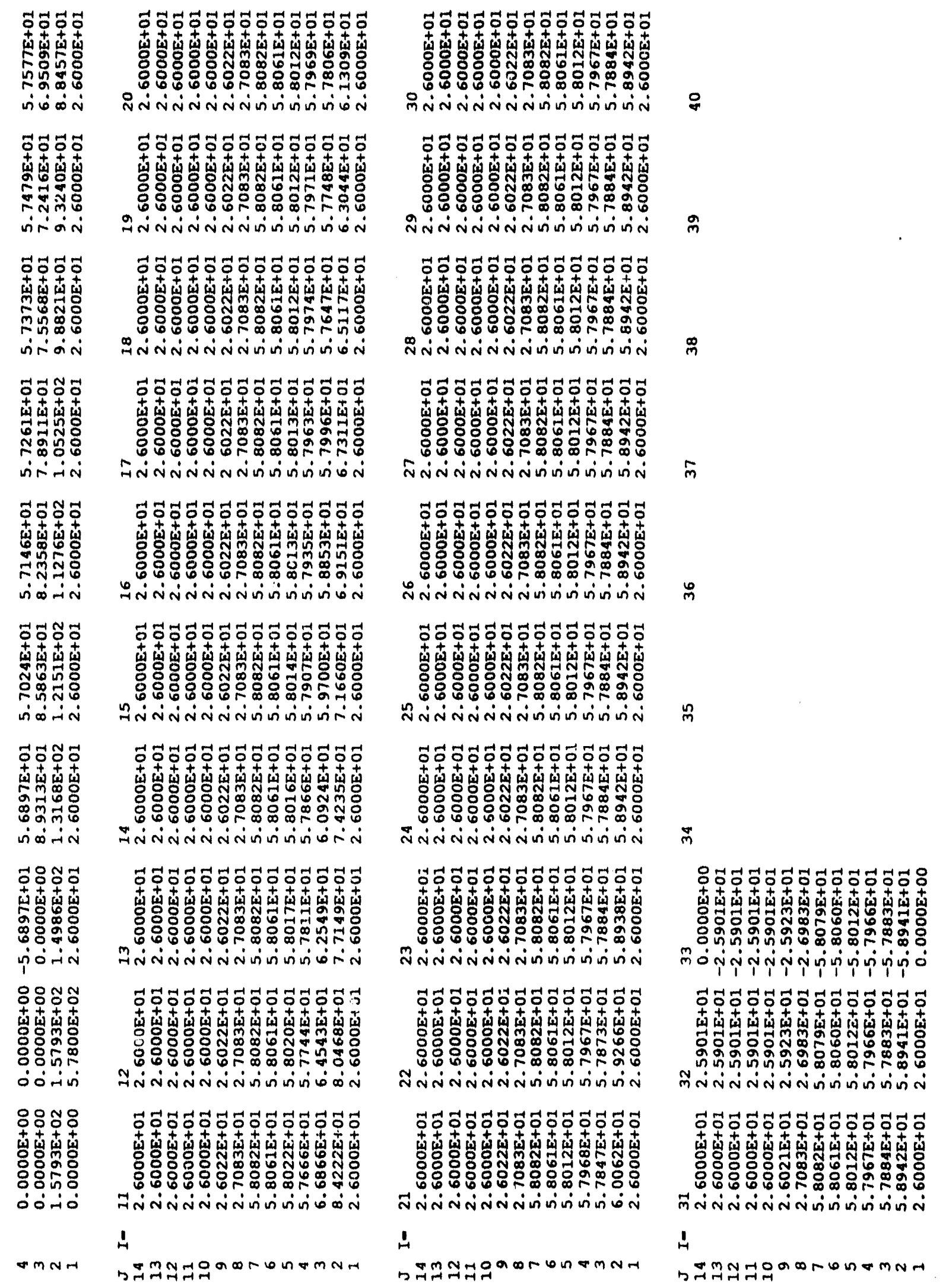




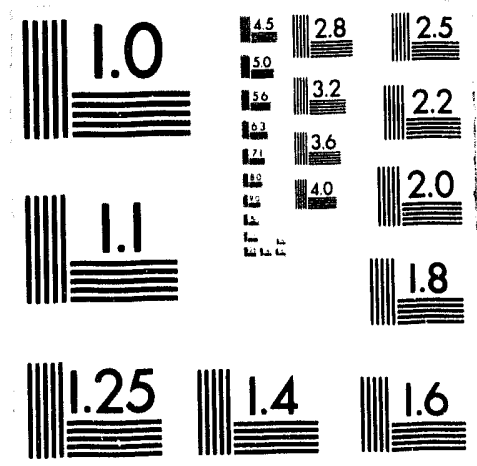



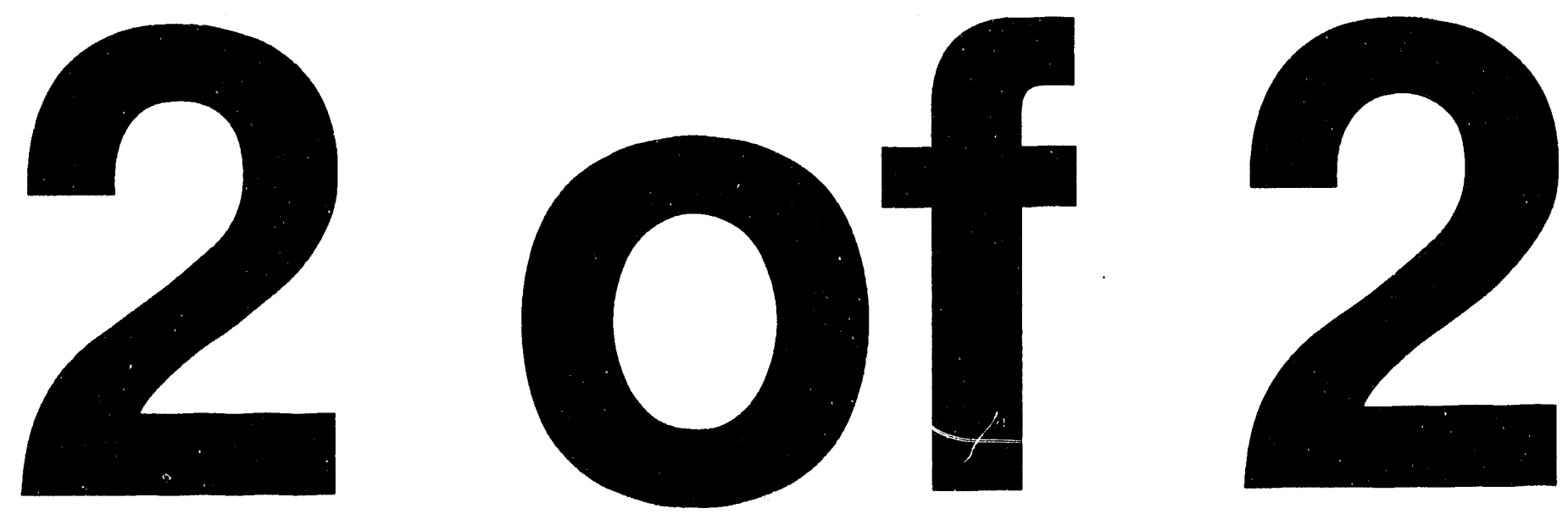


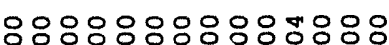

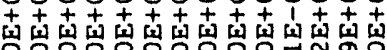

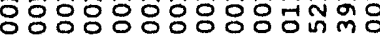

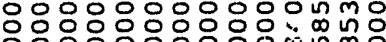

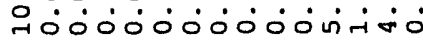

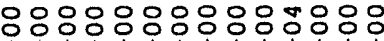

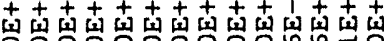

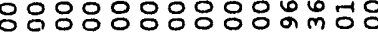

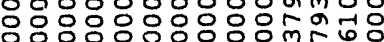

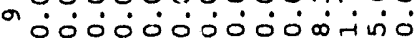

ㅇ๐ㅇㅇㅇㅇํㅇㅇㅇㅇํㅇ

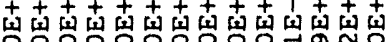

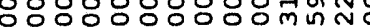

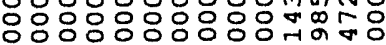

n 000000000.

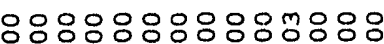

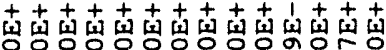

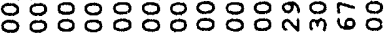

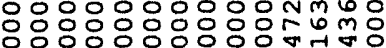

rojodóojominio

৪৪ㅇ৪ㅇํㅇㅇ

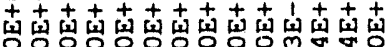

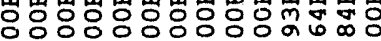

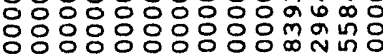

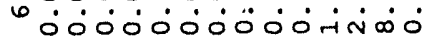

ㅇ๐ㅇㅇㅇㅇㅇㅇㅇㅇํㅇ

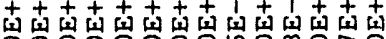

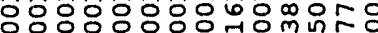

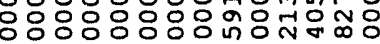

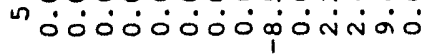

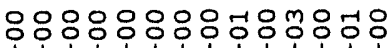

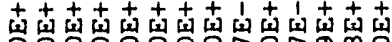

८०००:०८:

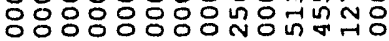

- O0000000

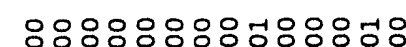

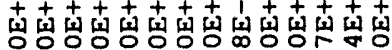

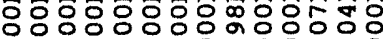

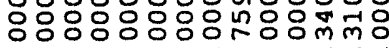

m O000000000170

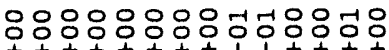

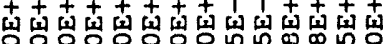

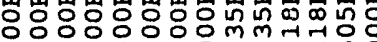

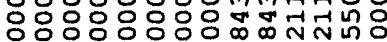

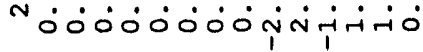

ㅇঃㅇঃঃঃㅇㅇ

南南南南南南南南南南

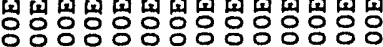

잉응ㅇㅇㅇㅇㅇㅇㅇㅇㅇㅇㅇㅇㅇㅇㅇํㅇ

-00000000000000

म

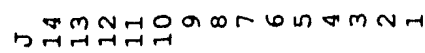

৪:ㅇ৪ㅇ๐๐ㅇ

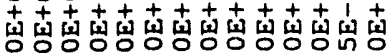

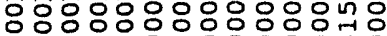

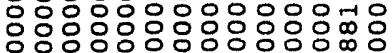

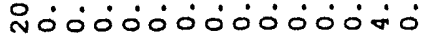

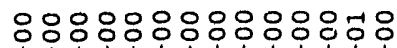

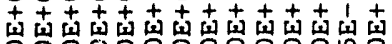

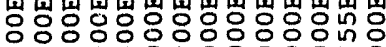

ㅇํㅇㅇㅇㅇㅇㅇㅇㅇㅇㅇㅇㅇㅇㅇํㅇํำ

नेojojojó00ं0்

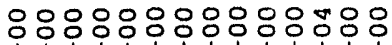

南南南南南南南南南出南南

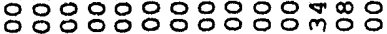

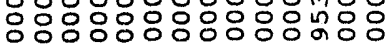

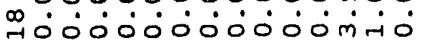

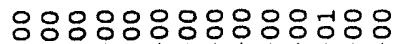

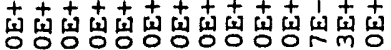

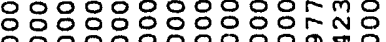

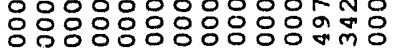

Fó00000000ं

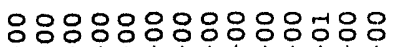

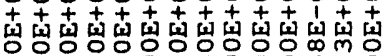

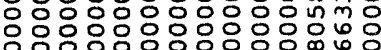

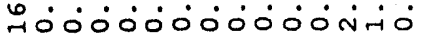

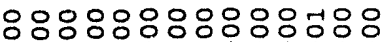

南南南南南南南南南

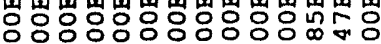

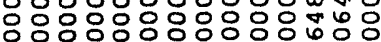

ñojo⿺jo,

ㅇ๐ㅇㅇㅇㅇㅇㅇㅁㅇㅇㅇ

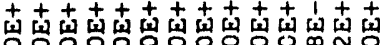

ํํㅇํํㅇํํㅇํㅇํำำ

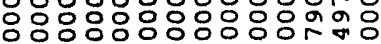

न00000000000ं

৪:ㅇㅇㅇㅇํㅇㅇㅠ

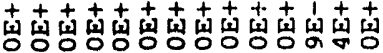

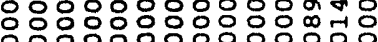

응ㅇㅇㅇㅇㅇㅇㅇㅇㅇㅇㅇㅇ유융

70000000000

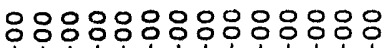

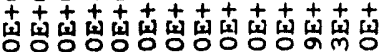

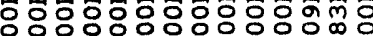

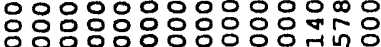

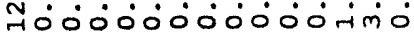

응ㅇㅇㅇㅇㅇㅇㅇㅇㅇㅇ

南南南南南南南出南南

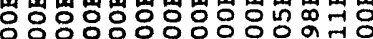

ㅇํㅇํㅇㅇㅇㅇㅇㅇㅇㅇํำ

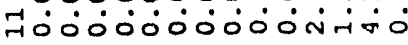

I

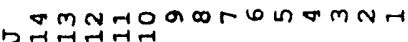

ㅇ৪ㅇㅇㅇ용요

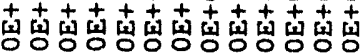

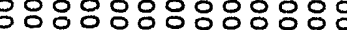

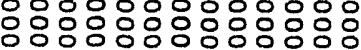

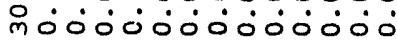

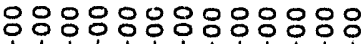

南南南南南声南南南南南

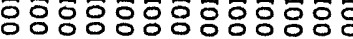

응ㅇㅇㅇㅇㅇㅇㅇㅇㅇㅇㅇㅇㅇㅇㅇㅇ

N่00000000000

ㅇঃঃㅇঃঃঃㅇ

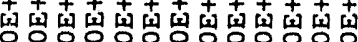

응응ㅇㅇㅇㅇㅇㅇㅇㅇ응

양ㅇㅇㅇㅇㅇㅇㅇㅇㅇㅇ

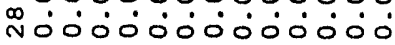

ㅇ๐ㅇ৪ㅇ৪ㅇ

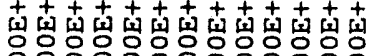

응ㅇㅇㅇㅇㅇㅇㅇㅇㅇㅇㅇㅇㅇㅇㅇㅇㅇㅇㅇㅇㅇ

Ñó0000000000

ㅇ৪ㅇㅇㅇㅇㅇㅇㅇㅇ

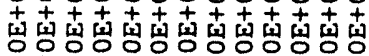

ㅇㅇㅇㅇㅇㅇㅇㅇㅇㅇㅇㅇㅇㅇㅇㅇㅇㅇㅇㅇㅇㅇㅇㅇㅇ

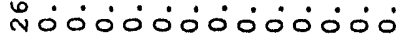

ㅇㅇㅇㅇㅇㅇㅇㅇㅇㅇ

南南南南南南南南南南

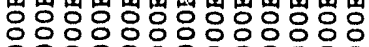

양ㅇㅇㅇㅇㅇㅇㅇㅇㅇㅇㅇㅇㅇㅇㅇํㅇ

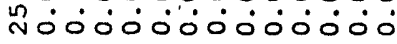

웅웅ㅇㅇㅇㅇㅇㅇㅇㅇㅇㅇ

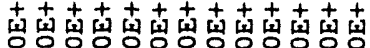

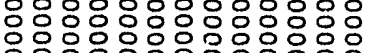

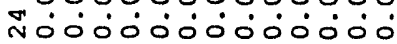

ㅇ৪ㅇ৪ㅇ৪ㅇ

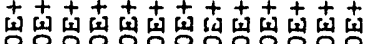

응ㅇㅇㅇㅇㅇㅇㅇㅇㅇ응

ㅇํㅇㅇㅇㅇㅇㅇㅇํ

Nั000000000்

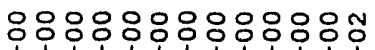

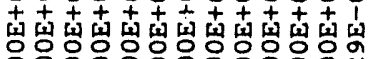

응ㅇㅇㅇㅇㅇㅇㅇㅇำ

ㅇํㅇㅇㅇㅇㅇำ

Nั0000000000ั

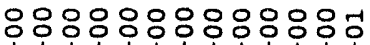

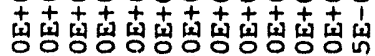

ㅇํㅇㅇㅇㅇㅇㅇㅇํㅇ

응ㅇㅇㅇㅇㅇㅇㅇㅇㅇㅇㅇㅇㅇㅇㅇํ

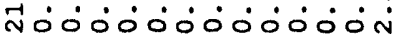

至

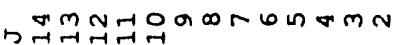




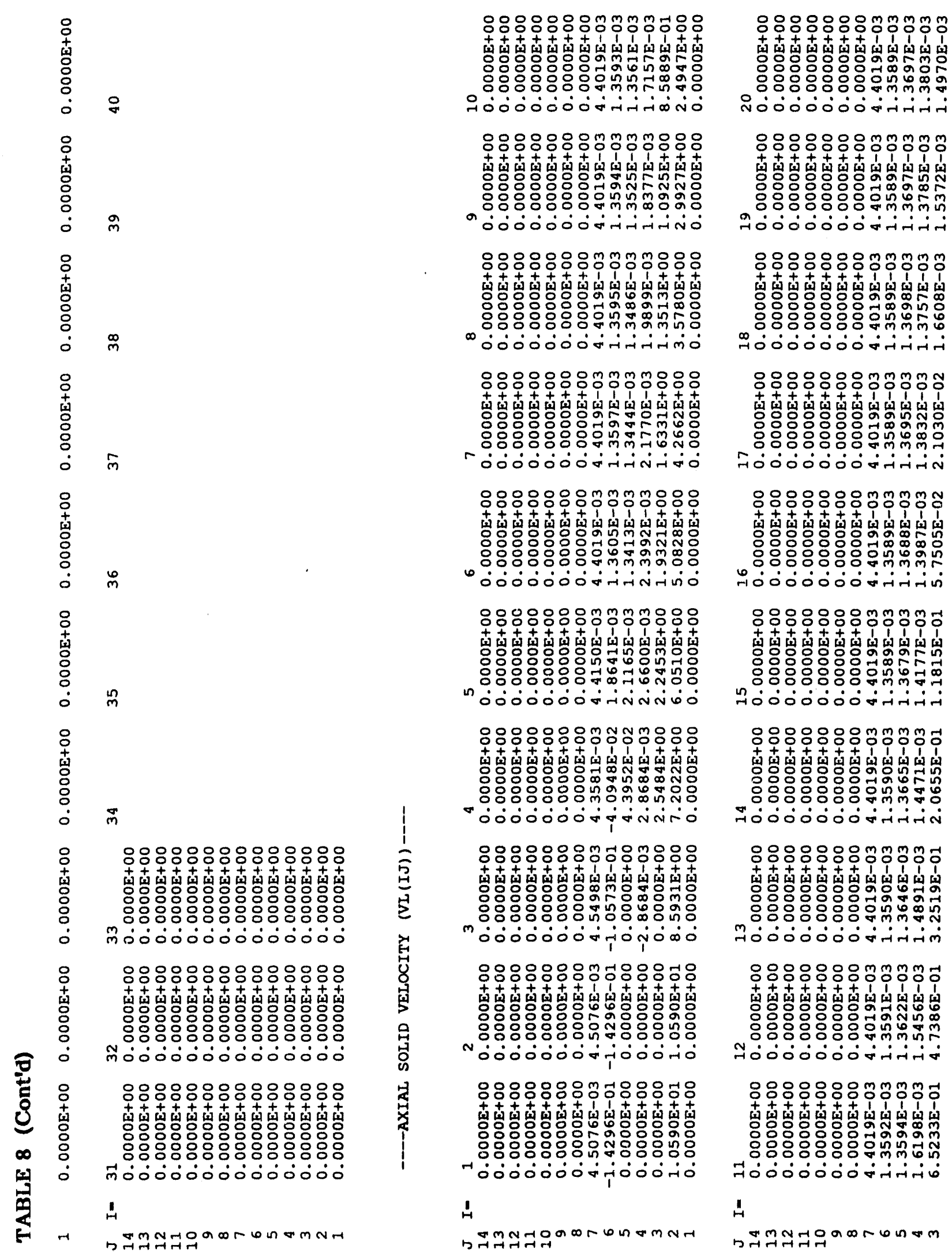




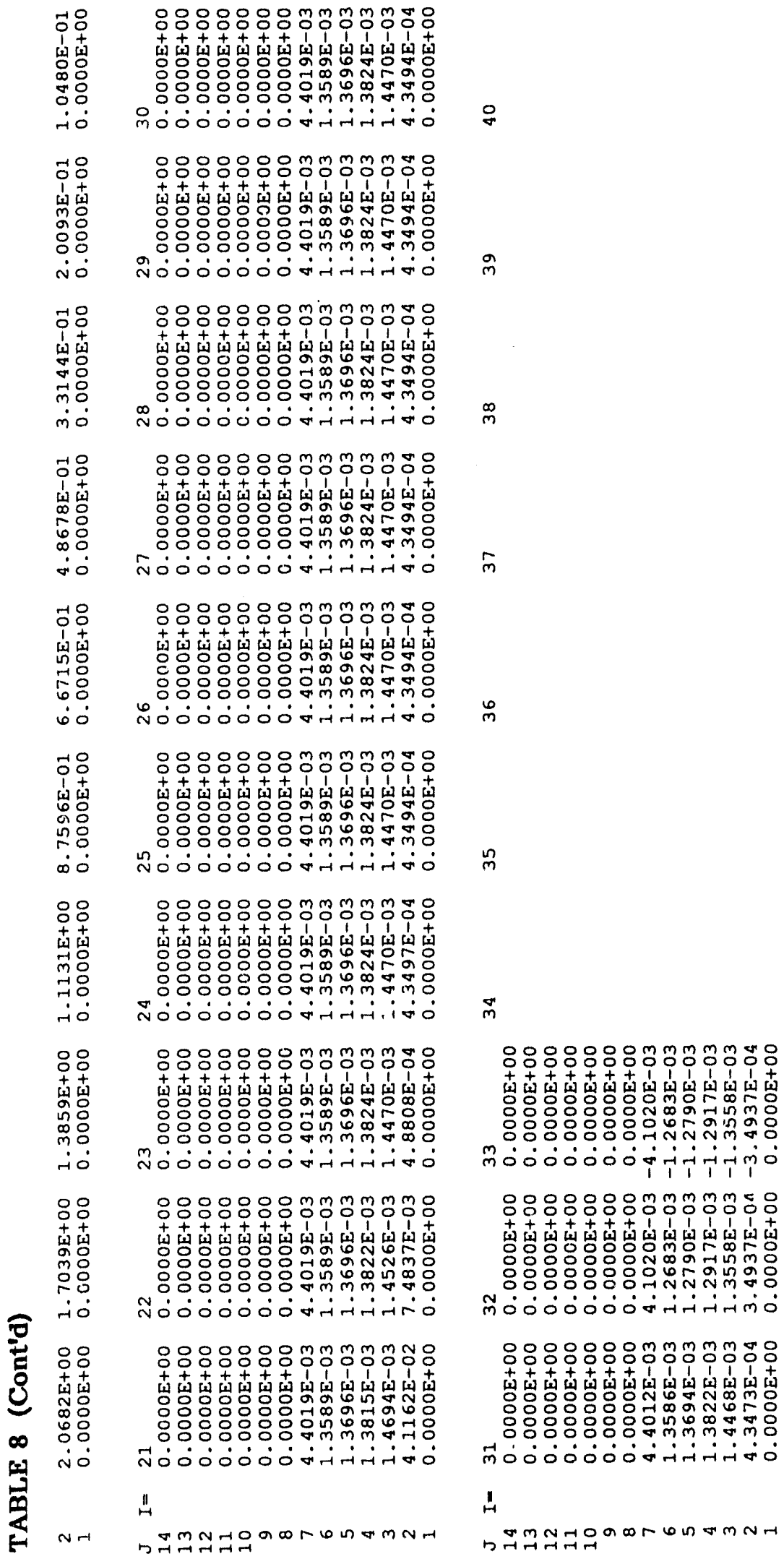

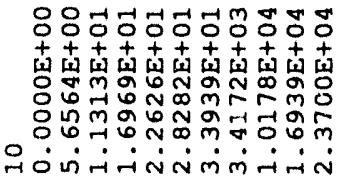

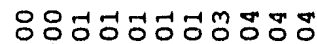

南南南南南南南南南

○ำ

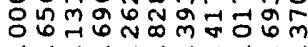

कांनंतरलंखिनंस

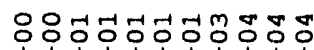

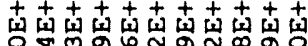

Oำ

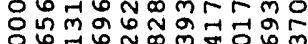

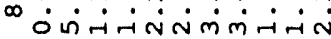

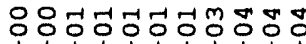
南南南南南血南南南 O

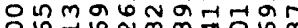

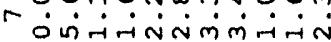

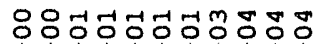

南南南南南南南南南

O

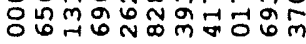

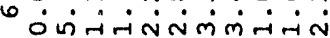

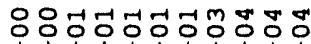

南克南南南南南南南南南

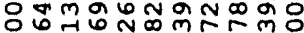

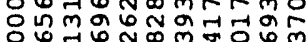

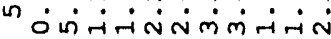

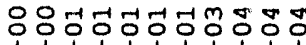

南南南南南南南南

O

응

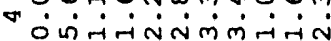

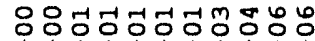

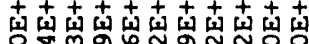

政政

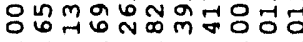

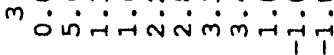

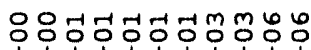

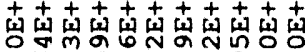

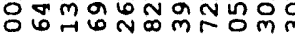
吅

Nंगंनंसंजिंबंनं

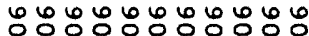

卉南卉十 +十+

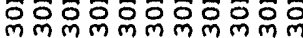

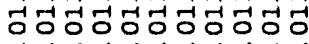

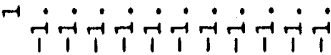
至

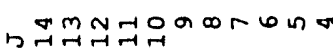




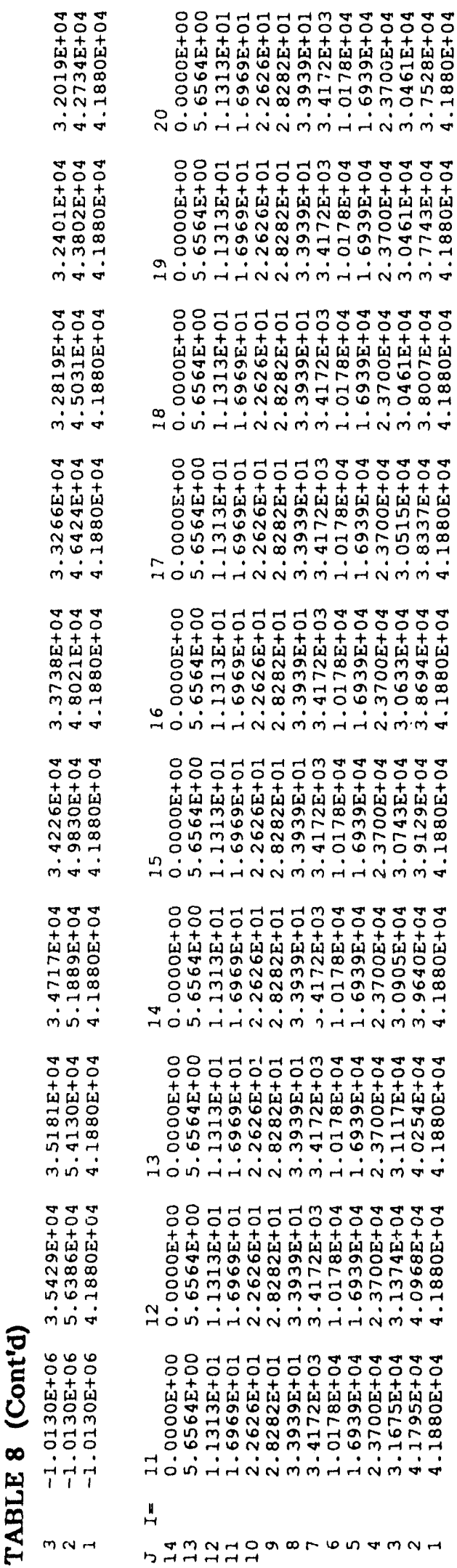

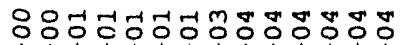

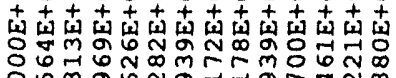

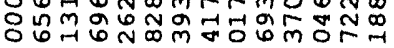

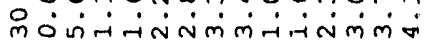

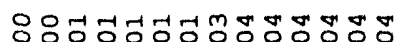

南南南南南南南南南南

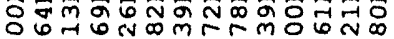

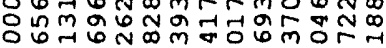

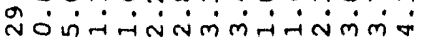

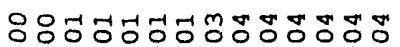

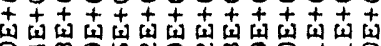
ㅇํㅇำ

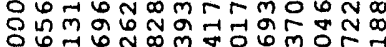

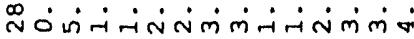

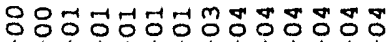

$+十+1+1+$

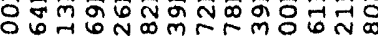

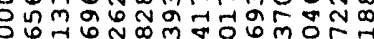

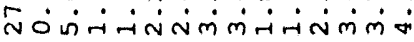

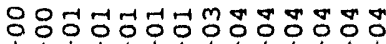
南南南血南血南南南南

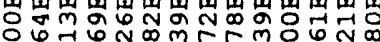

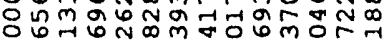

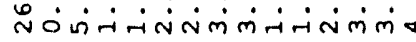

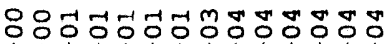
南南南南南南南南南南南南南南

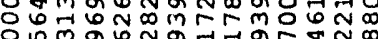

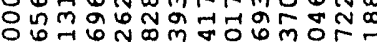

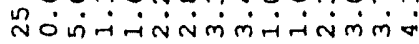

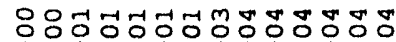

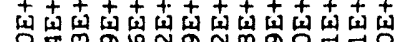
Oำ

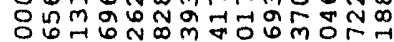

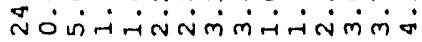

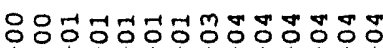

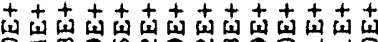

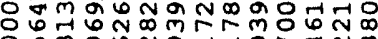

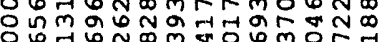

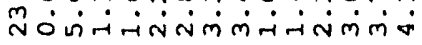

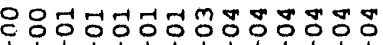
南南南南南南南南南南南南南 行的象 o पि

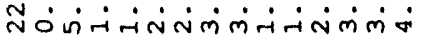

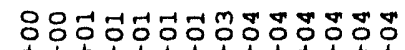
南南南南南南南南南南南

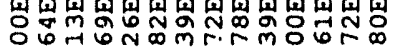

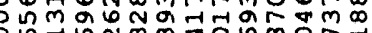

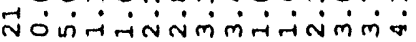

辛

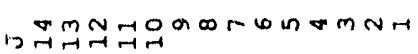

운

$\stackrel{\infty}{m}$

m

$\stackrel{\bullet}{m}$

而

m

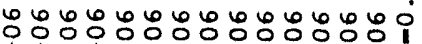

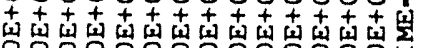

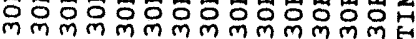

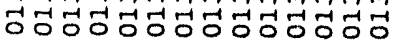

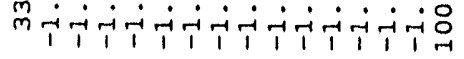

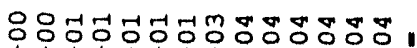

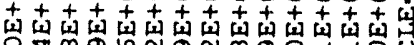

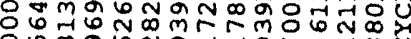

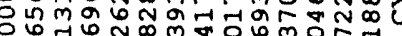

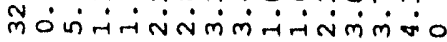

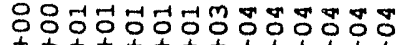

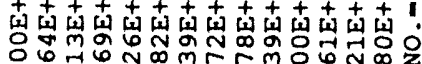
음

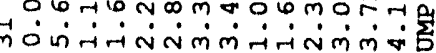
II

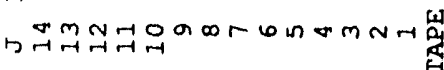




\section{NOMENCLATURE}

C

$\mathbf{C}_{\mathbf{d}}$

$\mathrm{C}_{\mathrm{g}}$

c

$\mathrm{D}_{\mathrm{g}}$

$d_{p}$

G

g

$\mathrm{K}_{\mathrm{x}}, \mathrm{K}_{\mathrm{y}}$

L

$\mathbf{P}$

$\operatorname{Re}_{\mathrm{y}}$

$\mathbf{r}$

$\mathrm{T}$

t

$\mathrm{U}_{\mathrm{g}}, \mathrm{U}_{\mathrm{s}}$

$\mathrm{v}_{\mathrm{g}}, \mathrm{v}_{\mathrm{s}}$

$\mathbf{x}$

y

z
Characteristic direction $(\mathrm{m} / \mathrm{s})$

Drag coefficient (see Eq. 3.11)

Speed of sound in gas, $\left(\frac{\partial P}{\partial \rho}\right)_{T}^{1 / 2}(\mathrm{~cm} / \mathrm{s})$

Compaction modulus

Residue of gas continuity equation, Eq. $5.19\left(\mathrm{~kg} / \mathrm{m}^{3}\right)$

Particle diameter (m)

Solids elastic modulus (Pa)

Acceleration due to gravity $\left(\mathrm{m} / \mathrm{s}^{2}\right)$

Drag coefficient between gas and solids phases, equivalent to $\beta_{\mathbf{x}}$ and $\beta_{\mathbf{y}^{*}}$ Mean Free Path, m

Pressure $(\mathrm{Pa})$

Reynolds number of solids particle (Eq. 3.12)

Radial coordinate (m)

Temperature (K)

Time (s)

Gas and solids phase velocities in the $x$ or $r$ direction, respectively $(\mathrm{m} / \mathrm{s})$

Gas and solids phase velocities in the y or $\mathrm{z}$ direction, respectively $(\mathrm{m} / \mathrm{s})$

Lateral coordinate $(\mathrm{m})$

Axial coordinate (m)

Axial coordinate (m) 


\section{Greek Symbols}

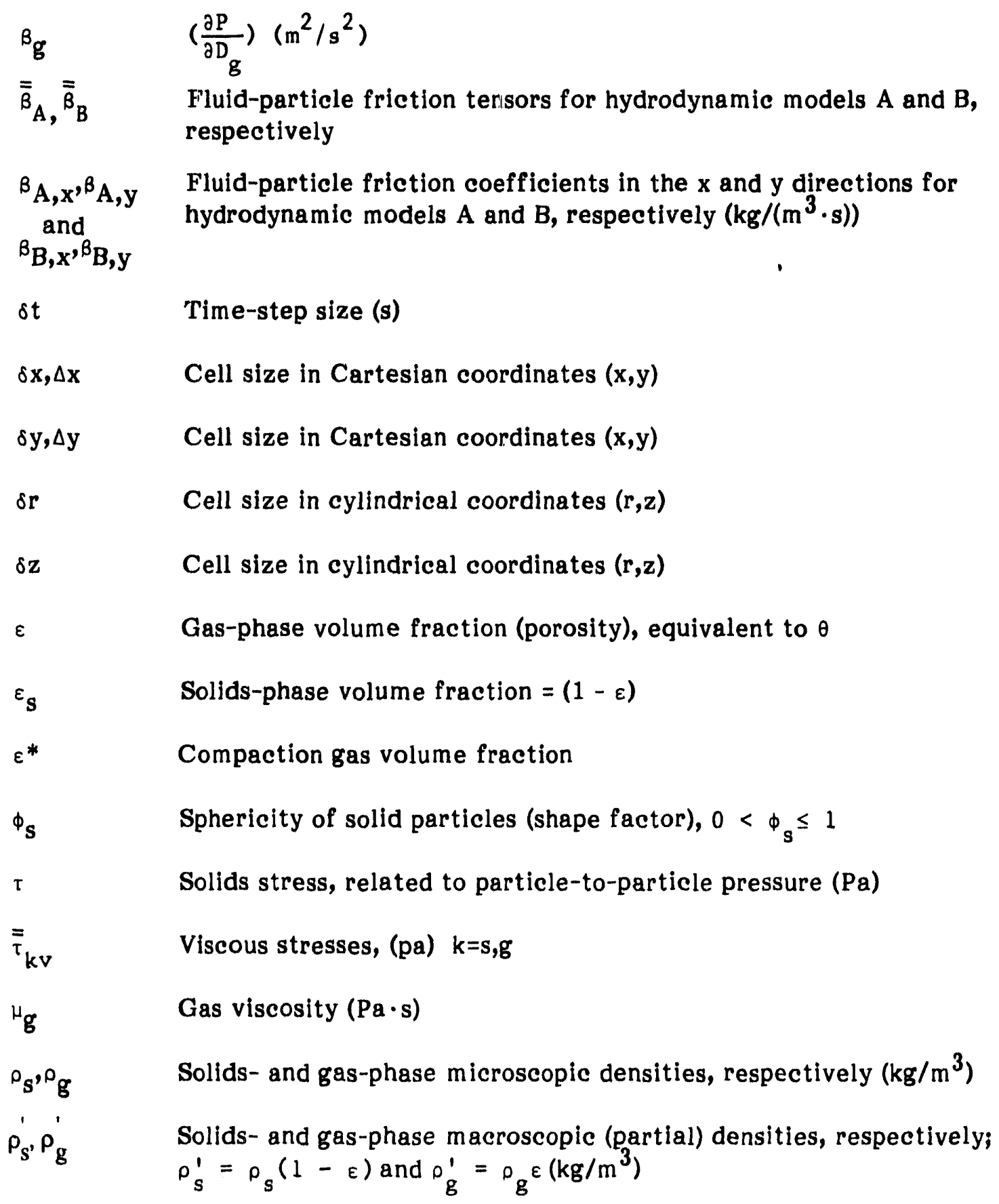

$\theta \quad$ Gas-phase volume fraction (porosity), equivalent to $\varepsilon$ 


\section{Inderes and Subscripts}

G Gas phase

$\mathrm{i}$ or $\mathrm{I} \quad$ Cell index in $\mathrm{x}$ or $\mathrm{r}$ direction

$\mathrm{j}$ or $\mathrm{J} \quad$ Cell index in $\mathrm{y}$ or $\mathrm{z}$ direction

$\ell \quad$ Liquid phase

n Index for time step

s Solids phase

$\mathbf{x}$

x-direction

y

y-direction 


\section{REFERENCES}

1. Lyczkowski, R.W., D. Gidaspow, and T.R. Galloway, Hydrodynamic Modeling of Fluidized-Bed Gasifiers and Combustors, Lawrence Livermore Laboratory Report UCID-17759 (April 19, 1978)

2. Rivard, W.C., and M.D. Torrey, K-FIX: A Computer Program for Transient, TwoDimensional, Two-Fluid Flow, Los Alamos Scientific Laboratory Report LANUREG-6623 (April 1977).

3. Gidaspow, D., B. Ettehadieh, and R.W. Lyczkowski, Computer Modeling of Fluidization of Sand in a Two-Dimensional Bed with a Jet, presented at the 74th Annual American Institute of Chemical Engineers Meeting (Nov. 8-12, 1981).

4. Gidaspow, D., et al. Theoretical and Experimental Hydrodynamics of a Jet in a Fluidized Bed of Particles, Proc. International Symp. on Powder Technology, 1981, $K$. linoya, K. Beddow, and G. Jimbo, eds., pp. 672-681, Society of Powder Technology, Kyoto, Japan (1982).

5. Gidaspow, D., C.L. Lin, and Y.C. Seo, Fluidization in Two-Dimensional Beds with a Jet: 1. Experimental Porosity Distribution, Industrial and Engineering Chemistry Fundamentals 22:187-193 (1983).

6. Gidaspow, D., Y.C. Seo, and B. Ettehadieh, Hydrodynamics of Fluidization: Experimental and Theoretical Bubble Size in a Two-Dimensional Bed with a Jet, Chemical Engineering Communications 22:253-272 (1983).

7. Gidaspow, D., and B. Ettehadieh, Fluidization in Two-Dimensional Beds with a Jet: 2. Hydrodynamic Modeling, Industrial and Engineering Chemistry Fundamentals 22:193-201 (1983).

8. Bouillard, J.X., R.W. Lyczkowski, S. Folga, D. Gidsapow, and G.F. Berry, Hydrodynamics of Erosion of Heat Exchanger Tubes in Fluidized-Bed Combustors, Canadian Journal of Chemical Engineering, 67:218-229, (April 1989).

9. Gidaspow, D., Hydrodynamics of Fluidization and Heat Transfer: Supercomputer Modeling, presented at Twenty-third National Heat Transfer Conf., Denver, Aug. 5, 1985; published in Applied Mechanics Review 39(1):1-23 (Jan. 1986).

10. Gidaspow, D., and M. Syamlal, Solid-Gas Critical Flow, presented at 1985 Annual American Institute of Chemical Engineers Meeting, Chicago, Paper 74e (Nov. 10$15,1985)$.

11. Bouillard, J.X., R.W. Lyczkowski, and D. Gidaspow, Porosity Distributions in a Fluidized Bed With an Immersed Obstacle, AIChE Journal, 35:(6)908-922 (June 1989). 
12. Lyczkowski, R.W., S. Folga, S.L. Chang, J.X. Boullaard, C.S. Wang, G.F. Berry, and D. Gidaspow, State-of-the-Art Computation of Dynamics and Erosion in Fluidized Bed Tube Banks, Proceedings of the 10th (1989) International Conference on Fluidized Bed Combustion, A.M. Manaker, ed., Vol. 1, pp. 465-478, American Society of Mechanical Engineers, New York (1989).

13. Bouillard, J.X., D. Gidaspow, and R.W. Lyczkowski, Hydrodynamics of Fluidization: Fast Bubble Simulation in a Two-Dimensional Fluidized Bed, accepted for publication in Powder Technology (1990).

14. Nicoletti, P.A., and A.R. Padhye, Comparison of K-FIX and FLUFIX Computer Codes Line-by-Line Listing, EG\&G Washington Analytical Services Center, Inc., Report, prepared under Contract DE-AC21-8SMC21353 for Morgantown Energy Technology Center, Morgantown, W. Va. (June 1986).

15. Syamlal, M., and D. Gidaspow, Hydrodynamics of Fluidization: Prediction of Wall to Bed Heat Transfer Coefficients, J. American Institute of Chemical Engineers $31(1): 127-135$ (1985).

16. Gidaspow, D., M. Syamlal, and Y.C. Seo, Hydrodynamics of Two Particle Size Fluidization, at Sixteenth Annual Meeting of the Fine Particle Society, Miami Beach, Fla. (April 22-26, 1985).

17. Gidaspow, D., et al., Hydrodynamics of Fluidization: Bubbles and Gas Compositions in the U-Gas Process, presented at the American Institute of Chemical Engineers Meeting, San Francisco, Nov. 1984; published in AIChE Symposium Series 80(241):57-64 (1985).

18. Gidaspow, D., et al., Hydrodynamics of a Lamella Electrosettler, AIChE Journal, 35(5):714-724 (May 1989).

19. Lyczkowski, R.W., and J.X. Bouillard, Interim Users Manual for FLUFIX/MOD 1:A Computer Program for Fluid-Solids Hydrodynamics, Argonne National Laboratory Report ANL/EES-TM-361, Argonne, IL, October 1986 (February 1989).

20. Harlow, F.H., and A.A. Amsden, Numerical Calculation of Multiphase Fluid Flow, J. Computational Physics 17:19-52 (1975).

21. Lyczkowski, R.W., et al., Characteristics and Stability Analyses of Transient OneDimensional Two-Phase Flow Equations and Their Finite Difference Approxima. tions, Nuclear Science and Engineering 66:378-396 (1978).

22. Nakamura, K., and C.E. Capes, Vertical Pneumatic Conveying: A Theoretical Study of Uniform and Annular Particle Flow Models, Canadian J. Chemica] Engineering 51:39-46 (1973). 
23. Lee, W.H., and R.W. Lyczkowski, The Basic Character of Five Two-Phase Flow Model Equation Sets, Proc. International Topical Meeting on Advances in Mathematical Methods for the Solution of Nuclear Engineering Problems, Munich, Vol. 1, pp. 489-511, American Nuclear Society, La Grange Park, Ill. (1981).

24. Rudinger, G., and A. Chang, Analysis of Non-Steady Two-Phase Flow, Physics of Fluids 7:1747-1754 (1964).

25. Lyczkowski, R.W., Transient Propagation Behavior of Two-Phase Flow Equations, in Heat Transfer: Research and Application, J.C. Chen, ed., American Institute of Chemical Engineers Symp. Series 75(174):165-174, New York (1978).

26. Kunil, D., and O. Levenspiel, Fluidization Engineering, John Wiley and Sons, Inc., New York (1969).

27. Ergun, S., Fluid Flow through Packed Columns, Chemical Engineering Progress 48(2)89-94 (1952).

28. Wen, C.Y., and Y.H. Yu, Mechanics of Fluidization, B.S. Lee, ed., American Institute of Chemical Engineers Series 62(62):100-112, New York (1966).

29. Pritchett, J.W., et al., A Numerical Model of Gas Fluidized Beds, presented at the 69th Annual Meeting of the American Institute of Chemical Engineers, Chicago, Dec. 2, 1976; published in AIChE Symp. Series 74(176):134-148 (1978).

30. Padhye, A., and T. O'Brian, Computer Simulation of Cold Flow Studies of the Westinghouse Gasifier, preprint, Seventh Annual Energy Source Technology Conf. Exhibition (1984).

31. Concha, F., and M.C. Bustos, A Modification of the Kynch Theory of Sedimentation, J. American Institute of Chemical Engineers 33:312-315 (1987).

32. Molerus, O., Theory of Yield of Cohesive Powders, J. Powder Technology 12:259275 (1975).

33. Rietema, K., and S.M.P. Mutsers, The Effect of Interparticle Forces on Expansion of a Homogeneous Gas Fluidization, Proc. International Symp. on Fluidization, Toulouse, France, pp. 32-33 (1973).

34. Piepers, H.W., et al., Effects of Pressure and Type of Gas on Particle-Particle Interaction and the Consequences for Gas-Solid Fluidization Behavior, J. Powder Technology 37:55-70 (1984).

35. Shinohara, K., Rheological Property of Particulate Solids, in Handbook of Powder Science and Technology, M.E. Fayed and L. Otten, eds., Van Nostrand Reinhold, New York, pp. 129-169 (1984).

36. Orr, C., Jr., Particulate Technology, Macmillan Co., New York, p. 421 (1966). 
37. Altiner, H.K., and J.F. Davidson, Powder Flow from an Aerated Hopper, in Fluidization, J.R. Grace and J.M. Madsen, eds., Plenum Press, New York, pp. 461460 (1980).

38. Fanucci, J.B., N. Ness, and R.H. Yen, On the Formation of Bubbles in GasParticulate Fluidized Beds, J. Fluid Mechanics 94(2):353-367 (1979).

39. Bouillard, J.X., Hydrodynamics of Sedimentation, Fluidization, and Erosion, doctoral dissertation, Department of Chemical Engineering, Illinois Institute of Technology, Chicago (Dec. 1986).

40. Lyczkowski, R.W., D. Gidaspow, and C.W. Solbrig, Multiphase Flow Models for Nuclear, Fossil, and Biomass Energy Production, in Advances in Transport Processes, A.S. Mujumdar and R.A. Mashelkar, eds., Wiley Eastern Ltd., New Delhi, Vol. 2, pp. 198-340 (1982).

41. Wang, W.C., et al., A Generalized Methodology for Estimating Minimum Fluidization Velocity at Elevated Pressure and Temperature, J. American Institute of Chemical Engineers 31(7):1086-1092 (1985).

42. Hamming, R.W., Numerical Methods for Scientists and Engineers, 2nd Ed., Dover Publications, Inc., New York (1986).

43. Prosperetti, A., Numerical Aspects of the Simmer-II Code, in Multiphase Processes in LMFBR Safety Analysis, A.V. Jones, ed., Harwood Academic Publishers, Paris, pp. 197-224 (1984).

44. Courant, R., E. Isaacson, and M. Rees, On the Solution of Nonlinear Hyperbolic Differential Equations by Finite Differences, Communication in Pure and Applied Mathematics 5(243) (1952).

45. Frankel, S.P., Some Qualitative Comments on Stability Considerations in Partial Difference Equations, Proc. Sixth Symp. in Applied Mathematics, American Mathematical Society, McGraw-Hill, New York, Vol. VI, pp. 73-75 (1956).

46. Gentry, R.A., R.E. Martin, and B.J. Daley, An Eulerian Differencing Method for Unsteady Compressible Flow Problems, J. Computational Physics 7:87-118 (1966).

47. Stewart, H.B., Stability of Two-Phase Flow Calculations Using Two-Fluid Models, J. Computational Physics 33:259-270 (1979). 


\section{APPENDIX A:}

\section{STABILITY CONDITIONS FOR THE FLUFIX/MOD1 NUMERICAL SCHEME}

\section{A.1 NECESSARY CONDITIONS FOR STABILITY}

Numerical solution of sets of transient two-phase equations usually requires the use of $\mathrm{K}$-FIX-type computer codes. In these initial-value problems, information is usually provided from the boundary and initial conditions and propagates to the inner computational domain, provided that the characteristics of the numerical scheme are real. Hence, obtaining a satisfactory numerical solution depends on whether information propagates on real paths from time $t$ to $t+\delta t$; every iteration at a new time level, $t+\delta t$ may be considered as a new initial-value problem starting from time $t$. A necessary condition for numerical stability is that the numerical characteristics be real.

As noted by Lyczkowski, Gidaspow, and Solbrig, ${ }^{40}$ the validity of two-phase flow models depends essentially upon their mathematical well-posedness. For example, the annular flow model with the pressure drop in the two phases, without the solids pressure term, leads to a mathematically unstable solution, because of the existence of imaginary characteristic directions. However, this model can still be solved numerically with an appropriate numerical strategy. Such a strategy was developed by Harlow and Amsden 20 and modified by Rivard and Torrey ${ }^{2}$ in the K-FIX code, which was transformed, for the treatment of solids-gas systems, to the FLUFIX code. In this appendix, we show that the numerical characteristics of the FLUFIX code are real, because the spatial acceleration terms (momentum fluxes) are kept at the old time level. Thus, this code can compute very reasonable solutions for a large variety of two-phase-flow problems.

We denote the iterative variables as tilde variables $\tilde{\varepsilon}, \tilde{P}, \tilde{v}_{g}$, and $\tilde{v}_{s} \cdot \quad$ Nontilde terms, such as explicit convective terms, are lumped into the right-hand sides of the equations. The numerical equations for one dimension can be formulated as follows:

$$
\begin{aligned}
& \frac{\partial \tilde{\varepsilon}_{g} \tilde{\rho}_{g}}{\partial t}+\frac{\partial\left(\tilde{\varepsilon}_{g} \tilde{\rho}_{g} \tilde{V}_{g}\right)}{\partial x}=0 \\
& \frac{\partial \tilde{\varepsilon}_{s} \tilde{\rho}_{s}}{\partial t}+\frac{\partial\left(\tilde{\varepsilon}_{s} \tilde{\rho}_{s} \tilde{V}_{s}\right)}{\partial x}=0 \\
& \left.\frac{\partial \tilde{\rho}_{g} \tilde{V}_{g} \tilde{\varepsilon}_{g}}{\partial t}+\tilde{\varepsilon}_{g} \frac{\partial \tilde{P}}{\partial x}=\frac{\partial \varepsilon_{g} \rho_{g} V_{g} V_{g}}{\partial x}-\tilde{\beta}_{\left(\tilde{V}_{g}\right.}-\tilde{V}_{s}\right)+\varepsilon_{g} \rho_{g} g \\
& \left.\frac{\partial \tilde{\rho}_{s} \tilde{V}_{s} \tilde{\varepsilon}_{s}}{\partial t}+\tilde{\varepsilon}_{s} \frac{\partial \tilde{P}}{\partial x}=\frac{\partial \varepsilon_{s} \rho_{s} V_{s} V_{s}}{\partial x}-\tilde{\beta}_{\left(\tilde{V}_{s}\right.}-\tilde{V}_{g}\right)+\varepsilon_{s} \rho_{s} g+G \frac{\partial \varepsilon}{\partial x}
\end{aligned}
$$


As specified above, the explicit convection terms of the momentum equations are written on the right-hand sides of the equations. This numerical system can be written with the following matrices, $A_{t}$ and $A_{x}$, as

$$
A_{t} \frac{\partial \tilde{U}}{\partial t}+A_{x} \frac{\partial \tilde{U}}{\partial x}=\text { Explicit convective terms }+F\left(\tilde{V}_{g}, \tilde{V}_{s}, \tilde{\varepsilon}, \tilde{P}\right)
$$

where $\tilde{U}=\left(\tilde{\varepsilon}, \tilde{\mathrm{p}}, \tilde{\mathrm{V}}_{\mathbf{g}}, \tilde{\mathrm{V}}_{\mathbf{s}}\right)$ and where:

$$
A_{t}=\left(\begin{array}{cccc}
\tilde{\rho}_{g} & \tilde{\varepsilon}_{g} C_{g}^{-2} & 0 & 0 \\
-\tilde{\rho}_{s} & 0 & 0 & 0 \\
0 & 0 & \tilde{\rho}_{g} \tilde{\varepsilon}_{g} & 0 \\
0 & 0 & 0 & \tilde{\rho}_{s} \tilde{\varepsilon}_{s}
\end{array}\right)
$$

and

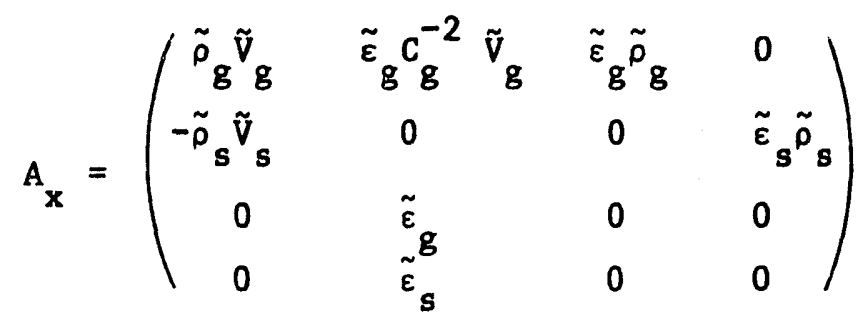

The characteristics $\lambda$ of this system are obtained by solving

$$
\operatorname{det}\left(A_{t} \lambda+A_{x}\right)=0
$$

which yields the polynomial $f(\lambda)$ :*

$$
f(\lambda)=\left(\lambda+v_{g}\right)\left[\left(\lambda+v_{s}\right) \lambda \varepsilon_{g} \rho_{s} C_{g}^{-2}-\varepsilon_{s} \rho_{g}\right]-\varepsilon_{g} \rho_{s}\left(\lambda+v_{s}\right)=0
$$

where $\lambda=0$ is a trivial solution consistent with $\operatorname{det}\left(A_{x}\right)$ being zero, since the two last rows of $A_{X}$ are linearly dependent. Equation A.9 can be written as follows:

$$
f(\lambda)=\lambda\left(\lambda+v_{g}\right)\left(\lambda+v_{s}\right) c-a\left(\lambda+v_{g}\right)-b\left(\lambda+v_{s}\right)=0
$$

*For convenience, the tildes are omitted frorn this point on. 
where:

$$
\begin{aligned}
& a=\varepsilon_{s} \rho_{g} \\
& b=\varepsilon_{g} \rho_{s} \\
& c=\varepsilon_{g} \rho_{g} C_{g}^{-2}
\end{aligned}
$$

For a mixture of incompressible phases, Eq. A.9 gives (for $\mathrm{C}=0$ ):

$$
\lambda=-\frac{V_{g} \rho_{g} \varepsilon_{s}+V_{s} \rho_{s} \varepsilon_{g}}{\rho_{g} \varepsilon_{s}+\rho_{s} \varepsilon_{g}}
$$

Equation A.14 clearly shows that the characteristics, $\lambda$, are real for the case of a mixture of incompressible phases, and it thereby satisfies our preliminary necessary condition for stability. It is possible to show that the numerical characteristics are also real for the case of a mixture of a compressible fluid and solids at subsonic flows. For the case of a dilute mixture $\left(\varepsilon_{\vec{g}}+1\right)$, the characteristic directions are real and can be expressed as

$$
\lambda=\frac{-v_{g} \pm c_{g}\left[\left(v_{g} / c_{g}\right)^{2}+4\right]^{1 / 2}}{2}
$$

and

$$
\lambda=-V_{s}
$$

At low gas velocity, the three characteristic directions remain real, as follows:

$$
\lambda_{1,2}=-v_{g} \pm C_{g}
$$

and

$$
\lambda_{3}=-\mathrm{V}_{\mathrm{s}}
$$


meaning that, in a dilute gas-solids mixture, information propagates at the speed of sound and at solids velocity. Evidently, this is the case for the pressure, $P$, and the voidage, $\varepsilon$.

In the general case, the characteristic polynomial $f(\lambda)$ is of third order in $\lambda$, so that there exists at least one real characteristic root $\lambda_{1}$. We shall show that the second and third roots of this polynomial are real for subsonic compressible flows. Equation A.9 can be written as follows:

$$
f(\lambda)=c\left(\lambda-\lambda_{1}\right)\left(\lambda^{2}+\alpha \lambda+\beta\right)
$$

By identification with Equation A.9, one can show that:

$$
\begin{aligned}
& \alpha-\lambda_{1}=V_{s}+V_{g} \\
& \beta-\alpha \lambda_{1}=V_{s} V_{g}-(a+b / c)
\end{aligned}
$$

For mixtures at low pressure $(c=\infty)$, $f$ has three real roots, which are $0, v_{s}$, and $V_{g}$. In the general case, the two other roots of Eq. A.19 are real if the following condition is satisfied:

$$
\alpha^{2} \geq 4 \beta
$$

where:

$$
\beta=\left(\lambda_{1}+V_{s}\right)\left(v_{g}+\lambda_{1}\right)-\frac{a+b}{c}
$$

To verify this condition, we should realize that $1 / \mathrm{C}$ at ambient conditions is of the order of $c_{g}^{2}$, so that $(a+b) / C$ is roughly equal to $\left(\rho_{s} / \rho_{g}\right) c_{g}^{2}$. From Eq. A.10, the solution domain is the intersection of a cubic having the three roots $0,-V_{g}$, and $-V_{s}$ and an increasing straight line that intersects the $x$ axis between $-V_{g}$ and $V_{s}$. Consequently, the root $\lambda_{1}$ is necessarily bounded by $2 C_{g}$ for subsonic flows. Hence, $\beta$ is almost always negative, and thus the condition of Eq. A.23 is verified. As a result, the numerical characteristics of Eqs. A.1-A.4 are real for subsonic flows. Other evidence, based on Fig. A.1, may be given graphically. This figure shows the plot of a cubic (first term of Eq. A.10) and a straight line (second term of A.10) vs. the characteristic velocity, $\lambda$. 


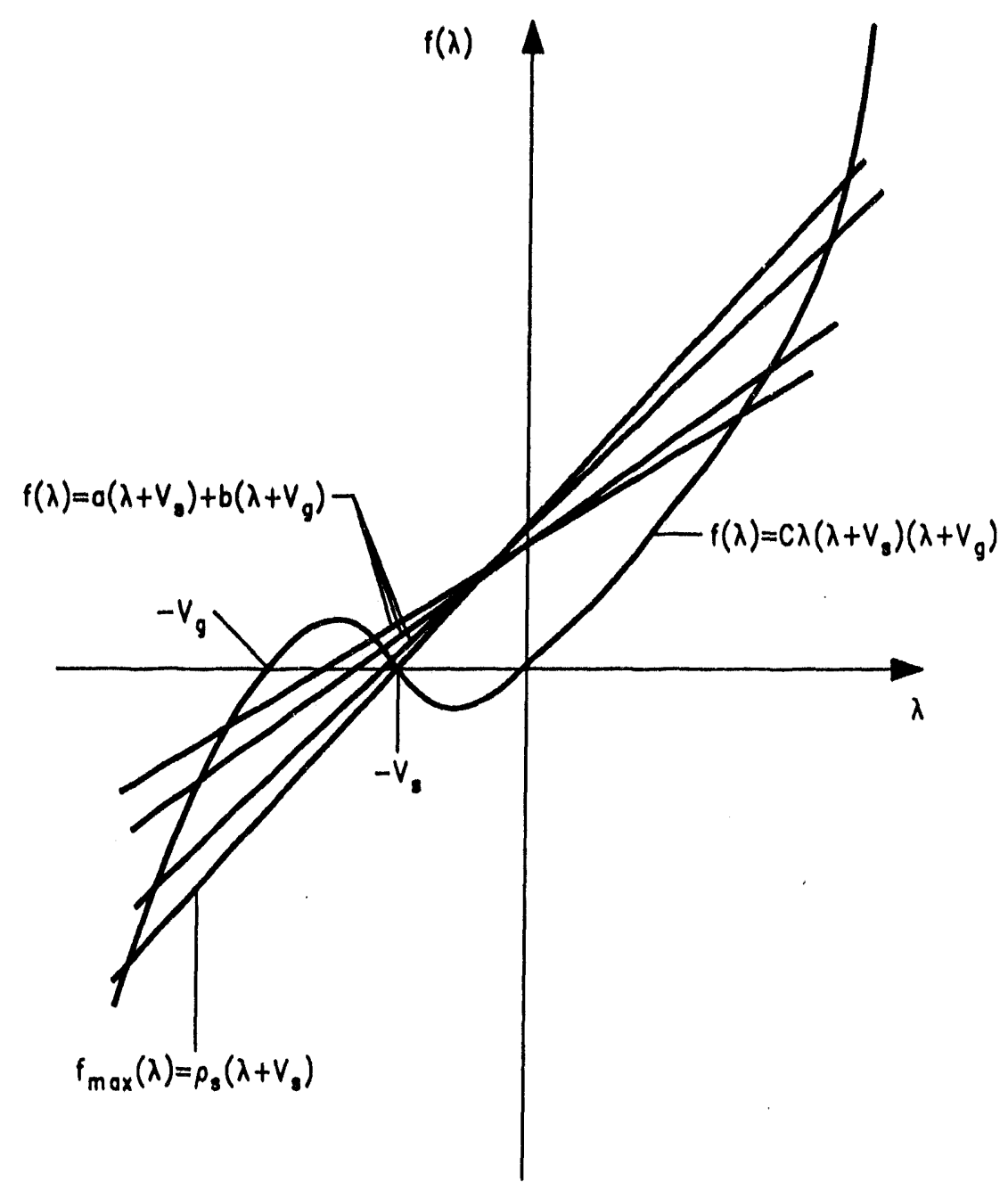

FIGURE A.1 Geometrical Determination of the Three Real Characteristic Roots

As the cublc, away from its roots $\left(-V_{s}, V_{g}, 0\right)$, grows faster than the linear term, Eq. A.10 has two real roots, which are larger in absolute value than the roots of the cubic. The dilute case $(\varepsilon \rightarrow 1)$ is represented by the straight line with a maximum slope. In this case, the largest absolute values of these roots are $C_{\mathbf{g}} \pm V_{\mathbf{g}^{*}}$. This figure shows also that the roots $\lambda_{i}$ are bounded by $2 C_{g}$ for subsonic flows.

In a homogeneous mixture of incompressible phases $\left(V_{s}=V_{g}=V\right)$, the information is advected at a velocity V. Courant, Isaacson, and Rees ${ }^{44}$ showed that an efficient numerical scheme to this problem is the cell donor technique. Since then, this technique has been popular in the literature and has been used under various labels and different rationales. It is commonly called the method of upwind differencing, which was called by Frankel a "unidirectional flow technique" 45 and by Gentry, Martin, and Daley a "donor cell mass differencing." 46 This technique possesses the fundamental transportive property that maintains the integral kinematic property of the continuum solution, as 
illustrated below. In this method, the information is advected into a cell only from those cells that are upstream and, conversely, information is carried from a cell to cells downstream. The convective terms are finite-differenced as follows:

$$
\left(\frac{\delta(u \varepsilon)^{n}}{\delta x}\right)_{i, j}=\left\{\begin{array}{l}
(u \varepsilon)_{i+1, j}^{n}-(u \varepsilon)_{i, j}^{n} / \Delta x \text { for } u \leq 0 \\
(u \varepsilon)_{i, j}^{n}-(u \varepsilon)_{i-1, j}^{n} / \Delta x \text { for } u \geq 0
\end{array}\right.
$$

Courant, Isaacson, and Rees ${ }^{44}$ demonstrated the essential link of the upwind difference technique with the method of characteristics. As noted above, this scheme possesses the fundamental transportive property (i.e., the effect of a perturbation is advected only in the direction of the velocity). For example, if there is a disturbance, $\varepsilon=\delta$, at $i=m+1$, the accumulation term downstream of the perturbation $(i=m+1)$, for $(\mathrm{U} \geq$ is $-\mathrm{U} \delta / \Delta \mathbf{x}$, and it is 0 upstream of the disturbance. In other words, we have:

$$
\left(\frac{\partial \varepsilon}{\partial t}\right)_{i, j}= \begin{cases}-U \delta / \Delta x & i=m+1 \\ 0 & i=m, m-1\end{cases}
$$

The perturbation propagates downstream in the velocity direction, and the scheme is said to be transportative. The disturbance does not propagate upstream. In our case, inspection of the finite-difference scheme shows that the FLUFIX scheme is transportative. In addition, the scheme is conservative, because it satisfies, at every instant and location, Gauss's divergence theorem.

In conclusion, where numerical characteristics are real, a finite-difference scheme of the FLUFIX type can lead to an acceptable numerical solution, provided that the stability (in the sense of von Neumann stability theory) is satisfied. However, it is important to keep in mind that the numerical solution does not strictly converge in the limit $(\Delta x, \Delta t \rightarrow 0)$, because the mathematical problem remains ill-posed. Fortunately, in most engineering problems we are not interested in having the limiting solution, which would require an enormous computational effort. Also, a fully implicit scheme is unlikely to be successful, because the characteristic directions are imaginary.

\section{A.2 STABILITY CRITERION}

The classical approach consists in applying the von Neumann technique by linearizing the system and assuming a Fourier decomposition of the variable $U$ (in one dimension) such that

$$
U=T(k) \exp (i k \Delta x)
$$


where $k=\pi /(n \Delta x)$ and $n=1,2, \ldots, N$. The amplification matrix, $T$, has its eigenvalues, which depend on $\beta$, the drag coefficient (shown to be the major cause of instabilities in many two-phase-flow finite-difference schemes ${ }^{43,47}$ ). To ensure numerical stability, their eigenvalues should have their modulus smaller than 1. Prosperetti analyzed a simplified one-dimensional version of the present numerical scheme for Hydrodynamic Model A. ${ }^{43}$ We refer interested readers to that work for the details, which involved much algebra, even for the simplest case. 


\section{APPENDIX B:}

\section{FLUFIX/MOD2 FORTRAN SYMBOLS AND DEFINITIONS}

In the following list of Fortran symbols, the array quantities are indicated by an index. They are all part of a common block. The array dimensions of most of them need to be changed when the input data file is changed. The indexes shown in the following table and the respective array dimensions to be used are: I $\rightarrow$ IB2 and IJ $\rightarrow$ IB2 - JB2. The rest are left unchanged unless otherwise specified.

Fortran

Symbol

Definition

\begin{tabular}{|c|c|}
\hline ABETA (IJ) & $\left(\frac{1}{B}\right)_{g}, j^{\prime}$ computed in BETAS and ITER \\
\hline BHITE & Input date line No. 5 \\
\hline$C(100)$ & Storage for constants initialized in SETC \\
\hline $\operatorname{CONV}(\mathrm{IJ})$ & Convergence criteria computed in BETAS \\
\hline CPSTOP & Input date line No. 2 \\
\hline CYCLE & $\begin{array}{l}\text { The calculation cycle at which to bein, read in } \\
\text { line No. } 20+N\end{array}$ \\
\hline DG & $\left(D_{g}\right)_{i, j}$, mass residue of the gas phase defined in Eq. $5.20 a$ \\
\hline DIAP & $d_{p}$, particle diameter, $\mathrm{cm}$, input data line No. $24+\mathrm{N}$ \\
\hline DR & $\delta r$, read in line No. 5 \\
\hline DT & $\delta t$, read in 1 ine No. $20+N$ \\
\hline DTODR & $\frac{\delta t}{\delta r}$ \\
\hline DTODZ & $\frac{\delta t}{\delta z}$ \\
\hline DTORBDR（I ） & $\frac{\delta t}{r_{i+\frac{1}{2}}^{\delta r}}$ \\
\hline DTORDR ( I ) & $\frac{\delta t}{r_{i} \delta r}$ \\
\hline
\end{tabular}




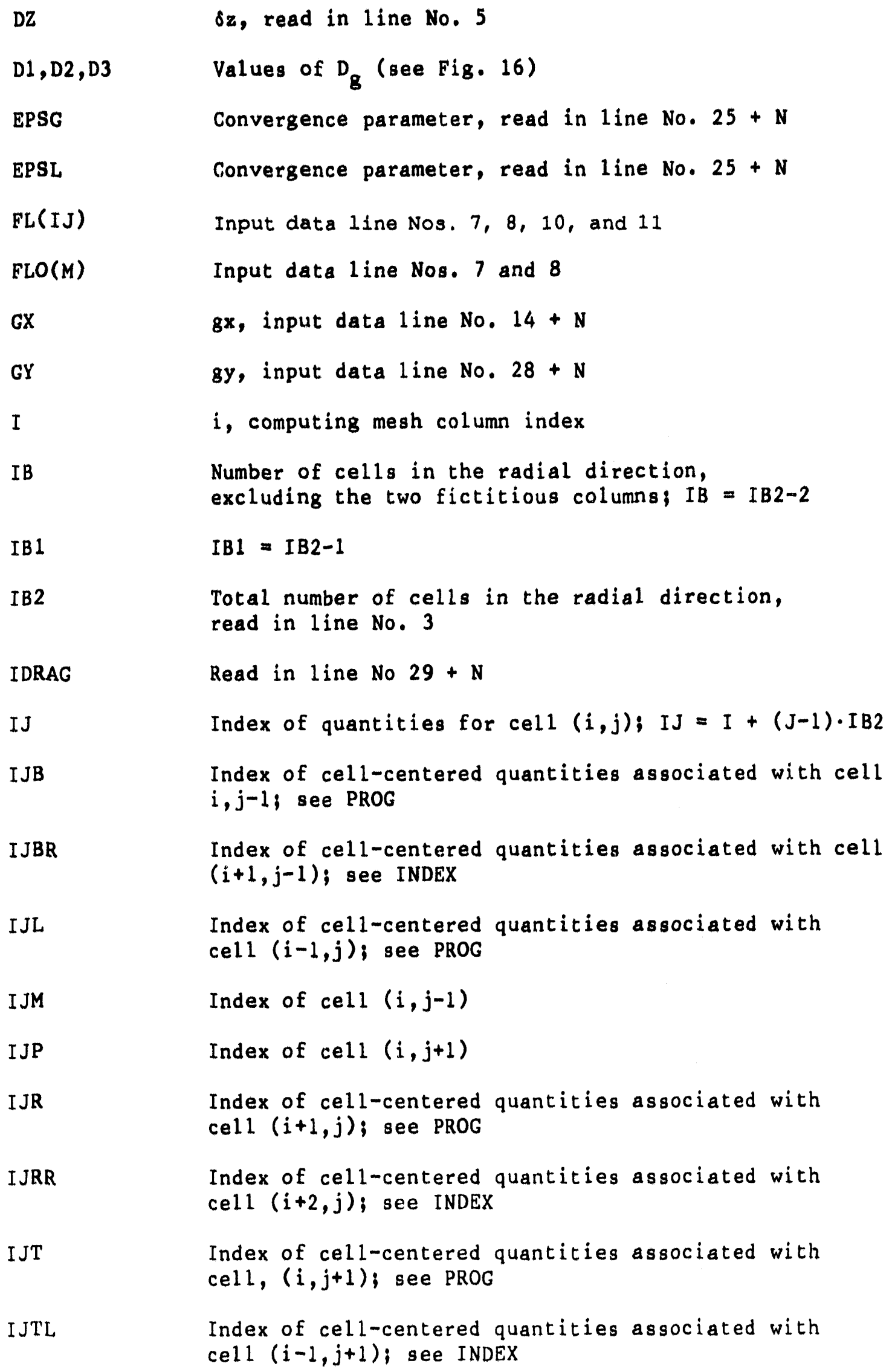




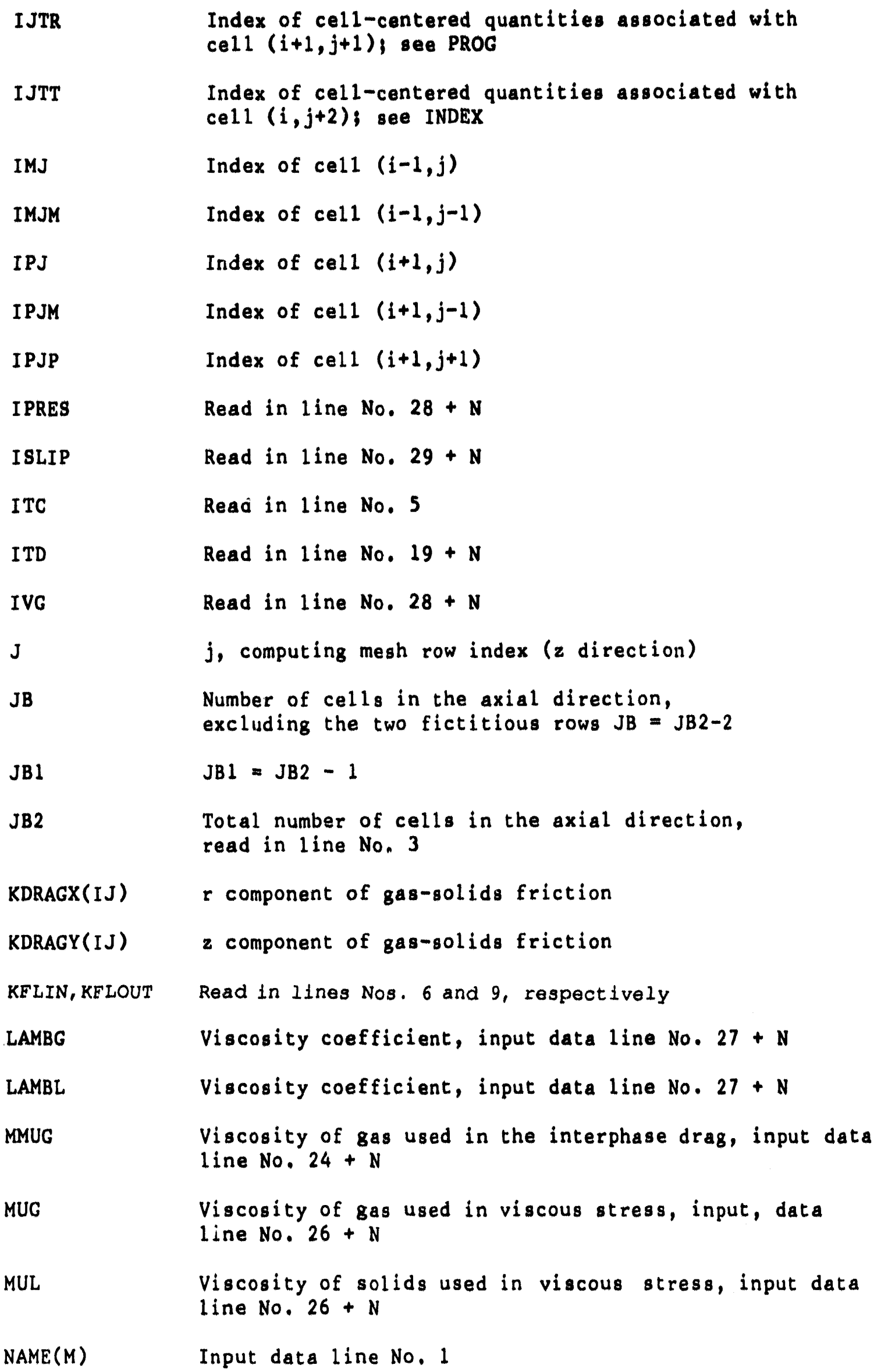


NIT

No

NSL(M)

NSO(M)

$O B(M, N)$

$P(I J)$

PHI

PINB

PINL

PINR

PINT

PO

P1, P2, P3

R(I)

RAGS

$R B(I)$

RDR

RDR2

RDZ

RDZ2

$\operatorname{RGFR(IJ)~}$

RGET(J)

$\operatorname{RGP}(\mathrm{IJ})$
Iteration counter used in ITER

Input data line No. 13

Input data line No. 12

Input data line No. $13+N$

Input data 1 ine No. $13+N$

Pressure in cell $(i, j)$

$\Phi_{8}$, the shape factor, input data line No. $25+N$

Input data line No. $17+\mathrm{N}$

Input data line No. $15+N$

Input data line No. $16+N$

Input data line No. $18+\mathrm{N}$

Input data 1 ine No. $14+N$

Values of pressure (Fig. 16)

$r_{i}$, radial coordinate of the center of cell $(i, j)$

$\mathrm{C}_{8}^{-2}$

$r_{i+\frac{1}{2}}$, radial coordinate of the right boundary of cell $(i, j)$

$\frac{1}{\delta r}$

$\frac{1}{(\delta r)^{2}}$

$\frac{1}{\delta z}$

$\frac{1}{(\delta z)^{2}}$

Flux of $\varepsilon_{g} \rho_{g}$ across the right boundary of cell $(i, j)$

Flux of $\varepsilon_{g}{ }_{g}$ across the top boundary of $\operatorname{cell}(i, j)$

$\left(\varepsilon_{8} \rho_{g}\right)^{n+1}+1$ 


\begin{tabular}{|c|c|}
\hline $\operatorname{RCPN}(I J)$ & $\left(\varepsilon_{8} \rho_{8}\right)_{i, j}^{n}$ \\
\hline RL & $\rho_{s}, s 01$ ids density \\
\hline RLFRL(IJ) & Flux of $\varepsilon_{s} \rho_{s}$ across the right boundary of $\operatorname{cell}(i, j)$ \\
\hline RLFTL(IJ) & Flux of $\varepsilon_{8} p_{s}$ across the top boundary of cell $(i, j)$ \\
\hline $\operatorname{RLP}(I J)$ & $\left(\varepsilon_{s} s^{n+1}\right)_{i, j}^{n+1}$ \\
\hline RLPN(IJ) & $\left(\varepsilon_{8} \rho_{s}\right)_{i}^{n}$ \\
\hline $\operatorname{ROG}(I J)$ & $\left(p_{8}\right)^{n+}$ \\
\hline RRB (I) & $\overline{r_{i+1 / 2}}$ \\
\hline $\begin{array}{l}\text { RRIDR } \\
\text { RUG(IJ) }\end{array}$ & $\frac{1}{r_{i}^{\delta r}}$ \\
\hline RUL(IJ) & ${\overline{\left(\varepsilon_{s} p_{s} u_{s}\right)_{i+1 / 2, j}}}_{n}^{n}$ \\
\hline RVG(IJ) & ${\overline{\left(\varepsilon_{8}{ }^{p}{ }_{8}{ }_{8}\right)^{n}}}^{n}$ \\
\hline $\operatorname{RVL}(I J)$ & $\overline{\varepsilon_{8} p_{8} v_{8}}$ \\
\hline
\end{tabular}

SCALE (4) Input data line No. 4

SLOPE Input data line No. $26+\mathbf{N}$

SUGB $\quad\left(\theta_{g r z}\right)_{i+\frac{1}{2}, j-\frac{1}{2}}$

Product of void fraction and shear stress used to compute sas radial momentum

succ

$$
\left(\theta_{8 \phi \phi}\right)_{i+\frac{1}{2}, j}
$$

Product of void fraction and azimuthal stress used to compute gas radial momentum.

SUGL

$$
\left(r \theta \tau_{8 r r}\right)_{i, j}
$$

Product of radius, void fraction, and radial stress used to comput. gas radial momentum. 
SUGR

SUGT

SULB

SULC

SULL

SULR

SULT

SVGB

SVGL

SVGR

SVGT

SVLB

SVLL

SVLR

SVLT

TEMPINB

TEMPINL

TEMPINR

TEMPINT

$$
\left(r \theta \tau_{g r r}\right)_{i+1, j}
$$

$$
\left(\theta \tau_{g \times 2}\right)^{i+\frac{1}{2}, j+\frac{1}{2}}
$$

$$
\left[(1-\theta) \tau_{\ell r z}\right]_{i+\frac{1}{2}, j-\frac{1}{2}}
$$

$$
\left[(1-\theta) \tau_{\ell \phi \phi}\right]_{i+\frac{1}{2}, j}
$$

$[r(1-\theta) \tau \ell r r] i, j$

$$
\left[r(1-\theta) \tau_{\ell r r}\right]_{i+1, j}
$$

$$
\left[(1-\theta) \tau_{\ell \tau z}\right]_{i+\frac{1}{2}, j+\frac{1}{z}}
$$

$$
\left.{ }^{(\theta \tau}{ }_{g z z}\right)_{i, j}
$$

$$
\left(r \theta \tau_{g r z}\right)_{i-\frac{1}{2}, j}+\frac{1}{2}
$$

$$
\left(r \theta \tau_{g z z}\right)_{i+\frac{1}{2}, j+\frac{1}{2}}
$$

$$
\left.{ }^{\left(\theta \tau_{g z z}\right.}\right)_{i, j+1}
$$

$$
\left[(1-\theta) \tau_{\ell z z}\right] i, j
$$

$$
\left[r(1-\theta) \tau_{\ell r z}\right]_{i-\frac{1}{z}, j+\frac{1}{z}}
$$

$$
\left[r(1-\theta) \tau_{\ell r z}\right]_{i+\frac{1}{2}, j}+\frac{1}{2}
$$

$$
\left[(1-\theta) \tau_{\ell z z}\right] i, j+1
$$

Input data line No. $17+\mathrm{N}$ Input data line No. $15+N$ Input data line No. $16+\mathrm{N}$ Input data line No. $18+\mathrm{N}$
Same as SUCL, but evaluated at mesh location $i+1, j$.

Same as SUGB, but evaluated at mesh location $i+\frac{1}{2}, j+\frac{1}{2}$

Same as SUGB, except for the solids.

Same as sucC, except for the solids.

Same as SUGL, except for the solids.

Same as SUGR, except for the solids.

Same as SUGT, except for the solids.

Product of void fraction and axial stress used to compute gas axial momentum.

Product of radius, void fraction, and shear stress used to compute gas axial momentum.

Same as SVGL, but evaluated at mesh location $i+\frac{1}{2}, j+\frac{1}{2}$.

Same as SVGB, but evaluated at mesh location $i, j+1$.

Same as SVGB, except for the solids.

Same as SVGL, except for the solids.

Same as SVGR, except for the solids.

Same as SVGT, except for the solids. 


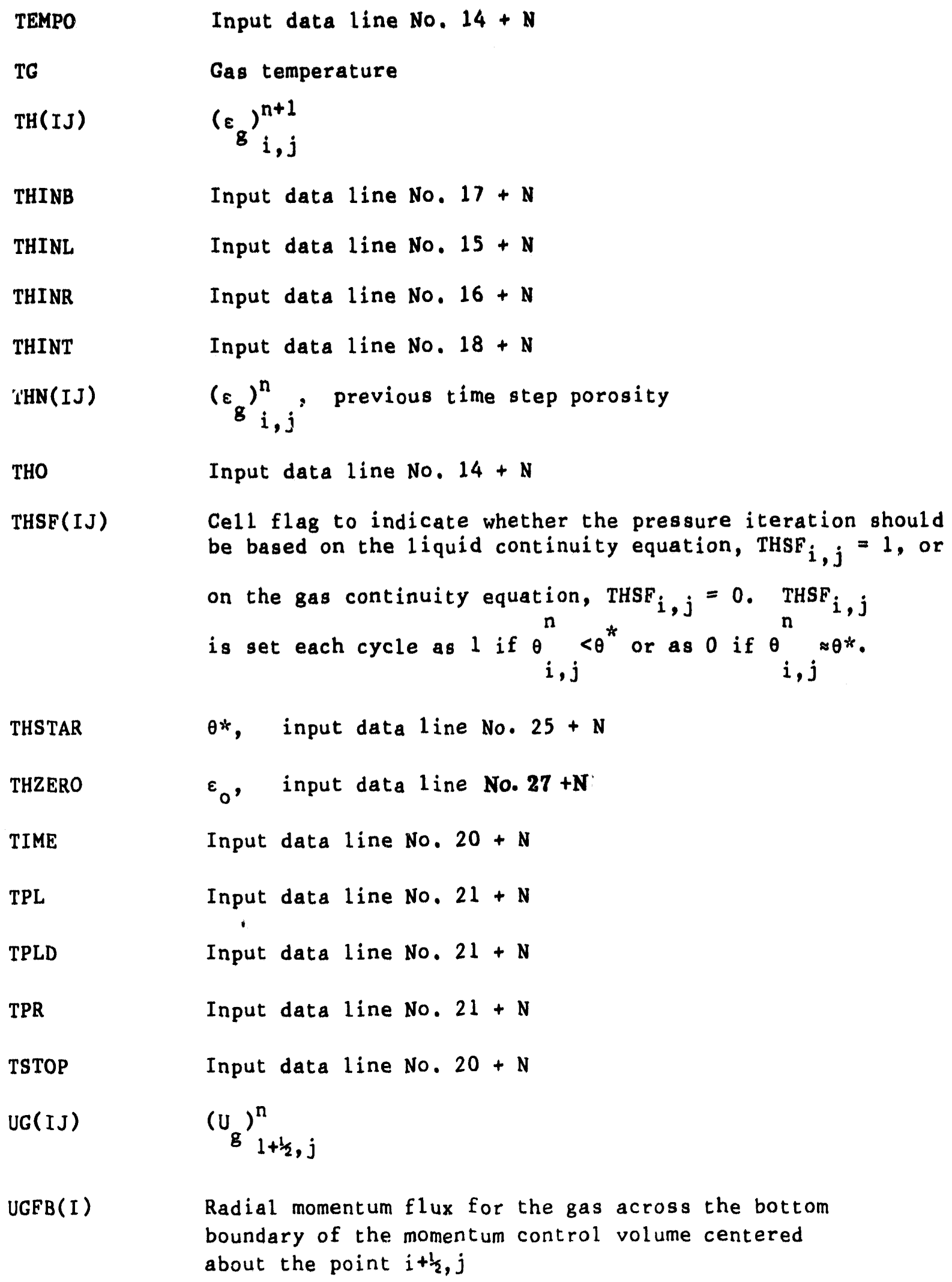


UGFL

UGFR

UGET

UINB

UINL

UINR

UINT

UL(IJ)

$\operatorname{ULFB(I)}$

ULFL

ULFR

ULFT

Uo

VG(IJ)

$\operatorname{VGFB}(I)$

VGFL
Radial momentum flux for the gas across the left boundary of the momentum control volume (described above)

Radial momentum flux for the gas across the right boundary of the momentum control volume (described above)

Radial momentum flux for the gas across the top boundary of the momentum control volume (described above)

Input data line No. $17+\mathrm{N}$

Input data 1 ine No. $15+N$

Input data 1 ine No. $16+N$

Input data line No. $18+\mathrm{N}$

$\left(U_{s}\right)_{i+\frac{1}{2}, j}^{n}$

Radial momentum flux for the solids across the bottom houndary of the momentum control volume centered about the point $i+\frac{1}{2}, j$

Radial momentum flux for the solids across the left boundary of the momentum control volume (described above)

Radial momentum flux for the solids across the right boundary of the momentum control volume (described above)

Radial momentum flux for the solids across the top boundary of the momentum control volume (described above)

Input data 1 ine No. $14+\mathrm{N}$

$\left(v_{g}\right)^{n}$

Axial momentum flux for the gas across the bottom boundary of the momentum control volume centered about the point $i, j+\frac{1}{2}$

Axial momentum flux for the gas across the left boundary of the momentum control volume (described above) 
VGFR

VGFT

VINB

VINL

VINR

VINT

$\operatorname{VL}(\mathrm{IJ})$

$\operatorname{VLFB}(I J)$

VLFL

VLFR

VLFT

vo
Axial momentum flux for the gas across the right boundary of the momentum control volume (described above)

Axial momentum flux for the gas across the top boundary of the momentum control volume (described above)

Input data line No. $17+\mathrm{N}$

Input data line No. $15+N$

Input data card No. $16+\mathrm{N}$

Input data card No. $18+\mathrm{N}$

$\left(v_{s}\right)_{i, j+\frac{1}{2}}^{n}$

Axial momentum flux for the solids across the bottom boundary of the momentum control volume centered about the point $i, j+\frac{1}{2}$

Axial momentum flux for the solids across the left boundary of the momentum control volume (described above)

Axial momentum flux for the solids across the right boundary of the momentum control volume (described above)

Axial momentum flux for the solids across the top boundary of the momentum control volume (described above)

Input data line No. $14+\mathrm{N}$ 


\section{Notice}

The FLUFIX/MOD2 Computer program may be obtained from:

Energy Science and Technology Software Center

P. O. Box 1020

Oak Ridge, TN 37833

Telephone (615) 576-2606

FAX (615) 576-2865

E-mail:ESTCS@ADONIS.OSTI.GOV 

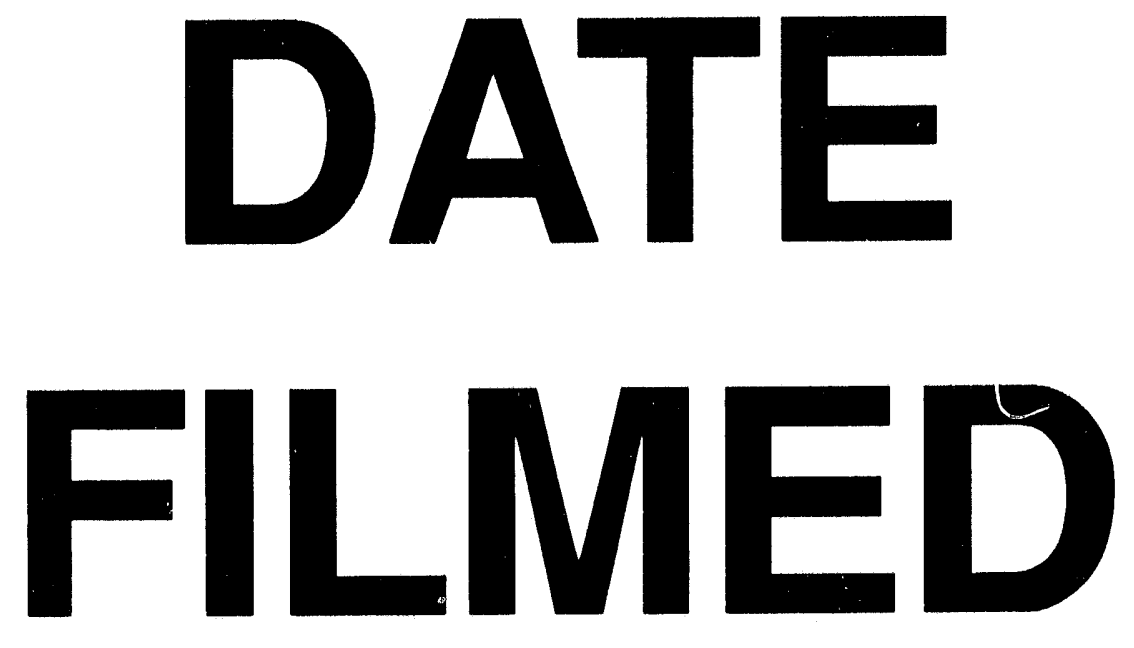

$6 / 2 / 94$
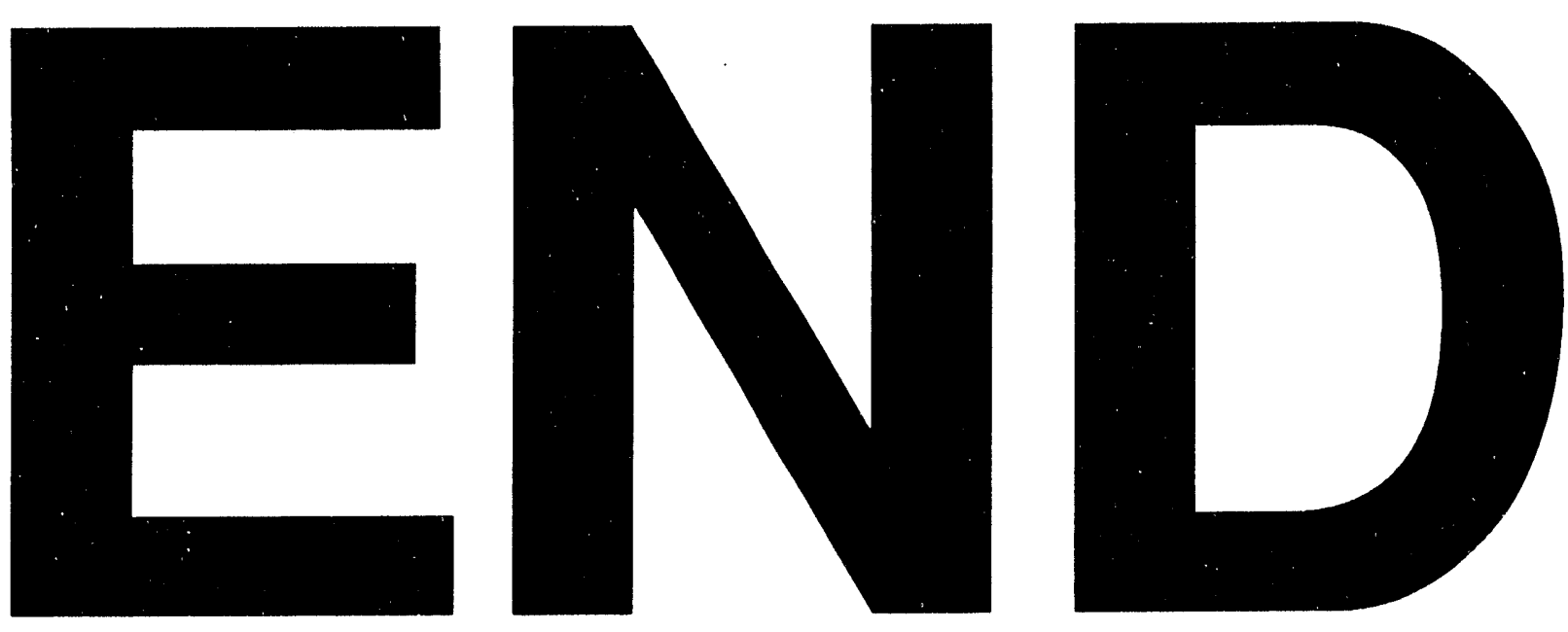


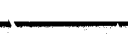

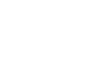

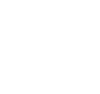

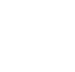

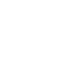

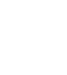

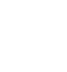

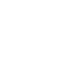

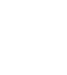

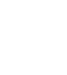
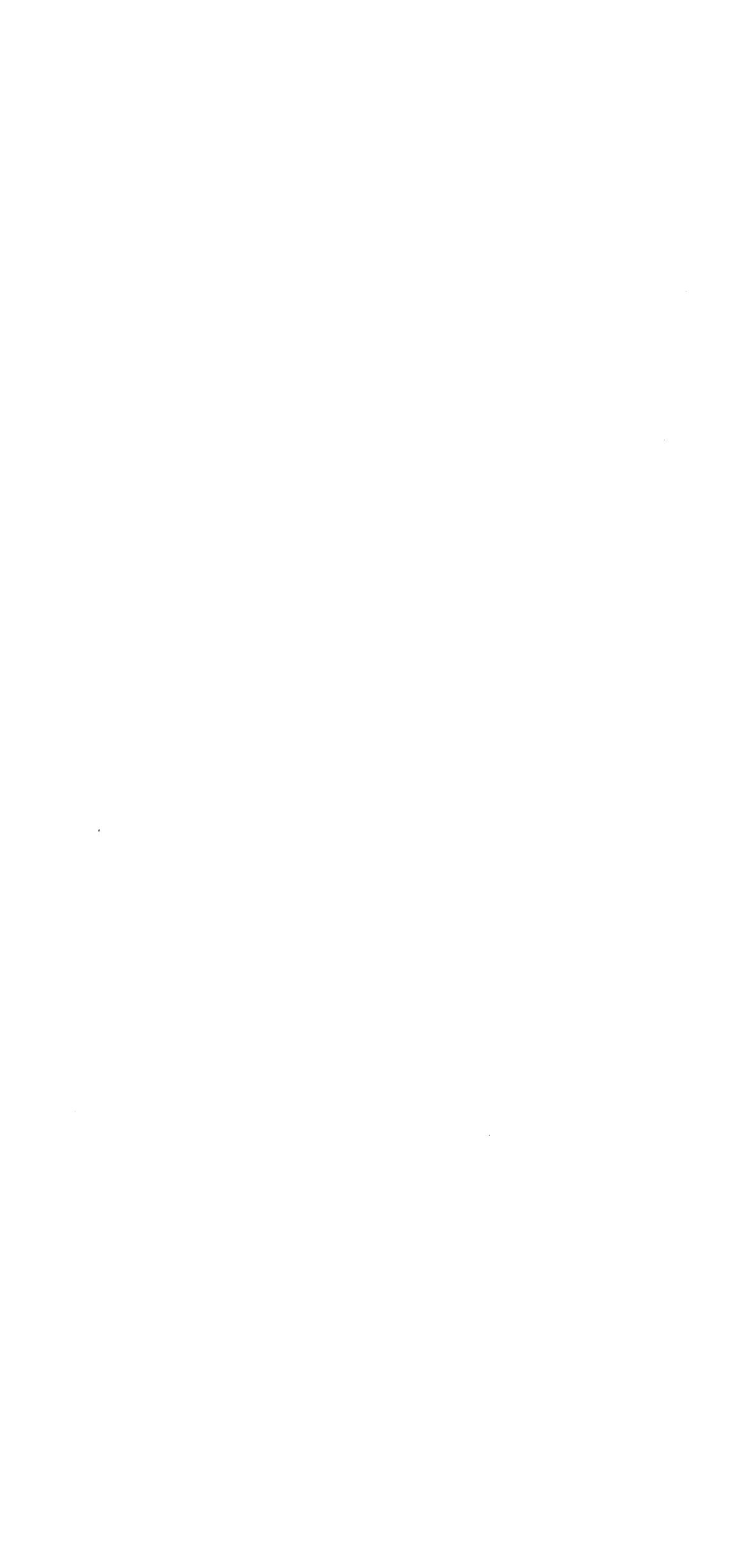